\title{
Developing Government Renewable Energy Projects
}

Kurt S. Myers

Thomas L. Baldwin

Jason W. Bush

Jake P. Gentle

July 2012

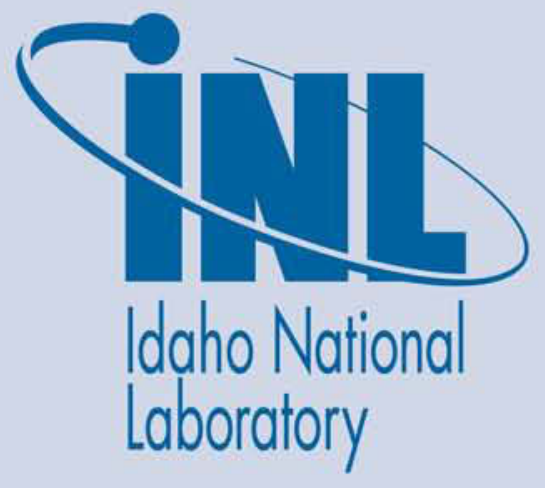

The INL is a U.S. Department of Energy National Laboratory operated by Battelle Energy Alliance 


\section{DISCLAIMER}

This information was prepared as an account of work sponsored by an agency of the U.S. Government. Neither the U.S. Government nor any agency thereof, nor any of their employees, makes any warranty, expressed or implied, or assumes any legal liability or responsibility for the accuracy, completeness, or usefulness, of any information, apparatus, product, or process disclosed, or represents that its use would not infringe privately owned rights. References herein to any specific commercial product, process, or service by trade name, trade mark, manufacturer, or otherwise, does not necessarily constitute or imply its endorsement, recommendation, or favoring by the U.S. Government or any agency thereof. The views and opinions of authors expressed herein do not necessarily state or reflect those of the U.S. Government or any agency thereof. 


\section{Developing Government Renewable Energy Projects}

INL/EXT-12-27022

Revision 0

July 2012

Approved by:

Name

Title [optional]

Name

Title [optional]

Name

Title [optional]

Name

Title [optional]
Date

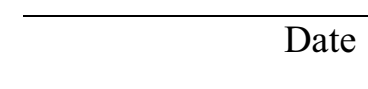

Date

Date 
INL/EXT-12-27022

\title{
Developing Government Renewable Energy Projects
}

\author{
Kurt S. Myers \\ Thomas L. Baldwin \\ Jason W. Bush \\ Jake P. Gentle
}

July 2012

Idaho National Laboratory
Idaho Falls, Idaho 83415

http://www.inl.gov

Prepared for the

U.S. Department of Energy

Assistant Secretary for Energy Efficiency and Renewable Energy

Under DOE Idaho Operations Office

Contract DE-AC07-05ID14517 


\section{EXECUTIVE SUMMARY}

The US Army Electronic Proving Ground has retained Idaho National Laboratory (INL) to conduct a study of past INL experiences and complete a report that identifies the processes that are needed for the development of renewable energy projects on government properties. These compiled guidelines for government renewable energy projects could include wind, hydro, geothermal, solar, biomass, or a variety of hybrid systems; however, for the purpose of narrowing the focus of this report, wind projects are the main topic discussed throughout this report. It is our thought that a lot of what is discussed could be applied, possibly with some modifications, to other areas of renewable energy. It is also important to note that individual projects (regardless the type) vary to some degree depending on location, size, and need, but in general these concepts and directions can be carried over to the majority of government renewable energy projects.

The INL has always maintained expertise in power systems and applied engineering and INL's renewable energy experiences date back to the 1980's when our engineers began performing US Air Force wind energy feasibility studies and development projects. Over the years INL has continued to apply this expertise to a variety of wind and other engineering projects that include Camp Lemonnier NEB, RAF Ascension Island, FE Warren AFB, Guam, Alaska, Vandenberg AFB, Galveston MCRC, Brooklyn MCRC, Great Lakes, Malmstrom AFB, Great Falls ANG, Twenty-nine Palms MCB, Barstow MCLB, Bridgeport MCB, AUTEC NB, San Nicolas Island NB, Dam Neck NB, New London NSB, DOE Pantex Plant, Idaho National Laboratory's Wind Project, Idaho Anemometer Loan Program and multiple smaller projects that provide schools with education outreach support and communities needing technical expertise guidance.

This report focuses on the initial development aspects that need to occur for any project to be a successful government renewable energy project. The initial development phase includes collecting pre-site visit information, conducting a site visit, meeting with all parties involved, identifying any impacts or obstacles and the appropriate mitigation options, determining potential project site locations, identifying types/amounts for meteorological tower and ideal site location, collecting prospecting data for $\sim 1 \mathrm{yr}+$ period, and completion of the wind or other resource assessment report.

Resource feasibility analysis reports are a valuable tool used for justifying and guiding a government renewable energy project. These reports will cover location details, wind parameters, energy production estimates, potential technology, compatibility, permitting, policies, specific site analysis, FAA or Mission impacts, configurations, interconnections, incentives, environmental assessment, economic analysis, and recommendations.

Conducting an Environmental Assessment or other environmental review is a requirement for all government projects. Renewable energy projects have both adverse and beneficial impacts on environmental resources. Adverse impacts need to be identified and mitigated to the greatest extent practicable to minimize the effects on the resources. Several government agencies and non-government agencies are available for consultation.

Government projects can have multiple hurdles standing in the way. Several interfaces should be addressed very early on in developing the project in order to better communicate the issues with all involved parties. All operational and mission personnel should be brought together to clearly discuss any adverse impacts and options for mitigation. File early as possible with the FAA to give yourself as much time as possible to mitigate any presumed hazard notices. 
Use the DoD Preliminary Screening Tool (PST) to get an idea of where any radar impacts might happen. Consult other bases that have had similar challenges and have successfully completed their renewable energy projects. Be ready to work with government agencies to find acceptable solutions to their concerns.

After 20+ years of working with Department of Defense and other government agencies to study, design, and build government renewable projects, INL has experienced the do's and don'ts for being successful with a project. 
This page intentionally left blank. 


\section{CONTENTS}

EXECUTIVE SUMMARY

TABLES

viii

ACRONYMS

ix

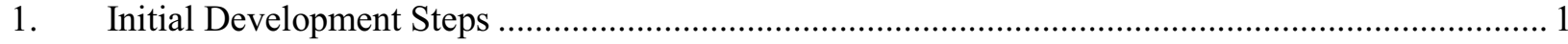

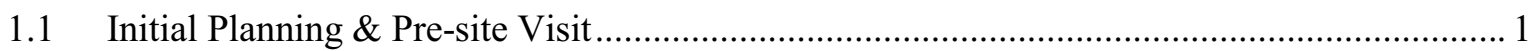

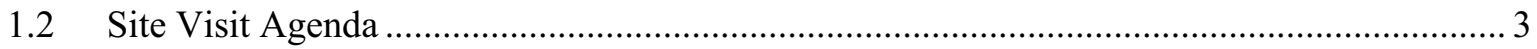

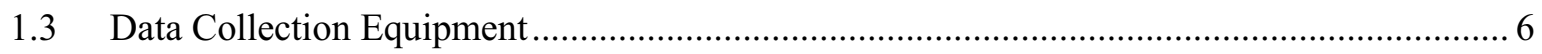

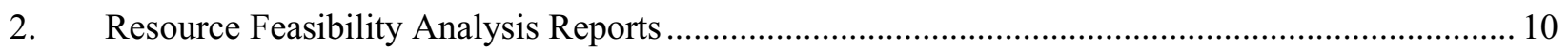

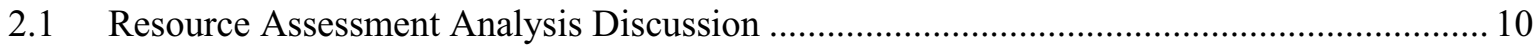

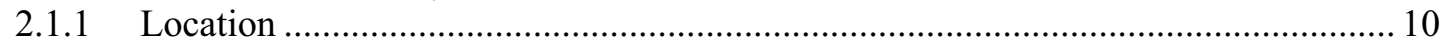

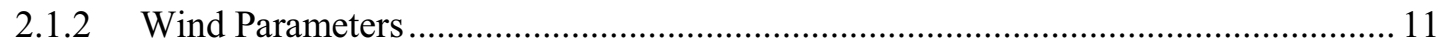

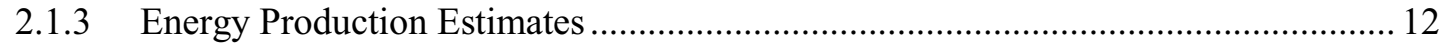

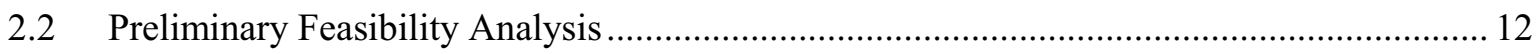

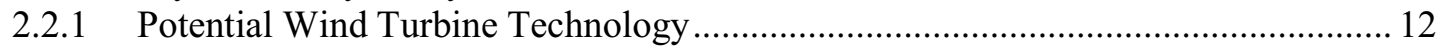

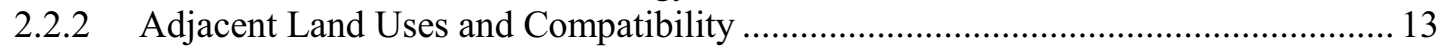

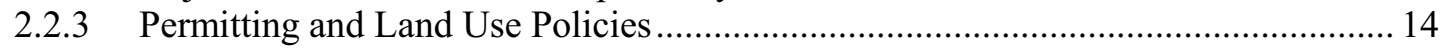

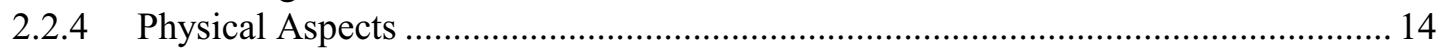

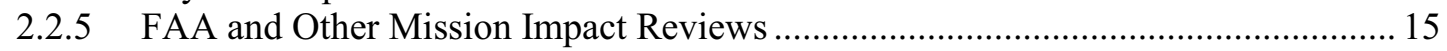

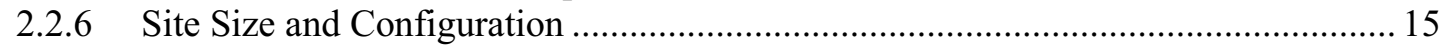

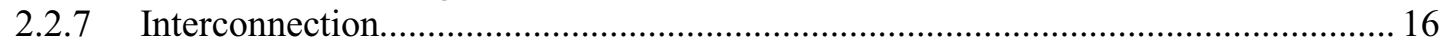

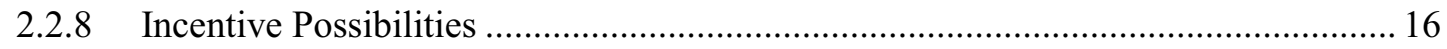

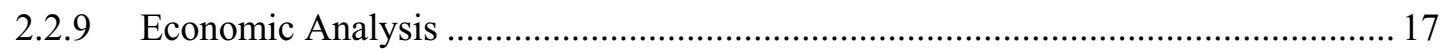

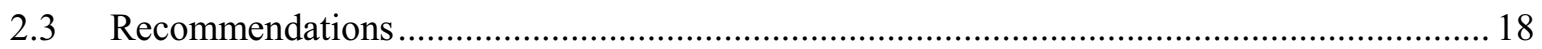

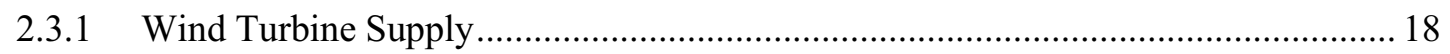

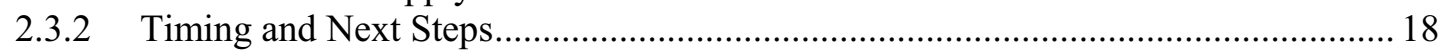

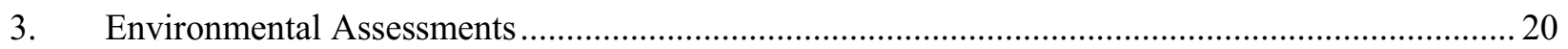

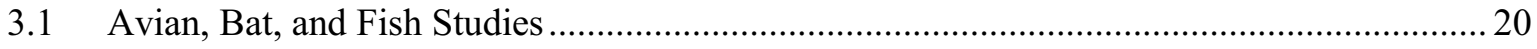

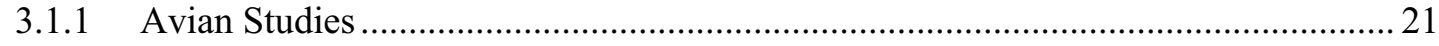

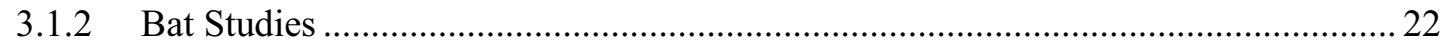

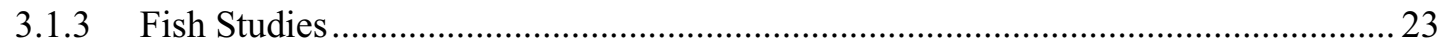

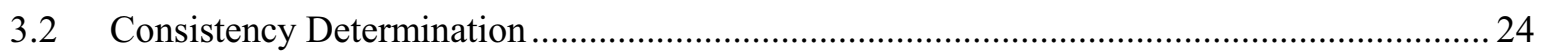

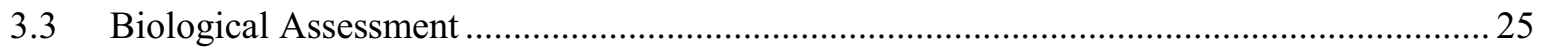

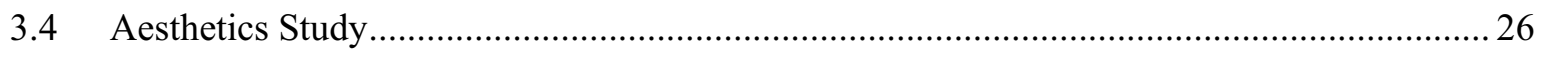

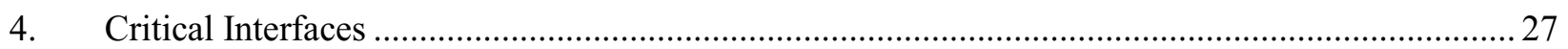

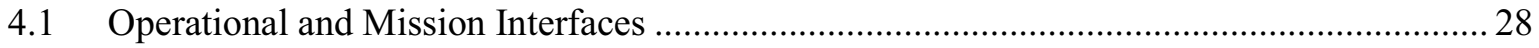

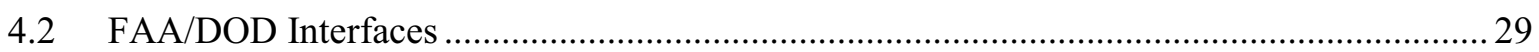

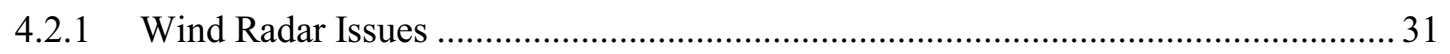

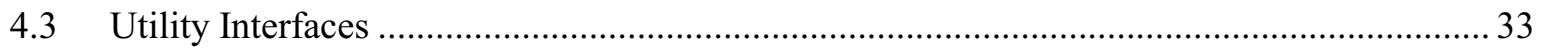

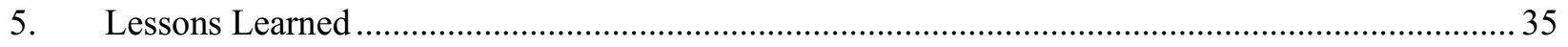




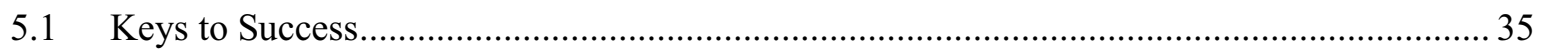

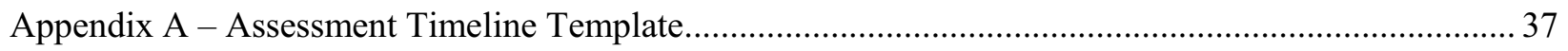

Appendix B - Wind Data Collection Equipment Vendor Data .......................................................... 38

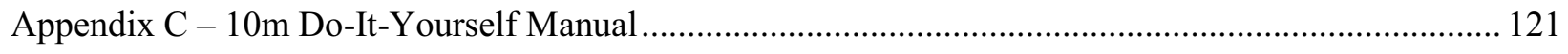

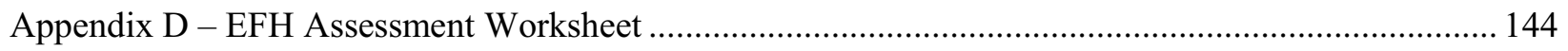

\section{FIGURES}

Figure 1: $660 \mathrm{KW}$ Vestas Wind Turbine at F.E. Warren AFB, Wyoming ............................................... 1

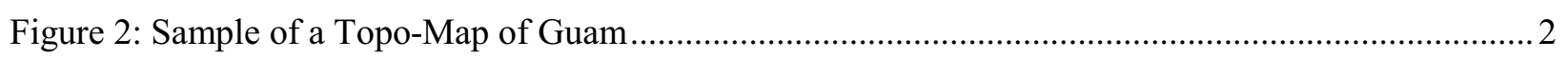

Figure 3: Initial site visit photo of radar tower at AUTEC, Bahamas...................................................... 3

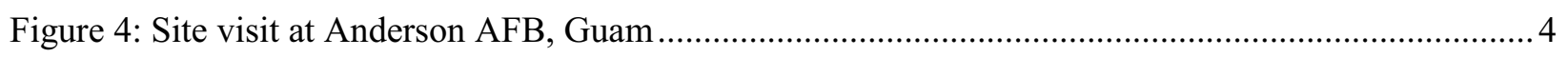

Figure 5: Gerald Fleischman Identifies flagging on a tree near Lava Hot Springs, ID............................. 5

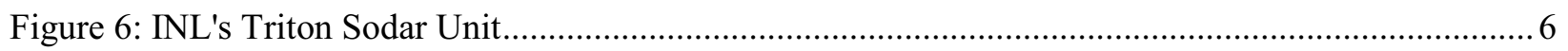

Figure 7: 34m Met Tower Installation at 29 Palms MCB, CA ......................................................... 7

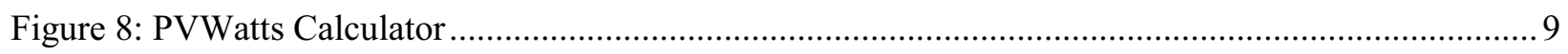

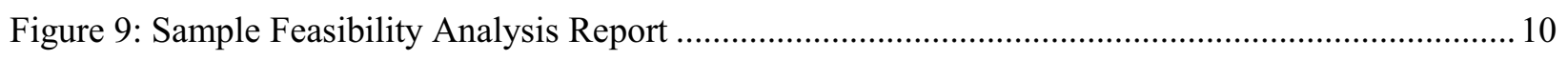

Figure 10: Topo \& Google Maps of Barstow MCLB, CA ….............................................................. 11

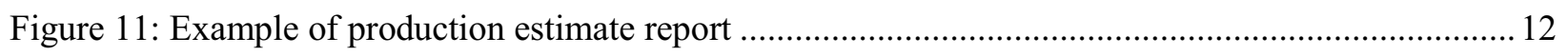

Figure 12: Wind turbines and Military Missions can co-exist............................................................... 14

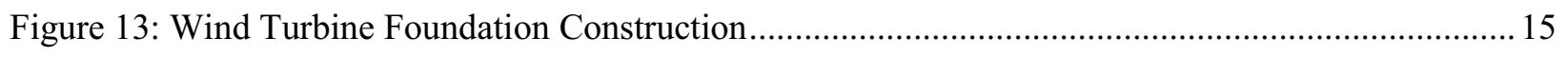

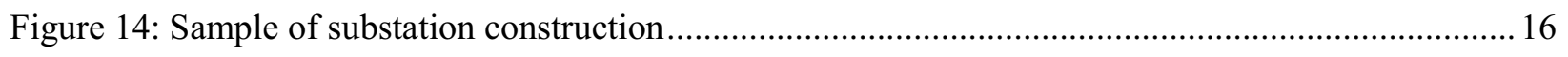

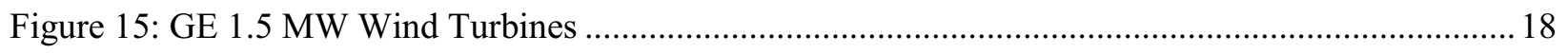

Figure 16: An EA ensures that bald eagle habitat is protected. ........................................................... 20

Figure 17: Coastal project sites can impact habitat used by avian, bats, and fish...................................20

Figure 18: Avian studies help determine if sage grouse leks are in or near a project site. ......................21

Figure 19: Some wind projects are curtailed during bat migration months............................................2 22

Figure 20: Conducting an EFH assessment ensures steelhead habitat is protected. ..................................23

Figure 21: Erecting a Met Tower at Cape Romanzof AFS, Alaska .........................................................2 24

Figure 22: U.S. Military deploys mobile solar power in Afghanistan. ................................................. 25

Figure 23: Photo simulation of a project site from 1.9 miles away. ........................................................ 26

Figure 24: Mitigating issues between missions and renewable projects..................................................2 27

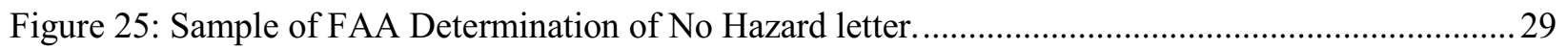

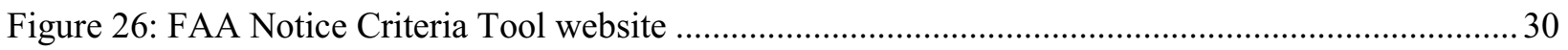


Figure 27: Bing Maps image of Radar at Buckley AFB, CO ............................................................ 31

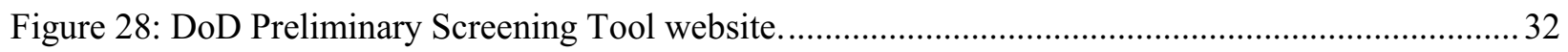

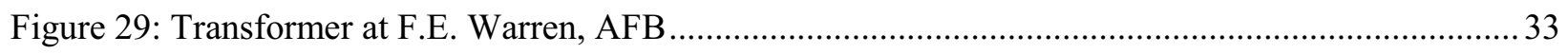

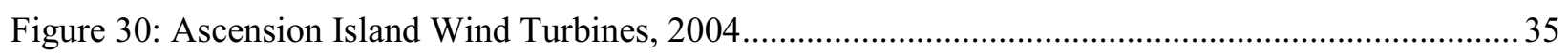

Figure 31: Kurt Myers at the Ascension Island Wind Turbine Site ...................................................... 36

\section{EQUATIONS}

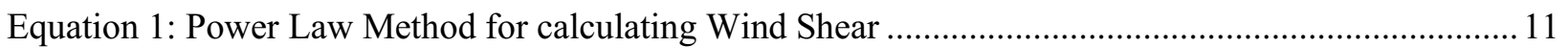

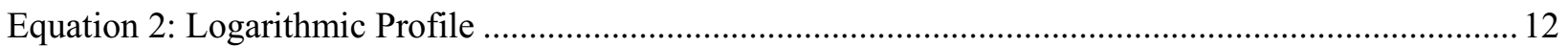

TABLES

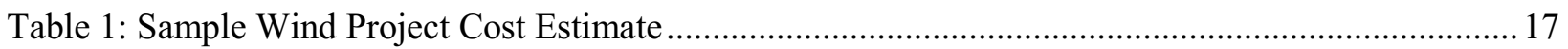




\section{ACRONYMS}

AFB:

AFS:

AGL:

ANG:

ATC:

AUTEC:

Availability:

BA:

DOD:

DOE:

EA:

ECIP:

ESA:

ESPC:

EFH:

EULA:

INL:

FAA:

$\mathrm{kW}$ :

$\mathrm{kWh}$ :

LCC:

$\mathrm{m}$ :

$\mathrm{m} / \mathrm{s}$ :

MCB:

MCLB:

MCRC:

Met (tower)

MW:

NAVFAC ESC:

NB:

NCT:

NEB:
Air Force Base

Air Force Station

Above ground level

Air National Guard

Air Traffic Control

Atlantic Undersea Test and Evaluation Center

The percentage of time that a wind turbine is available to operate

Biological Assessment

Department of Defense

Department of Energy

Environmental Assessment

Energy Conservation Investment Program

Endangered Species Act

Energy Savings Performance Contract

Essential Fish Habitat

End User Lease Agreement

Idaho National Laboratory

Federal Aviation Administration

Kilowatt

Kilowatt-hour

Life cycle cost

Meters

Meters per second

Marine Corps Base

Marine Corps Logistics Base

Marine Corps Reserve Center

Meteorological tower, with wind data measurement equipment (anemometers)

Megawatt

Naval Facilities Engineering Service Center

Naval Base

FFA Notice Criteria Tool

Naval Expeditionary Base 
NEPA: $\quad$ National Environmental Policy Act

Net metering: A method of crediting customers for electricity that they generate on-site to offset their own electricity consumption

NOAA: National Oceanic \& Atmospheric Administration

NREL: $\quad$ National Renewable Energy Laboratory

NSB: $\quad$ Naval Submarine Base

O\&M: $\quad$ Operations and maintenance

OEAAA: Obstruction Evaluation / Airport Airspace Analysis

PPA: $\quad$ Power purchase agreement

PST: DoD Preliminary Screening Tool

RAF: Royal Air Force

SGIP: $\quad$ Self Generation Incentive Program

UESC: Utility Energy Service Contract

USFWS: $\quad$ U.S. Fish \& Wildlife Service

VAR: $\quad$ Volt-amperes reactive power

Weibull: $\quad$ A mathematical function used to describe frequency distributions of wind speeds

Wind shear: The increase or decrease in wind speed at higher elevations above the ground 
This page intentionally left blank. 


\section{Developing Government Renewable Energy Projects}

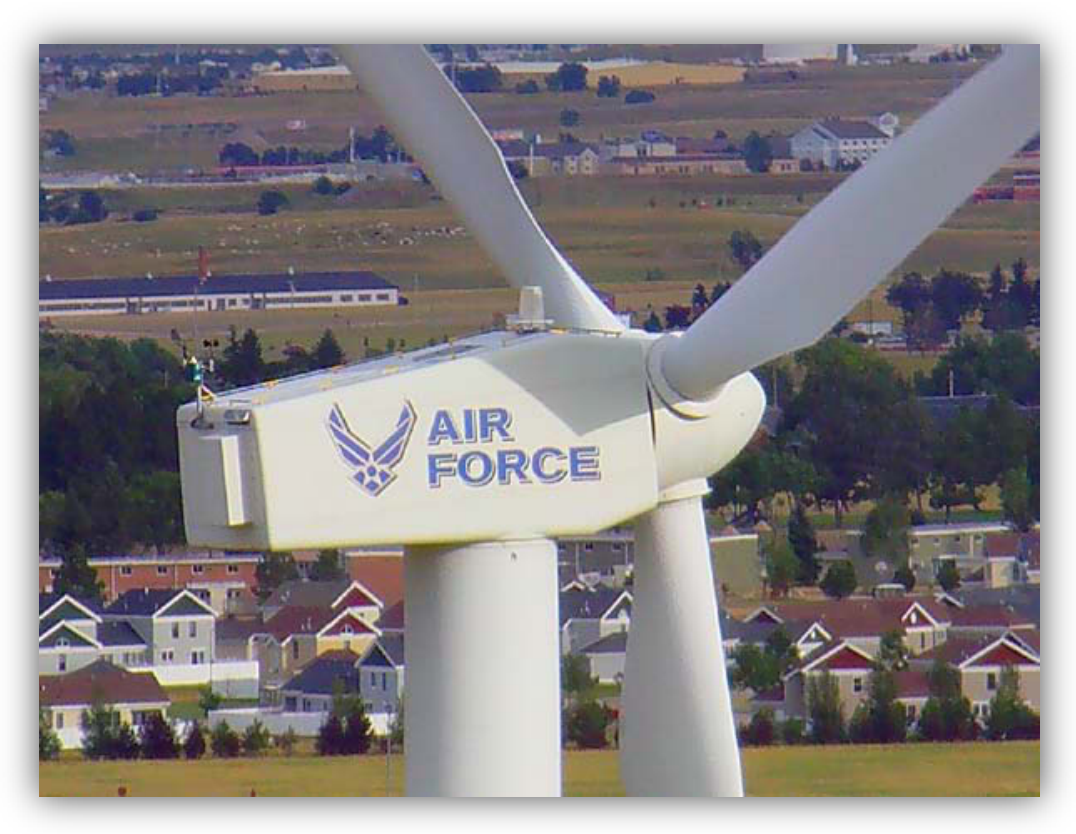

Figure 1: 660 KW Vestas Wind Turbine at F.E. Warren AFB, Wyoming

\section{Initial Development Steps}

The initial development phase is where the basic, ground-breaking work is done to determine if the project will be feasible and if justification is sufficient for additional work scope to occur. Note that this report is geared more towards wind projects.

\section{$1.1 \quad$ Initial Planning \& Pre-site Visit}

Once a potential government site for hosting renewable energy has been identified, some basic project information can be compiled. A lot of this information can be gathered before or during the initial site visit (see Appendix A for Assessment Timeline Template):

- Compile contact list of personnel involved with project (Energy manager, Facility manager, Military mission personnel such as AirOps or Radar, etc.)

- Identify any potential environmental issues for the Project area (such as Bat migrating zone, Sage grouse leks, historical artifacts, view-shed issues, etc)

- Identify any Base exclusion areas (firing range, housing area, etc.)

- Identify any potential mission impacts (AirOps, Radar, etc.)

- Collect maps of project area (wind maps / topo maps) and then indentify potential sites based on best elevation / least obstacles, potential wind "hot" spot, and possible transmission line options

- Gather current daily/annual load details (KW), Monthly energy consumption for 1-2 years, and any documentation of energy costs $(\$ / K W h)$ or any other unique rate structure

- Collect any pre-existing data from the site or nearby sites (such as wind data, solar data, etc.) and briefly evaluate potential 
- Collect any information about road infrastructures and soil integrity in potential site location(s)

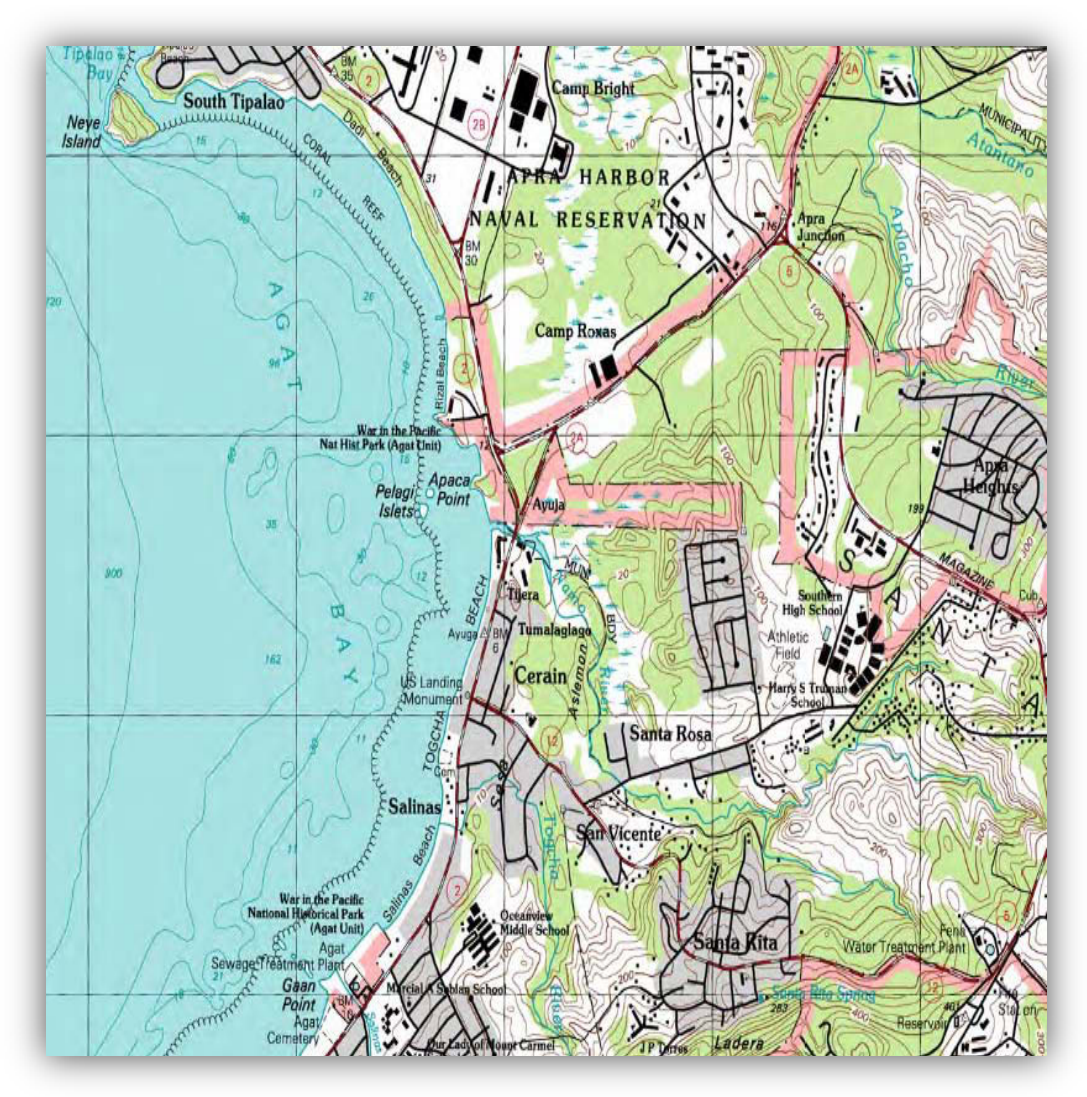

Figure 2: Sample of a Topo-Map of Guam 


\subsection{Site Visit Agenda}

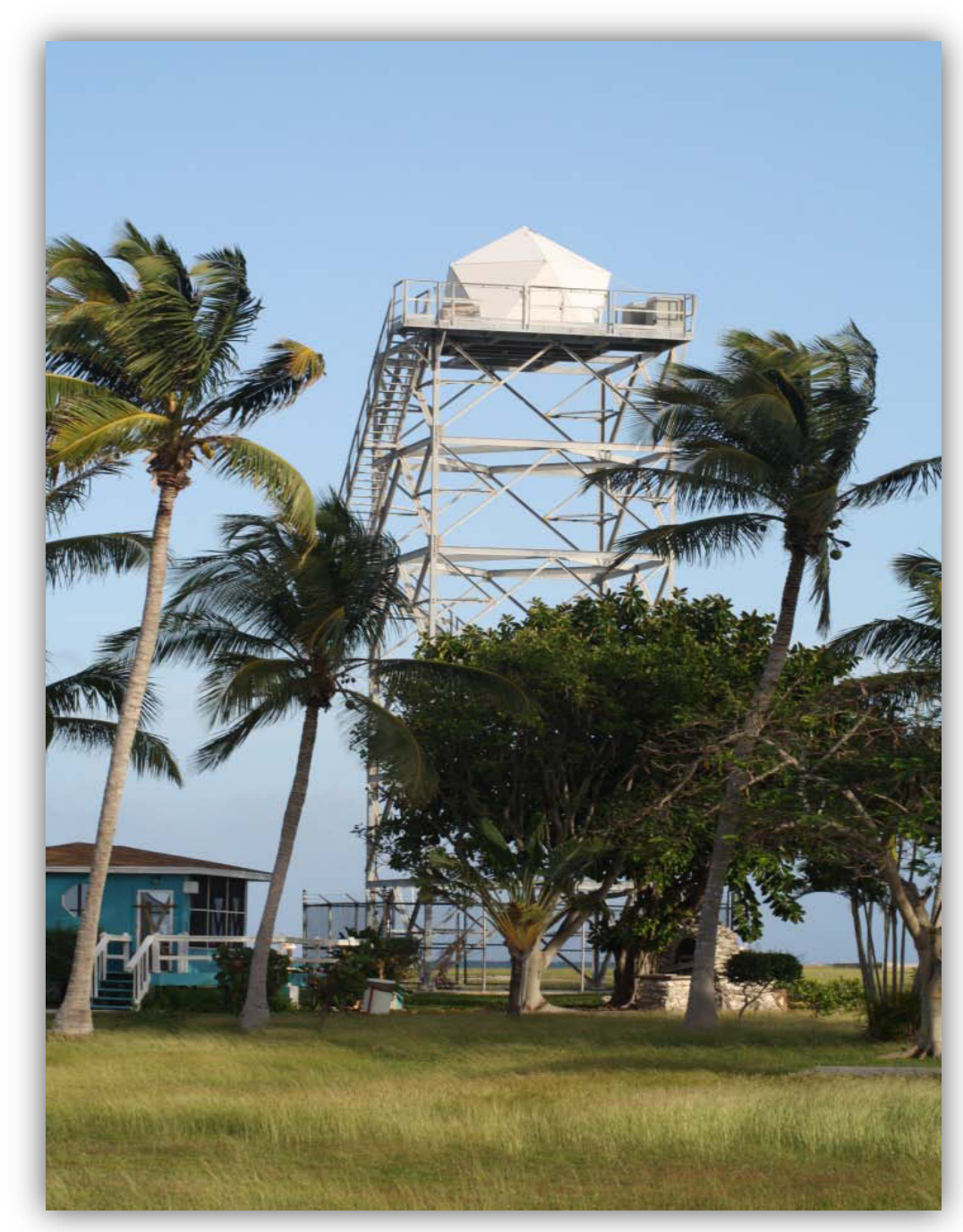

Figure 3: Initial site visit photo of radar tower at AUTEC, Bahamas

During the initial site visit there is multiple tasks that can be performed and having an agenda will help stay organized while completing those tasks. An example Site visit agenda is:

- Meet base personnel and conduct safety briefing \& explain planned activities.

- These people should include:

- Representative from Base Command

- Base Energy Manager

- Base Environmental Manager

- Civil Engineering

- Base Meteorological Manager 


\section{- Base Planning}

- Meet individually with various groups to interview and collect data (meteorology, power load and rates, transmission system, environmentally sensitive regions, etc.)

- Discuss access requirements for various areas of potential site locations and make necessary arrangements to investigate sites

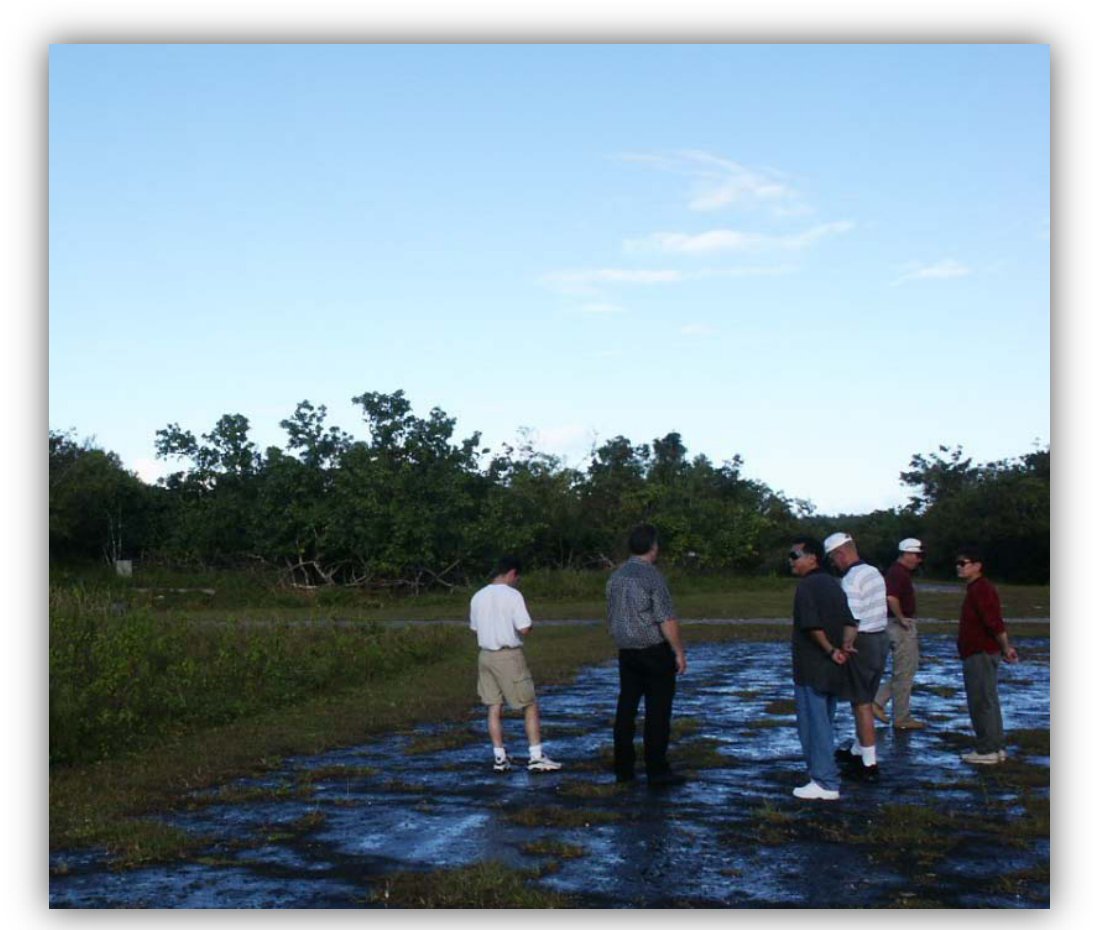

Figure 4: Site visit at Anderson AFB, Guam

- Perform field visit to potential sites of interests (noted on pre-site visit maps and with appropriate base personnel)

○ Look for:

- Flagging on trees

- Spot forward of ridge \& perpendicular to prevailing wind

- Spot on a hill that is the highest elevation in the area

- Trough where local wind might funnel

- An available area with low current use of the land, and no obstructions (trees, buildings, etc.)

- Line of sight issues with nearby radar

- Proximity of transmission lines

- Ground conditions that might complicate Met tower install, turbine foundation, roadways, etc. (Rocky terrain, sandy terrain, etc.) 
- Identify the best location and several alternate locations that best resemble an ideal turbine location

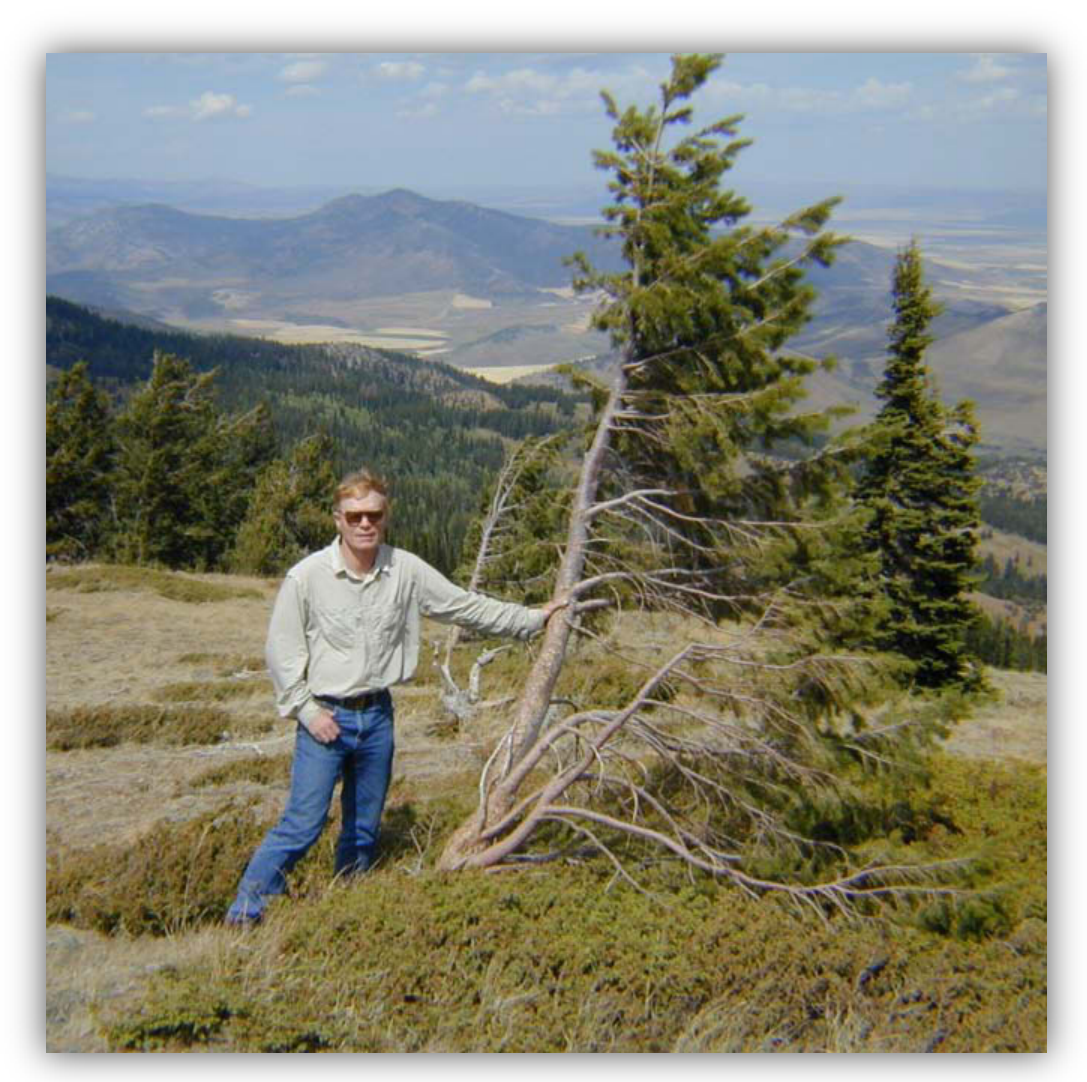

Figure 5: Gerald Fleischman Identifies flagging on a tree near Lava Hot Springs, ID

- Verify any environmental or mission impacts in or near potential sites determined during field visit

- Photograph site locations to document for later use

- Conduct out brief to discuss results of the site visit assessment, answer questions, and outline next steps

When the pre-site collection and site visit have been completed, several post-site visit decisions can be made:

- Determine type/size of Data collecting equipment

- Generally this would include a tower over 30 meters which provides two different collection heights in order to determine wind shear

- Set Date for equipment installation and determine responsibility for ordering equipment

- Determine who is responsible for swapping data chip and when the swaps should occur $\left(1^{\text {st }}\right.$ month, every 3 months, etc.)

- Determine who will analyze data and compile wind resource report 


\subsection{Data Collection Equipment}

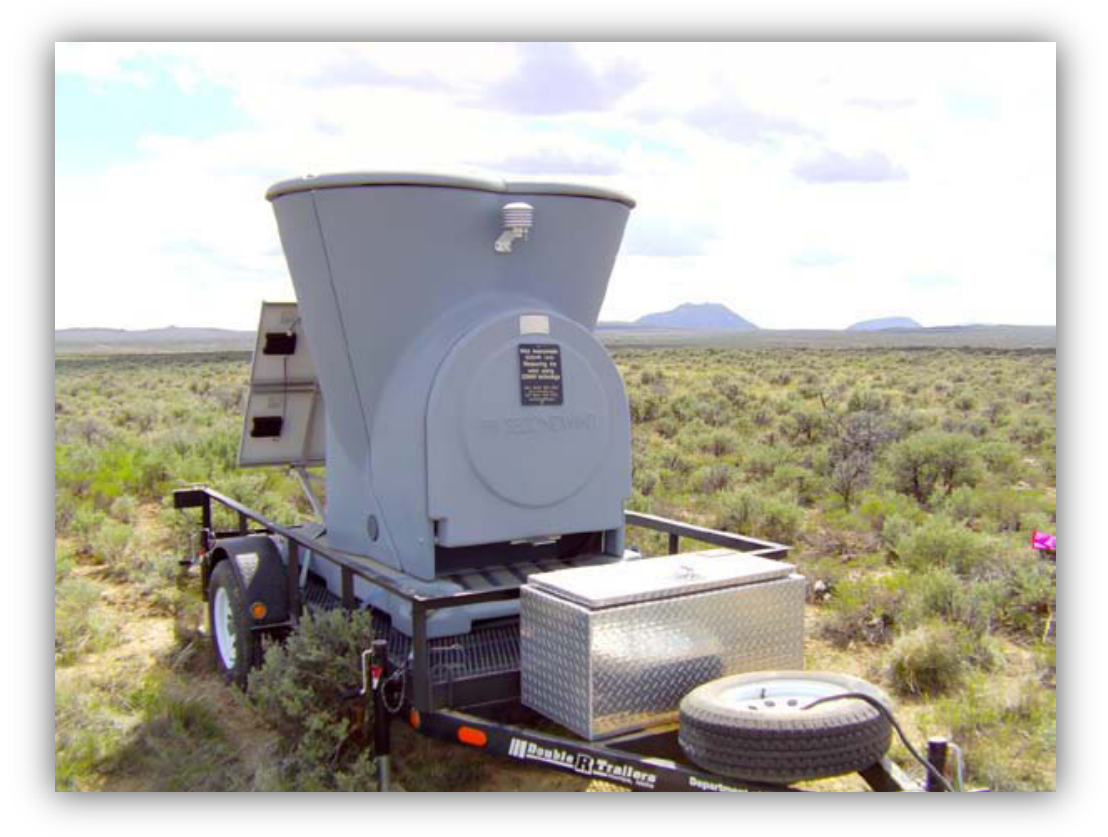

Figure 6: INL's Triton Sodar Unit

The wind resource in an area needs to be validated because it varies significantly at specific sites within a geographical area. Several sources such as wind maps, people's

experiences/opinions, and flagging can give you a general idea as to the potential of wind but are never good enough to be used as justification to proceed with a wind project. It is also important to note that people's perceptions of a "windy spot" are not always reliable because we all see and feel things differently.

There are several equipment options for collecting wind data. Vendor data sheets have been included in Appendix B as extra information but please note: references to any specific commercial product, process, or service by trade name, trade mark, manufacturer, or otherwise, does not necessarily constitute or imply its endorsement, recommendation, or favoring by the U.S. Government or any agency thereof. With that said, it is important to decide what type of wind data collecting equipment will work best for the project being planned. For example, is the project small enough $(<100 \mathrm{KW})$ to use prospecting data towers or is it large enough $(100 \mathrm{KW}+)$ for developmental quality equipment. Wind Meteorological (Met) towers range from the prospecting 10 meter tower all the way up to development quality 80 meter towers. Two other options for collecting wind data at the developmental quality level are sodar units and lidar units. Sodar, or Sonic Detection and Ranging, is a wind profiling instrument which measures the scattering of sound waves by atmospheric turbulence. Lidar, or Light Detection and Ranging, is an instrument that uses light to measure distance and other properties of a target. Both Sodar's and Lidar's can collect wind data at multiple levels such as every 5 Meters from 40 to 200 meters. Price ranges for this equipment would start with Met towers usually being the cheapest option, Sodar's being a mid-range option, and Lidar's being the most expensive. However, the exact costs vary depending on brand, size, type, specifications, etc. 


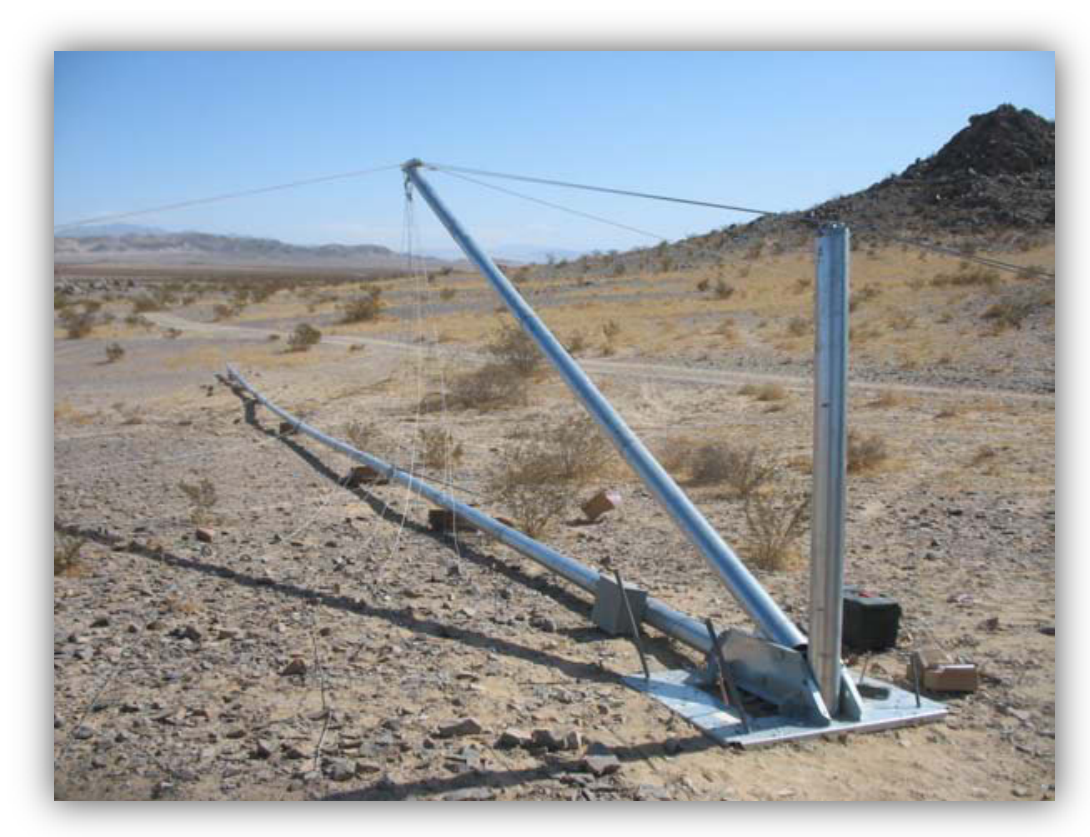

Figure 7: 34m Met Tower Installation at 29 Palms MCB, CA

The most common means of data collection for a government project would be done with a Met tower and the size varies depending on several factors. Funding, timing, and project size all play a part in deciding whether to use a do-it-yourself 10m tower (see Appendix C), a 34m tower, or the larger $50 \mathrm{~m}-80 \mathrm{~m}$ towers.

After the Met tower equipment has been purchased and an install date has been set, there are further tasks that can be completed:

- File NOTAMS (Notice to Airmen, if AirOps is present)

- Verify that the site has significant clearance (stay away from power lines)

- Verify any environmental approvals have been received

- Verify site has been cleared of ordinance, if necessary

- Verify any other mission conflicts have approved install

- Verify base requirements for courtesy lighting on Met Tower (NVG lighting, L-810 lighting, or smaller AV70 lighting)

- Double check site install location matches the coordinates of the actual approved site location

The task of installing a Met tower can be contracted out to a professional Met tower installer who has the tools, experience, and expertise to ensure the install is a success, especially when doing the larger $50+$ meter towers. If the appropriate sized winch is available then contracting is not always necessary and can be performed with a team of $3-4$ people. The following guidelines and precautions should be considered when performing a Met tower install:

Installation should be supervised by an experienced installer of wind data towers and equipment (i.e. more than 10 successful tower installations). All other installers supporting 
the effort should have experience and/or training specific to these types of tower or equipment installations.

Before the start of any wind data equipment installation, the job supervisor should conduct a pre-job briefing/review to discuss the specific job, and if there are any site-specific conditions or differences to address.

If mechanical auguring truck or backhoe is necessary for installation of tower anchors, the operation of that equipment will be performed by a qualified operator. If mechanical hand augers/drills, mechanical hammers or hammer drills are necessary for installation of tower anchors then that also should be addressed with a qualified operator.

If installing a wind data tower in an agricultural area, notify appropriate parties and install warning devices as needed (i.e. guy wire visual warning flags or bird diverters, red and white paint scheme in top of tower, etc.). Towers can pose a threat to low-flying crop dusting aircraft. Ensure that appropriate FAA, site specific, and base requirements are met before installing a wind data tower. Permitting height requirements can vary from county to county and site to site. Generally, tower lighting is not required by FAA as long as the tower is less than 200 feet tall.

When performing outside field-work, weather conditions need to be reasonable to support installation without major body stress, and that site access and working conditions are not significantly impacted due to muddy conditions, snow or other similar issues. Do not raise the tower if sustained winds are over $25 \mathrm{mph}$. Do not raise the tower if lightning storms are within a close proximity to the installation site.

Other warnings and important instructions ${ }^{\text {a. }}$ :

- Do not climb tower.

- Do not use mechanical tensioning devices to adjust guy wires.

- Do not stand in line with, directly in front of, or behind any tensioned cable.

- Do not oil tower joints. This can cause tower failure if the tubes "self flare".

- Do determine the soil type at your site and install the correct anchors.

- Do place tower anchors according to manufacturer's recommendations.

- Do properly ground the tower electrically.

- Do stand to the side of any tensioned cables.

Note: Tall Towers can be installed on slopes up to 12 degrees. When laying out a Tall Tower installation on a slope, measure the tabulated distances along the ground to place the anchors. It is not necessary to compensate for the slope. Tall Tower guys are cut long enough to allow for installation on slopes up to 12 degrees while maintaining the ideal angle between the tower and the guys.

Note: The side guy anchors and the base plate should be on a straight line. If it is not possible to place them exactly in line, it is better to move an anchor in or out along this line, but no more than $1.5 \mathrm{~m}$ ( 5 feet) off the line. Some sites may require a compromise of this, as anchors may not be able to be located at the preferred spot.

Note: Extra care will have to be taken while raising the tower if:

- The anchor placement is not perpendicular to the tower.

\footnotetext{
${ }^{a}$ Courtesy of NRG Tall Tower Installation Manual-Rev.7.11 Please refer to www.nrgsystems.com
} 
- The anchors are not at the same elevation.

- The side anchors and base plate are not in a straight line.

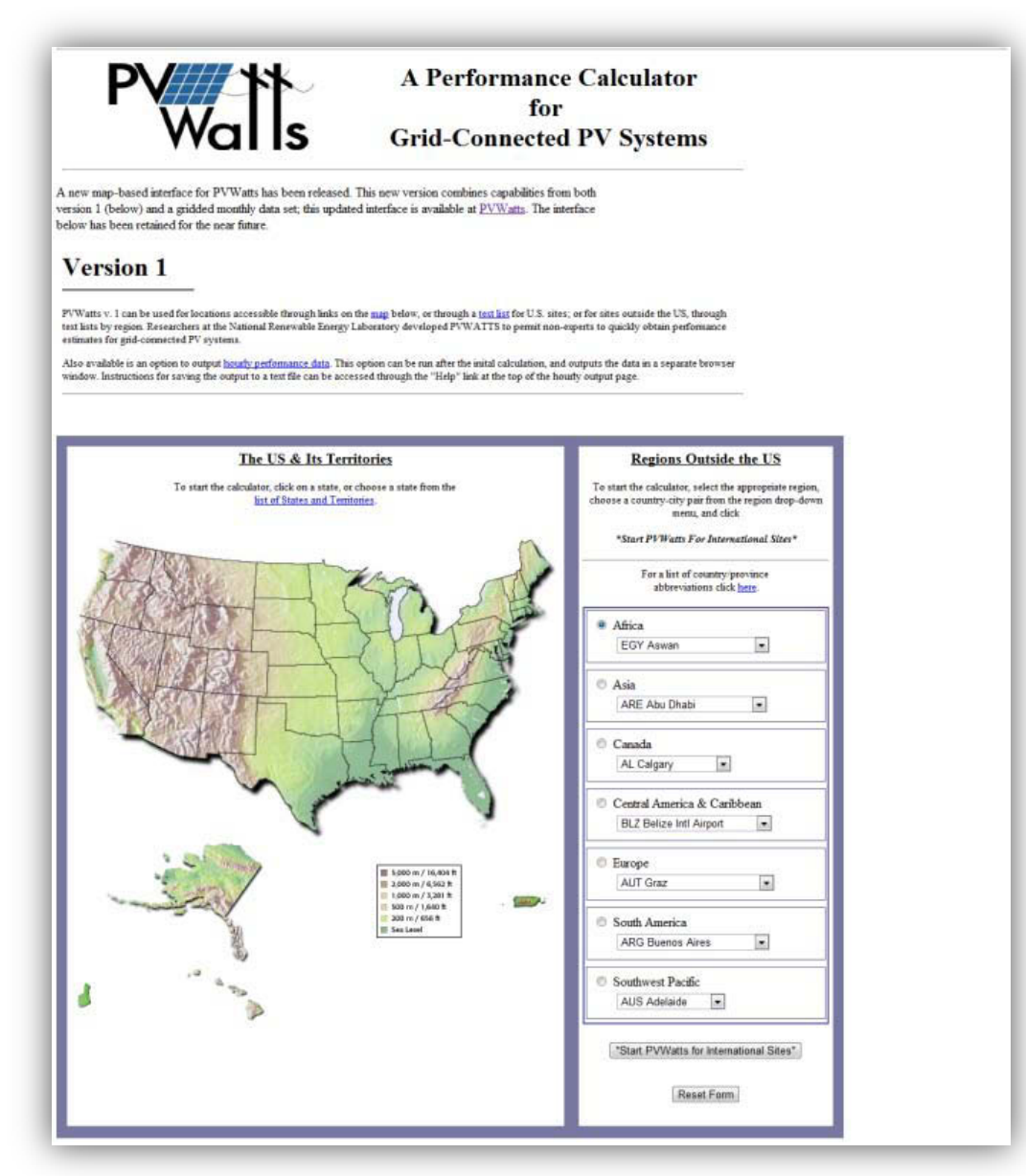

Figure 8: PVWatts Calculator

Solar resource data differs from wind as it has very little variance over a large geographic area. NREL's solar resource maps and their PVWatts website can be used to determine a fairly accurate idea of a sites solar resource. A site that is in a sunny place (i.e. no shading from obstacles), is reasonable close to a grid connection point, and shows good potential on solar maps or PVWatts, would most likely be an ideal location as long as other factors such as high temperatures and soiling are accounted for. 


\section{Resource Feasibility Analysis Reports}

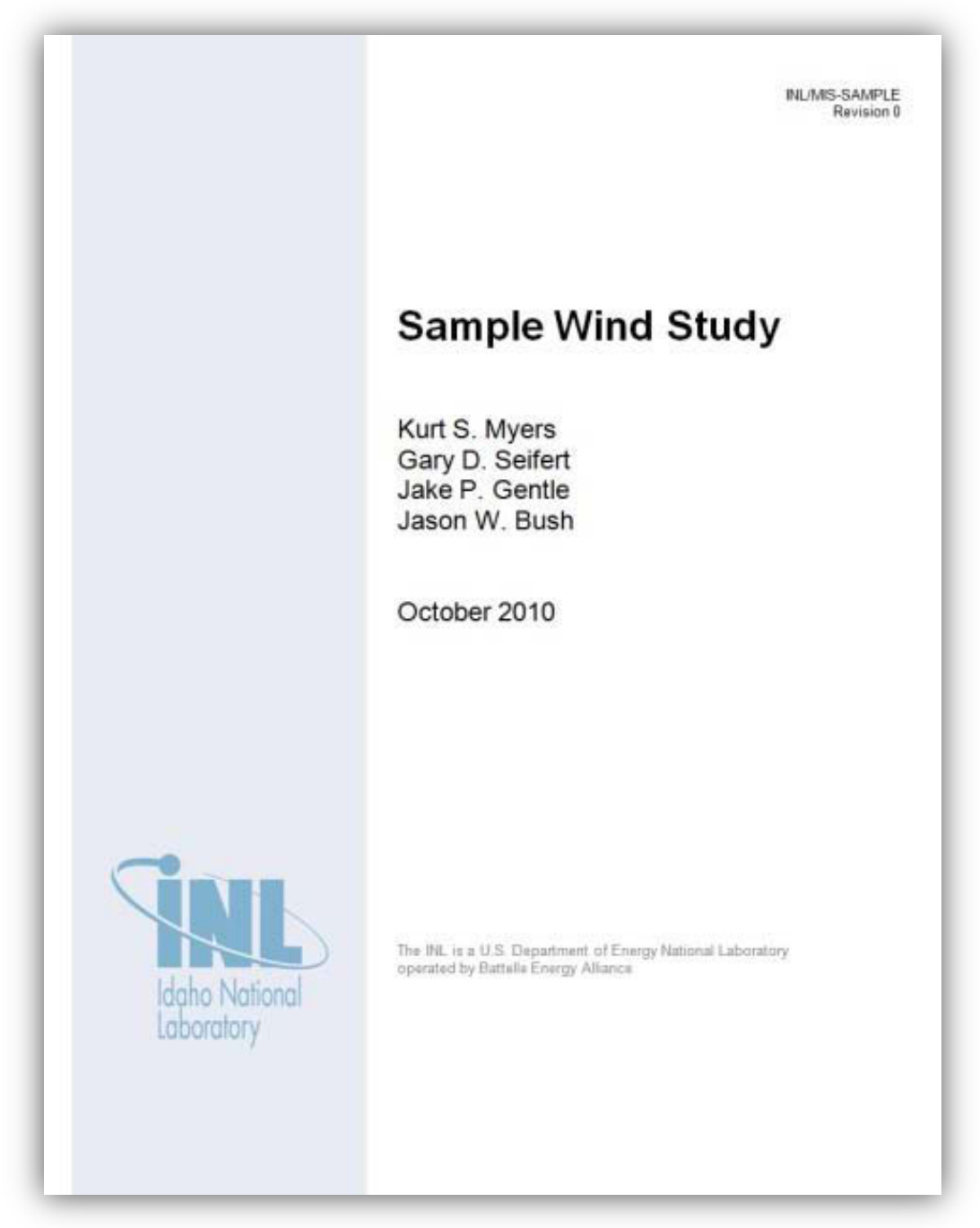

Figure 9: Sample Feasibility Analysis Report

Resource feasibility analysis reports are a valuable tool used for justifying and guiding a government renewable energy project. INL has years of experience completing feasibility reports, and the next sections and sub-sections go over what to expect from a feasibility report and is based on an actual wind feasibility report. However, please be aware that other renewable energy sources could also be analyzed and would have very similar topics as the ones discussed below.

\subsection{Resource Assessment Analysis Discussion}

\subsubsection{Location}

The first section of a feasibility report contains location details as well as a general description of the area, base, and site location. This can include detailed topo maps and Google earth images. 


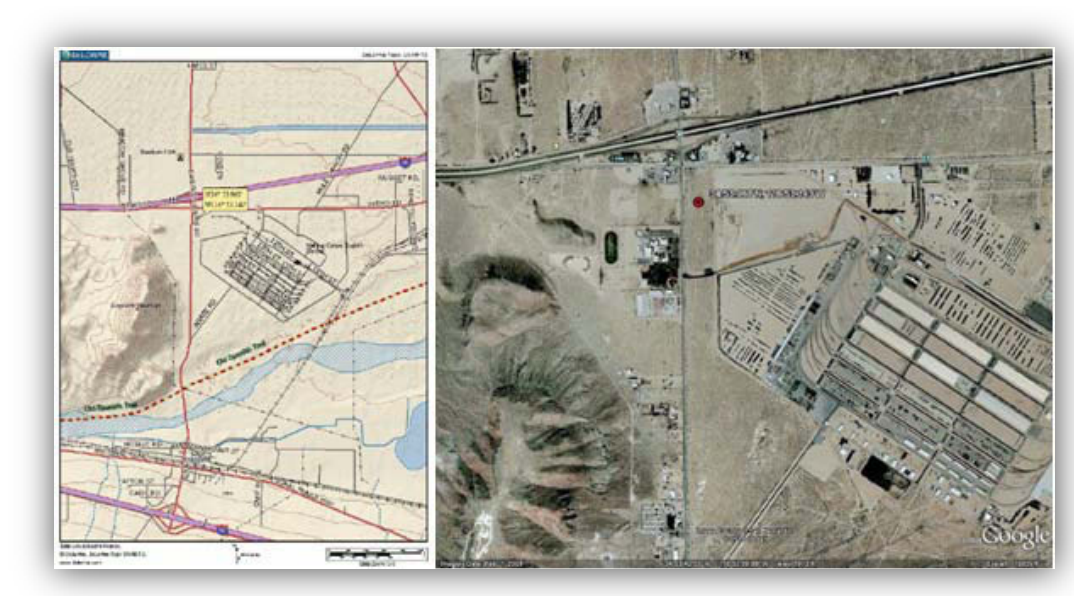

Figure 10: Topo \& Google Maps of Barstow MCLB, CA

\subsubsection{Wind Parameters}

This section of the feasibility report addresses the wind data that has been collected by giving details of:

- Date Range

- Met Tower Type

- Site Number

- Location (Coordinates)

- Boom Length

- Anemometer Heights

- Wind Vane Heights

- Temperature Sensor Types

It also discusses the results from the data collected such as the annual wind speed average, the weibull shape alpha, the wind shear (using the power law method), and turbulence intensity. Any comparisons to other data obtained from the local area will be stated as well as an estimate for a conservative long-term annual average. Another technique that is often used to estimate a wind profile is done using the logarithmic profile. Here a graphical plotting of the data collected will produce a site specific equation based on a natural logarithmic fitting of the data collected and the surface roughness.

$$
\begin{aligned}
& \alpha=\log \{V 2 / V 1\} / \log \{Z 2 / Z 1\} \\
& \mathrm{V} 2=\text { wind speed average at height } Z 2, \\
& \mathrm{~V} 1=\text { wind speed average and height } \mathrm{Z} 1
\end{aligned}
$$




\section{$\mathrm{WSz}=(\mathrm{u} * / \mathrm{k}) * \mathrm{LN}[\mathrm{Z} / \mathrm{Zo}]$}

Equation 2: Logarithmic Profile

\subsubsection{Energy Production Estimates}

Here the energy production estimates are done using the above wind data analysis and will compare the differences in production for different sizes, models and brands of wind turbines. There are a lot of options when looking at wind turbines and this energy production comparison can be a very useful tool to narrow down which turbines would be a great fit for a specific site. This report can identify the production differences between a low wind turbine model and a medium wind turbine model. This information can help justify the higher cost for a larger rotor, low wind turbine.

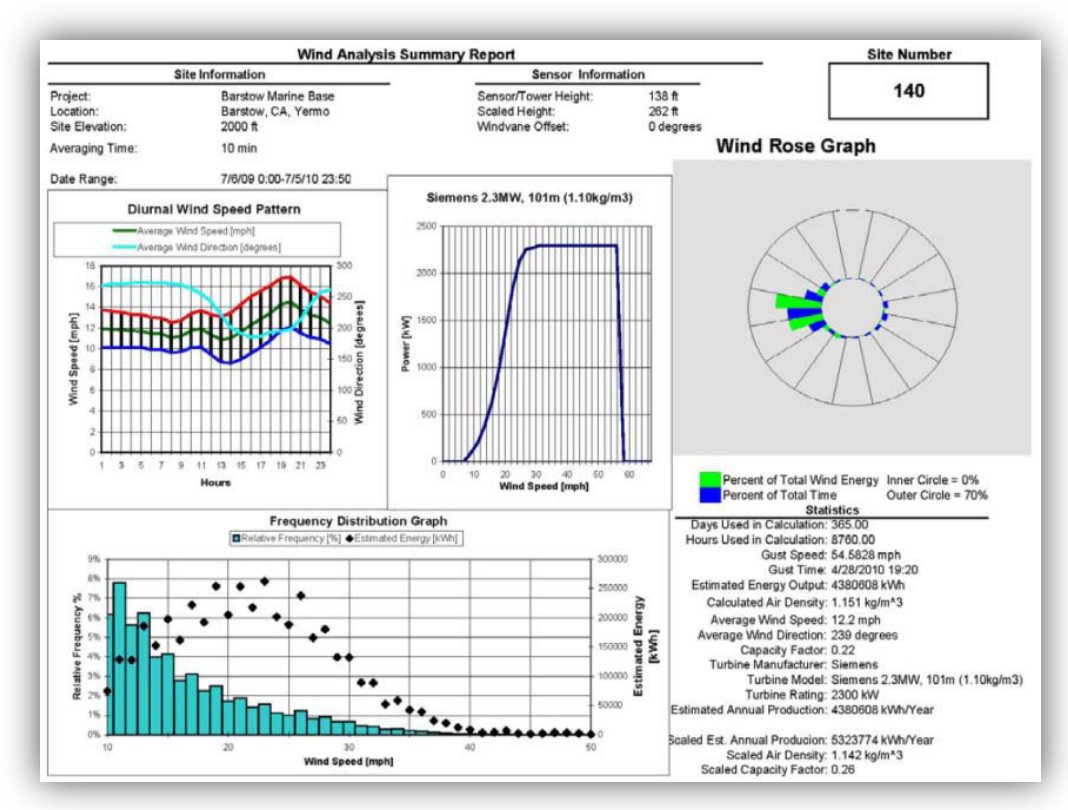

Figure 11: Example of production estimate report

\subsection{Preliminary Feasibility Analysis}

\subsubsection{Potential Wind Turbine Technology}

This section details modern options for wind turbine technology and why a certain turbine would be considered for a project. Even though typical energy loads vary depending on the project, they are usually large enough to implement turbines ranging from 1.0 to 4.0 MW in size. However, there are times when large turbines cannot be used and several smaller ones should be considered. With that said, in the past there have been times when it was difficult to procure small numbers of large wind turbines. In more recent years, things have been a lot better with regards to purchasing large 
individual turbines for smaller wind projects. We've talked to all the major vendors about several small wind projects and most of them have been willing to support. This includes GE, Vestas, Siemens, Suzlon, and could probably be extended to RePower, Clipper, Acciona, Nordex and Fuhrlander. Most of these companies (with the exception of probably the last 3 in this list) have significant numbers of turbines installed in the US, and most of those have significant numbers moving toward the Western US. Good contacts are made relatively easy with most of these companies, and the support we have received recently has been quite good. Most of the manufacturers listed above now have the experience and installed product base to provide a good product with support in the U.S.

It is highly recommended that the turbine selected has a quality warranty, maintenance plan and contract. Third party maintenance companies can be accessed through a contracting process, but experience and contract terms are important in getting the kind of service expected. It can also depend on the number of projects in the local area as to how successful you will be in finding good maintenance companies. The other item to consider with O\&M is to get some training done for the Base engineering and operations shop, and to perform the first-level, less-technical troubleshooting, monitoring and resets on the turbines with on-base personnel to support the maintenance contractor. This type of interaction will keep the turbines running more often, and reduce unnecessary visits, down-time (before somebody notices that the turbine is not running), and extra costs from the regular maintenance contractor.

\subsubsection{Adjacent Land Uses and Compatibility}

This section looks at the siting of the turbines beyond finding a site with good wind. Potential turbine sites should also be looked at for compatibility with the surrounding area and base missions. Ideally an undeveloped, un-utilized, sizeable area of barren land (with good wind) is what to look for. Reviews should be done for environmental conditions and a site with low sensitivity is also ideal. Some conditions that could need attention are:

1. Nearby bodies of water that could attract migratory birds or birds of prey.

2. Moderate levels of human use and habitation within 1/4 mile.

3. A wind turbine of the large size class can be a very tall structure when compared to the rest of the structures in the siting area. Visual impacts can be a concern for some, and although that is usually not a showstopper for most wind projects, it is something to be aware of. While usually supported by a majority, some wind projects inspire a minority of people to push a negative agenda.

4. Endangered species such as the Pygmy Rabbit, Sage Grouse, or Desert Tortoise may be in the area, and mitigation or relocation may be necessary.

It is worthwhile to conduct thorough, fact finding reviews for environmental, public, and military operations issues and deal with them upfront. Military operation reviews should also include airspace and radar compatibility. 


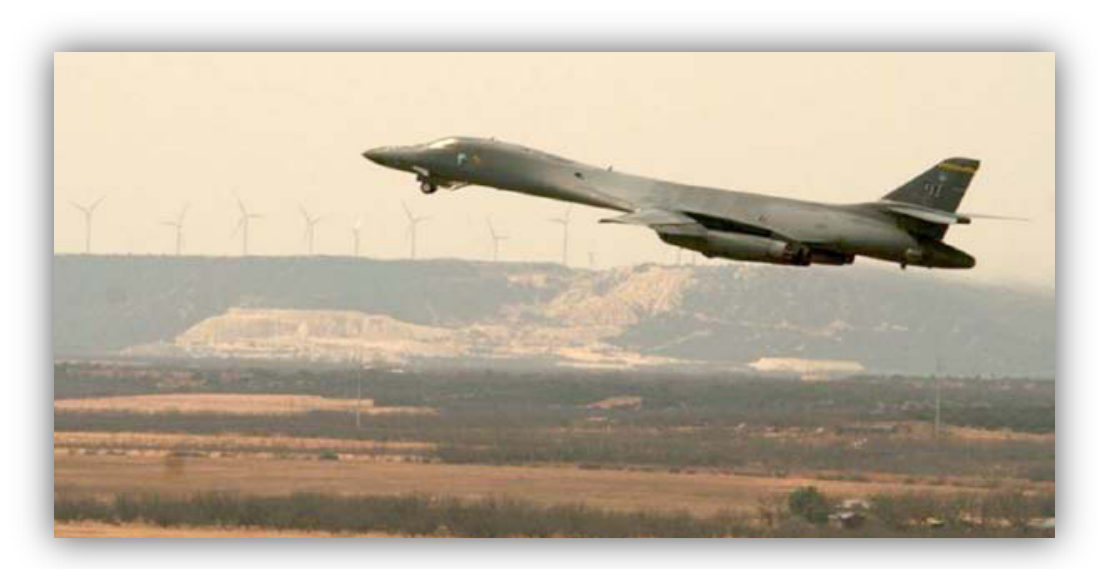

Figure 12: Wind turbines and Military Missions can co-exist

\subsubsection{Permitting and Land Use Policies}

This section identifies any permitting or policy issues that might come into play depending on the specific site. Typically government projects will be on federal land and fall under the jurisdiction of the federal agency responsible for the land. City, county and state officials should be consulted to determine if any approvals or permits are needed for you particular site.

\subsubsection{Physical Aspects}

This section deals with what happens after the site has cleared the review and approvals processes. Basic assumptions of soil and terrain type can be made but a seismic investigation and subsurface soils testing and analysis by a qualified geotechnical and civil engineering consultant will be needed to be certain. Surface evidence, soils investigation and observation of nearby structure construction will help determine if there are any obstacles to watch out for with the foundation construction. Access to the site also needs to be looked at to determine if there are existing paved roads and/or heavily compacted dirt and gravel areas near/at the site. A crane pad area also needs to be identified that would be suitable for use during the construction phase. Setbacks from main roads and property lines should typically be at least 1-1.5 times the tip height of the wind turbine, although in tight areas on federal projects allowances can be made for slightly closer setbacks, as long as blades will not overhang roads or property lines or get close to any overhead lines during or after turbine assembly and erection. 


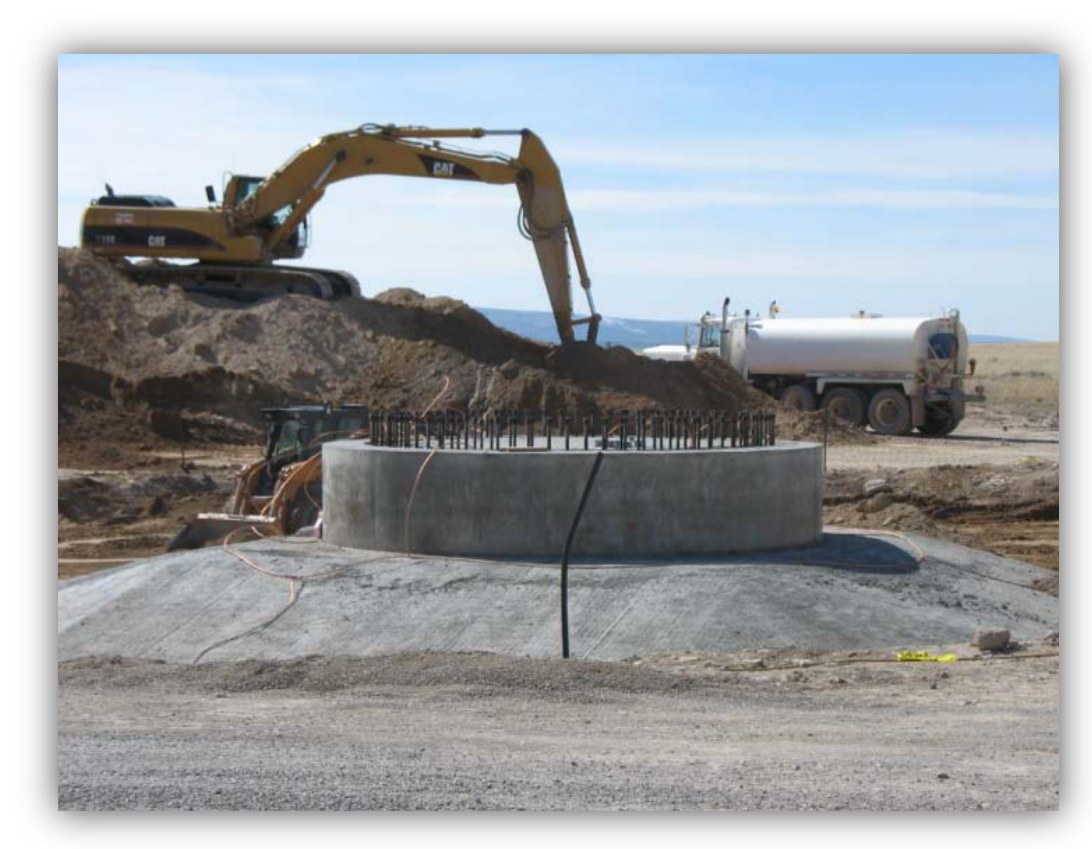

Figure 13: Wind Turbine Foundation Construction

\subsubsection{FAA and Other Mission Impact Reviews}

This part of the report goes over the Federal Aviation Administration (FAA) procedures and other mission impacts. The FAA requires structures over 200 feet to be filed in their OEAAA system for regulatory review, and lighting per FAA standards is typically required. Proximity to airports, military air space, and helicopter operations will be analyzed and any air traffic concerns in the proposed location addressed. If the decision is made to move forward with a wind turbine installation, a filing will be required with the FAA via the 7460 process to review the proposal for potential obstructions to air traffic and for interference with radar systems. Other operational reviews for potential impacts to Base missions should also be undertaken within the facility, so that major stakeholders have a good understanding of the potential project and if it will have any significant impacts to their missions. The expected requirement for lighting from the FAA will be a white turbine (industry standard is actually a little offwhite to somewhat reduce visual impacts) with a medium intensity flashing red light (type L-864) on top of the turbine for nighttime use.

\subsubsection{Site Size and Configuration}

Here an analysis of the potential turbine site and the turbine considered for the project are examined. Land size available in the project site determines the amount of turbines that can be laid out for a site. Wind speed and prominent direction also factor in to how and where the turbines are laid out. Other factors in considering layouts are setbacks, radar or air space areas, environmental issues, wake zones (if multiple turbines), and the roughness of the terrain (nearby buildings, trees, etc.). 


\subsubsection{Interconnection}

This area of the report deals with transmission of the power and analyzes the electrical interconnection options. From the beginning, when looking at potential wind turbine sites, it is important to think about how and where the power can be tied in and if any pre-existing distribution lines are available. Furthermore, a system study can be performed during the project design to determine the best interconnect options, costs, electrical parameters (load flow, system voltages, cable sizing, VAR support, short circuit study, etc.), and utility interfaces that will be required. The system design study will determine if any grid upgrades will be necessary for the project and if there will be additional costs. Typically interconnecting to the existing electrical grid will result in a type of "net metering" arrangement where the turbine is on the secondary side of the substation and utility meter.

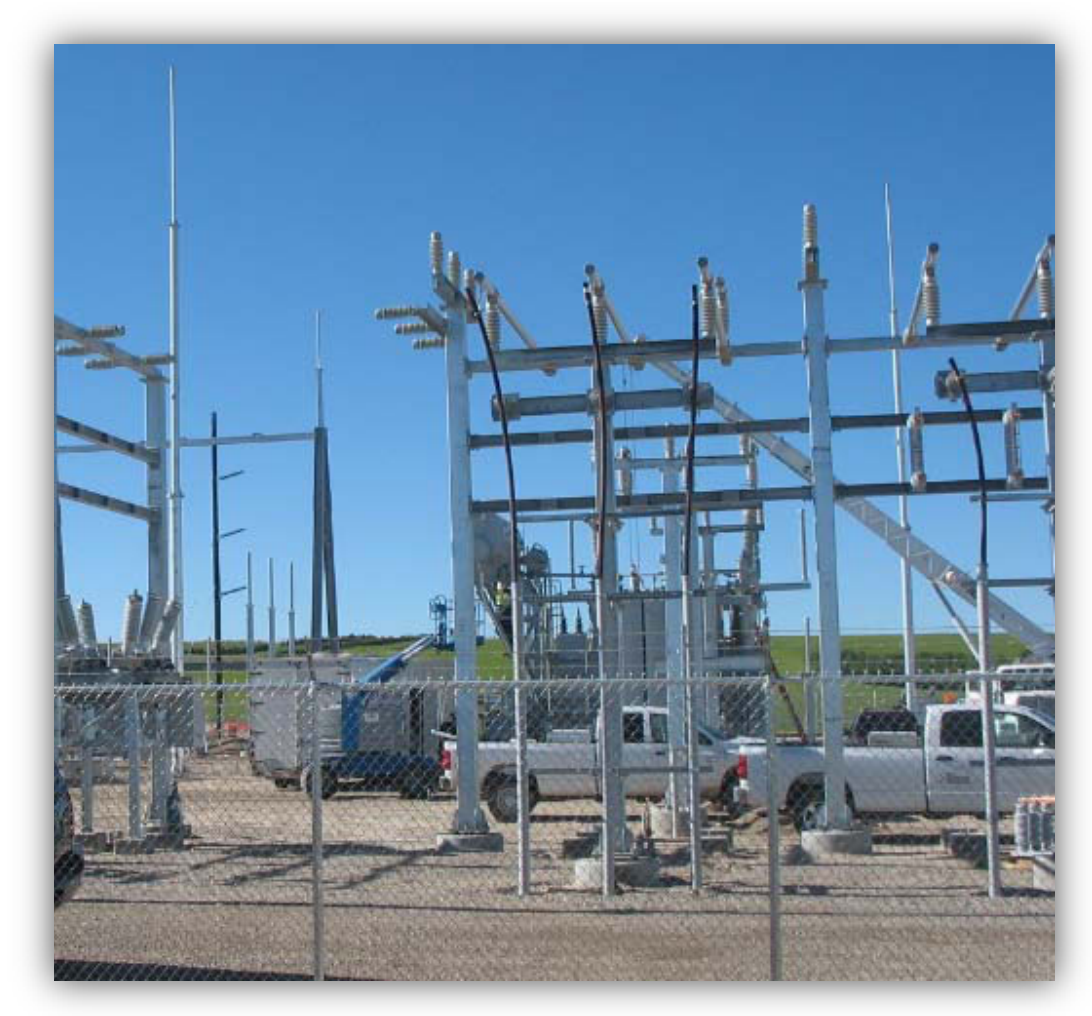

Figure 14: Sample of substation construction

\subsubsection{Incentive Possibilities}

This section details any state and federal incentives that might apply and that can be utilized to make a project more attractive. These incentives don't always fit certain projects exactly, but can be used in guiding the plans for a potential project. Several incentives to look for are net metering incentives, feed-in tariffs, and the Self Generation Incentive Program (SGIP). Analysis will be done on the incentive factors, turbine supply, and the previous reviews, siting, interconnection, and O\&M factors and then a recommended project size will be suggested for the project. 


\subsubsection{Economic Analysis}

In this part of the report we perform an economic analysis by running scenarios with potential wind turbines, incentives, siting layouts, and interconnection options. This analysis is centered on construction of the potential project utilizing ECIP funding. Of course there are other ways to develop and finance this type of project, but it is estimated that ECIP funding enables the greatest benefit to the government when dealing in renewable project development, payback period and accounting to meet renewable energy goals. Other business and financing models can be run utilizing the energy production estimates above if other development scenarios are desired. However, those types of analyses will be left to others, or on request outside of the scope of this kind of report. Other types of business models and financing for wind project development on federal land could include Utility Energy Service Contracts (UESC), Energy Savings Performance Contracts (ESPC), End User Lease Agreements (EULA), private financing and power purchase agreements (PPA), or other options.

Typical assumptions made for the ECIP LCC analyses and project construction cost estimates include: an operating period of 20 years, project's on-line date, initial warranty period of 2 years, discount rate of $3 \%$, other rates and factors given by current year FEMP rates, $100 \%$ government funded, offset SCE energy rate and ancillary charges, and annual O\&M costs.

An example of estimated project construction costs that would be used for the LCC analyses are shown in the table below. ${ }^{* *}$ These numbers may not be current and will probably vary as market/technology changes over time. They are just included as an example of the kind of information this type of report could provide.

\begin{tabular}{|c|c|}
\hline \multicolumn{2}{|c|}{ Sample Wind Project Cost Estimate } \\
\hline Cost & Description \\
\hline$\$ 2.2 \mathrm{M}$ & Cost per 1.5MW, 77m rotor turbine \\
\hline$\$ 300 \mathrm{~K}$ & Shipping cost per turbine \\
\hline$\$ 1.3 \mathrm{M}$ & $\begin{array}{c}\text { BOP install costs per turbine, if doing only one } \\
\text { turbine, includes crane, turbine electrical, } \\
\text { electrical collector system/cables, foundation, } \\
\text { civil, final design, etc. }\end{array}$ \\
\hline$\$ 200 \mathrm{~K}$ & $\begin{array}{c}\text { Transformer, interconnect switch/equipment } \\
\text { Wind days and other contingency }\end{array}$ \\
\hline$\$ 150 \mathrm{~K}$ & \begin{tabular}{c} 
SCADA package and extra engineering \\
\hline$\$ 75 \mathrm{~K}$
\end{tabular} \\
\hline $\begin{array}{c}\text { Extra electrical (utility) and civil (unusual } \\
\text { foundation or access road conditions) }\end{array}$ \\
\hline$\$ 25 \mathrm{~K}$ for utility, $\$ 50 \mathrm{~K}$ civil & Performance design \\
\hline$\$ 200 \mathrm{~K}$ & Government project management, SIOH \\
\hline Total project cost & $\$ 4.8 M$, or \$3.2/Watt installed \\
\hline
\end{tabular}

Table 1: Sample Wind Project Cost Estimate 


\subsection{Recommendations}

\subsubsection{Wind Turbine Supply}

This is where we summarize the previous recommendations that have been discussed. These will include current market conditions, ideal manufacturers and models of wind turbines, the sizes of turbines that best suit the project and possible other options, and if the timing of the project could affect any contracting or procurement efforts.

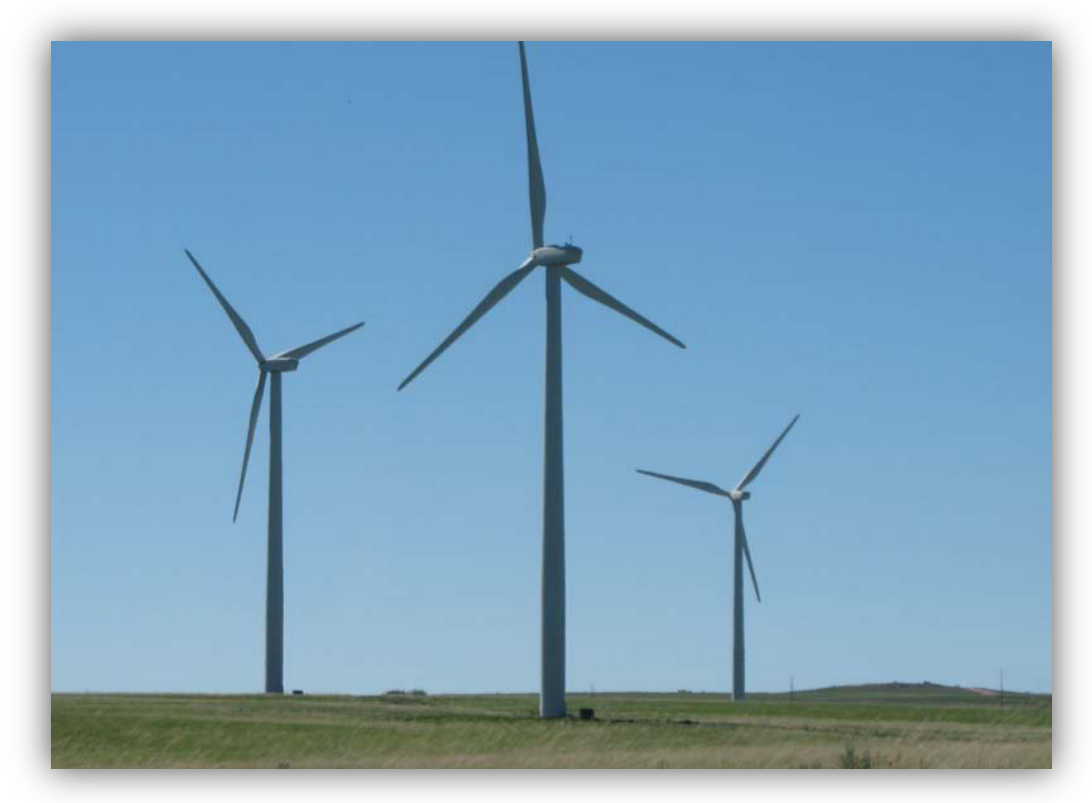

Figure 15: GE 1.5 MW Wind Turbines

\subsubsection{Timing and Next Steps}

Finally, this last section addresses what to work on next and any items that should be further addressed by engineering, project designers and the utility. These items that can be further addressed typically include:

- $\quad$ Timing

- Reviews

- Planning

- Utility Interface

- Funding

- Incentives

- Economic Calculations 
Future steps include identifying areas where experts will need to be hired (design, construction, etc.) Utility negotiations need to be finalized and construction contracts executed. Construction site preparation should include:

- Grading and road improvements/construction

- Trenching, cable-laying, and transformer installation

- Foundation and crane pad construction

- Fencing and erosion projects

- Substation construction/improvements and testing

Turbine and tower transportation will need arranged, installation and interconnection completed, and then testing and commissioning. Operations and maintenance contracts should be executed and routine maintenance checks and repairs performed. 


\section{Environmental Assessments}

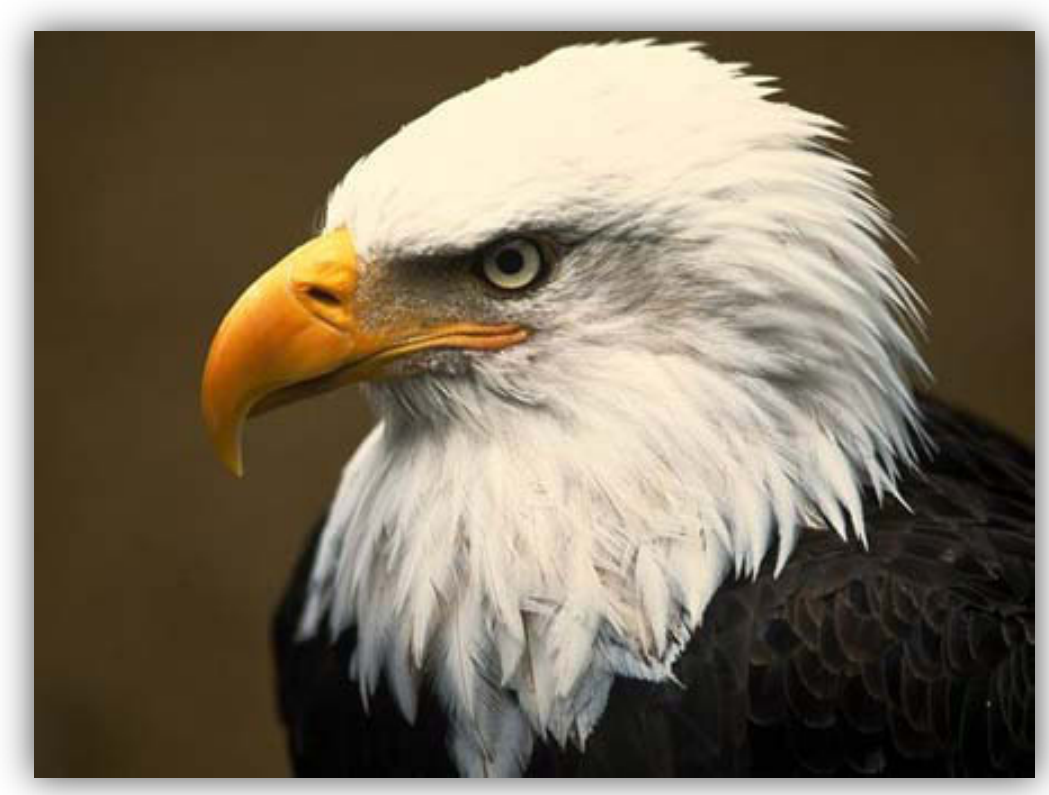

Figure 16: An EA ensures that bald eagle habitat is protected.

Environmental Assessment (EA) reports are prepared in accordance with the National Environmental Policy Act (NEPA) of 1969, as amended. An EA is prepared to evaluate the potential environmental impacts from alternative energy sources. The purpose of an alternate energy project is to generate clean, renewable energy. The alternative energy project would most likely have both adverse and beneficial impacts to environmental resources. Adverse impacts would be identified and mitigated to the greatest extent practicable to minimize the effects on the resources.

\subsection{Avian, Bat, and Fish Studies}

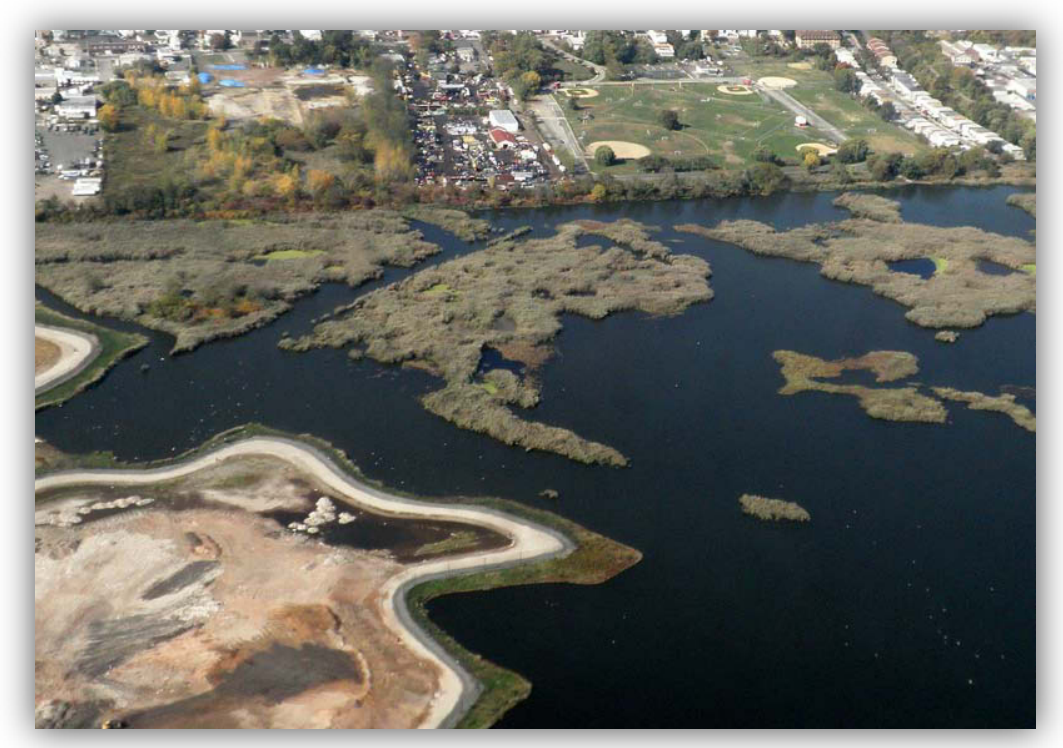

Figure 17: Coastal project sites can impact habitat used by avian, bats, and fish. 
It is necessary to conduct field studies to assess a project's potential impact to avian, bats, and fish. Other sensitive wildlife species such as the desert tortoise, pygmy rabbit, etc. could be impacted by renewable energy projects and studies similar to the avian, bat, and fish studies should be conducted. Several governmental agencies and non-governmental agencies are available for consultation. The studies should be 12 month in length and should document observations detailing abundance, behavior, and fatalities at the project site. Any on-site towers or tall structures would be ideal areas for conducting avian and bat fatality searches. The primary objectives of these studies are:

1. Perform a pre-construction inventory of resident avian, bat, and fish species and habitat in the vicinity of the proposed turbine sites;

2. Identify pre-construction migratory, nesting, and winter avian/bat use (abundance and behavior) of the project site, including use of migration stopover, resting, or feeding areas in the vicinity of the development site;

3. Assess potential risk from renewable project operation to avian, bat, and fish species, primarily through monitoring of fatalities at existing tall structures on or near project sites; and

4. Establish an adaptive post-construction management and impact monitoring plan based on results of the pre-construction studies and subsequent monitoring results following project installation.

\subsubsection{Avian Studies}

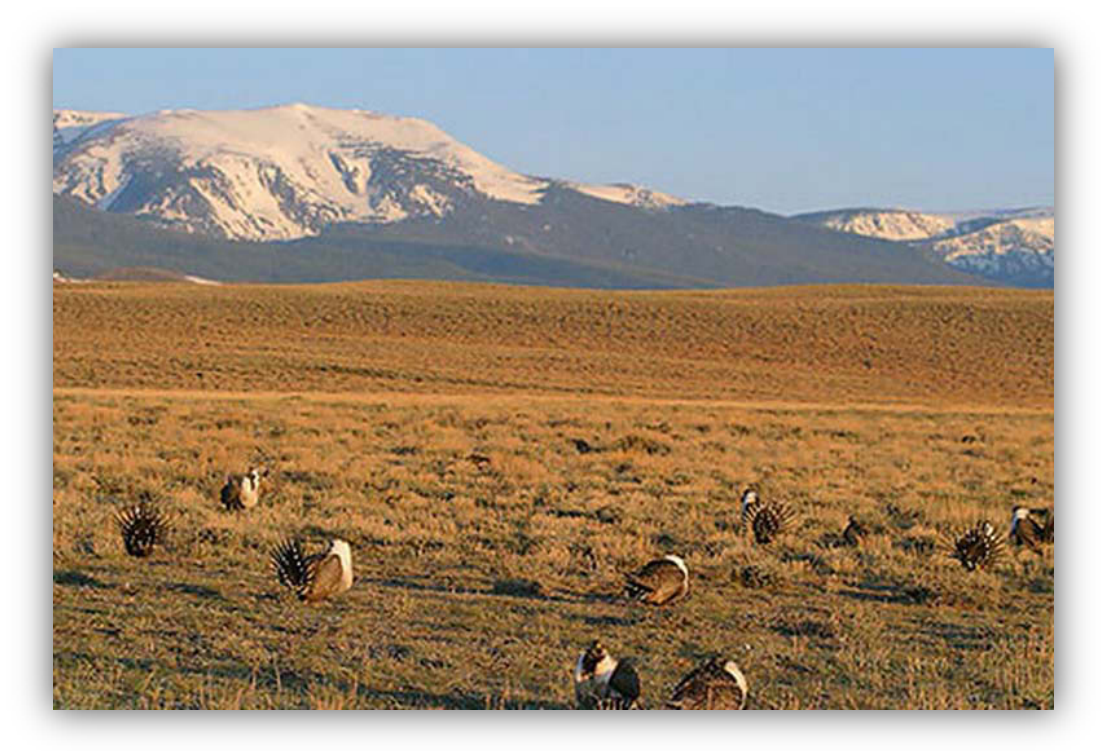

Figure 18: Avian studies help determine if sage grouse leks are in or near a project site.

Avian observations should be conducted once per week at count locations with an unobstructed view of the proposed project development area. Throughout the 52-week period, visits to observation sites should be conducted at least once per week for a minimum of 15 minutes per day at each location to record activity. These field surveys should be conducted in the morning between 7:00 am and 9:00 am. Data should be recorded for avian/fish/wildlife observed within a 1 kilometer $(0.62$ mile) radius of the count locations, including the project development locations. Data for each observation should include: species identity, number of individuals, and behavior of individuals (to include altitude, flight direction, feeding vs. flying/migrating, resting, etc.).

During migration or mating seasons 15 -minute observations at each location should be conducted at least twice per week. These surveys should also be conducted between 7:00 and 9:00 am and will take the place of the weekly surveys discussed above. Additionally, during peak migration days, consider conducting additional observations, from alternate locations, which offer unobstructed, panoramic views of the project area. These additional observations should take place on fall and spring days when weather 
front movement is conducive to migratory activity. These spot observations should vary during daytime and evening hours (between 6:00 am and 9:00 pm). Data collected during migration season surveys should be noted as such and include the date and times of observations, species observed, numbers of individuals, and behavior. Behavioral information includes the path where birds were flying in relation to the proposed project area(s), height of flight (below, within, or above the project height zone), perching behavior, and hunting behavior. Local weather data, including temperature, sky conditions, wind direction, and wind speed should also be recorded.

\subsubsection{Bat Studies}

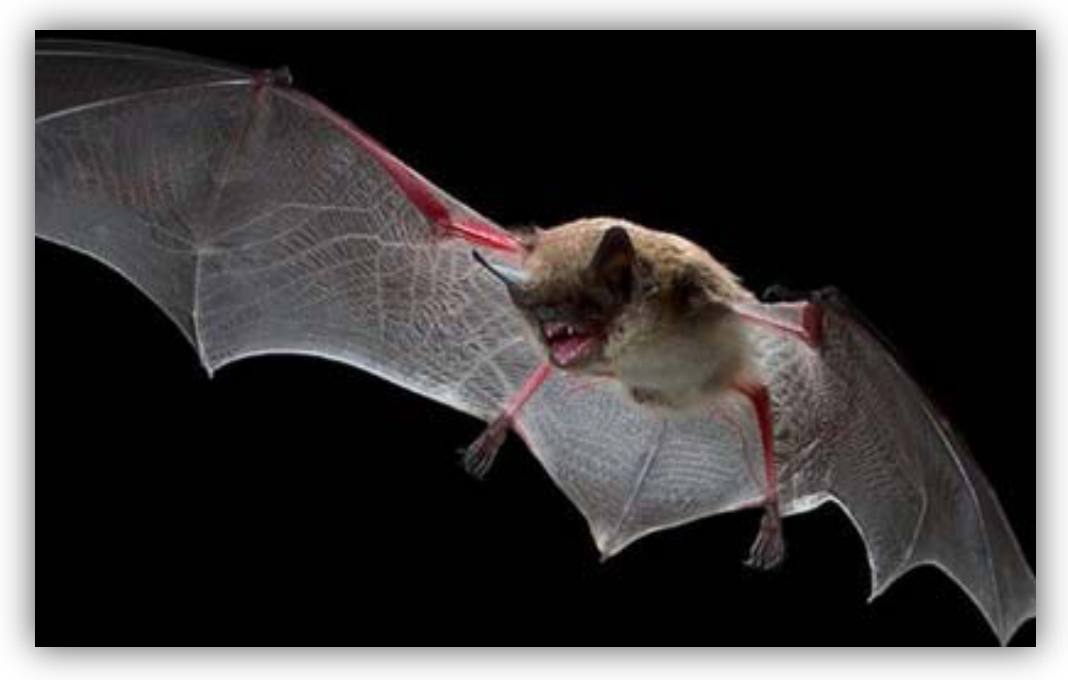

Figure 19: Some wind projects are curtailed during bat migration months.

Passive acoustic bat surveys in the project area for documenting bat activity can be contracted out to private industry companies. These surveys should focus on the late spring - summer - early fall time frame when bats are the most active (approximately April - October). Multiple Anabat acoustic detectors should be deployed throughout the project area. Detectors can be deployed on pre-existing towers (such as Met Towers) or deployed on poles approximately 10 meters in height. Data should be downloaded biweekly and analyzed routinely during the survey period.

When considering the level of activity documented, it is important to acknowledge that numbers of recorded bat call sequences are not necessarily correlated with number of bats in an area. Acoustic detectors do not allow for differentiation between a single bat making multiple passes and multiple bats each recorded a single time. Quantitative comparisons of detection rates among detectors, seasons, or habitats are not possible, nor are direct correlation with weather variables, or linking detection rates to bat abundance. General trends must be interpreted with caution due to the limitations of this technology. 


\subsubsection{Fish Studies}

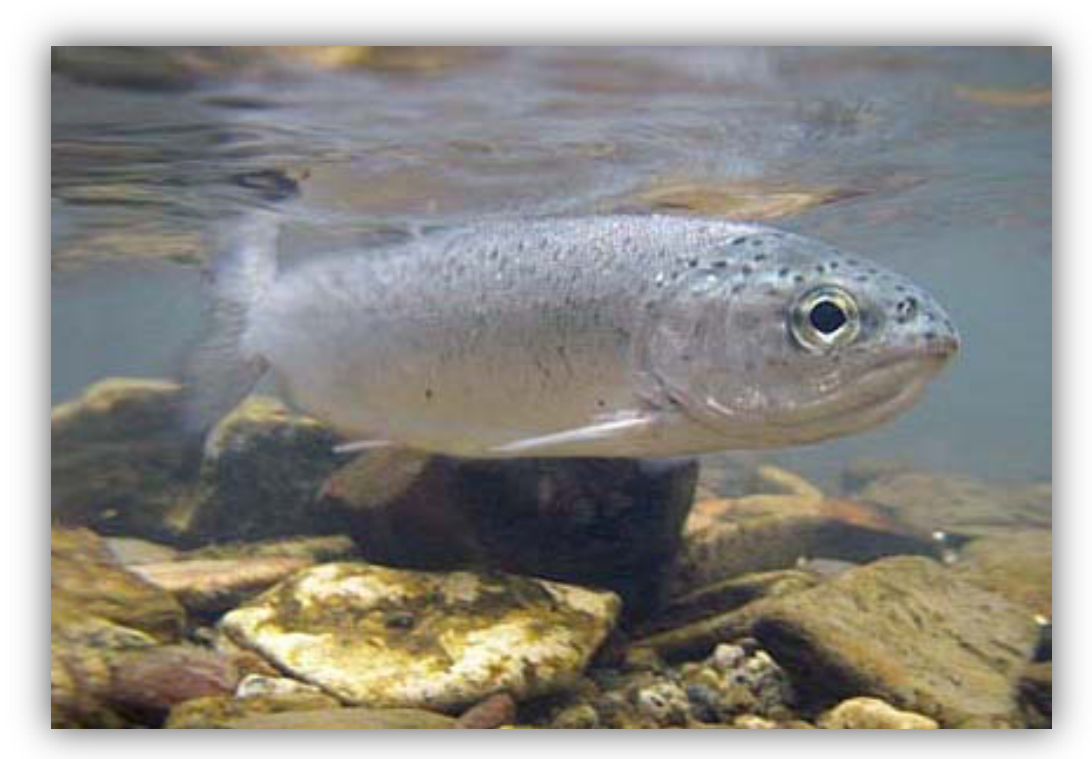

Figure 20: Conducting an EFH assessment ensures steelhead habitat is protected.

The 1996 amendments to the Magnuson-Stevens Fishery Conservation and Management Act mandates that federal agencies must consult with NOAA - National Marine Fisheries Service (NMFS) regarding any of their actions or proposed actions that are authorized, funded, or undertaken which may adversely affect Essential Fish Habitat (EFH). In turn NMFS must provide recommendations to federal and state agencies on such activities to conserve EFH. These recommendations may include measures to avoid, minimize, mitigate, or otherwise offset adverse effects on EFH resulting from actions or proposed actions authorized, funded, or undertaken by that agency. EFH is broadly defined to include "those waters and substrate necessary to fish for spawning, breeding, feeding, or growth to maturity." An adverse affect means any impact that reduces the quality and/or quantity of EFH. Adverse affects may include direct or indirect physical, chemical, or biological alterations of the waters or substrate and loss of, or injury to, benthic organisms, prey species and their habitat, and other ecosystem components. Adverse affects to EFH may result from actions occurring within EFH or outside of EFH and may include site-specific or habitat-wide impacts, including individual, cumulative, or synergistic consequences of actions. An EFH Assessment must be submitted by a Federal agency to NOAA Fisheries as part of the EFH consultation.

An EFH Assessment must include the following information:

1) A description of the proposed action.

2) An analysis of the potential adverse effects of the action on EFH, and the managed species.

3) The Federal agency's conclusions regarding the effects of the action on EFH.

4) Proposed mitigation if applicable.

The EFH assessment will lead you through a series of questions that will provide an initial screening to determine if a more thorough discussion of the action and its impacts and further EFH consultation is necessary. Appendix X provides a worksheet that may be used to develop the initial required EFH Assessment and help you assemble the needed information for determining the extent of any further consultation required. Consultation through NOAA Fisheries regarding other NOAA-trust resources may also be necessary if a proposed action results in adverse impacts. 


\subsection{Consistency Determination}

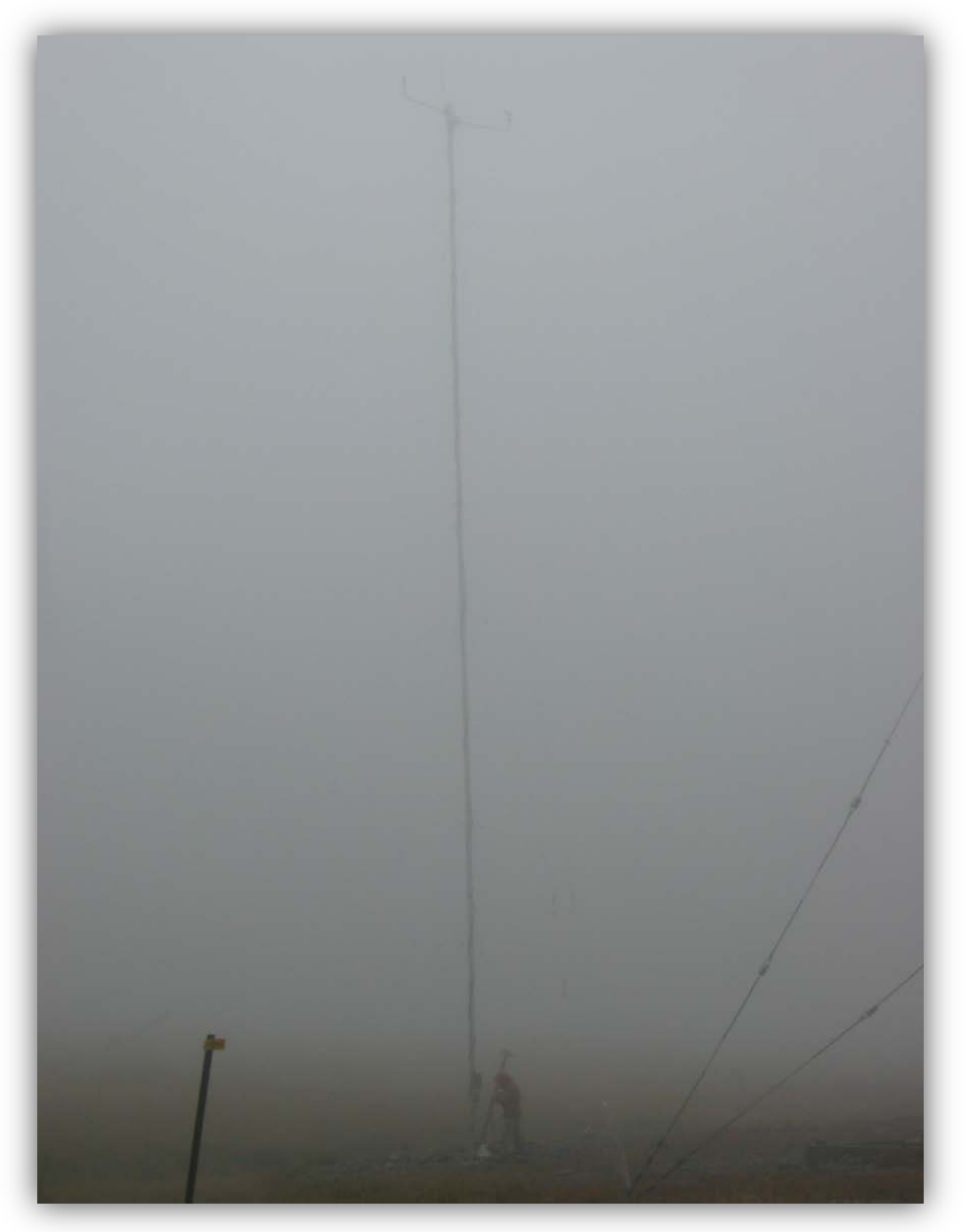

Figure 21: Erecting a Met Tower at Cape Romanzof AFS, Alaska

The consistency determination identifies any effects to the resources at a project site and also identifies applicable enforceable policies and the agencies that administer them. Furthermore, the consistency determination ensures that any effects to resources have been mitigated to the minimal or acceptable level. Effects can include, but are not limited to, topography, geology and soils, land use, surface waters, wetlands, floodplains, air quality, noise, hazardous materials, hazardous waste management, vegetation and terrestrial wildlife, Avian and bats, threatened and endangered species, essential fish habitat, socioeconomics, cultural resources, transportation, aesthetics, and cumulative impacts. Applicable enforceable policies can include, but are not limited to, Fisheries Management, Subaqueous Lands Management, Wetlands Management, Dunes Management, Non-point Source Pollution Control, Shoreline Sanitation, Air pollution Control, and Coastal Lands Management. 


\subsection{Biological Assessment}

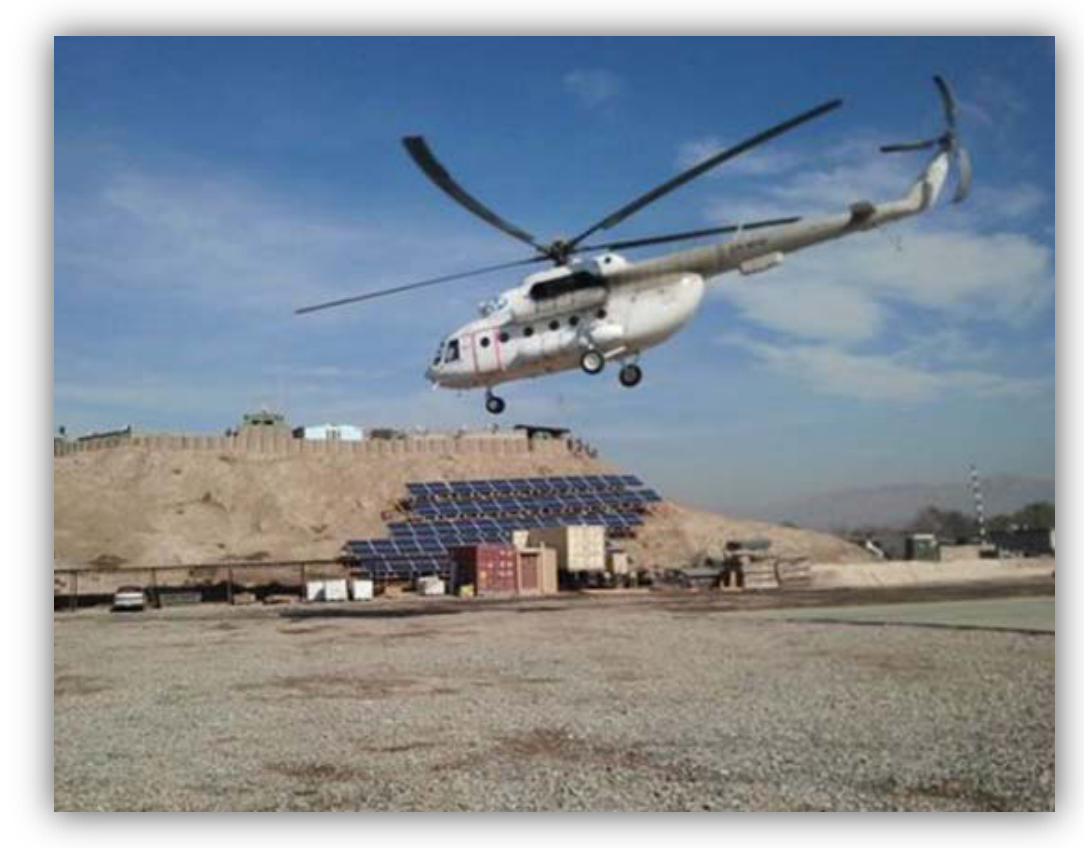

Figure 22: U.S. Military deploys mobile solar power in Afghanistan.

Section 7(c) of the Endangered Species Act (ESA) of 1973 requires that a Biological Assessment (BA) be prepared for all federal actions that may affect federally listed or proposed endangered or threatened species. The BA will consider the potential impacts to listed species (federally endangered, threatened, or proposed candidate species) under the jurisdiction of the U.S. Fish and Wildlife Service (USFWS) and located in the proposed project area. A species list for the County/State that the project is located in can be generated at the USFWS website http://www.fws.gov/endangered/ . Any species on the USFWS list that has a potential for being in the project area should be extensively studied to determine any impacts that a project might have. Both direct and indirect effects should be considered with these studies. Potential avian impacts associated with construction and operation of the proposed action could include loss of habitat; disturbances associated with the presence or activity of construction equipment; disturbances such as barriers to flight paths (specific to wind projects) due to the presence of the turbines and the risk of collision with wind turbine blades. Finally, the BA would need to address any actions to reduce adverse effects and/or cumulative effects from proposed project. 


\subsection{Aesthetics Study}

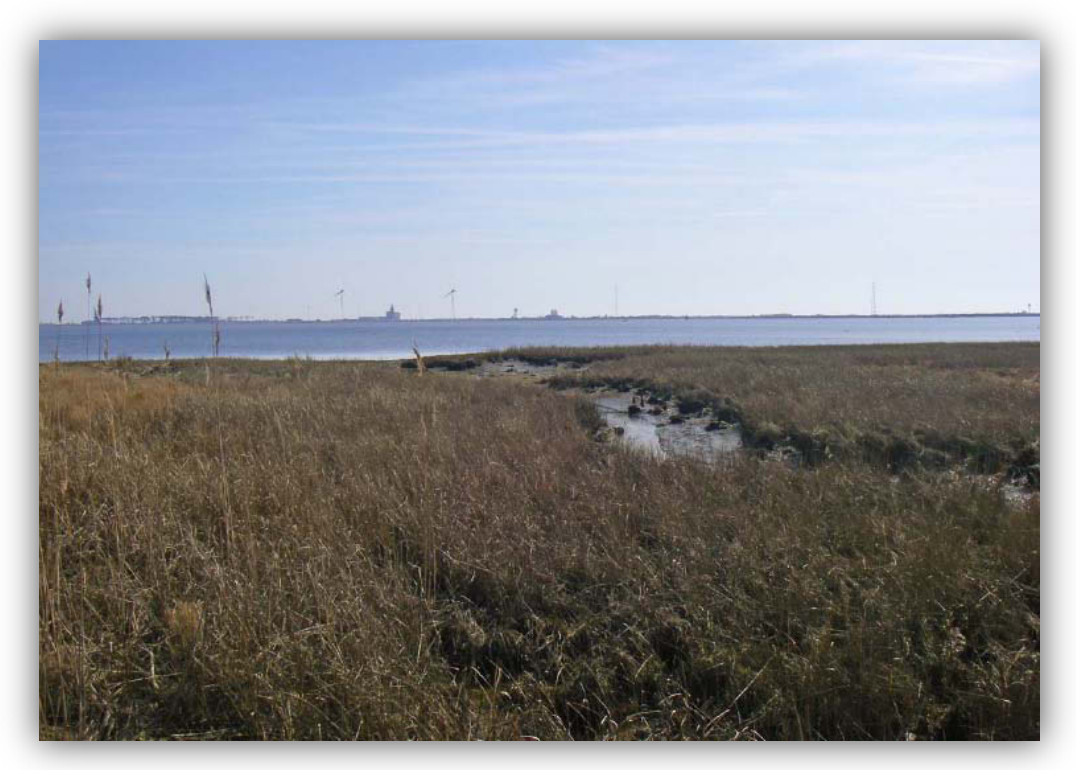

Figure 23: Photo simulation of a project site from 1.9 miles away.

Aesthetics studies assess the project site, the surrounding areas, and the view shed. Images (such as Figure 23) can be digitally altered with computer software technology to demonstrate the impact a project would have on the view shed before the project is actually constructed. Pre-existing tall structures such as trees, towers, buildings, etc. will lessen the view shed impact a project could have. View shed concerns are mainly focused on wind projects; however, reflections from large solar projects could also have an impact. To lessen the view shed impact of wind turbines, manufactures typically paint the turbines a shade of white that blends in well with the sky. 


\section{Critical Interfaces}

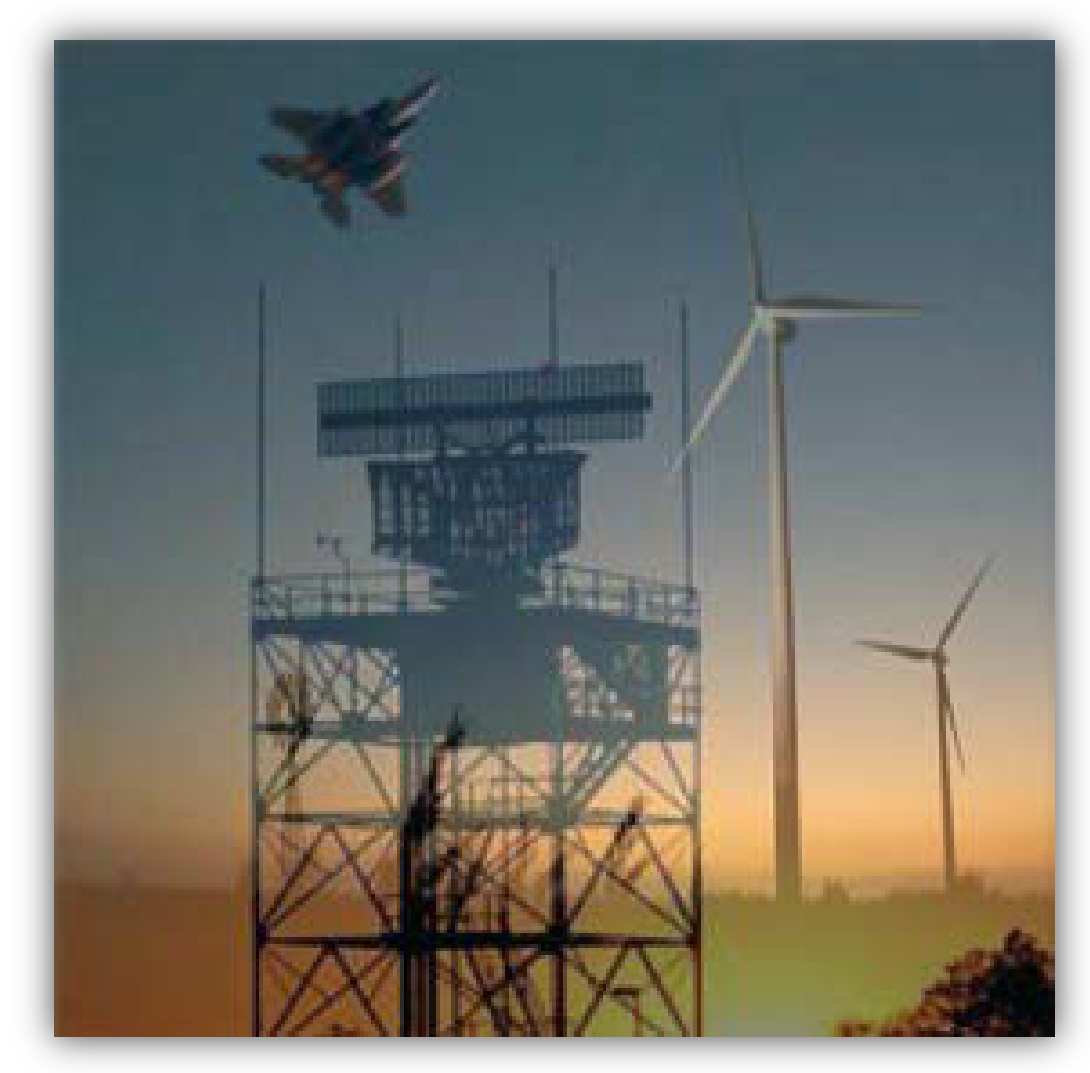

Figure 24: Mitigating issues between missions and renewable projects.

Government projects can have multiple hurdles standing in the way. Some of the areas that present the most challenging hurdles are the Operational and Mission impacts, the FAA/DoD reviews and adjustments, and the interaction processes with the Utilities. A key to mitigating even the most challenging hurdles is to address the issues as early as possible.

For government energy projects especially, there are a few items to focus on that often have significant impacts on the success of a project:

1. Base encroachment committees can be good places to discuss the potential project, disseminate information and get reviews started early from the Operational and Mission perspectives.

2. If a project is deemed economic and able to move forward, equipment warranties, short and longterm operations and maintenance agreements, costs and responsibilities need to be planned carefully and worked out in advance. Warranty coverage and repair is different from O\&M, and performance requirements are also very important. Supply chain, spare parts lists, government equipment tracking/transfers, and manufacturer's long-term stability prospects should be considered carefully. Ability to access funds for repairs is also a major consideration.

3. Communications requirements, Information Technology (IT or Base comms) and cyber/security requirements, and ability for O\&M remote access to the information are critical aspects to government energy projects. These can take significant amounts of time to review, design and approve, and can lead to poor system availability and performance if issues cannot be resolved in a timely manner. 
4. Performance designs and clear specification guidelines are critical to procurement success and system quality. Just specifying standard codes and requirements, and leaving all the major design decisions up to a final design/implementation contractor can lead to an undesirable outcome. Technical expertise is needed on the government side to review and procure energy systems successfully. Procurement strategies need to be developed along with the technical steps in an energy project to arrive at the most suitable contractual arrangement for a particular Base or government facility (i.e. ECIP, ESPC, UESC, PPA, or other).

\subsection{Operational and Mission Interfaces}

The Executive orders, Energy Bill of 2006, and American Clean energy and Security Act of 2009 all requires energy reduction, encourages the purchase of green power and on-base generation of green power. Renewable energy projects meet these three requirements. Wise use of O \& M dollars realized through energy savings will help the base or government facility meet their energy reduction goals. Each government site or military base has its own unique set of operational and mission interfaces. Certain government procedures and power struggles can slow down or kill a project. So it is important to have a champion (energy manager, base engineer, etc.) that will push a project through the process from beginning to the end. If the champion leaves before the project is completed it is often difficult for the replacement to get up to speed and have the same vigor needed to successfully complete the project. Several military personnel such as the energy manager, environmental manager, facility manager, meteorological manager, base planning personnel, military mission personnel (AirOps or Radar), civil engineering personnel, and base command personnel will need to meet at the very beginning of the project and stay active throughout. It is the ability to successfully communicate and work with all of these individuals that will lead to viable solutions to any adverse impacts that might come up. 


\subsection{FAA/DOD Interfaces}

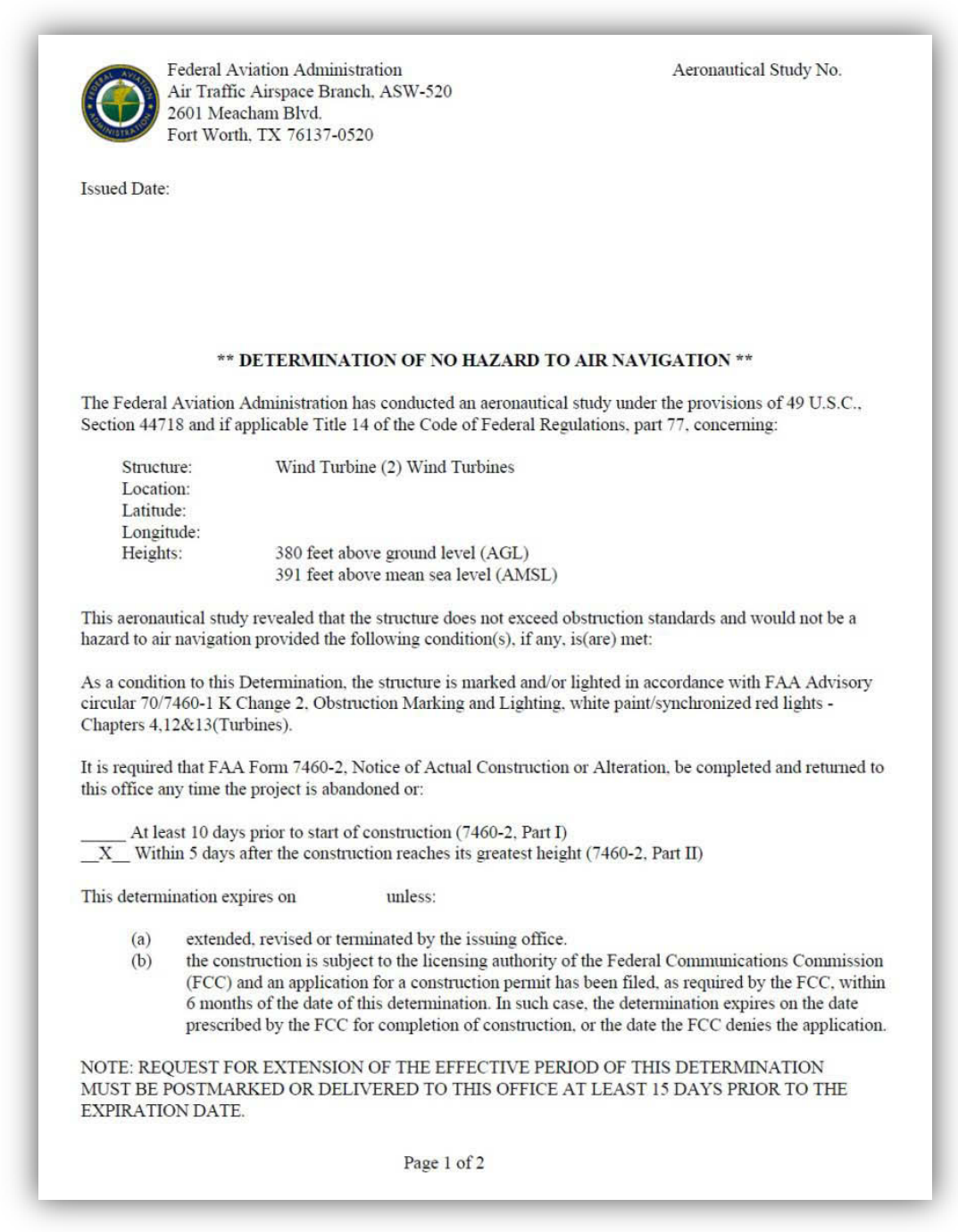

Figure 25: Sample of FAA Determination of No Hazard letter.

In administering Title 14 of the Code of Federal Regulations CFR Part 77, the prime objectives of the FAA are to promote air safety and the efficient use of the navigable airspace. To accomplish this mission, aeronautical studies are conducted based on information provided by proponents on an FAA Form 74601, Notice of Proposed Construction or Alteration (https://oeaaa.faa.gov/oeaaa/external/portal.jsp). Advisory Circular 70/7460-1K, Obstruction Marking and Lighting, describes the standards for marking and lighting structures such as buildings, chimneys, antenna towers, cooling towers, storage tanks, supporting structures of overhead wires, etc.

You must file with the FAA at least 30 days prior to construction if:

1. Your structure will exceed $200 \mathrm{ft}$ above ground level

2. Your structure will be in proximity to an airport and will exceed the slope ratio

3. Your structure will emit frequencies, and does not meet the conditions of the FAA Colocation Policy

4. Your structure will be in an instrument approach area and might exceed part 77 Subpart $\mathrm{C}$ 
5. Your structure will be on an airport or heliport

Figure 26 shows the FAA Notice Criteria Tool (NCT) that will assist in applying the appropriate slope calculations per Part 77 Notice Criteria.

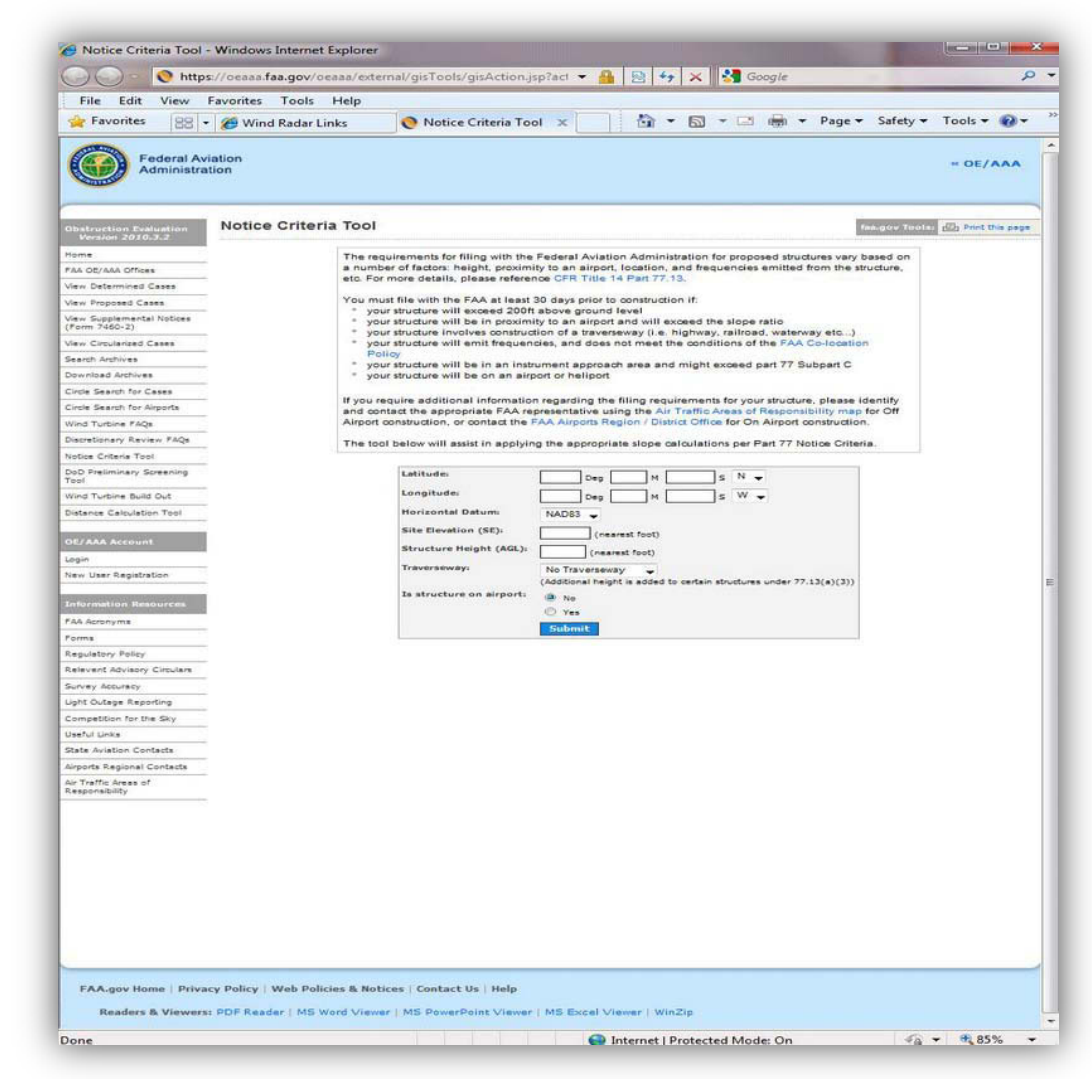

Figure 26: FAA Notice Criteria Tool website

If you file with the FAA and receive a Notice of Presumed Hazard, you should first talk to the FAA specialist that issued the notice. Gather all the details and facts and make sure you understand the issues and what your options are. You can engage consultants to help mitigate the issues surrounding the Notice and to request meetings to discuss the issues and possible mitigation. For example, in at least one instance, INL was able to mitigate the issue by using a shorter tower that was able to drop the rotor swept area below the view of the weather radar's lowest beam, hence eliminating the presumed hazard. 


\subsubsection{Wind Radar Issues}

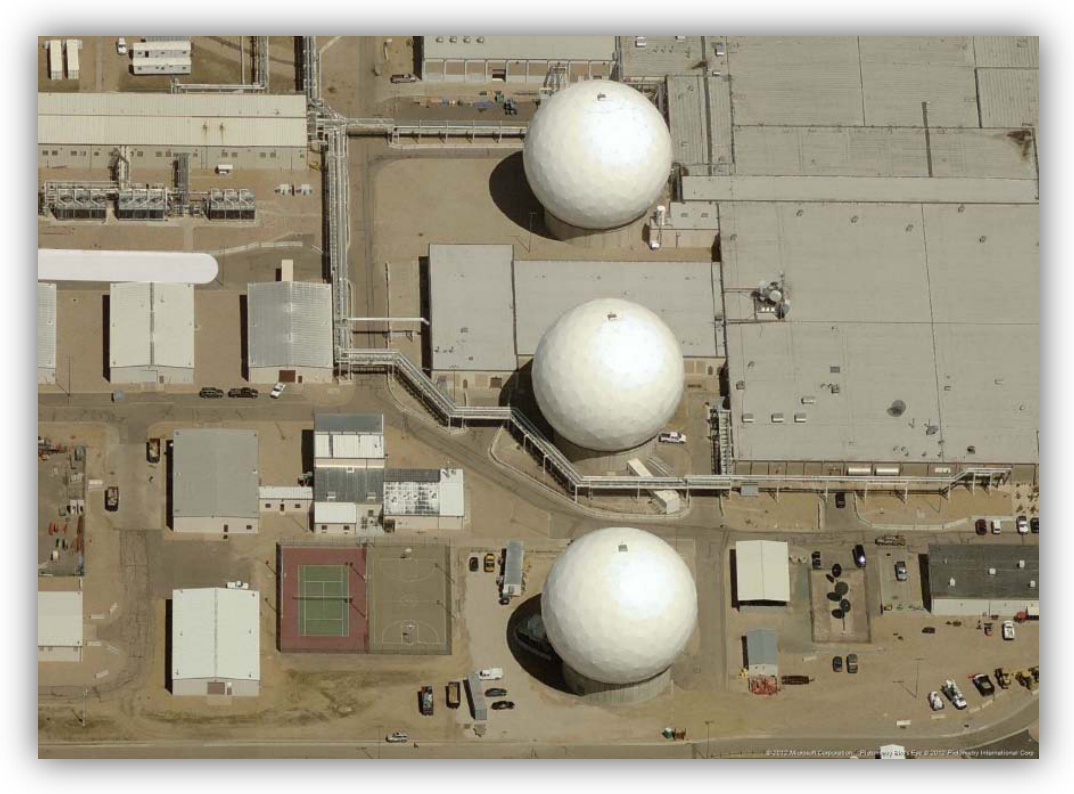

Figure 27: Bing Maps image of Radar at Buckley AFB, CO

From 2004 - 2010, deployment of wind power systems around the world has grown significantly. This growth has led to many interaction issues between wind farms, military, aviation and radar systems. Building a wind project involves many considerations, including consultation with various aviation interests, both civil and military, and also with weather radar installations. These parties may raise objections to a proposed wind farm for a variety of reasons. Data from the national network of Weather Surveillance Radar-1988, Doppler (WSR-88D) systems are a key component in the decision making process of issuing weather forecasts and severe weather warnings, and supporting air traffic safety. Experience has shown that when wind farms are located "close" to weather radar systems, the turbine towers, rotating blades, and the wake turbulence induced by the blades negatively impact data quality and so degrade the performance of radar algorithms. Another example, the wind turbines might appear as echoes on the display of radar used in air traffic control (ATC). These echoes may distract the air traffic controller from the aircraft echoes which are his main interest, and can reduce the effectiveness of the radar by masking genuine aircraft returns. This is a potential threat to the safety of air traffic, both civil and military. The US government is also concerned about the same issues and initiated a military readiness review in 2006, and issued interim policies that had the unfortunate effect of delaying over 4 billion dollars of wind projects. Diligent efforts reduced this impact significantly and established new and reasonable policies. The INL has been active in the education, analysis and guidance as this issue was addressed in 2006. After all, it is important to protect our borders, to provide air traffic support, to forecast the weather, and to precede with rapid development of domestic sustainable energy resources. They are all vital to national security.

Mitigation and coexistence is the goal for wind energy projects, yet sometimes defense entities are focused on absolute's aimed at eliminating wind radar interaction, creating impasses in many locations. Many mitigation methods have been successfully implemented, including wind project/turbine site adjustments, radar (software or hardware) upgrades, and improved assessments. Several radar manufacturers are confident that the majority of radar systems can be upgraded to perform well in the presence of wind turbines. For example, systems using ASR-9 systems already have good experience mitigating wind systems (ref-Palm Springs) and Britain is having good luck with their ASR-11 in presence of turbines. 


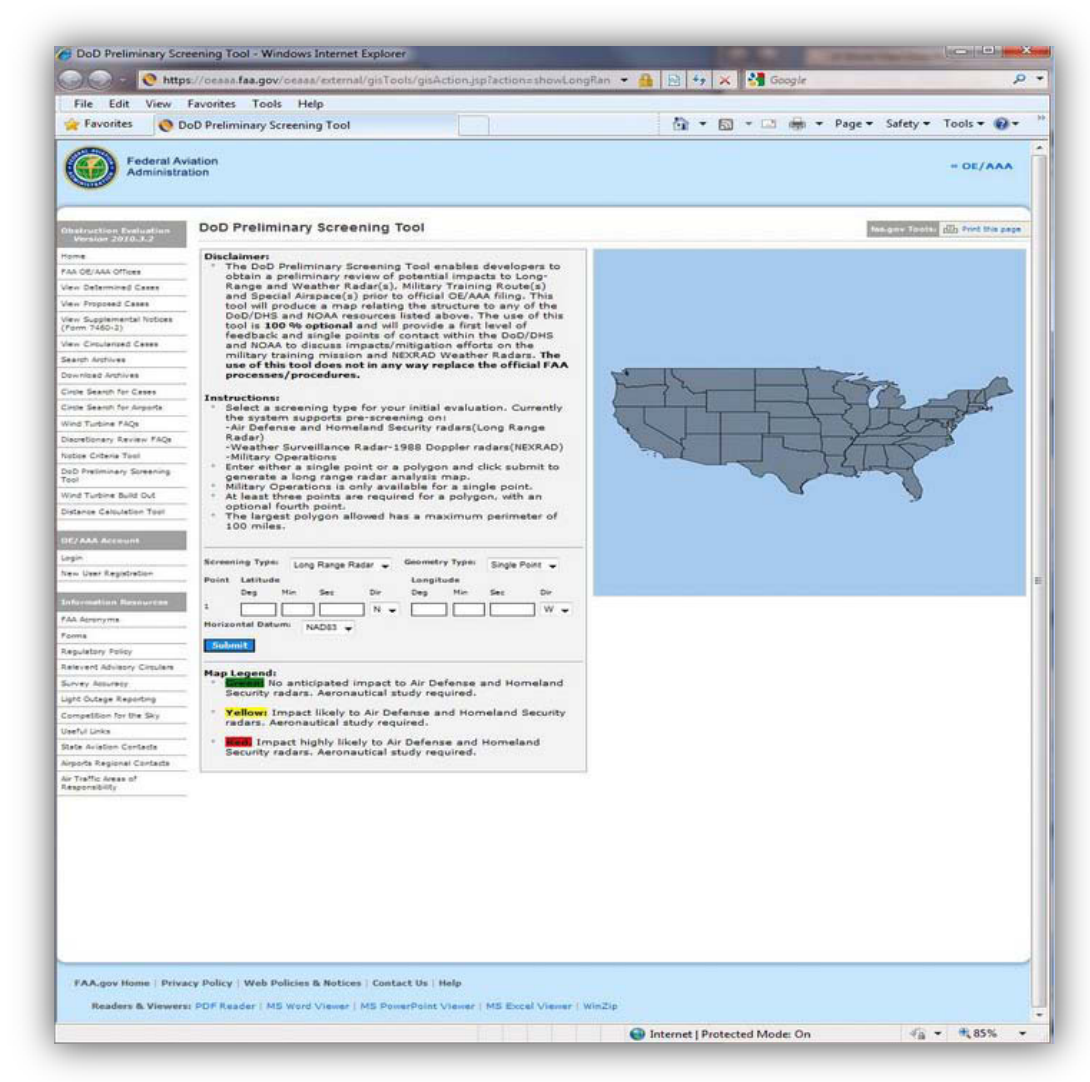

Figure 28: DoD Preliminary Screening Tool website.

There are several websites that can help you determine if your project has any potential radar hurdles. Figure 28 shows the DoD Preliminary Screening Tool (PST) (https://oeaaa.faa.gov/oeaaa/external/gisTools/gisAction.jsp?action=showLongRangeRadarToolForm) that enables you to get a preliminary review of potential impacts to Long-Range and Weather Radar(s), Military Training Route(s) and Special Airspace(s) prior to official OE/AAA filing. This tool will produce a map relating the structure to any of the DoD/DHS and NOAA resources listed above. The use of this tool is $100 \%$ optional and will provide a first level of feedback and single points of contact within the DoD/DHS and NOAA to discuss impacts/mitigation efforts on the military training mission and NEXRAD Weather Radars.

A number of U.S. government installations have both wind turbines and functional radar, and the British military also has a track record of successfully addressing this challenge. Wind turbines are currently being installed and used at military bases and near airports in the U.S. and elsewhere, and experience at those sites demonstrate that Wind Radar is a solvable challenge.

These military and civilian installations have wind turbines and functional radar:

- F.E. Warren Air Force Base, Wyoming - one 2MW \& two 660-kW turbines

http://www.warren.af.mil/news/story.asp?id=123132150

- $\underline{\text { U.S. Navy at Guantanamo Bay, Cuba - four 950-kW turbines }}$

http://www.navy.mil/search/display.asp?story_id=18059

- U.S. Air Force Space Command on Ascension Island - four 225-kW \& two 900-kW turbines

http://www.inl.gov/powersystems/ascension_island.shtml 
- U.S. Navy at San Clemente Island Base - three 225-kW turbines

http://www.nelp.navy.mil/pdf_cases/Conservation_Wind_Power_SCI.pdf

- Logan International Airport in Boston, Massachusetts - near Hull, MA turbines

http://www.ceere.org/rerl/publications/whitepapers/AWEA_Hull_2003.pdf

Wind projects are relatively close to Long Range Radar facilities in:

- Mt. Laguna, California (twenty-five 2 MW turbines)

- McCamey, Texas (322 turbines totaling $356 \mathrm{MW}$ )

Therefore, it is important that every effort be made to understand and apply, where appropriate, the effective mitigation measures that are already in use around the world. Be ready to work with government agencies to find acceptable solutions to their concerns. Remember, early communication between affected parties in a wind farm development is the key to identifying possible problem areas and the solutions to those problems.

\subsection{Utility Interfaces}

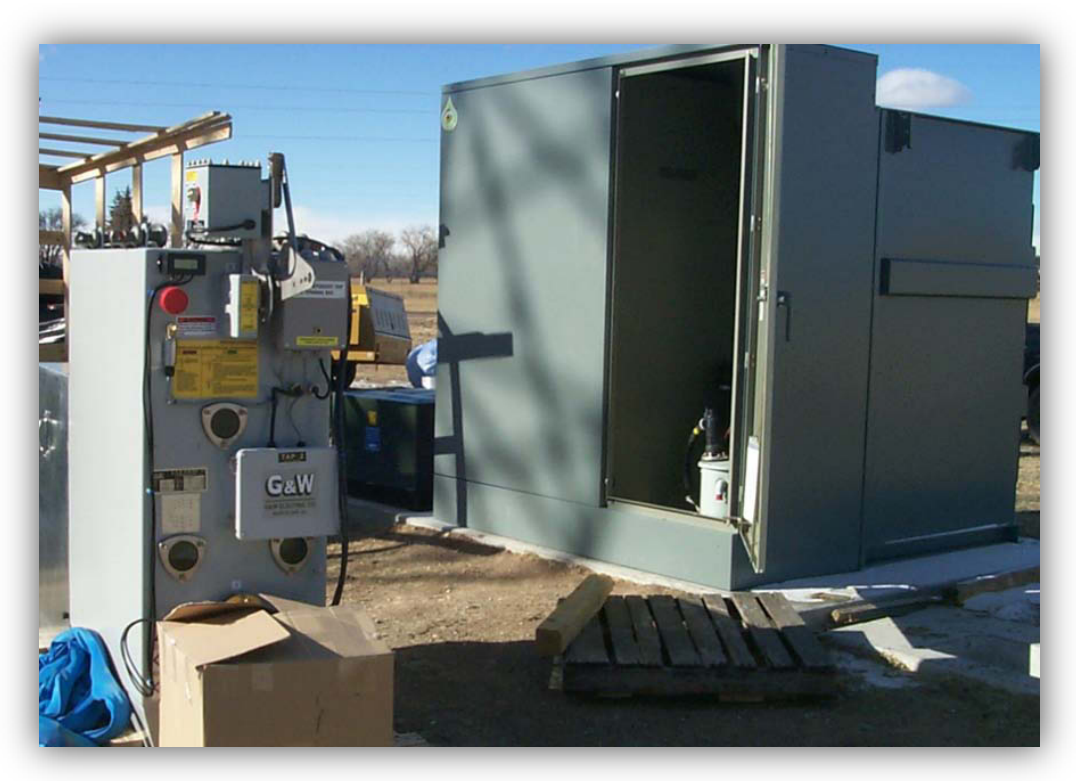

Figure 29: Transformer at F.E. Warren, AFB

Section 2.2 .7 briefly discussed transmission of the power and the electrical interconnection. It mentions that from the beginning it is important to think about how and where the power can be tied in and if any pre-existing distribution lines are available. Furthermore, there are other areas and issues to address. Answering the following list of questions will ensure a good start to a successful interconnection process.

1. Are utility interconnections/interactions required? If so, get in the queue as early as possible...

2. What are the Public Utility Commission (PUC)/State rules? 
3. Will this project ever export power?

4. Is the tie-in for this project behind the meter, using net metering, PURPA or some other?

5. What are any possible utility charges? (i.e. departing load, transmission access, firming, integration services, etc.)

6. What are the sizes of cable needed?

7. What is the transformer sizes needed?

8. Any impedances and/or charging capacitances?

9. Will any interconnect equipment and relays be needed?

10. What are the metering arrangements?

11. Do you have one-lines and proposed electrical parameters to provide to the utility?

12. Have you looked at the existing rate structures and power/energy use?

13. Have you planned ahead to accommodate for economics and PUC rules as well as to avoid any negative changes to existing rate schedules?

14. What voltage will you be connecting at?

15. What is the state of the existing system and cables?

16. Have you performed any basic load flow modeling, short circuit analysis, and coordination surveys?

17. Have you looked at existing system loading and voltages?

18. Have you incorporated the proper equipment and personnel protection into your design while also keeping costs reasonable?

19. Have you performed soil sampling and has that input been used for proper cable sizing and grounding design?

20. Is this a complex system that will need advanced control system design, detailed performance-based specifications, and additional drawings?

21. Will you use fiber optic, phone line (regular or DSL), Ethernet converters, wireless, cell, satellite, microwave, RS-232/485, or some other communication option?

22. When deciding on a communication design, SCADA, metering, etc., did you consider long term O\&M and their monitoring arrangement?

23. What are the manufacturer's and utilities options?

24. What kind of security issues will you face on a government system?

25. Will extra voltage support and/or ride-through systems be required (mostly for larger systems or high penetration micro-grid/island systems)?

26. Will you need synchronous condenser, extra options on wind turbines, switched cap banks or SVAR or DVAR at substation, and/or transformer tap changers?

27. Do you have any other power quality issues such as harmonics, distribution grids that have higher numbers of fault events, etc.?

28. How is the project going to be managed, designed, procured/contracted, and reviewed, construction managed and commissioned/tested? 
Be sure not to over look a small hurdle as sometimes they will become more challenging than anticipated. Remember, the sooner issues are addressed; the better the chances are for mitigating them.

\section{Lessons Learned}

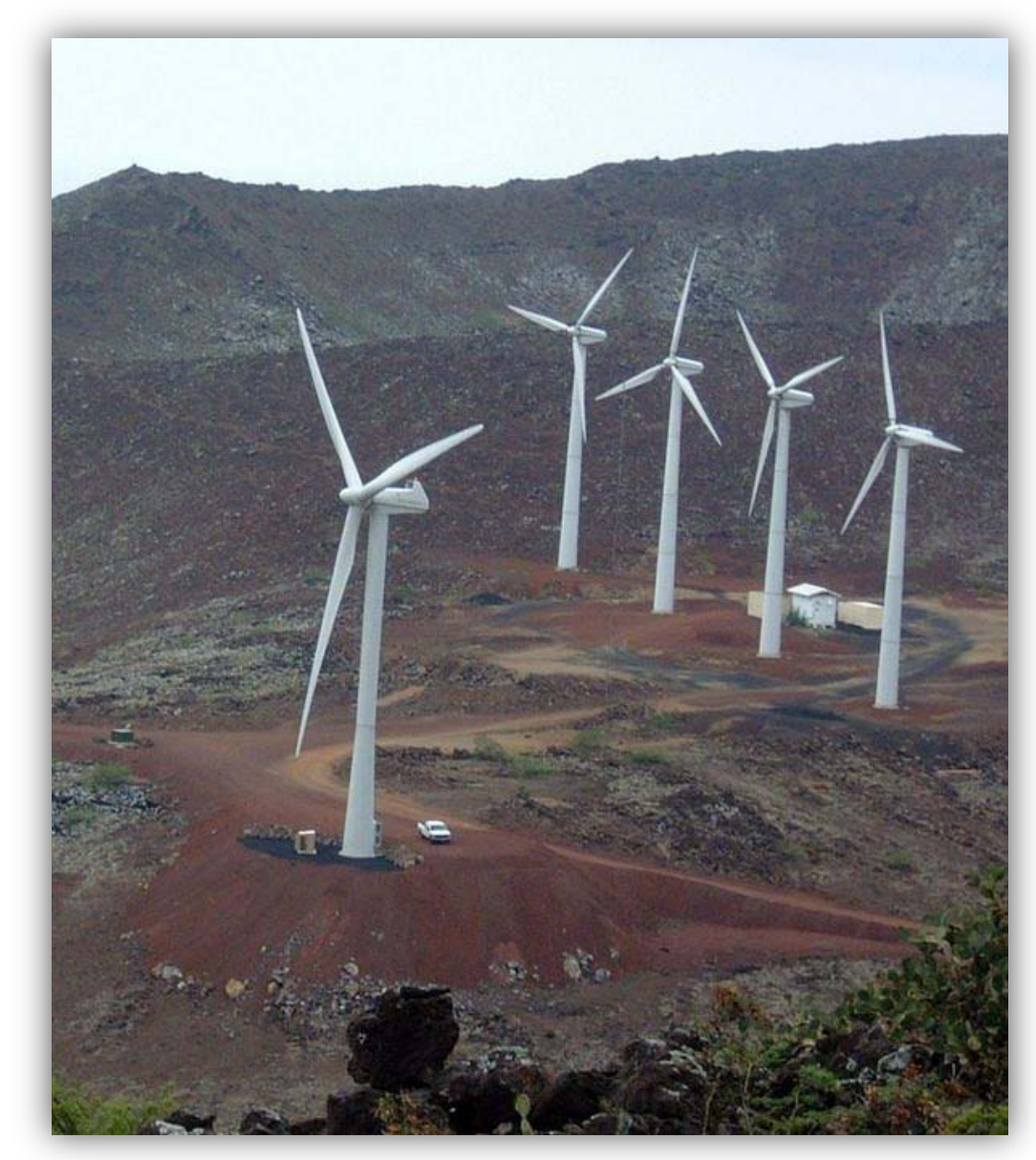

Figure 30: Ascension Island Wind Turbines, 2004

After 20+ years of working with DoD and other government agencies to study, design, and build government renewable projects, INL has experienced the do's and don'ts for being successful with a project. The following contains an accumulation of that knowledge.

\subsection{Keys to Success}

- Having good to excellent wind resource

- High cost of electricity

- Avoiding or minimizing any and all obstacles

- Every project needs a champion that will push it through the process from beginning to the end 
- Create the partnerships at the beginning

- Always perform resource assessments

- Use performance based specifications

- Plan and model loads upfront

- Control system design and integration is crucial

- Integrate load management into the control system for stability and high penetration

- Penetration can be above $25 \%$ if designed and planned for

- Wind/diesel systems are very compatible

- Warranty and long term O\&M is very important for achieving high availability percentages

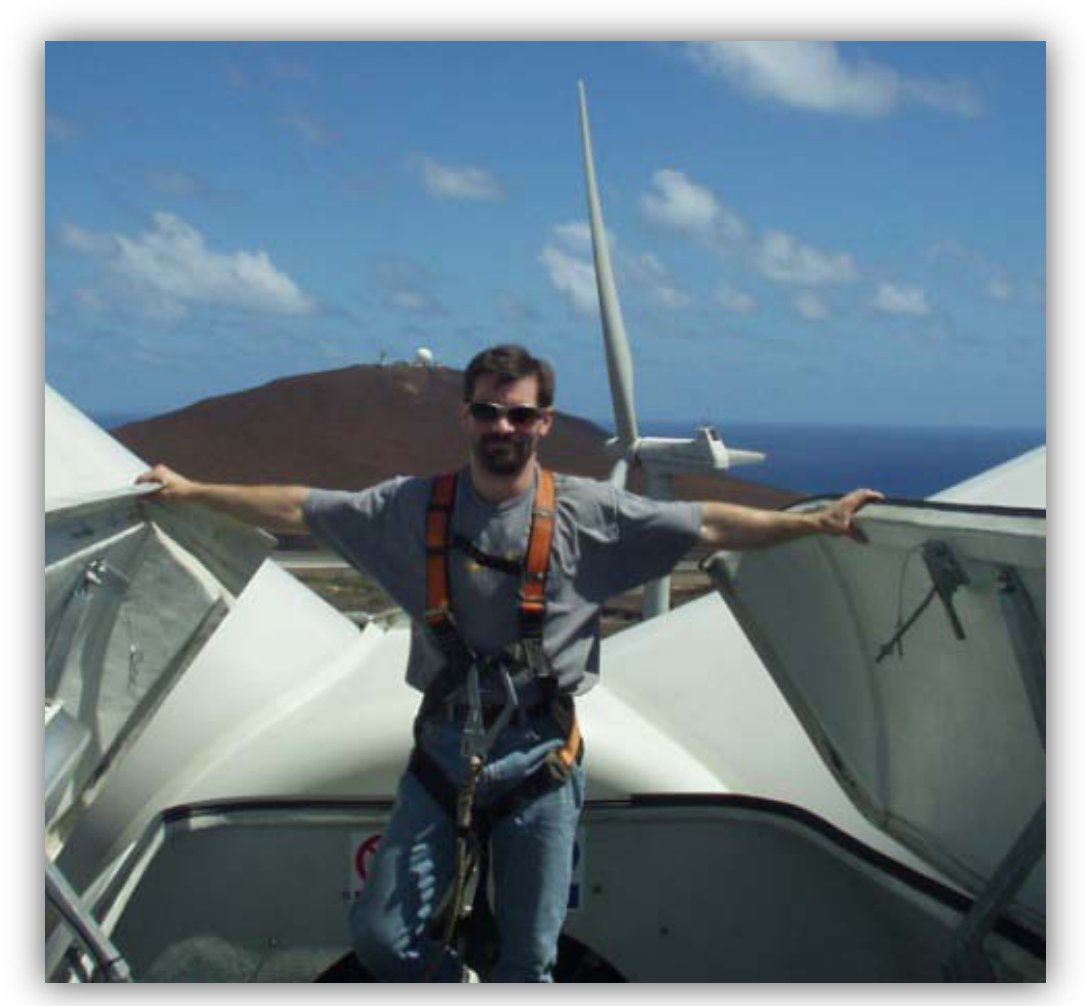

Figure 31: Kurt Myers at the Ascension Island Wind Turbine Site 


\section{Appendix A - Assessment Timeline Template}




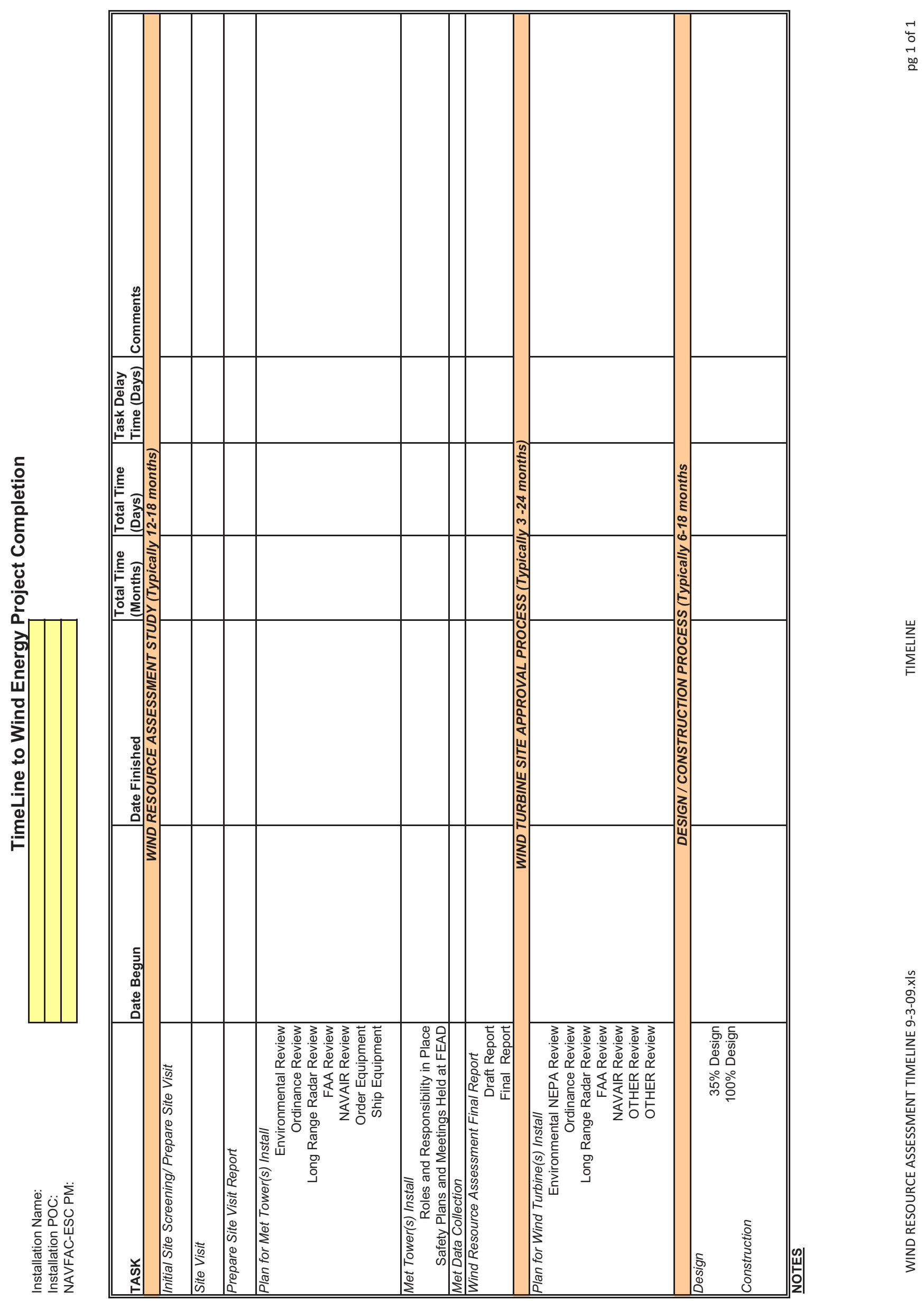

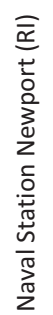


Appendix B - Wind Data Collection Equipment Vendor Data 


\section{TRITON Sonic Wind Profiler The Wind Industry's Leading Remote Sensing System}

\section{Reducing uncertainty in site selection}

Wind farm developers and their investors rely on wind measurement data to select viable sites for wind farms, and to select locations for wind turbines. Data on wind resources at and above hub height improves site assessments and reduces project uncertainties.

\section{A resource assesment system for today's wind turbines}

\section{Second Wind's Triton Sonic Wind}

Profiler is an advanced sodar that provides wind data well above the rotor tip-height of today's large wind turbines. Triton also captures extensive data on anomalous wind events such as speed and direction shear and turbulence that directly affect wind turbines' power output - and that could affect a windfarm's performance.

\section{Low power}

\section{consumption}

Triton requires only 7 Watts of power for continuous operation, far less than other remote sensing systems. Technology innovations like low-power amplifier chips and the Blackfin ARM - one of the lowest-power CPUs on the market - enable Triton to be powered by two solar panels and to run continuously without being attended.

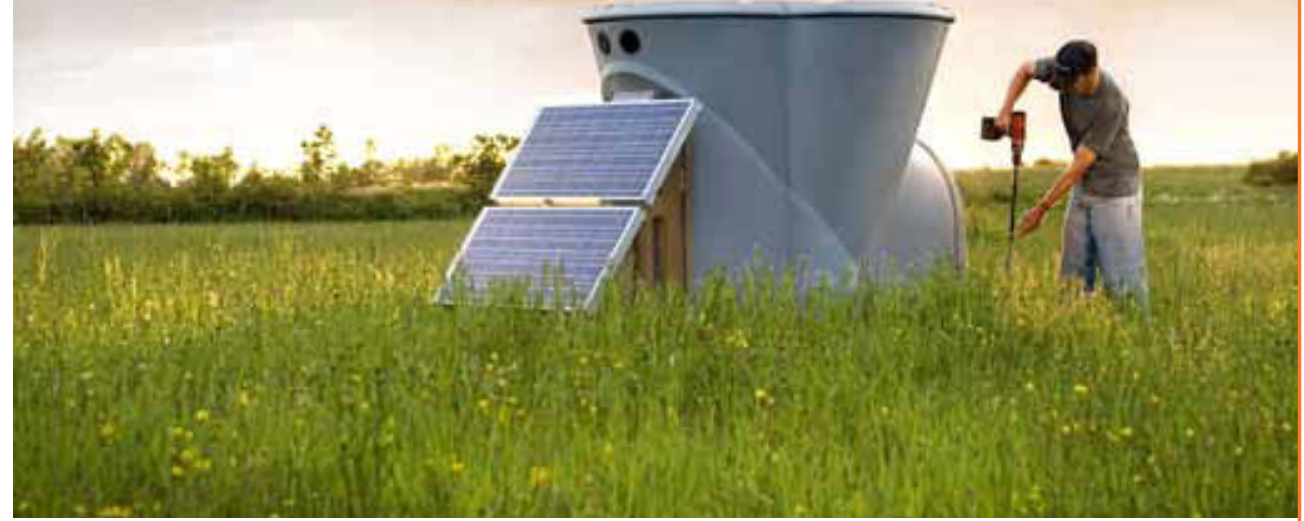

\section{High height data}

Triton's ability to capture wind data at heights up to 200 meters reduces uncertainty inherent in the use of extrapolated data from meteorological towers. At 120 meters, high quality filtered data captured by Triton normally exceeds $80 \%$ (averaged over a 12-month period). Triton's performance has been validated by studies correlating measurements from anemometers at a number of sites.

\section{Key Benefits}

- High height data - to $200 \mathrm{~m}$

- No permitting required

- Extremely low power consumption (7 Watts)

- Data access and monitoring via SkyServe web portal

- Ease of deployment - installed and collecting data within 2 hours

- $>95 \%$ operational uptime based on more than 190 commercial systems deployed worldwide since April 2008

\section{Independent Validation}

Studies released in 2010 by Energy Research Centre of the Netherlands (ECN) and National Renewable Energy Laboratory (NREL) showed excellent correlation between Triton and tower measurements. See www.secondwind.com/validations.

\begin{abstract}
"I think there is a great future for remote sensing. The combination of well validated SODAR devices and traditional anemometry is a very good one and GL Garrad Hassan is already using remote sensing data in combination with conventional methods and data."
\end{abstract}

\section{-Andrew Garrad President, GL Garrad Hassan}




\section{TRIT@N}

SONIC WIND PROFILER

\section{Monitoring and near- real-time data access via SkyServe ${ }^{\circledR}$}

Download and analyze your wind data at any time, from any location via the Internet. Our SkyServe wind data service delivers ten-minute averages over a secure web server, and graphical display tools make the data easy to read and understand. Second Wind's support team monitors the Triton fleet daily via SkyServe.

\section{Easy to deploy and relocate}

In a fast-paced industry, speed provides a competitive advantage. The low-profile Triton can be deployed and transmitting data within a few hours. By contrast, meteorological towers require a two-to-six-month permitting process and days to erect. With no moving parts, solid-state electronics, and a tough, lightweight low-density polyethylene (LDPE) enclosure, Triton is well equipped for redeployments in the toughest environments, in all climates.

\section{The most cost-effective}

\section{wind measurement}

\section{system available}

A fully installed Triton costs less than an 80-meter meteorological tower wind assessment system and substantially less than a lidar system.

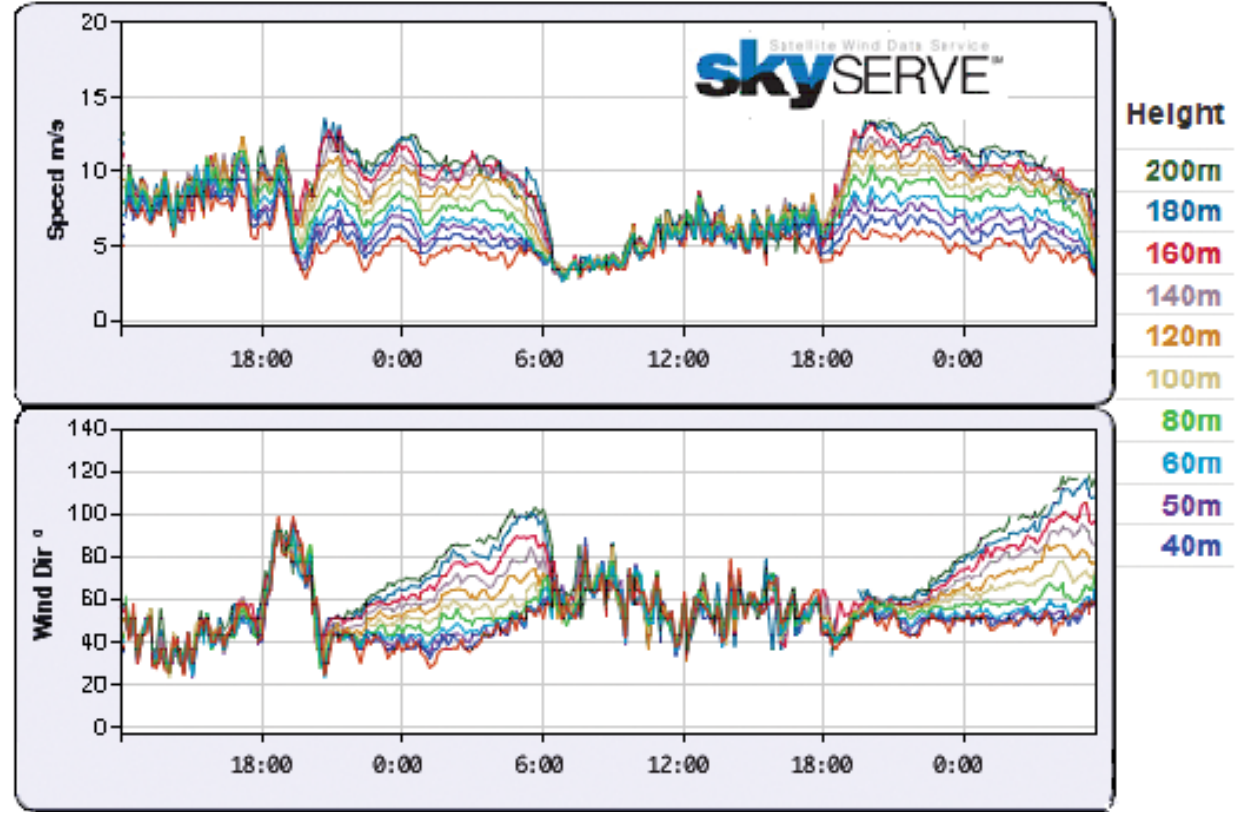

The wind industry's leading remote sensing system

There are more than 200 Tritons in operation with leading wind project developers and operators, utilities, and wind resource assessment service providers in diverse locations spread over five continents (North America, Europe, Africa, Asia, and Australia).

Triton is changing the way the wind industry measures the wind. To learn how you can obtain valuable insight into your project's financial performance, contact Second Wind today.
For every stage of your wind project

Use Tritons for:

- Greenfield prospecting

- Micrositing and turbine suitability

- Wind speed and direction shear

- Hub height wind speed validation

- Ramp event forecasting

- Power curve testing and nacelle anemometer correlation

\section{Do you want to learn more about how you can use Triton to reduce uncertainty throughout the life of your wind energy project? Call us today at 617-776-8520 ext. 1, or email tritonsales@secondwind.com}



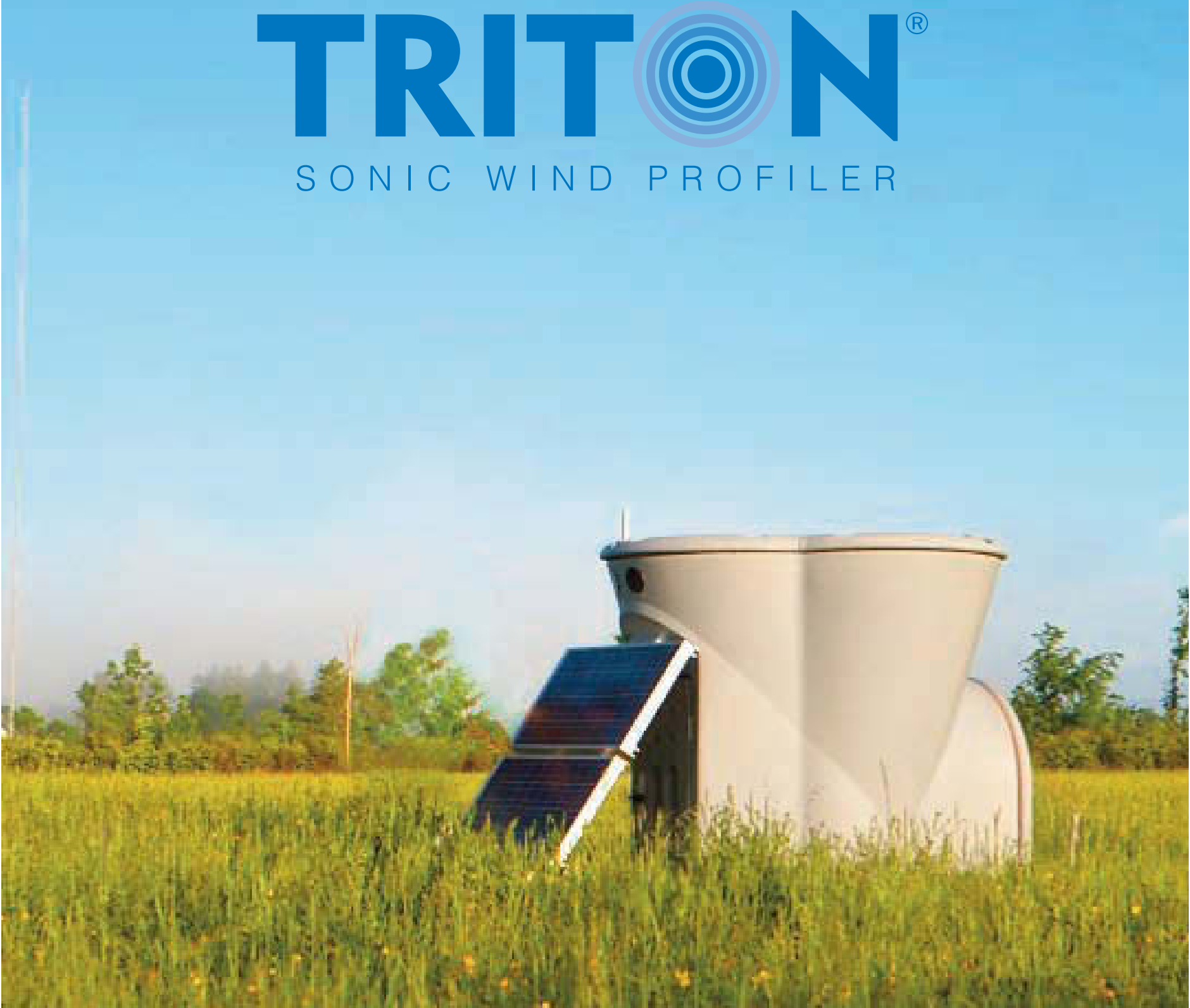

The Wind Industry's Leading Remote Sensing System

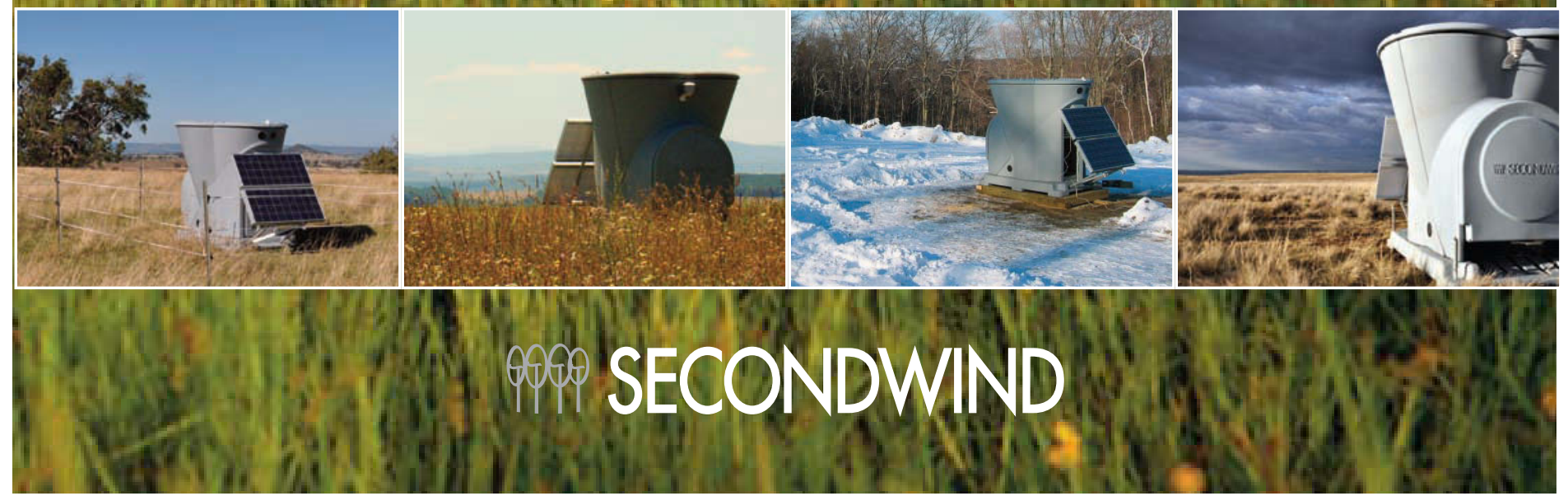




\section{TRITON ${ }^{\circledR}$ SONIC WIND PROFILER SPECIFICATIONS}

\section{DATA CAPTURE}

\begin{tabular}{|c|c|}
\hline Maximum height & $200 \mathrm{~m}$ \\
\hline $\begin{array}{l}\text { Wind data capture } \\
\text { heights }\end{array}$ & $\begin{array}{l}40,50,60,80,100,120,140,160, \\
180,200 \mathrm{~m}\end{array}$ \\
\hline Wind speed range & 0-25 m/s (0-55 mph) \\
\hline $\begin{array}{l}\text { Data recovery rate } \\
\text { (unfiltered) }\end{array}$ & $>98 \%$ (at all heights) \\
\hline $\begin{array}{l}\text { Filtered data recovery } \\
\text { rate* }\end{array}$ & $\begin{array}{l}>95 \% \text { at } 60 \mathrm{~m} ;>90 \% \text { at } 80 \mathrm{~m} \text { (with }>90 \% \\
\text { Quality Factor }\end{array}$ \\
\hline Filtered data correlation & Within $2 \%$ of anemometers \\
\hline Data upload rate & $\begin{array}{l}\text { Every } 10 \text { minutes, via communications link. } \\
\text { Automatic data buffering and backfilling } \\
\text { protocol. }\end{array}$ \\
\hline SD memory & $\begin{array}{l}2 \text { GB SD card records a minimum of } 2 \text { years } \\
\text { of } 10 \text { minute data. }\end{array}$ \\
\hline \multicolumn{2}{|c|}{$\begin{array}{l}\text { *Filtered data recovery rate represents the percentage of Triton data with a Quality } \\
\text { Factor }>90 \% \text { averaged over a } 12 \text {-month period to account for seasonal and diurnal } \\
\text { effects. Application of a minimum QF of } 90 \% \text { removes low quality data associated with } \\
\text { atmospheric stability, atmospheric absorption, and precipitation events. The Triton's } \\
\text { Filtered Data Recovery Rate is equivalent to "directionally filtered data" from met tower } \\
\text { mounted anemometers. }\end{array}$} \\
\hline
\end{tabular}

\section{POWER SUPPLY}

\begin{tabular}{|c|c|}
\hline Power consumption & $7 \mathrm{~W}$ (average) \\
\hline Solar panels & 2 panels, each rated @ 85 W \\
\hline Internal batteries & $\begin{array}{l}\text { Leak-proof AGM marine batteries, rated } \\
12 \mathrm{~V}, 92 \mathrm{Ah} .\end{array}$ \\
\hline Battery capacity & $\begin{array}{l}\text { Internal shipping-safe mounting system } \\
\text { holds up to } 4 \text { batteries, for } 20 \text { days of } \\
\text { operation without charging. (See note under } \\
\text { "Mirror Heater System/Battery Capacity") }\end{array}$ \\
\hline
\end{tabular}

\section{INSTALLATION}

\begin{tabular}{ll} 
Footprint & $2 \mathrm{~m} \times 3 \mathrm{~m}\left(6^{\prime} \times 9^{\prime}\right)$ with solar panels fitted \\
\hline Orientation & $\begin{array}{l}\text { Dual-axis accelerometer for automatic } \\
\text { correction for out-of-level. Site location } \\
\text { determined by GPS. }\end{array}$ \\
\hline Leveling of base & Within $3^{\circ}$ of level in $\times$ and y axes \\
\hline
\end{tabular}

\section{OPERATION}

\begin{tabular}{|c|c|}
\hline Ambient temperature & $-40^{\circ} \mathrm{C}$ to $+65^{\circ} \mathrm{C}\left(-40^{\circ} \mathrm{F}\right.$ to $\left.+150^{\circ} \mathrm{F}\right)$ \\
\hline $\begin{array}{l}\text { Frequency of } \\
\text { sound beams }\end{array}$ & $\begin{array}{l}4,500 \mathrm{~Hz} \text { (nominal), with automatic } \\
\text { temperature correction }\end{array}$ \\
\hline Number of sound beams & 3 \\
\hline Data sampling rate & $\begin{array}{l}\sim 100 \text { 'chirps' per sound beam per } 10 \\
\text { minute period }\end{array}$ \\
\hline Duration of sound 'chirp' & $60-100$ milliseconds \\
\hline Sound level at ear level & $\begin{array}{l}87 \mathrm{dBa} \text { at } 0 \mathrm{~m} ; 63 \mathrm{dBa} \text { at } 50 \mathrm{~m} \text { (intermittent } \\
\text { sound source) }\end{array}$ \\
\hline
\end{tabular}

\section{TRANSPORTATION}

Dimensions

$2 \times 2 \times 2 \mathrm{~m}\left(6^{\prime} \times 6^{\prime} \times 6^{\prime}\right) .1 .2 \mathrm{~m}\left(3^{\prime} 11^{\prime \prime}\right)$ wide base fits pick-up truck bed or trailer

Weight $\quad 350$ to $450 \mathrm{~kg}$ (750 to $1000 \mathrm{lbs}$ ) depending on configuration

Integrated shipping Triton and all accessories ship as one unit

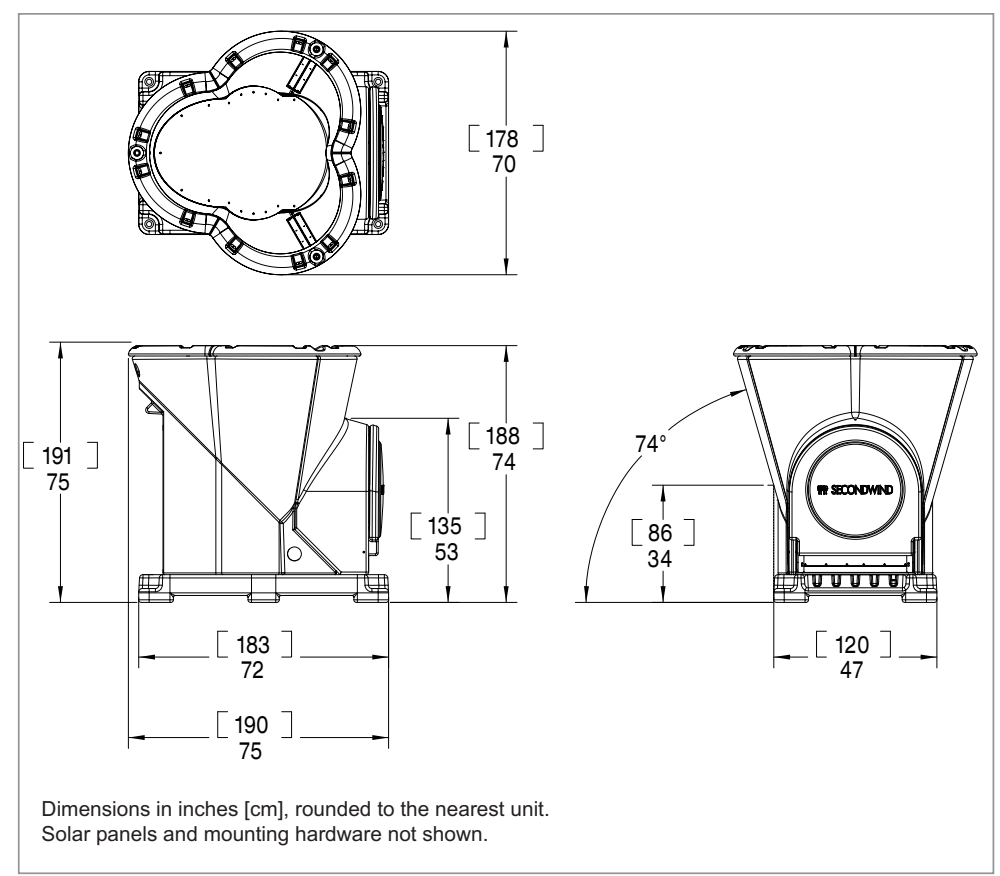

\section{MIRROR HEATER SYSTEM}

\begin{tabular}{ll} 
Energy source & LPG (propane) \\
\hline $\begin{array}{l}\text { Storage capacity } \\
\text { (to be provided }\end{array}$ & Triton enclosure has nesting locations for \\
by the customer) & (1) $18 \mathrm{~kg}(40 \mathrm{lbs}$.) and (1) $14 \mathrm{~kg}(30 \mathrm{lbs})$. \\
& LPG bottles with a combined capacity of \\
& $32 \mathrm{~kg}$ (70 lbs.). \\
\hline Run time & Up to 200 hours of snow melting with 32 \\
& $\mathrm{~kg}(70 \mathrm{lbs}$.$) internal propane supply.$ \\
\hline Heater control & $\begin{array}{l}\text { Intelligent system with satellite control } \\
\text { capacity }\end{array}$ \\
\hline Battery capacity & For heater-equipped Tritons, frequent \\
& heater activations will reduce the time of \\
& battery operation without a charging event.
\end{tabular}

\section{Configurations}

\section{STANDARD TRITON}

Includes 2 batteries, 2 solar panels, Globalstar modem and antenna, and 4 screw-in ground anchors.

\section{TRITON WITH HEATER PREP}

Standard Triton plus 2 additional batteries, heatable mirror, and heater tubing.

\section{TRITON WITH MIRROR HEATER}

Above, plus complete mirror heater system.
Second Wind Inc. 366 Summer Street, Somerville, MA 02144 USA | www.secondwind.com Tel. (617) 776-8520 | Fax (617) 776-0391 | tritonsales@secondwind.com 


\section{Now,}

\section{a real choice}

\section{in 60 meter}

\section{towers.}

Second Wind introduces the
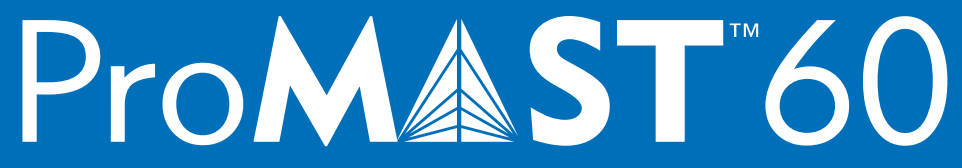

Easier compliance with IEC specifications

Aot-dipped galvanized steel to resist corrosion

^ Competitive pricing, volume discounts, and completely customizable tower packages 


\section{ProMAST 60}

Now you have a real choice in 60 meter towers

The ProMast 60 is designed to offer the wind farm developer an economical yet rugged solution to tower-based wind resource assessment.

\section{The ProMast 60 is built for today's wind} measurement projects

With diameters of $22.2 \mathrm{~cm}$ OD at the bottom and $16.5 \mathrm{~cm}$ OD at the top, the ProMast 60 allows the installation of very stable booms, in compliance with IEC specifications.

This minimizes boom vibration and reduces uncertainty in your wind data. And the ProMast 60 is made of hot dipped galvanized steel to resist corrosion and stand up to the toughest environments.

\section{Second Wind offers volume discounts}

If you're buying more than one tower, you can save money. Contact us for more information on how you can turn multiple tower purchases into enormous cost savings.

\section{Second Wind will customize your tower package with no price penalty}

Second Wind sells the Nomad 2 Wind Data Logger and any sensor you could want to buy - including Class 1 anemometers such as Vector, Thies, and WindSensor (Risø). Our standard package includes Second Wind's C3 anemometers and PV- 1 vanes, but we will substitute any sensor and still offer you savings.

\section{You don't have to buy the whole package}

Do you just need a tower? No problem. We offer our tower at very competitive prices. You do not have to buy sensors you don't need. And our volume discounts apply to towers-only as well as to complete tower systems. 


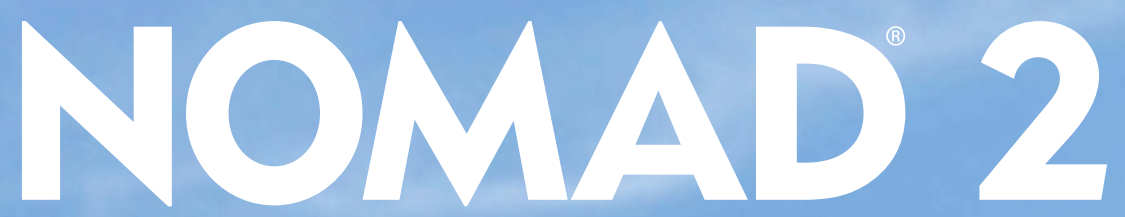

WIND RESOURCE DATA LOGGER

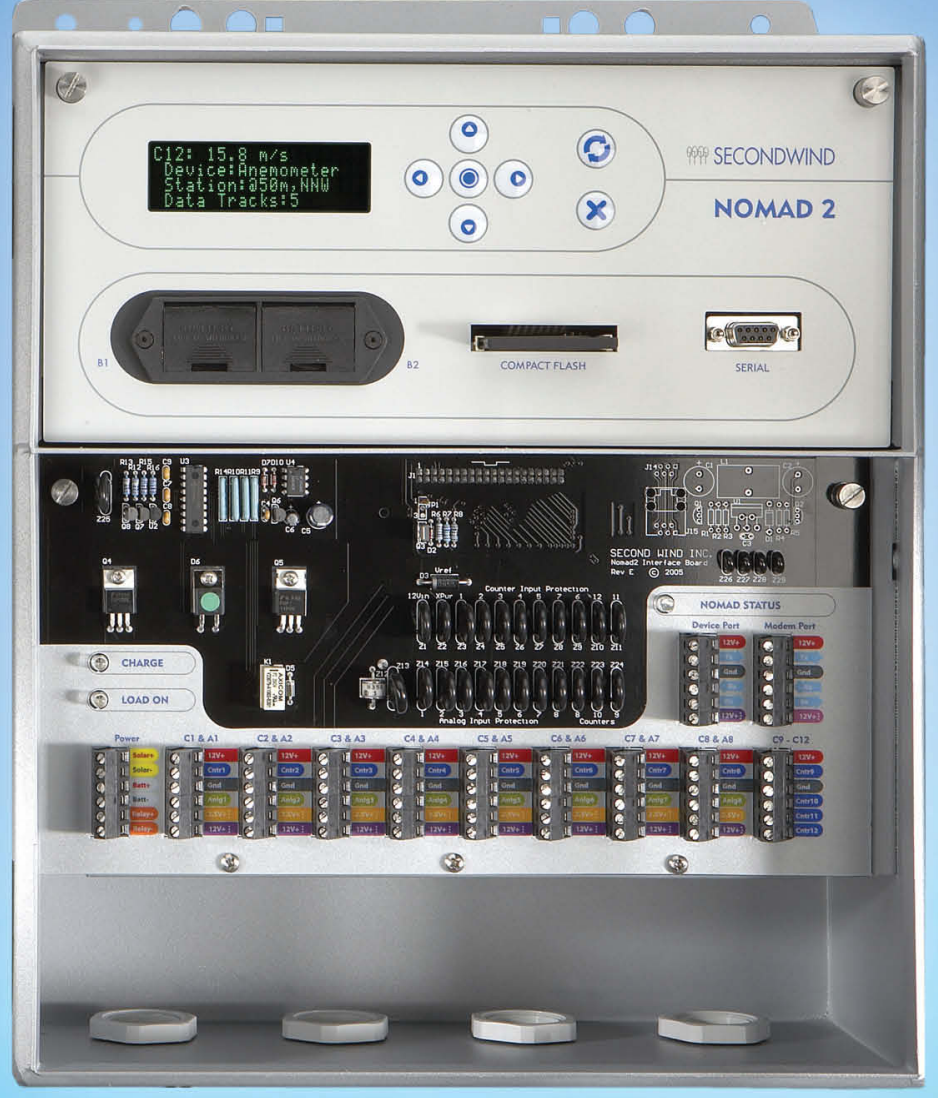

The Wind Industry's Most Flexible Data Logger

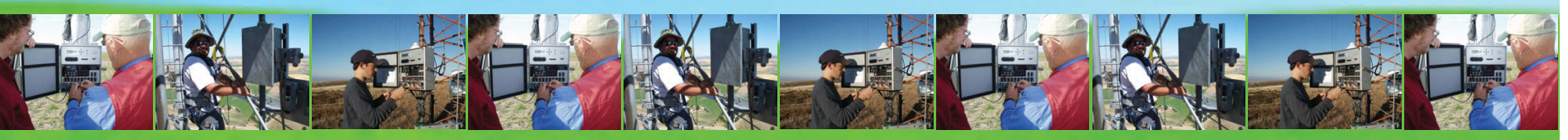

MPP SECONDWIND 


\section{NOMAD ${ }^{\mathrm{TM}} 2$ WIND DATA LOGGER SPECIFICATIONS}

\section{SENSOR INPUTS}

12 counter inputs - Configurable for AC \& pulse anemometers, other frequencyoutput devices, and high/low digital or relay state signaling

- Frequency range $\mathrm{DC}$ to $2 \mathrm{kHz}$

- High display resolution with low frequency anemometers

- Input high/low threshold configurable for OV or 3V

- Configurable filtering for low frequency devices

- 1 -second count integration, $\pm 0.02 \%$ accuracy

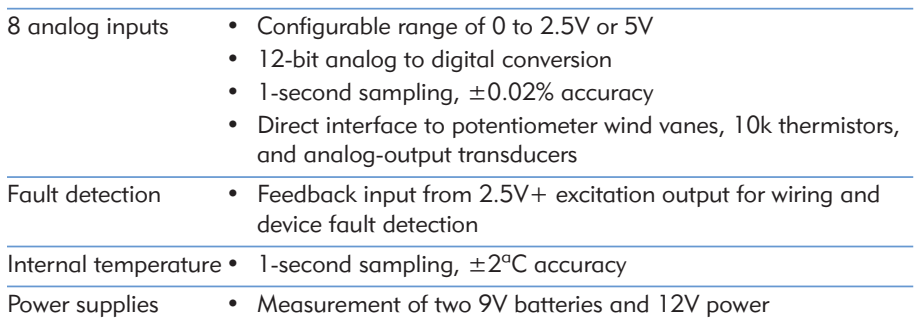

\section{OUTPUTS}

\begin{tabular}{|c|c|}
\hline $2.5 \mathrm{~V}+$ excitation: & $\begin{array}{l}\text { - } 2.5 \mathrm{~V}+\text { smart-switched excitation distributed to all input } \\
\text { terminal blocks for energy-conserving measurement of } \\
\text { potentiometers and thermistors } \\
\text { - Calibrated to } \pm 5 \mathrm{mV}, 25 \mathrm{ppm} /{ }^{\circ} \mathrm{C}, 250 \mathrm{~mA} \text { max }\end{array}$ \\
\hline $\begin{array}{l}12 \mathrm{~V} \text { transducer } \\
\text { power }\end{array}$ & $\begin{array}{l}\text { - } 12 \mathrm{~V}+\text { smart-switched transducer power output } \\
\text { distributed to all input terminal blocks for energy-conserving } \\
\text { operation of electronic transducers } \\
\text { - } 1 \text { Amp maximum }\end{array}$ \\
\hline $12 \mathrm{~V}$ modem power & $\begin{array}{l}\text { - } 12 \mathrm{~V}+\text { configurable switched modem power output for energy- } \\
\text { conserving operation of cellular \& other modems } \\
\text { - } 1 \text { Amp maximum }\end{array}$ \\
\hline Relay output & $\begin{array}{l}\text { - For de-icing or other control applications } \\
\text { - SPST dry contact, } 1 \text { Amp maximum, AC or DC } \\
\text { - Modbus-controlled }\end{array}$ \\
\hline
\end{tabular}

\section{POWER SUPPLY}

9 Volt batteries: $\quad-2$ parallel standard $9 \mathrm{~V}$ batteries in sliding receptacles

- Up to 6 months operation with alkaline, up to one year with lithium $\left(-40^{\circ} \mathrm{C}\right)$ batteries that have no shipping restrictions

12 Volt Power: $\quad$ 12V (10-18V DC) input for internal primary or rechargeable batteries, external DC power supply, or regulated solar panel

- Two-screw removable internal mounting for lead-acid batteries for higher power transducer, controls, and communication gear, standard sizes up to $20 \mathrm{AH}$, extreme environment sizes up to $8 \mathrm{AH}$

Solar: $\quad$ Optional on-board solar charging regulator/controller

\section{SERIAL PORTS}

- 3 independent RS232C serial ports, up to $115 \mathrm{kBaud}$

Local port $\quad$ Direct straight-cable connection to laptop or PC

- Standard pinout DB9, DCE

Remote port $\quad$ Connects to modem, radio, or asynch network adapter

- Auto-wakeup Rx input

- Internally connected for SWI-supplied modem options

- Field-wireable terminals for customer-installed devices

Device Port:

- Connects to and logs from communicating transducers including multifunction Phaser ${ }^{\circledR}$ power transducers \& ultrasonic anemometers

- Pollable Modbus RTU for SCADA and other general applications

\section{ESD PROTECTION}

- All inputs, outputs, and serial port signaling transient and fault protected

- No additional lightning protection needed

\section{USER INTERFACE}

\begin{tabular}{|c|c|}
\hline Local Display: & $\begin{array}{l}\text { - } 4 \times 20 \text { alphanumeric character display, LCD or VFD } \\
\text { - Configurable smart-switched power } \\
\text { - Automatic temperature-compensating LCD contrast }\end{array}$ \\
\hline Keypad & - 7-key sealed membrane keypad \\
\hline Remote interface & $\begin{array}{l}\text { - Full display, configuration, data transfer, \& firmware } \\
\text { upgradability by local port or modem connection to any PC via } \\
\text { NOMAD Desktop }\end{array}$ \\
\hline Status light: & $\begin{array}{l}\text { - Heartbeat LED indicates operational status independent of } \\
\text { display }\end{array}$ \\
\hline
\end{tabular}

\section{INPUT AND DATA PROCESSING}

\begin{tabular}{ll} 
Wind speed & - Slope \& offset scaling, auto-zeroing for counter inputs \\
\hline Wind direction & - Modulo $360^{\circ}$ and true vector processing \\
& - Deadband location correction \\
\hline Temperature & - Thermistor linearization to device accuracy $\left( \pm 0.1^{\circ} \mathrm{C}\right)$ \\
Math functions & - Average, standard deviation, maximum, time of maximum, \\
& minimum, time of minimum, total, cycles, sample value
\end{tabular}

\section{PHYSICAL}

\begin{tabular}{|c|c|}
\hline Operating temp: & - $-40^{\circ}$ to $85^{\circ} \mathrm{C}$ all specifications (Vacuum Fluorescent Display) \\
\hline $\begin{array}{l}\text { LCD temperature: } \\
\text { Internal RT clock }\end{array}$ & $\begin{array}{l}\text { - } \mathrm{LCD} \text { operates from }-20^{\circ} \text { to } 70^{\circ} \mathrm{C} \text {, storage }-30^{\circ} \text { to } 80^{\circ} \mathrm{C} \\
\text { - } \pm 1 \text { minute/month accuracy, internet time-server adjustable } \\
\text { - } \text { Backed up by socketed } 2032 \text { Lithium coin cell ( } 10 \text { year life) }\end{array}$ \\
\hline Wire \& cabling & $\begin{array}{l}\text { - } 12 \text { six-screw, } 0.2^{\prime \prime}(5 \mathrm{~mm}) \text { cage clamp style terminal blocks } \\
\text { - Signal, ground, excitation, switched \& unswitched } 12 \mathrm{~V} \text { power } \\
\text { distributed to each of } 8 \text { terminal blocks } \\
\text { - Standard SMA-F bulkhead connector for external antennas } \\
\text { - Four } 3 / 4^{\prime \prime} \mathrm{npt} / \mathrm{pg} 21 \text { knockouts for cable \& conduit installation }\end{array}$ \\
\hline Enclosure & $\begin{array}{l}\text { - Integrated waterproof instrument enclosure, wire and cable } \\
\text { - Uunction box, and lockable rain shed } \\
\text { - Upper section NEMA4/IP66 (watertight), lower section } \\
\text { - } 16 \text { ga. steel, } 14 \text { ga. mounting flanges, TGIC powdercoated } \\
\text { - } 14 \text { x } 12 \text { × } 5.5 \text { inches ( } 350 \times 300 \times 140 \mathrm{~mm}), 20 \mathrm{lbs} \text {. ( } 9 \mathrm{~kg} \text { ) } \\
\text { - Mini-rack mounting for internal modem options } \\
\text { - Swing-out panels for modem and } 12 \mathrm{~V} \text { battery access } \\
\text { - Surface, truss-tower, or tube-tower mounting } \\
\text { - Single no-tools padlockable hasp closure }\end{array}$ \\
\hline
\end{tabular}

\section{AVAILABLE OPTIONS}

- Vacuum Fluorescent Display

- GSM/GPRS, CDMA, and AMPS cellular modems

- Satellite modem (Iridium)

- Landline telephone (POTS) modem

- Integrated solar charging systems, including charge regulator, panel, mounting brackets, and lead-acid batteries
Second Wind Inc. 366 Summer Street, Somerville, MA 02144 USA | www.secondwind.com Tel. (617) 776-8520 | Fax (617) 776-0391 | tritonsales@secondwind.com 
Nomad Desktop is a suite of software tools that work with NOMAD 2 wind resource assessment data loggers. Use Nomad Desktop to configure the NOMAD 2, exchange files with the NomAD 2, view real-time data remotely, analyze data with reports and graphs, and export data to other applications.

\section{Graphs and Reports}

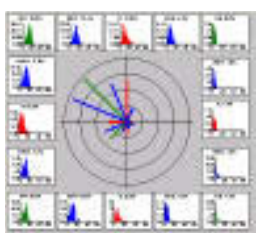

\section{Wind Rose Graph}

A Wind Rose Graph is a radial graph of the frequency of occurrence of winds by point of compass. Use this graph to see where the wind energy at your site is coming from. The Wind Rose is surrounded by 16 wind speed distribution graphs, one corresponding to each bar on the wind rose, showing the energy of the wind from each direction in addition to the occurrence.

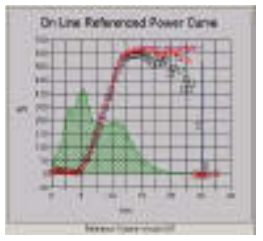

\section{Power Curve Graph}

The Power Curve Graph shows the power output of a wind turbine as a function of wind speed. This graph can plot power data from an actual turbine, or show the expected energy output based on the power curve supplied by the manufacturer. In addition to the power curve plot, this graph also displays the wind speed distribution. Power curve data can be further modified to account for the time the wind turbine was "On Line", be filtered by wind direction, and be adjusted to correct for air density.

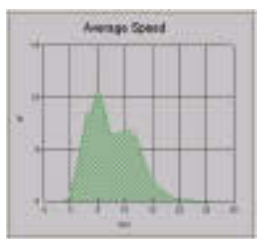

\section{Distribution Graph}

The Distribution Graph creates a frequency-of-occurrence distribution for any data track in the database. The graph can be edited by range of values, width of bins, and interpretation of the $Y$-axis as percentage, number of occurrences, or time.

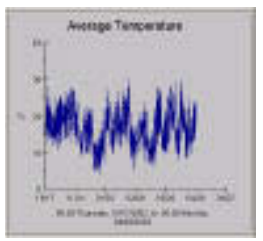

Time Series Graphs

The Time Series Graph and the Scrolling Time Series Graph plot any track in the database as a function of time. The Time Series Graph displays all of the data for a particular input on one screen. The Scrolling Time Series Graph limits the display to 144 data points at a time to show more detail, and a bar at the bottom of the plot allows you to scroll through the data. The "Hot Hits" feature allows you to click on a data point to view the value, date, and time-stamp of that point.

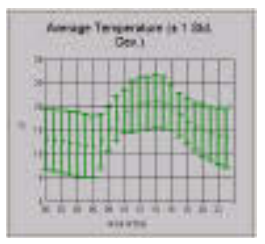

\section{Diurnal Graph}

The Diurnal Graph displays the diurnal trend (daily variation) of any track in the database. All data is binned by hour of day, and the high/low bars show one standard deviation around the average value. This graph shows the hourly trend of data, for example it may be noticeably windier around 3 p.m. every day.

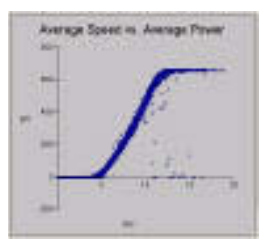

\section{X-Y Graph}

The X-Y Graph is a scatter plot showing the relationship between any two variables. This can be used to show the correlation between two anemometers at different heights, for example, or to plot power output as a function of wind speed. The two tracks can be from the same NOMAD 2 or from two different NOMAD 2's in the database.

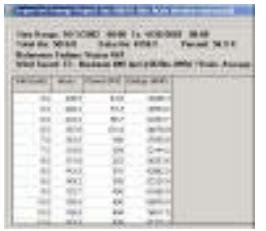

\section{Expected Energy Report}

The Expected Energy Report displays the the expected energy output of a wind turbine based on the wind data collected at a site. This report is similar to the Power Curve Graph, but is presented in report format. Data can be corrected for air density. The report presents a tabular format of wind speed, hours, power $(\mathrm{kW})$, and energy $(\mathrm{kWh})$, with totals displayed at the bottom. 


\section{Tools}

\section{Site \& Input Configuration}

Configuring the NOMAD 2 data logger to collect exactly the data you need is quick and easy with Nomad Desktop. The Site \& Input Configuration page allows you to identify your data with a Site Name, Latitude, Longitude, and Elevation. Set the local time of the site with the GMT Offset and Daylight Savings options. Choose from one of over 60 pre-configured wind industry sensors or enter your own input configuration. Further identify sensors with a Serial Number, Units, and Height and Azimuth on the tower. Set up tracks by selecting a function and interval from the drop-down selections.

\section{Communication Configuration}

If your NOMAD 2 has a modem installed for remote communication, use the Communication Configuration file to turn on the modem for one or two time intervals daily, set up a user name and password for security, and save the phone number of the modem to the database for one-click connection. If you would like to use the e-mail feature, enter the ISP information, up to three e-mail recipients, and the time of day to send the e-mail, and NOMAD 2 will e-mail the previous day's data file to all recipients daily.

\section{Import Data Files into the Database}

Whether data is collected by Compact Flash card, direct or remote connection to the NOMAD 2, or by e-mail, all data is imported into a single database for complete analysis. All information about the data logger (e.g. site name, location) and about the sensors (e.g. slope and offset, height, azimuth, etc.) is stored in the database and displayed on graphs and reports. The import screen will display the numer of data records added, the number of new configurations added, and the progress of the import.

\section{Multi-Track Export}

The Multi-Track Export function allows you to create a spreadsheet containing data from multiple tracks. This is a very useful tool for wind resource assessment and modeling. The data from all selected tracks is exported to a CSV format that can be read by spreadsheet programs such as Microsoft Excel. When using the Multi-Track Export function, users can choose one of 5 different averaging intervals: None, $10 \mathrm{~min}, 20 \mathrm{~min}, 30 \mathrm{~min}$ or 1 hour.

\section{Reference Power Curve Editor}

This button launches a Reference Power Curve Editor to create, view, and adjust reference curves for use with the Power Curve Graph and the Expected Energy Report. Nomad Desktop is supplied with 67 reference turbine power curves based on manufacturer-supplied data, and for approximate predictions of energy production based on wind resource assessment that may be all you need. But for full-blown power performance testing, you have the ability to make your own reference curves based on your specific contracts, turbines, and location.

\section{Communications}

\section{Connect to Nomad 2}

Communicate with NOMAD 2 via serial cable, or choose from our AMPS, GSM, or satellite modem options. Once connected to the NOMAD 2, you can Zoom the inputs to see live data, and Zoom the NOMAD 2 to see information about the logger itself. While connected, transfer files to and from the logger including Site \& Input Configuration files, Communication Configuration files, data files, System Log files, and anything else stored on the Compact Flash card.

\section{Zoom}

With the Zoom Inputs button you can view the scaled values of a connected NOMAD 2's configured inputs in real time. Use this feature to make sure your sensors are all working properly, and check on battery power. With the Zoom Nomad2 button you can view information about the logger itself, including the serial number, the latest versions of software loaded into the logger, the last time the logger was rebooted, and how much space is left on the Compact Flash card. The Zoom features can be used while connected by serial cable or by dial-up modem.

\section{Upload and Download Files}

The Download button allows you to transfer files from the Compact Flash card in a connected Nomad 2 to your computer. Although primarily used for picking up NomAD 2 Data Files (NDF's), you can also download the System log in the Compact Flash card's root directory to look at the connected NOMAD 2's operational history, retrieve old configurations, or get any other type of file on the card.

NOMAD 2 is field upgradeable. Transfer files from your computer to the Compact Flash card in a connected NOMAD 2. With Upload you can transfer: Site \& Input Configurations (N2Config.new files), Nomad Communication Configurations (N2ComCfg.new files), Time Adjustment Files (N2Time.new files), and Firmware Upgrades (N2Flash.new files). Uploading is usually the most convenient way to reconfigure remote modem-equipped NOMAD 2s. Uploading can also be used to reconfigure Direct Connected NomaD 2s as an alternative to transferring Compact Flash cards. 


\section{NRG 34 m TallTower ${ }^{\mathrm{TM}}$ Installation Manual \& Specifications}

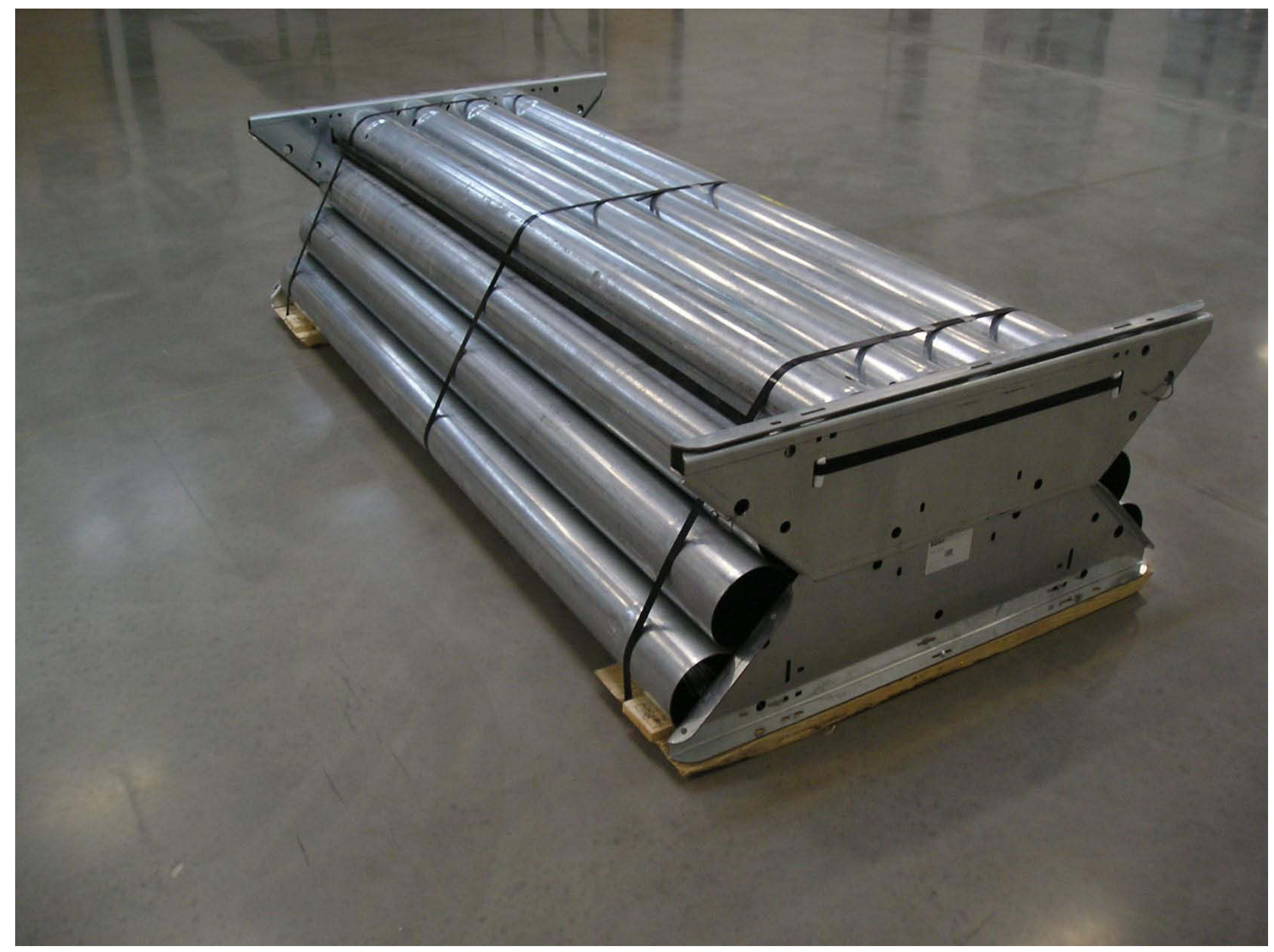

Global leader in wind measurement technology

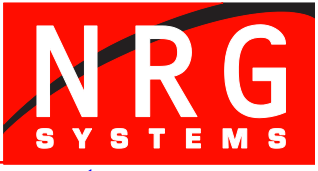

110 Riggs Road · Hinesburg ·VT 05461 USA ·TEL (802) 482-2255 · FAX (802) 482-2272 · EMAIL sales@nrgsystems.com 
Specifications are subject to change without notice. 
Installation of guyed towers is inherently dangerous. To minimize risks, read and follow the tower installation instructions explicitly. Do not install during an electrical storm. Installation in agricultural areas may pose a threat to low flying crop dusting aircraft. Notify appropriate parties and install warning devices as needed. We assume no responsibility or liability in connection with any act, error, omission, or for any injury, loss, accident, delay, inconvenience, irregularity or damage related to any TallTower installation.
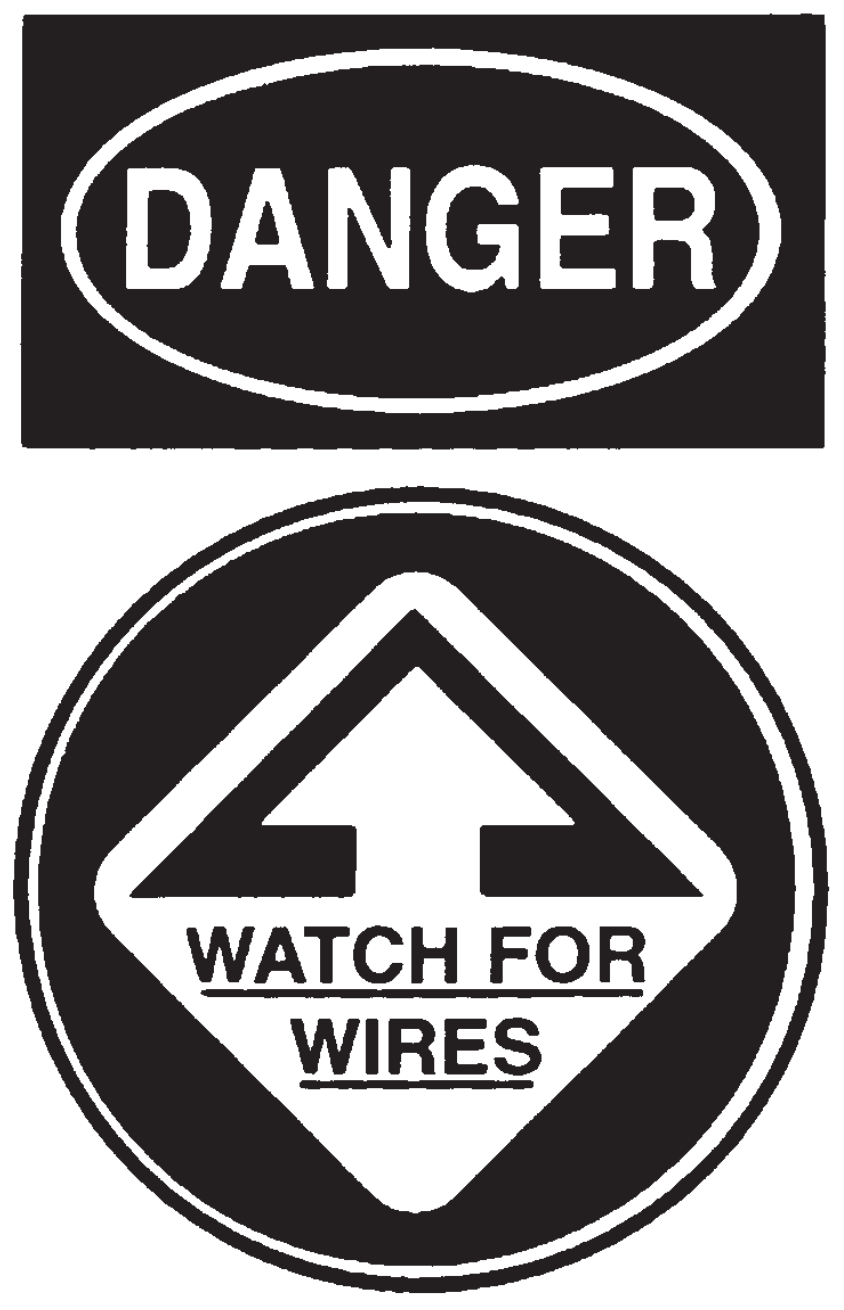

\section{DANGER: YOU CAN BE}

\section{KILLED}

\section{IF THIS TOWER COMES NEAR ELECTRIC POWER LINES or IF YOU INSTALL THIS TOWER DURING AN ELECTRICAL STORM.} FOR YOUR SAFETY, FOLLOW THESE INSTALLATION INSTRUCTIONS. 


\section{Table of Contents}

WARNINGS 6

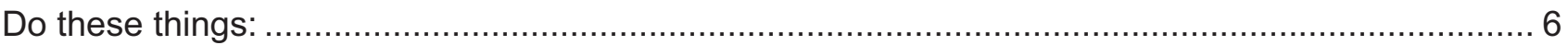

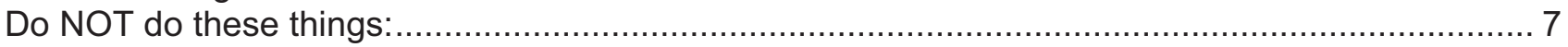

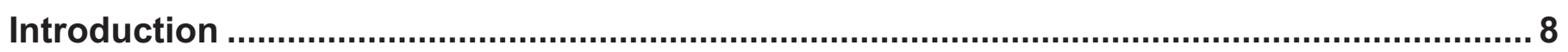

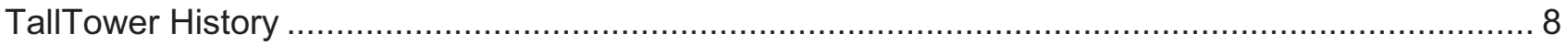

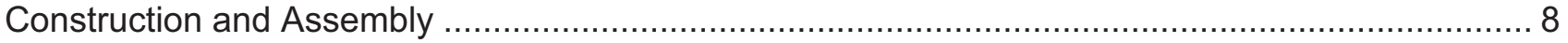

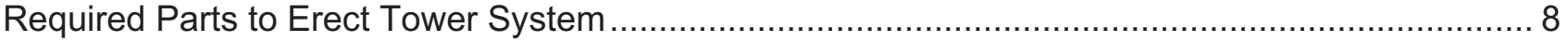

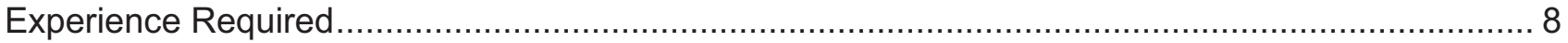

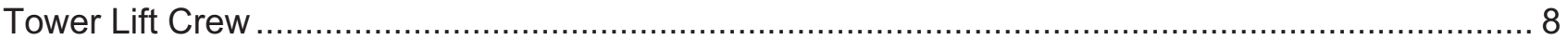

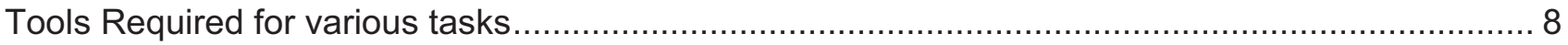

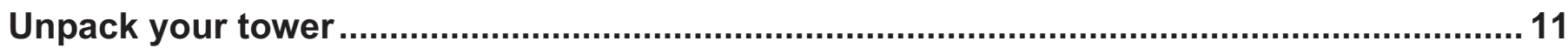

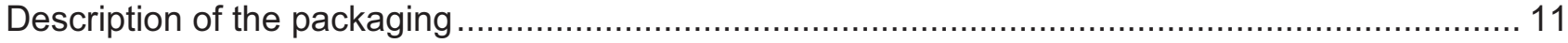

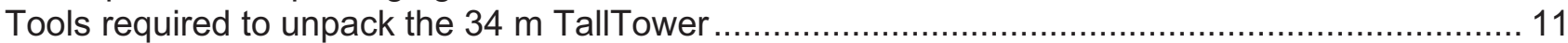

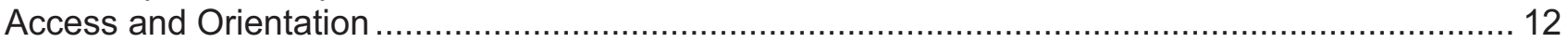

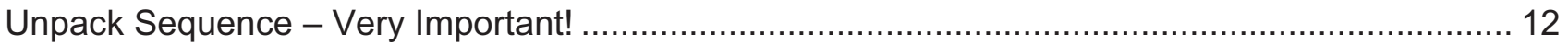

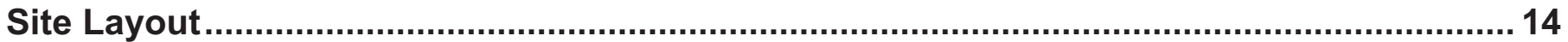

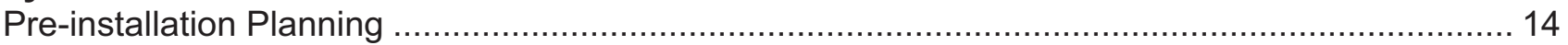

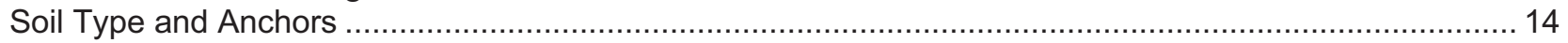

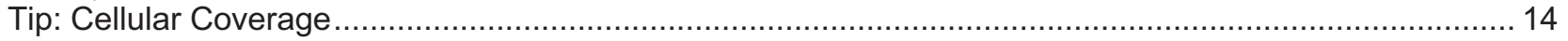

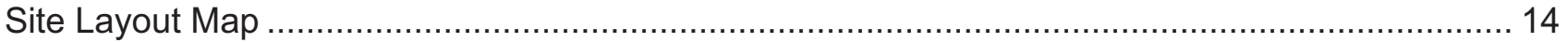

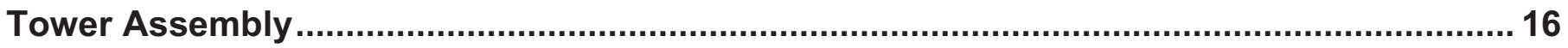

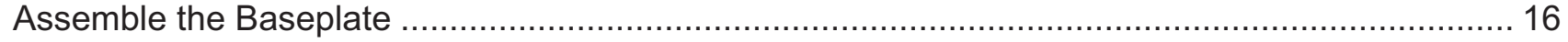

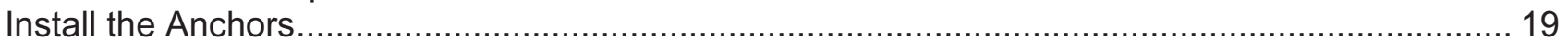

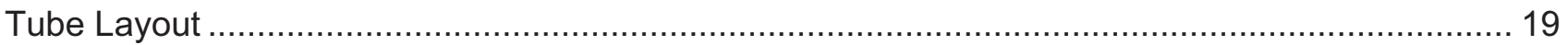

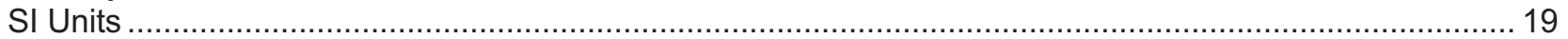

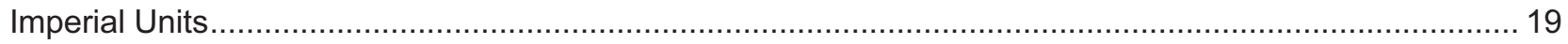

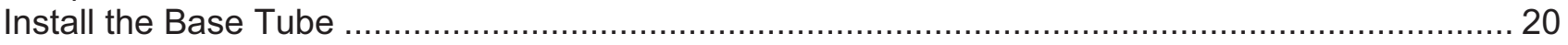

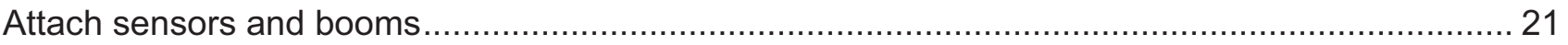

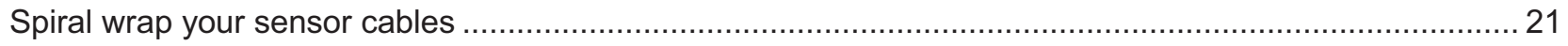

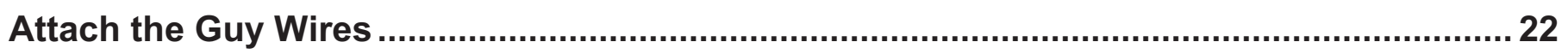

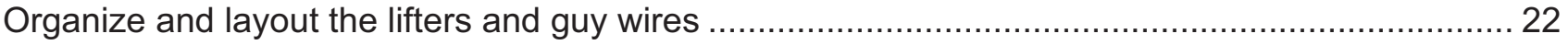

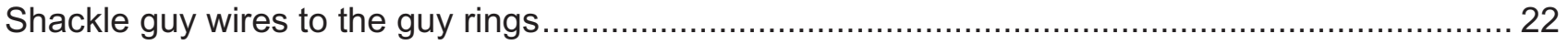

Roll out each guy wire from the tower to its anchor point ......................................................... 22

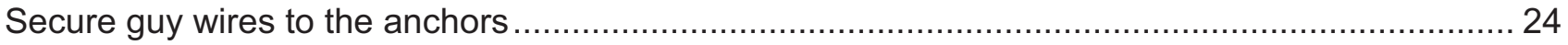

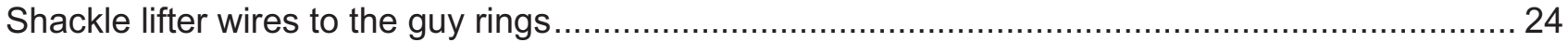

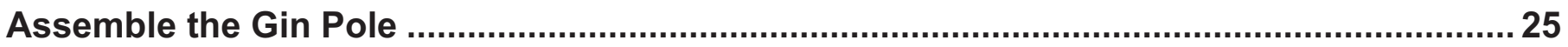

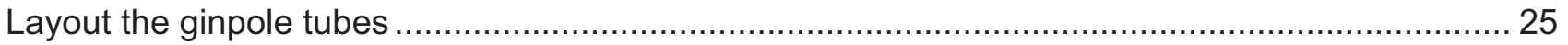

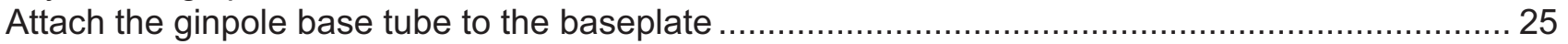

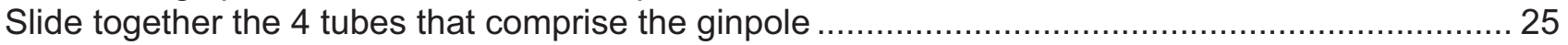

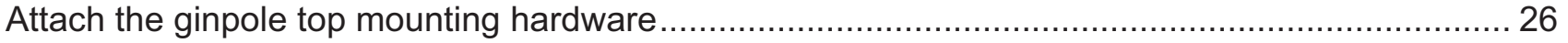

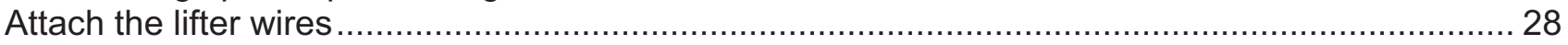

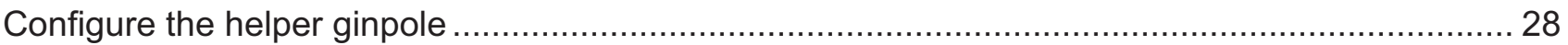




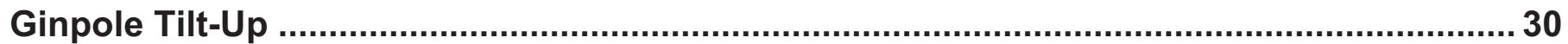

Confirm all lifters and shackles are secure …………......................................................... 30

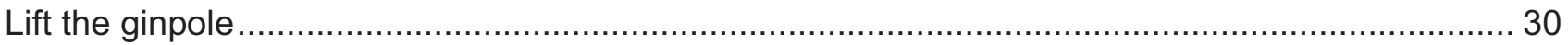

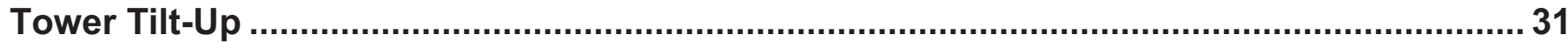

Understanding Guy Wire Tensioning While Raising TallTower (Do not raise the tower yet) ............31

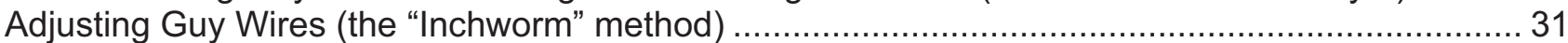

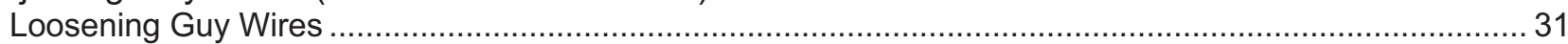

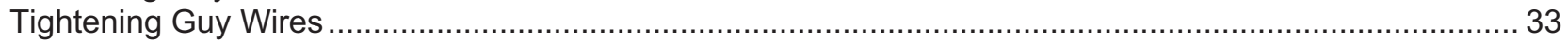

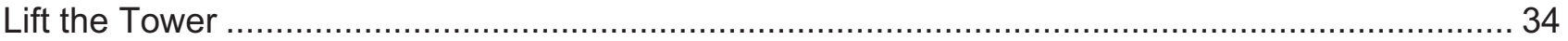

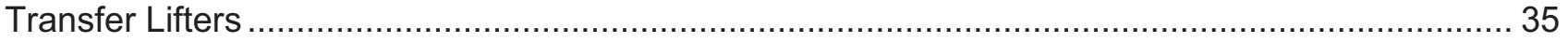

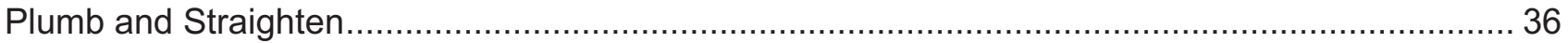

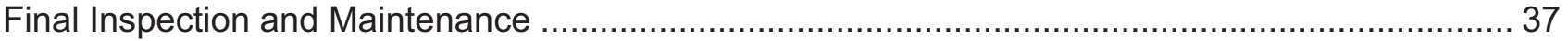

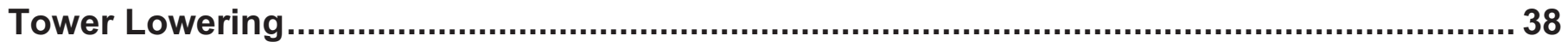

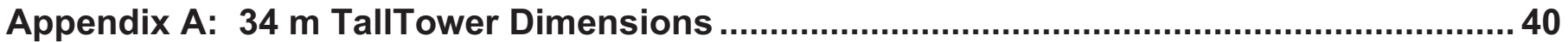

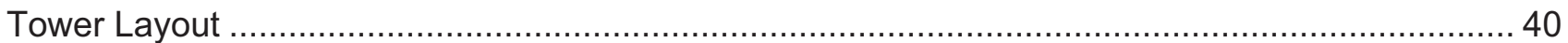

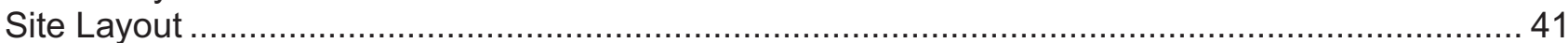

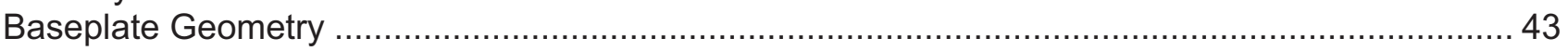

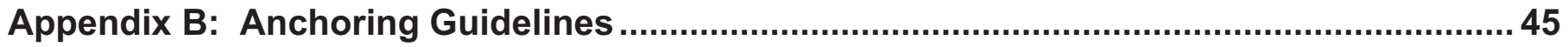

Determine site soil and anchor type before you order your tower ............................................. 45

Anchor Choices and other considerations ........................................................................ 45

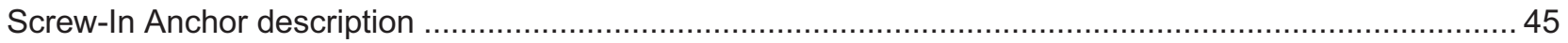

Arrowhead Anchor description .................................................................................................... 47

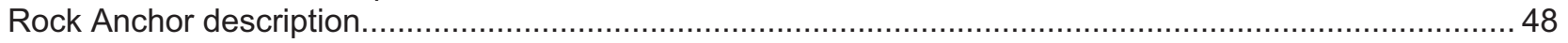

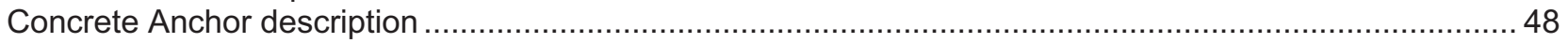

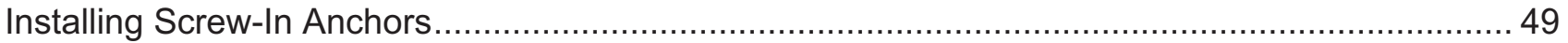

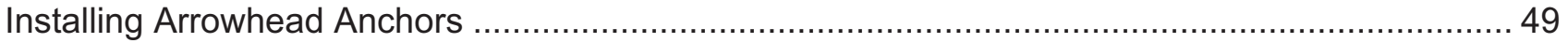

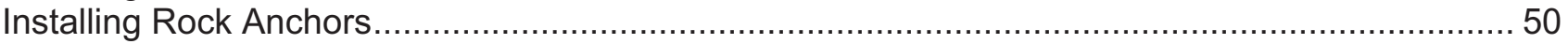

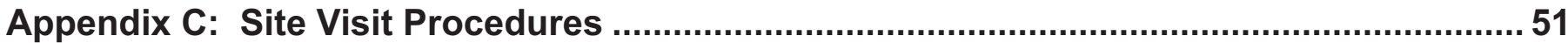

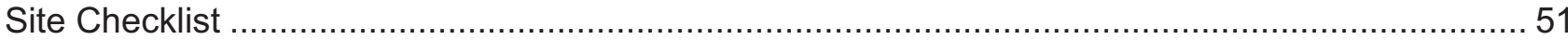

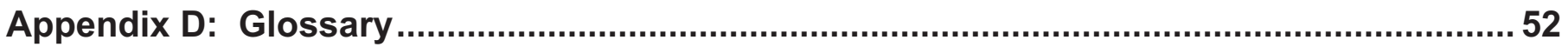

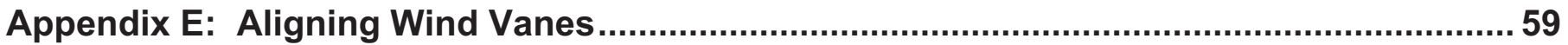

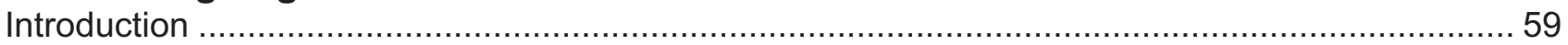

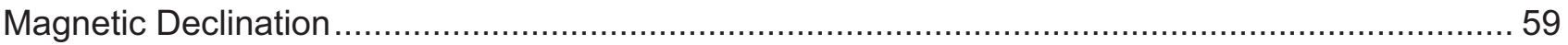

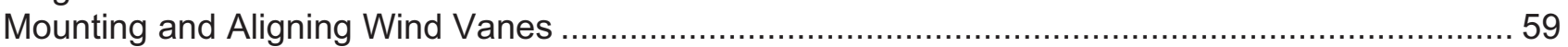

Using Data Analysis Software to Correct for Magnetic Declination .......................................................... 62

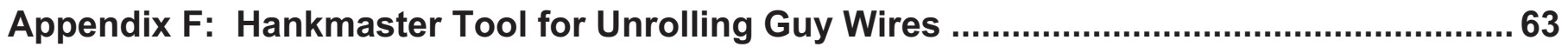

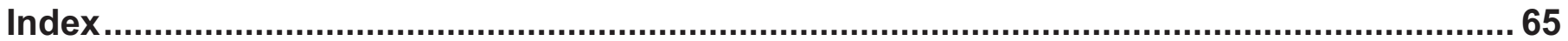




\section{WARNINGS}

\section{Do these things:}

Read and follow the Tower Installation Manual!

Determine the soil type at your site and install the correct anchors.

Place tower anchors according to anchor manufacturer's recommendations.

Properly ground the tower electrically.

Stand to the side of any tensioned cables.

Thoroughly understand tower erection procedure before beginning installation. All crew members should read the manual before arriving at the installation site!

Review glossary so that you are familiar with all tower parts and terminology.

If you are NOT familiar with erecting towers of this type, seek professional guidance. We will gladly help answer any questions.

If you have never installed a TallTower before, seek the assistance of a qualified installer.

If you are not thoroughly familiar with all components of the tower, including all hardware and how all components function, DO NOT attempt to install this tower yourself. Tall guyed towers are dangerous, and you or members of your crew can be injured or killed.

If installing the TallTower in an agricultural area, notify appropriate parties and install warning devices as needed. Towers can pose a threat to low-flying crop dusting aircraft.

If you are unsure of how to anchor your tower, seek professional guidance. 


\section{Do NOT do these things:}

DO NOT climb this tower.

DO NOT erect tower within $1 \frac{1}{2}$ times the tower height of electric power lines.

DO NOT install this tower during an electrical storm.

DO NOT erect tower within $1 \frac{1}{2}$ times the tower height of walkways, roads, or buildings.

DO NOT permit unauthorized personnel onto the site while the tower is being installed.

DO NOT raise or lower the tower on a day with high winds or gusty winds.

DO NOT use mechanical tensioning devices to adjust guy wires.

DO NOT use rebar anchors.

DO NOT stand in line with, directly in front of, or behind any tensioned cable. 


\section{Introduction}

\section{TallTower History}

NRG TallTowers ${ }^{\mathrm{TM}}$, the original tilt-up tubular towers, were first introduced in 1982 and soon became the industry standard to quickly and easily get sensors up and into the wind to start measurements. TallTowers are delivered in complete kits, assembled on the ground and then tilted up and secured with guy wires.

\section{Construction and Assembly}

The NRG TallTower ${ }^{\mathrm{TM}}$ is of galvanized steel tube construction and is guyed at four levels in four directions. Sections slide together without the use of bolts or clamps. The tower is tilted up from the ground with a gin pole and winch (winch is not included). Lifting of the tower is done by one set of guy wires (lifting wires) attached to the gin pole. The tower is stabilized sideways with two side guy wire sets. The base plate is hinged so both the tower and gin pole can pivot to the erected position.

\section{Required Parts to Erect Tower System}

NRG 34 meter TallTowers are supplied complete with ready to assemble tubes, baseplate, guy rings, precut guy wires, screw-in anchors, grounding kit, and associated hardware. Screw-in earth anchors are included and are suitable for many soil types. Other anchor types are available. It is your responsibility to determine which type of anchor is appropriate for your specific site.

Please refer to the anchoring guidelines in Appendix B of this manual for more information.

A winch and ginpole (ginpole is included with the purchase of this tower) are also required to raise the tower.

The ginpole for the $34 \mathrm{~m}$ TallTower is NOT compatible with other NRG TallTowers. The ginpoles from other NRG TallTowers are not compatible with the $34 \mathrm{~m}$ tower.

Please see the Glossary for pictures and descriptions of tower parts, hardware, and accessories.

\section{Experience Required}

If you have no prior experience with TallTower installation, seek assistance from a qualified installer.

\section{Tower Lift Crew}

We suggest the following organization to form an efficient and safe crew to erect NRG TallTowers. Each member of the lift crew should have a good understanding of the tasks they are required to perform during the lift.

Five Member Crew:

Crew leader: This person will operate the winch and coordinate the other members. It is especially important to maintain clear communication among the members of the crew. The tower footprint is large and walkie-talkie radios are highly recommended.

Side guy wire tenders: These two people will attend to each side guy anchor and adjust side guy wires. They must be familiar with taking in and letting out guy wires. See the pictures describing the "inchworm" technique for safely adjusting guy wires.

Observers: Two people to assist adjusting side guys, tending the back guy wires at the end of the lift, and otherwise observing guy wires.

\section{Tools Required for various tasks}

- $1 / 4$ inch nut driver (for sensor installation)

- $5 / 16$ inch nut driver (for hose clamps)

- $7 / 16$ inch (11 mm) socket wrenches (for wire rope clips) - one per crew member

- Large adjustable wrench (for large bolts)

- $\quad 1 / 2$ inch wrench, socket or open (for base plate assembly and unpacking

- Piece of rebar or similar (for turning anchors) 
- Hand sledge (for ground rods)

- Small adjustable wrench (for opening/closing acorn clamps)

- Small pliers (for sensor cotter pins)

- Small Phillips head (+) screwdriver (for set screws)

- Flat (-) screwdriver (for antenna mounting assembly)

- Knives (to cut electrical tape) - one per crew member

- Level, preferably with a magnetic base (to straighten the tower)

- Compass (for aligning direction sensors)

- Permanent marker (for labeling lower ends of cables)

- (2) $12 \mathrm{~V}$ deep cycle marine battery (for electric winch)

- Hankmaster $5000^{\mathrm{TM}}$ guy wire tool (optional)

- Gloves

- 2-way radios or walkie talkies

- Electric drill with 5/16 inch bit (for unpacking and attaching top tube)

- Band cutters (for unpacking)

- $2.5 \mathrm{~m}$ (8 feet) stepladder (for reaching end of ginpole on sloped sites)

- Rebar, rock bolts, or steel cable to secure tower base

- 8 wood posts (10 cm x $10 \mathrm{~cm} \times 1 \mathrm{~m} / 4 \mathrm{in}$. $\times 4$ in. $\times 3 \mathrm{ft}$.) to support tower

- Sawhorse to support ginpole

- Wire cutters 


\section{Unpack your tower}

\section{Description of the packaging}

The $34 \mathrm{~m}$ TallTower packaging was designed to reduce cardboard waste, protect the tower components and allow for more economical shipment. All the tower components including anchors and ground kit are now included in one package. If you purchased this tower as part of an NRG-NOW System, the electronics, sensors and associated accessories are packaged separately.

It is very important that you understand how to unpack the contents of the packaging safely. The recommended sequence to unpack the tower is described in this section of the manual.

The tubes may shift position suddenly when bands are cut, so please read this section carefully to avoid serious injury.

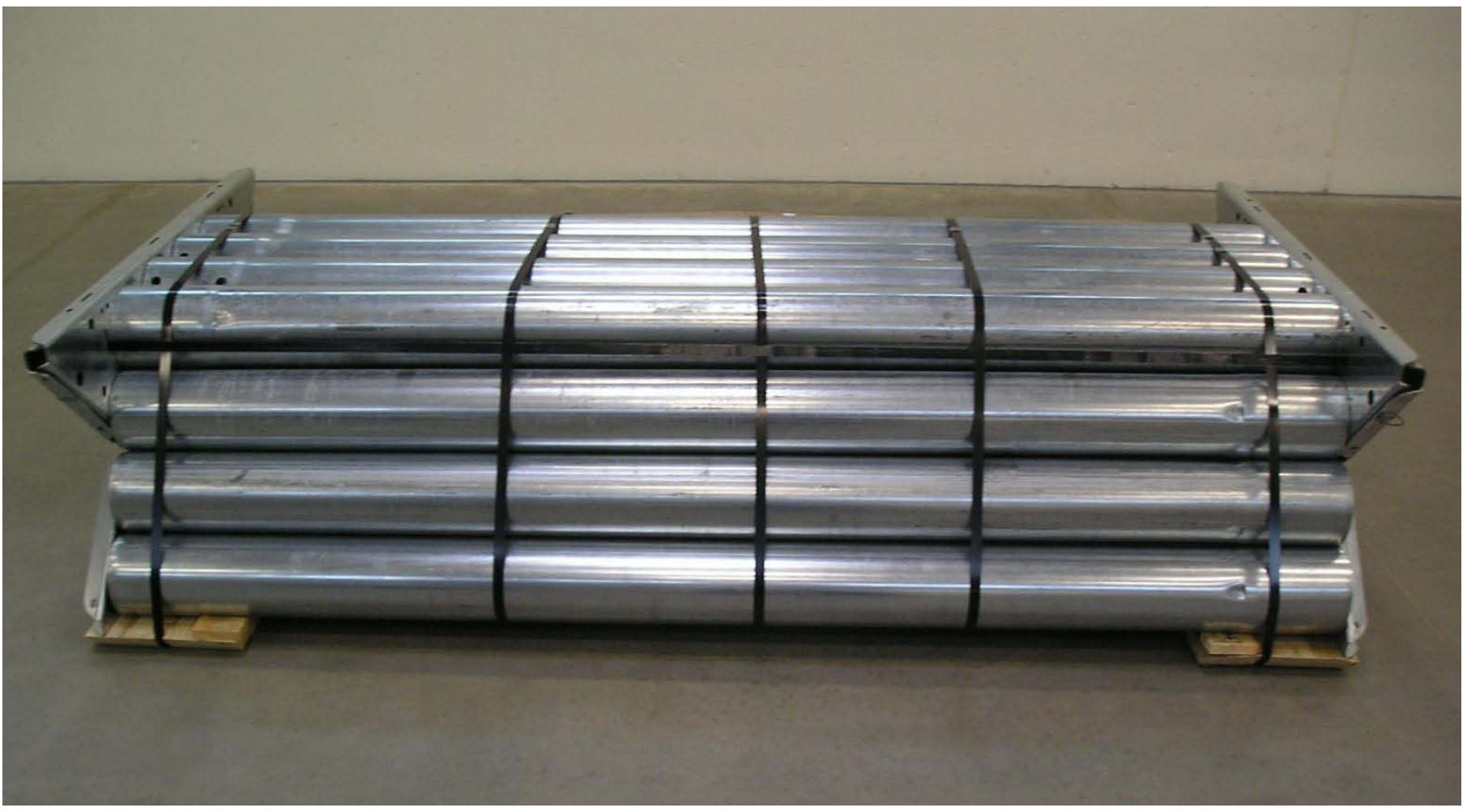

Tools required to unpack the $\mathbf{3 4} \mathbf{m}$ TallTower

- $5 / 16$ inch nut driver or electric drill with 5/16 inch bit

- $1 / 2$ inch wrench for bolts

- Band cutters

- Gloves 


\section{Access and Orientation}

Ideally, you will want access to both ends of the packaging to unpack the contents. If a forklift is available, that is also ideal. Remove the $34 \mathrm{~m}$ TallTower package from the truck with the forklift and set it on an unobstructed flat area before unpacking.

It is also possible to unpack the contents with access to only one end of the tower packaging. For example, the $34 \mathrm{~m}$ TallTower may have been placed into a truck with one end against the front wall of the truck's cargo area and no forklift available to remove it from the truck. In this case, you will be able to follow instructions in this section of the manual to unpack the contents and unload from the truck by hand.

Note: You will NOT be able to unpack the contents if the tower package has been loaded into a truck sideways. If it has been loaded into a truck sideways, you will not have required access to the ends and will need a forklift to remove the tower package.

\section{Unpack Sequence - Very Important!}

Once you are ready to unpack the contents, follow these steps. With the banding cutters, cut the single horizontal band (\#4) and discard.
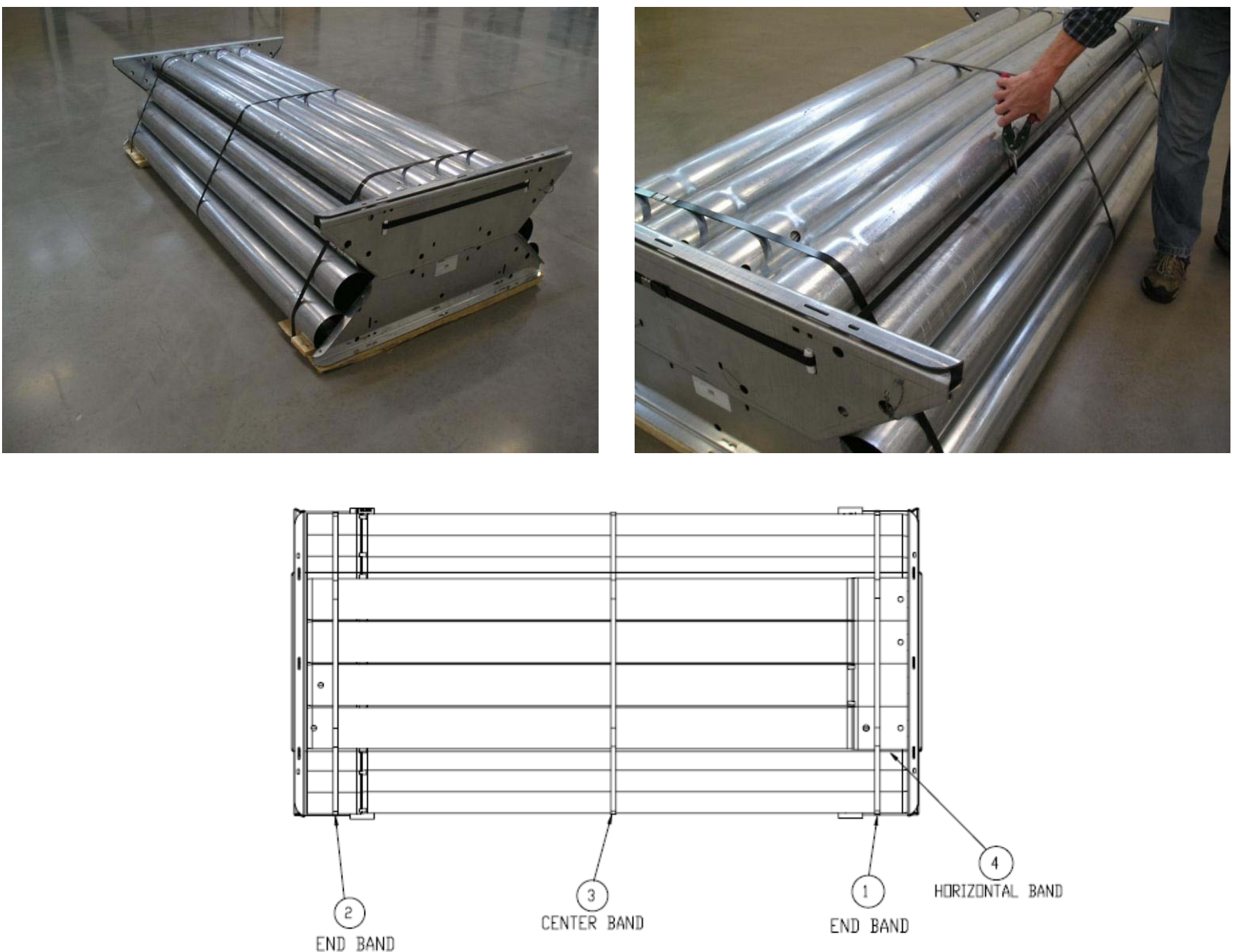

Figure 1 
With the nut driver (or powered screwdriver), remove the 4 wood screws that fasten each end plate assembly down to the wood pallet. Set aside the 2 end plate assemblies. If you can only remove one end plate assembly, that is OK. Remove the end plate and set aside.
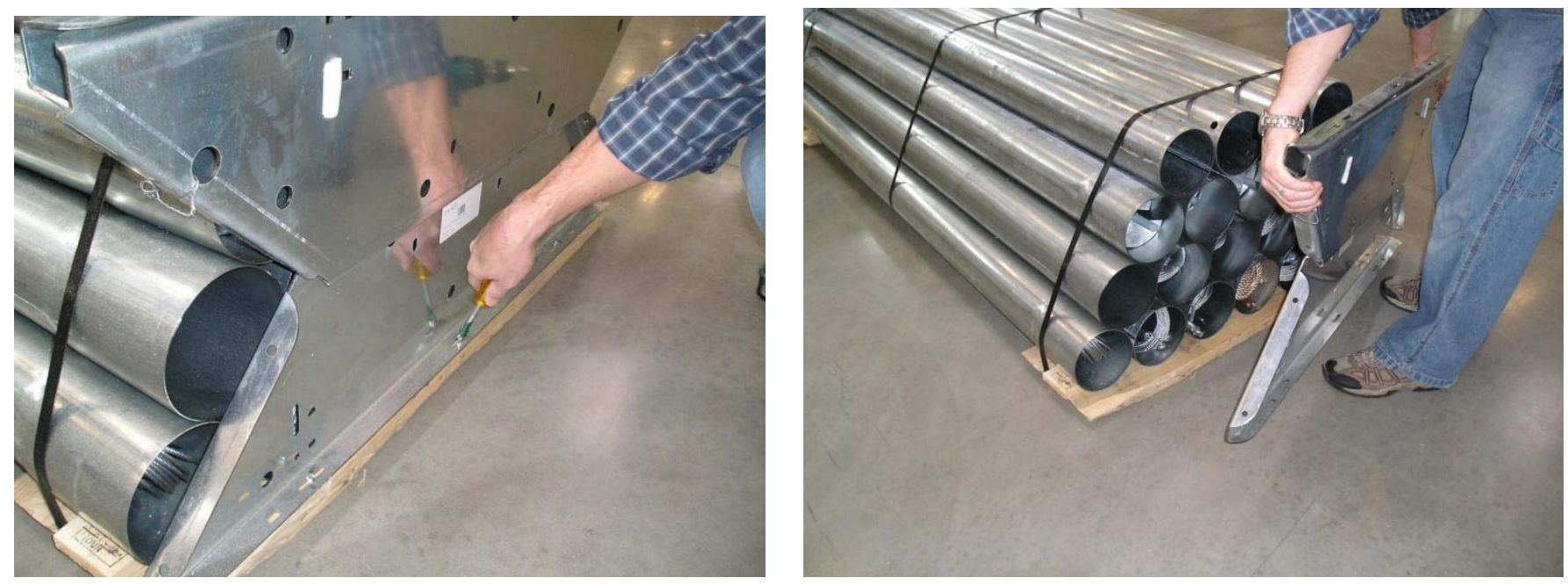

The tube contents will now be exposed. Beginning at the top, remove the contents of the tubes. These contents will include: screw-in anchors, coils of cable, ground rods, guy rings, rocker plates, and the hardware kits.
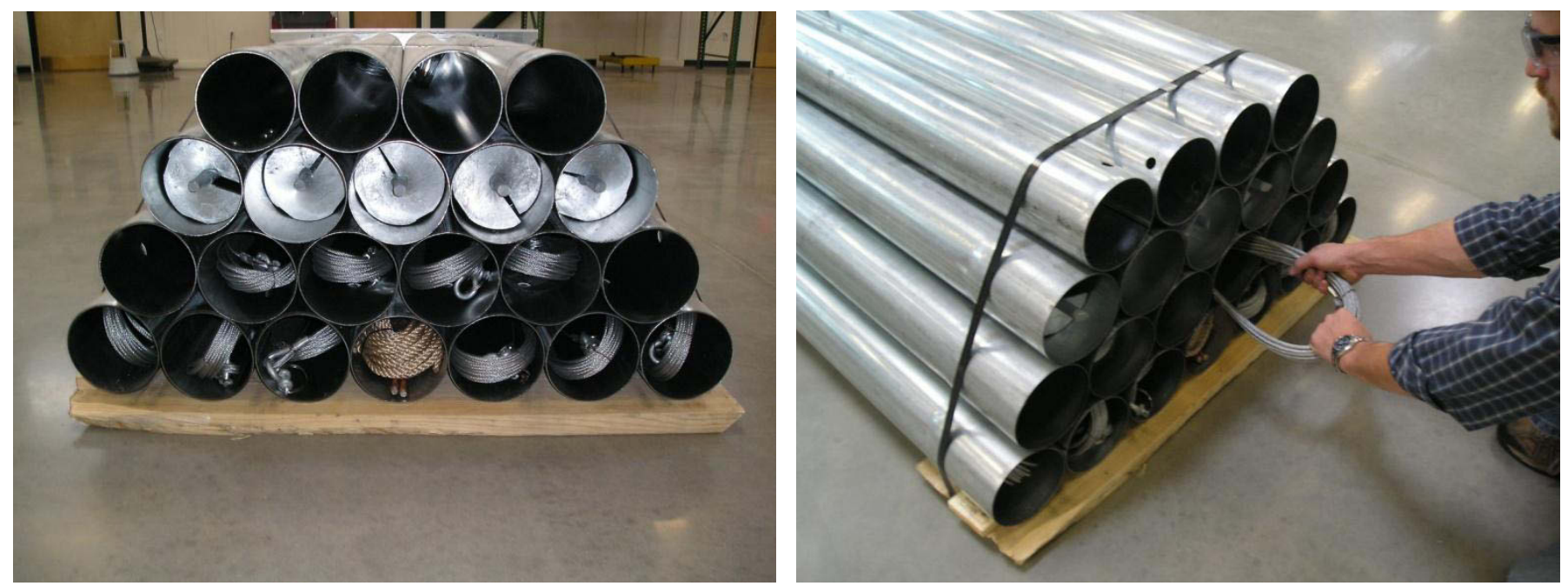

At this point, there should only be $152 \mathrm{~mm}$ ( 6 inch) diameter tubes remaining on the pallet. With the band cutters, cut the outer bands (\#2 \&\#1) and center band (\#3) as shown. Remove tubes.

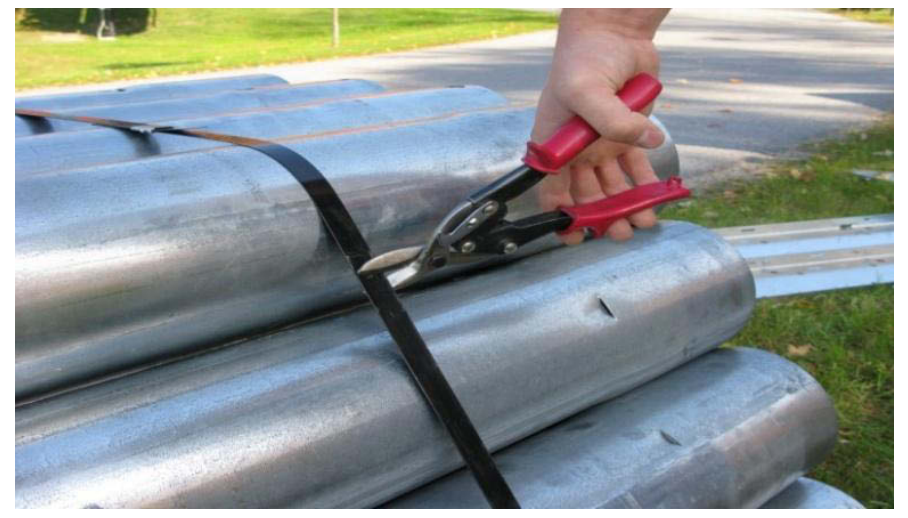




\section{Site Layout}

\section{Pre-installation Planning}

It is a good idea to visit the site before you order your wind measurement system. You will need to make arrangements regarding how to unload your tower system. Some site preparation may also be necessary.

During the first lift of a tower, the many slip joints will settle to the full engagement. During this settling, the distances from the base to any given point on the tower will shorten, and the individual tubes may rotate. Therefore, it is recommended that the tower be "pre-lifted" before the sensors are permanently attached. The "pre-lift" can be only a few feet, but the entire tower should leave the ground. Doing this also is a good way to avoid endangering the booms, sensors, and cabling should there be an unforeseen problem.

\section{Soil Type and Anchors}

Before ordering your tower, research the site soil and anchor type required. It is your responsibility to determine which type of anchor is appropriate for your specific site. Depending on the soil type, anchoring can take varying levels of planning, effort and time. Be sure to know what soil types you are dealing with as part of your preinstallation planning process.

Note: (5) 6 inch diameter screw anchors are included with the tower. Other anchor types must be ordered separately. Please refer to the anchoring guidelines in Appendix B of this manual for more information.

\section{Tip: Cellular Coverage}

This is also a good opportunity to identify what type of cellular service is available at the site for those who will be using an NRG iPack to transmit data. Contact us for more information on NRG iPacks.

\section{Site Layout Map}

Lay out locations for the tower baseplate, guy anchors and the winch anchor. Lay out the site so that the tower is laid out downwind of the baseplate so that the tower will be lifted into the wind. If the site is on a steep slope, lay out the site so that the tower is laid out uphill of the baseplate. Unless the slope is steep, it is more important to have the tower lifted into the wind.

Measure carefully to place the anchor points, paying extra attention to the placement of the winch anchors. Verify that the anchor radii and the diagonal distances between anchors are correct. 


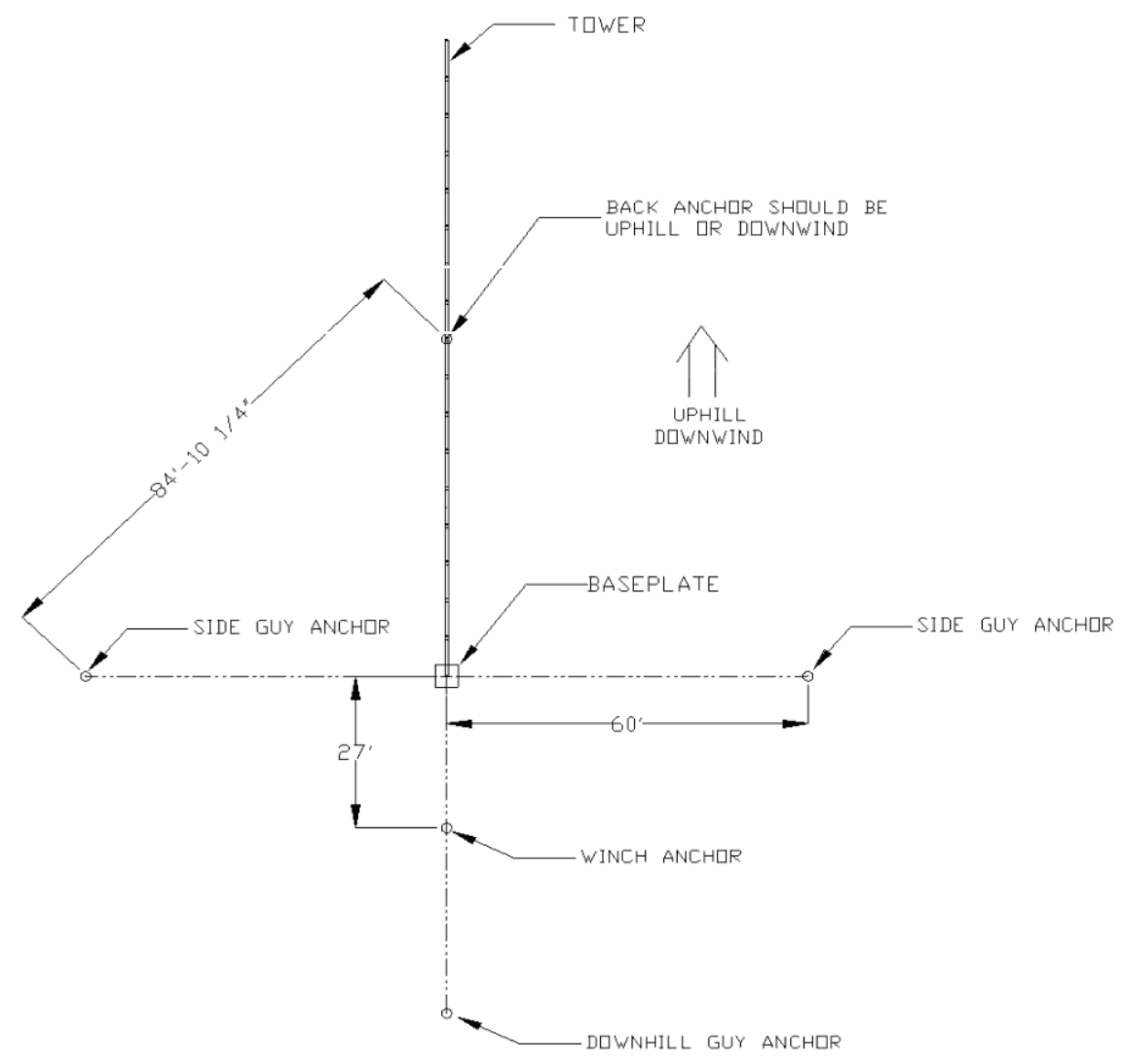

Figure 3: Site Layout Map (bird's eye view)

NOTE: TallTowers can be installed on slopes up to $10^{\circ}$. When laying out a TallTower installation on a slope, measure the calculated distances along the ground to place the anchors. It is not necessary to compensate for the slope. TallTower guy wires are cut long enough to allow for installation on slopes up to $10^{\circ}$ while maintaining the ideal angle between the tower and the guys.

NOTE: The side guy anchors and the base plate should be on a straight line. If it is not possible to place them in the locations shown, it is better to move them in or out along the line to the baseplate than to move them off the line. Do not move them more than $1 \mathrm{~m}$ ( 3 feet) off the line, although some sites may require a compromise because anchors may not be able to be located at the preferred spot.

NOTE: Extra care will have to be taken while raising the tower if:

- anchor placement is not perpendicular to the tower as it lays on the ground.

- anchors are not at the same elevation.

- side anchors and base plate are not in a straight line.

NOTE: Any of these conditions will affect the side guy wire tension as the tower is raised. Tension will have to be adjusted periodically as the tower is lifted.

Placement of the winch anchor is critical. Make sure that you measure carefully and set the anchor heads close to ground level. Angle all the anchors toward the tower at 45 degrees.

All this is important for proper distribution of forces and for clearance and proper operation of the ginpole. See Site Layout Map and Anchor the Winch for more information. 


\section{Tower Assembly}

\section{Assemble the Baseplate}

The baseplate will be located according to the site layout map described in the previous section. It is often easiest to assemble the baseplate in this location. Assemble 4 of the 6 large triangular baseplate sections as shown below, inserting (8) 5/16" x 3/4" carriage bolts in holes closest to the center of each triangular baseplate section. Leave nuts somewhat loose; tighten by hand only.
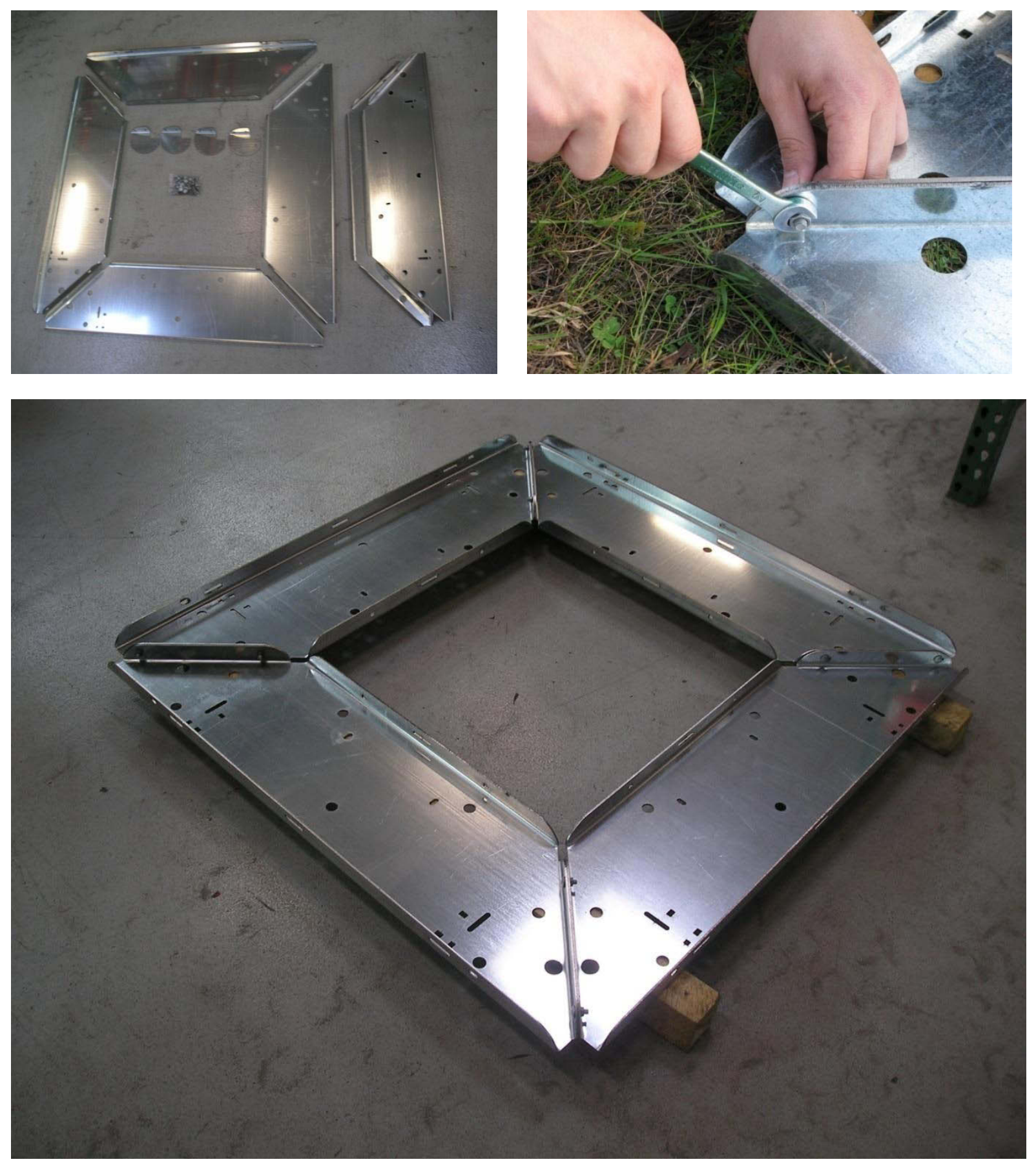

Flip over the baseplate assembly, and prop up on one edge with a block of wood to allow access to underside of baseplate. Attach vertical pieces to the center of the baseplate as shown below, with bent edges facing outward. 

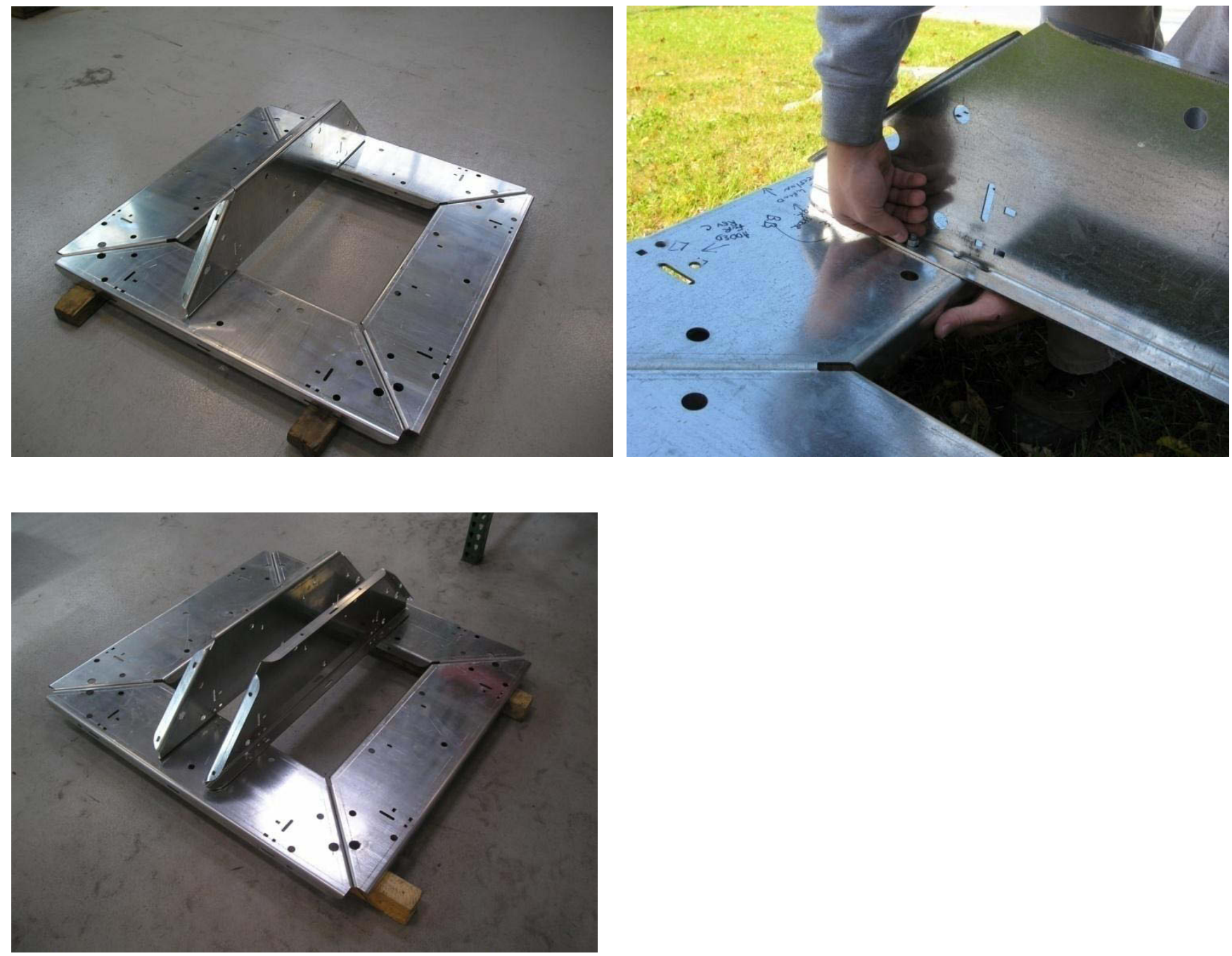

Install the gussets (4) as shown below. Be sure to install the gusset bolts with the carriage bolt head away from the gussets. Tighten all bolts in the baseplate.
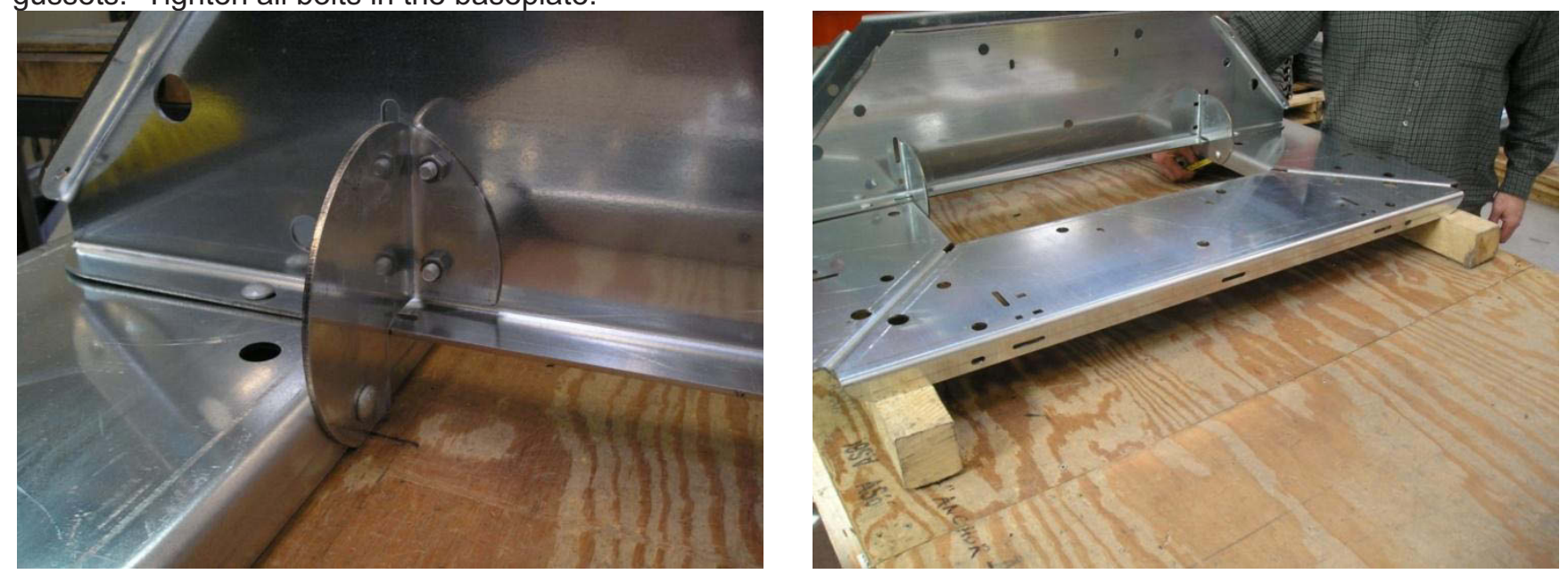

At the beginning of a lift, particularly for the gin pole, the winch forces are largely horizontal. These forces tend to slide the baseplate toward the winch and/or tip the baseplate up on edge. To counteract these forces, it is highly recommended that the baseplate be anchored against sliding and tipping. There are several possible techniques depending on the terrain, soil, and subsequent operations under the tower. 
Rods driven through the baseplate into the soil - With firm, deep soil, drive several pieces of rebar through the holes in baseplate into the soil. Angle them away from the winch and place as many as practical along the baseplate front edge (farthest from the winch).

Rock anchors to the baseplate - On rock, or shallow soils, attach rock anchors to the baseplate, particularly along the front edge. These should be positioned and attached to hold the edge of the baseplate down as well as keep it from sliding.

Cable to the Guy Anchor - A cable made up as a bridle connected to the tower bolt can be run to the inner anchor opposite the winch or to an anchor nearer the baseplate. See below for details.

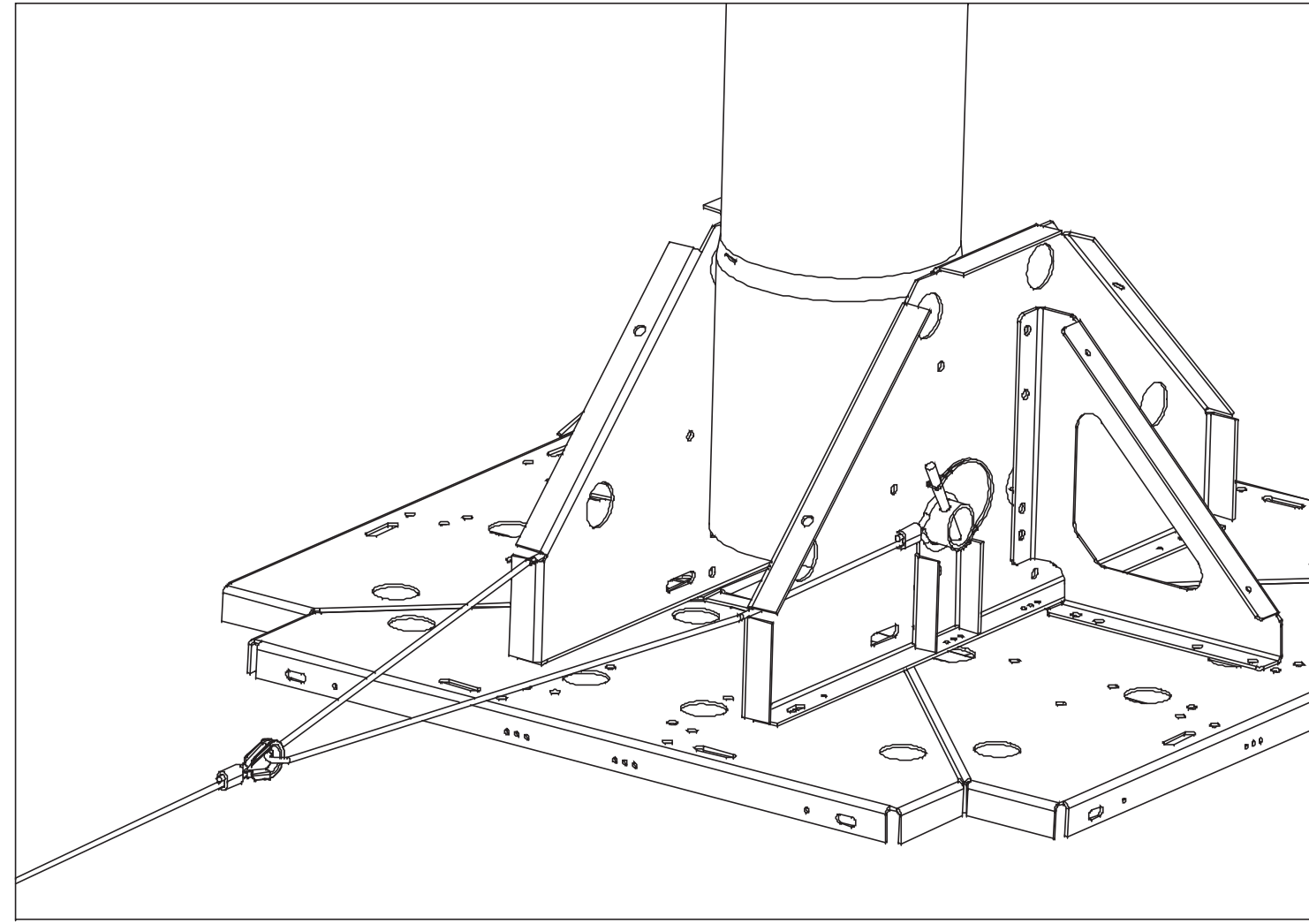

Figure 4

Drive ground rods through the baseplate holes so they can provide additional anchoring for the baseplate.
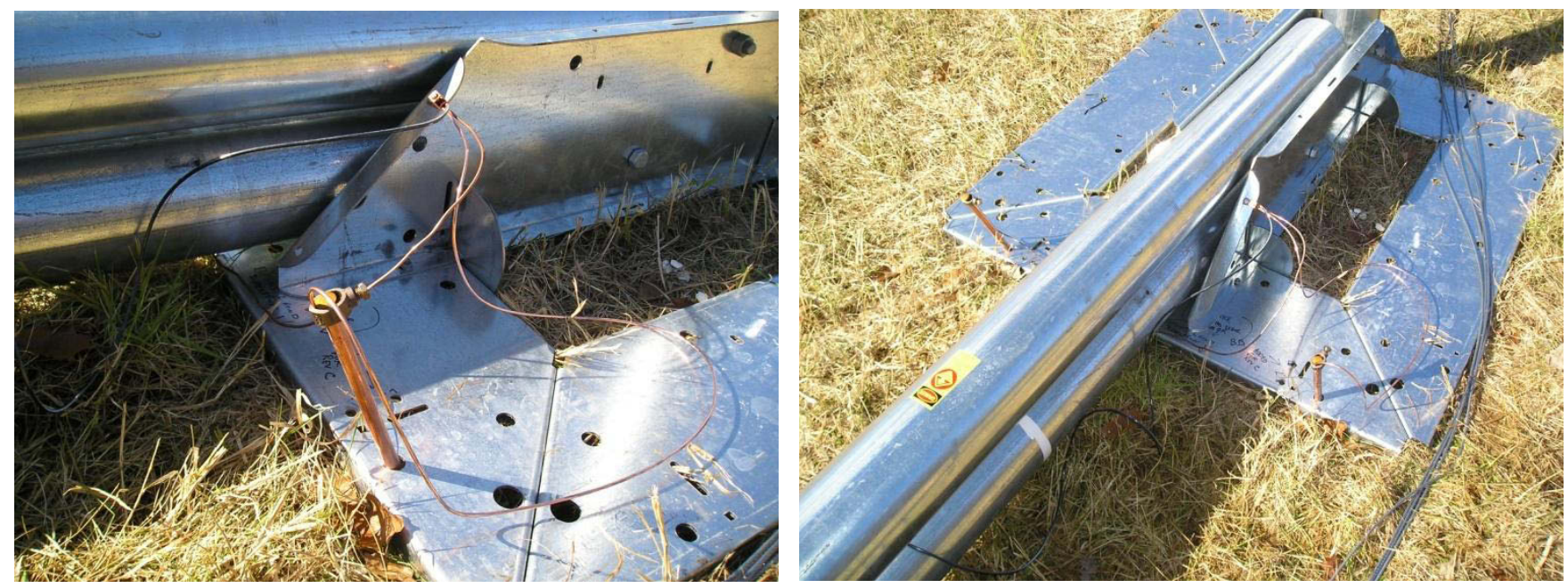


\section{Install the Anchors}

See Appendix B: Anchoring Guidelines at the end of this manual for more information on installing anchors.

Depending on the soil type, anchoring can take varying levels of planning, effort and time. Be sure to know what soil types you are dealing with as part of your pre-installation planning process.

Leave the eye of screw-in anchors about $150 \mathrm{~mm}$ (6 inches) above ground.

\section{Tube Layout}

Lay out the disassembled tube sections on the ground according to sequence described, beginning at the baseplate. Pay close attention to the location of the guy rings.

\section{SI Units}

\begin{tabular}{|c|c|c|c|}
\hline \multicolumn{4}{|c|}{$\begin{array}{l}\text { Sequence of tubes in each section } \\
\text { A guy ring is placed over the last tube listed in each section. }\end{array}$} \\
\hline Section 1 & Section 2 & Section 3 & Section 4 \\
\hline $\begin{array}{l}\text { Base Tube + } \\
\text { (4) } 2.2 \mathrm{~m} \text {, } \\
152 \mathrm{~mm} \text { dia. } \\
\text { tubes }\end{array}$ & $\begin{array}{l}\text { (4) } 2.2 \mathrm{~m} \text {, } \\
152 \mathrm{~mm} \text { dia. } \\
\text { tubes }\end{array}$ & $\begin{array}{l}\text { (4) } 2.2 \mathrm{~m} \text {, } \\
152 \mathrm{~mm} \text { dia. }\end{array}$ & $\begin{array}{l}\text { (4) } 2.2 \mathrm{~m} \text {, } \\
152 \mathrm{~mm} \text { dia. } \\
\text { tubes }\end{array}$ \\
\hline $\begin{array}{l}\text { Lifters } \\
\text { attached to } \\
\text { this guy ring } \\
\text { are color } \\
\text { coded: } \\
\text { Red }\end{array}$ & $\begin{array}{l}\text { Lifters } \\
\text { attached to } \\
\text { this guy ring } \\
\text { are color } \\
\text { coded: } \\
\text { White }\end{array}$ & $\begin{array}{l}\text { Lifters } \\
\text { attached to } \\
\text { this guy ring } \\
\text { are color } \\
\text { coded: } \\
\text { Black }\end{array}$ & $\begin{array}{l}\text { Lifters } \\
\text { attached to } \\
\text { this guy ring } \\
\text { are color } \\
\text { coded: } \\
\text { Yellow }\end{array}$ \\
\hline
\end{tabular}

Table 1

\section{Imperial Units}

\begin{tabular}{|c|c|c|c|}
\hline \multicolumn{4}{|c|}{$\begin{array}{l}\text { Sequence of tubes in each section } \\
\text { A quy ring is placed over the last tu }\end{array}$} \\
\hline Section 1 & Section 2 & Section 3 & Section 4 \\
\hline $\begin{array}{l}\text { Base Tube + } \\
\text { (4) } 87 \text { inch, } \\
6 \text { inch dia. } \\
\text { tubes }\end{array}$ & $\begin{array}{l}\text { (4) } 87 \text { inch, } \\
6 \text { inch dia. } \\
\text { tubes }\end{array}$ & $\begin{array}{l}\text { (4) } 87 \text { inch, } \\
6 \text { inch dia. } \\
\text { tubes }\end{array}$ & $\begin{array}{l}\text { (4) } 87 \text { inch, } \\
6 \text { inch dia. } \\
\text { tubes }\end{array}$ \\
\hline $\begin{array}{l}\text { Lifters } \\
\text { attached to } \\
\text { this guy ring } \\
\text { are color } \\
\text { coded: } \\
\text { Red }\end{array}$ & $\begin{array}{l}\text { Lifters } \\
\text { attached to } \\
\text { this guy ring } \\
\text { are color } \\
\text { coded: } \\
\text { White }\end{array}$ & $\begin{array}{l}\text { Lifters } \\
\text { attached to } \\
\text { this guy ring } \\
\text { are color } \\
\text { coded: } \\
\text { Black }\end{array}$ & $\begin{array}{l}\text { Lifters } \\
\text { attached to } \\
\text { this guy ring } \\
\text { are color } \\
\text { coded: } \\
\text { Yellow }\end{array}$ \\
\hline
\end{tabular}

Table 2 


\section{Install the Base Tube}

Identify the base tube. The base tube has a hole drilled through the flared (wider) end. Attach the base tube to the baseplate using the $3 / 4$ " $\times 8$ " bolt through the lower holes in the center of the baseplate sides. Secure the bolt with the provided nut.

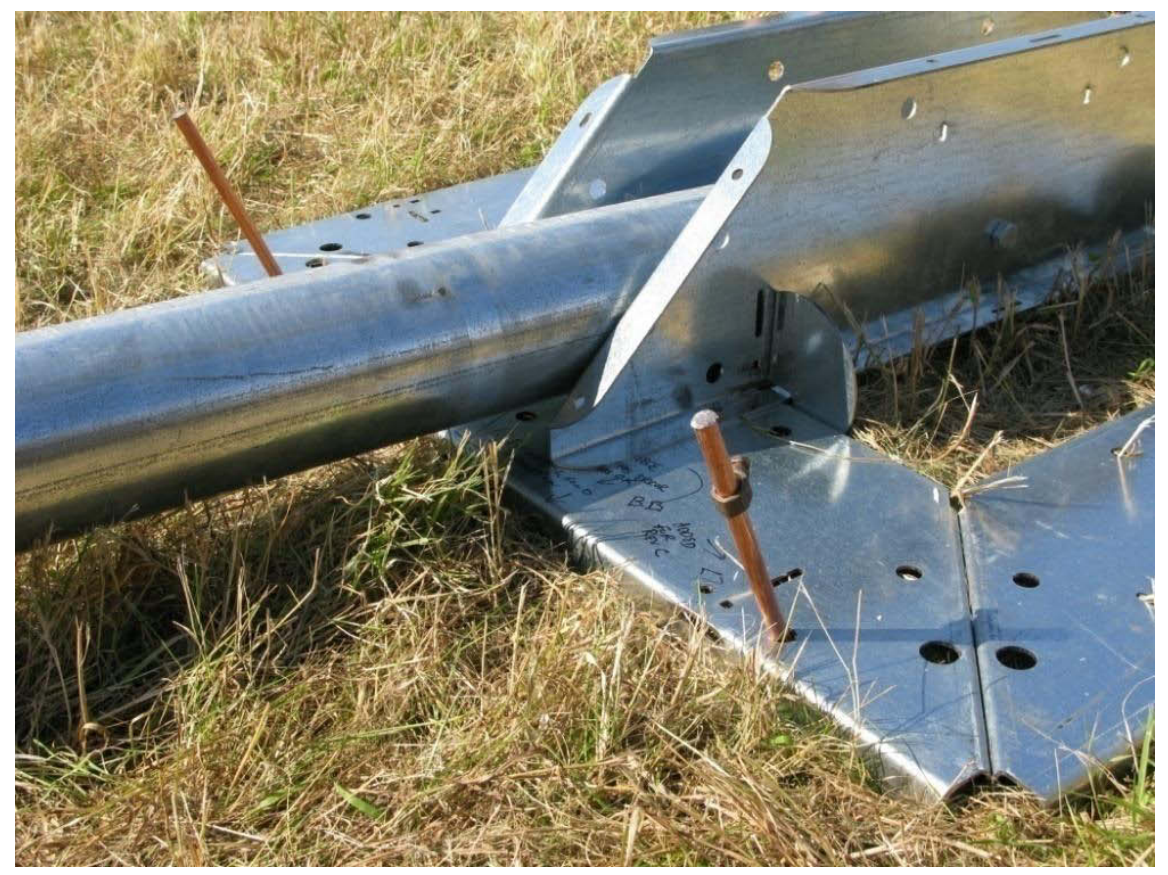

Slide tube sections together until the end of the interior tube is inserted all the way into the outer tube's flare. The inner tube will be stopped. Aligning the weld seams (visible in interior of tube) of each tower section will make it easier to slide the sections together. Continue to assemble the tubes and place guy rings over the tubes according to the sequence above. Make sure the guy ring is placed so the guy ring corners are bent towards the baseplate, and the guy ring corners are in line with each anchor point. Place wood blocks every 5 to 6 meters (15-20 feet) to support the tower above the ground, keeping the tower as straight as possible.

Note: Do not use oil on tower joints. This can cause tower failure if the tubes self-flare.

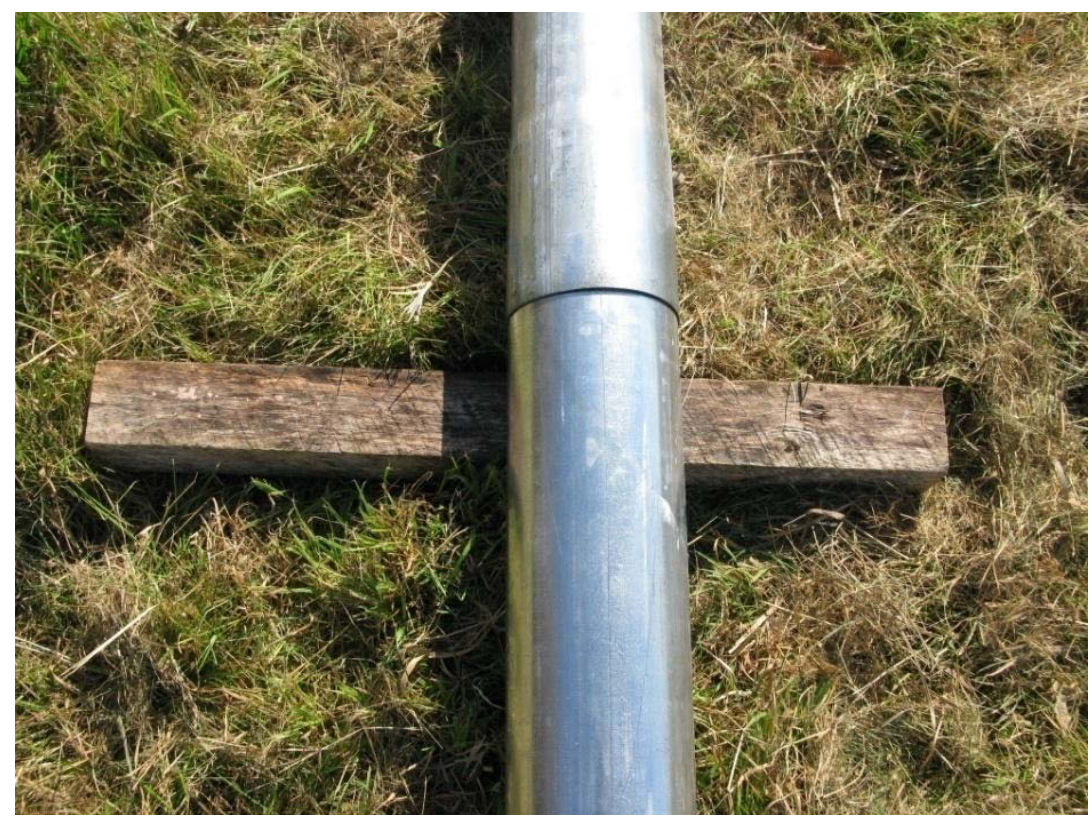




\section{Attach sensors and booms}

Assemble the sensors, sensor boots and sensor signal cables to the booms. Wrap the sensor signal cables to the boom as shown below. Secure with weather rated electrical tape such as Scotch Super 88. Secure the booms to the tower with the supplied hose clamps.

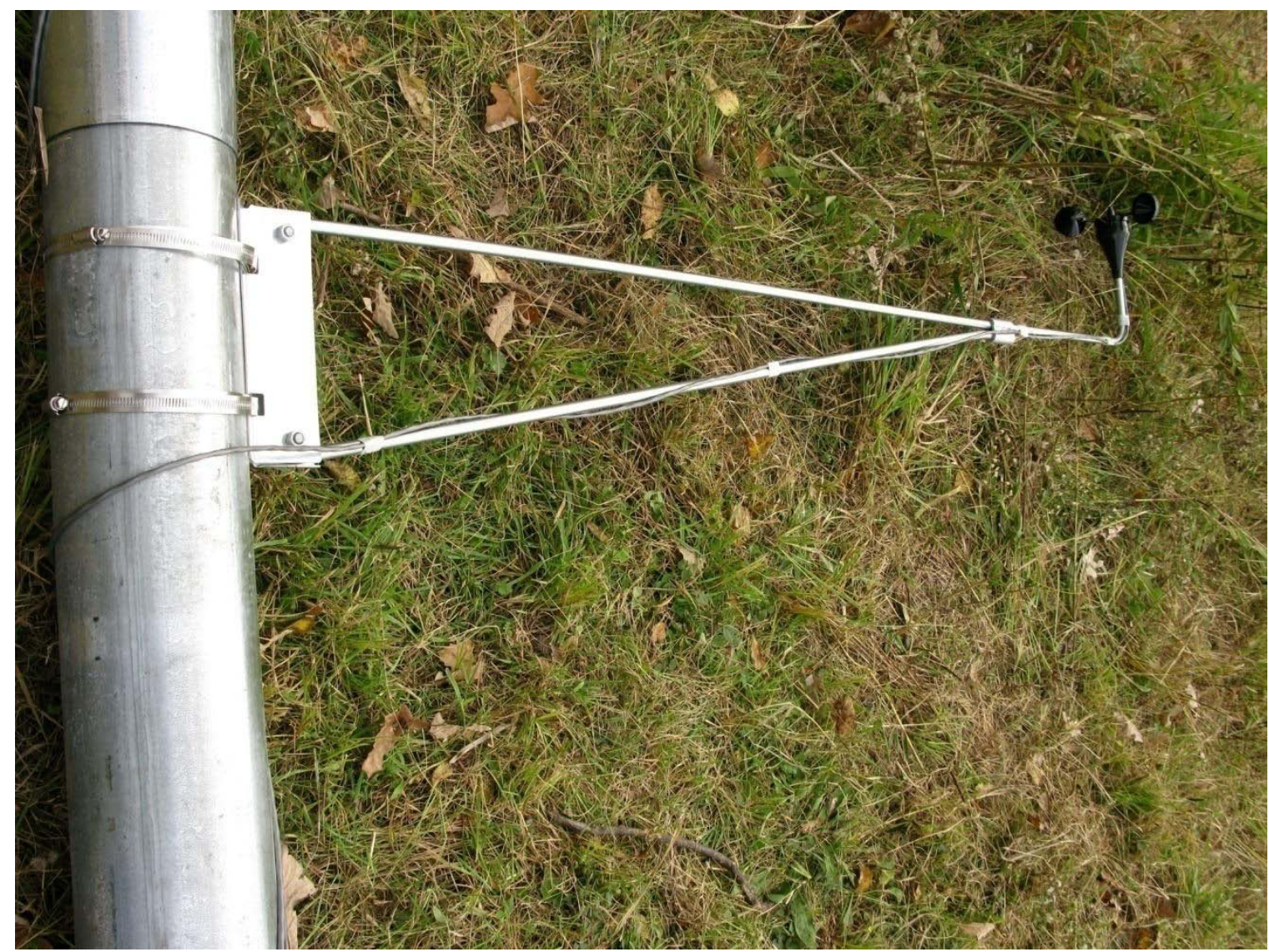

If you purchased the sensors and booms as part of a NRG-NOW System, cabling was supplied for (1) $34 \mathrm{~m}$ level direction vane, (2) $34 \mathrm{~m}$ level anemometers, and (1) $20 \mathrm{~m}$ level anemometer. It is always easiest to run the cables from the sensor and booms down the tower. Refer to Appendix $E$ for wind vane alignment tips.

\section{Spiral wrap your sensor cables}

Spiral wrap sensor cables around the tower, one wrap per tube joint. The spiral promotes vortex shedding and reduces natural frequency oscillations of the tower. Use electrical tape to tape the sensor cables and ground cables to the tower every few meters. Also tape cables to the tower above and below each guy ring. Where the cables cross each guy ring, protect the cables by wrapping them with a thick layer of electrical tape as shown below. 


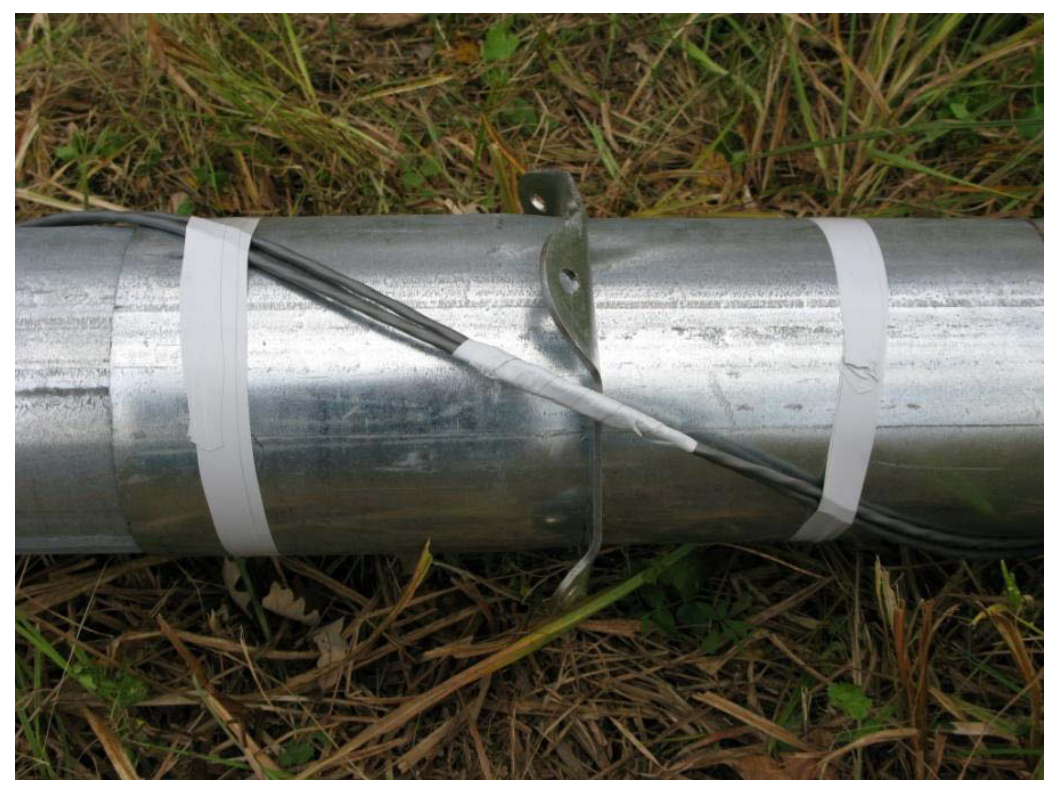

\section{Attach the Guy Wires}

\section{Organize and layout the lifters and guy wires}

Sort out and identify the guy wires and place three sets at each guy ring level. These guy wires are all the same length and are interchangeable. Sort out and identify each lifter wire. The lifter wires are NOT interchangeable. The lifter wires are color coded and are assigned to the guy ring shown in the table below. You will have 12 guy wires and 4 lifter wires. All wires MUST be placed correctly.

Highest level $=4$ (yellow)

\begin{tabular}{|l|l|l|}
\hline Guy Ring Level & Length & Lifter Color \\
\hline 1 & $10.5 \mathrm{~m}(34.56 \mathrm{feet})$ & Red \\
\hline 2 & $16.9 \mathrm{~m}(55.45 \mathrm{feet})$ & White \\
\hline 3 & $24.3 \mathrm{~m}(79.69 \mathrm{feet})$ & Black \\
\hline 4 & $31.98 \mathrm{~m}(104.94 \mathrm{feet})$ & Yellow \\
\hline
\end{tabular}

\section{Table 3}

Identify the lifter wire for each level. It is recommended that back guy wires (the guy wires opposite the winch) are attached to their guy rings, rolled out, and secured to their anchors first, followed by the side guy wires to eliminate crossing.

\section{Shackle guy wires to the guy rings}

Secure the back guy wires first to their corresponding guy rings using the shackles. Attach the guy wires to the guy ring holes under the tower tube. Roll out the back guy wires to their anchor points and secure as described below. Next secure the side guy wires to their corresponding guy rings using the shackles. These guy wires will attach to the side guy ring holes. Roll the side guy wires out to their anchor points and secure as described below.

\section{Roll out each guy wire from the tower to its anchor point}

Roll out side and back guy wires from their guy rings to their anchor points. Do not allow twists or kinks in the guy wires. The guy wire and lifter coils can be uncoiled in a hand over hand method while walking out towards each anchor or unrolled using a "Hankmaster 5000" tool (see Appendix F). 


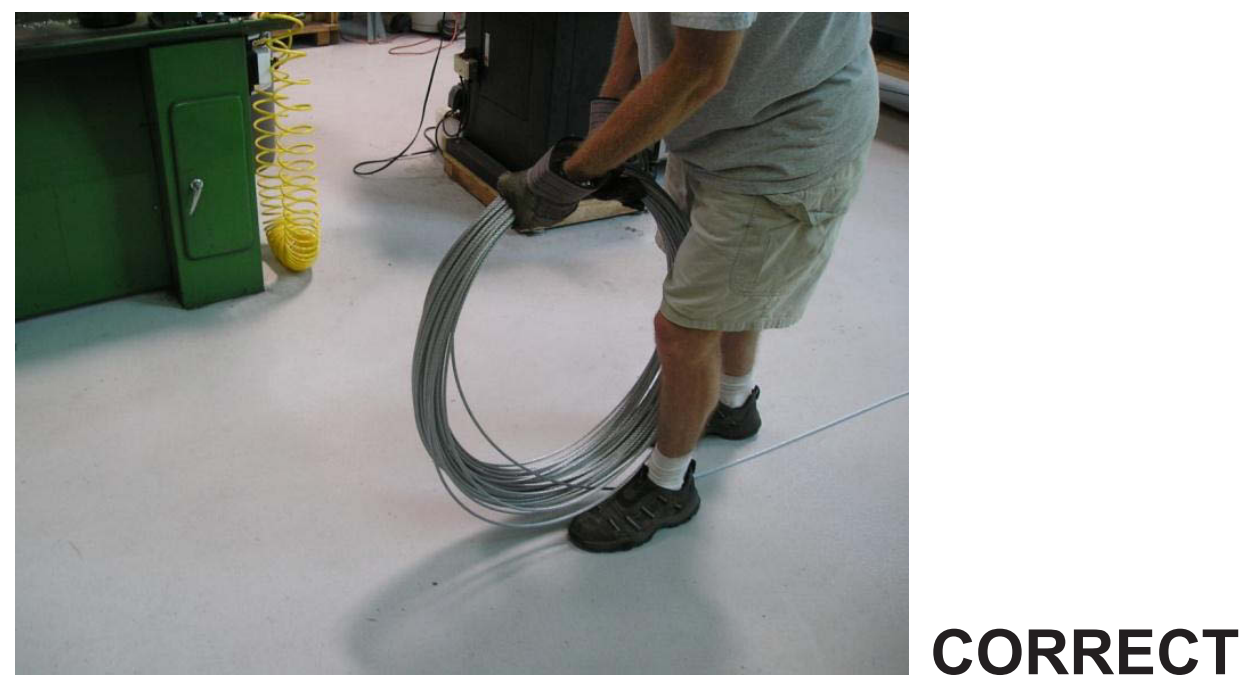

Do not un-spool cable off the side of the coil as shown below.

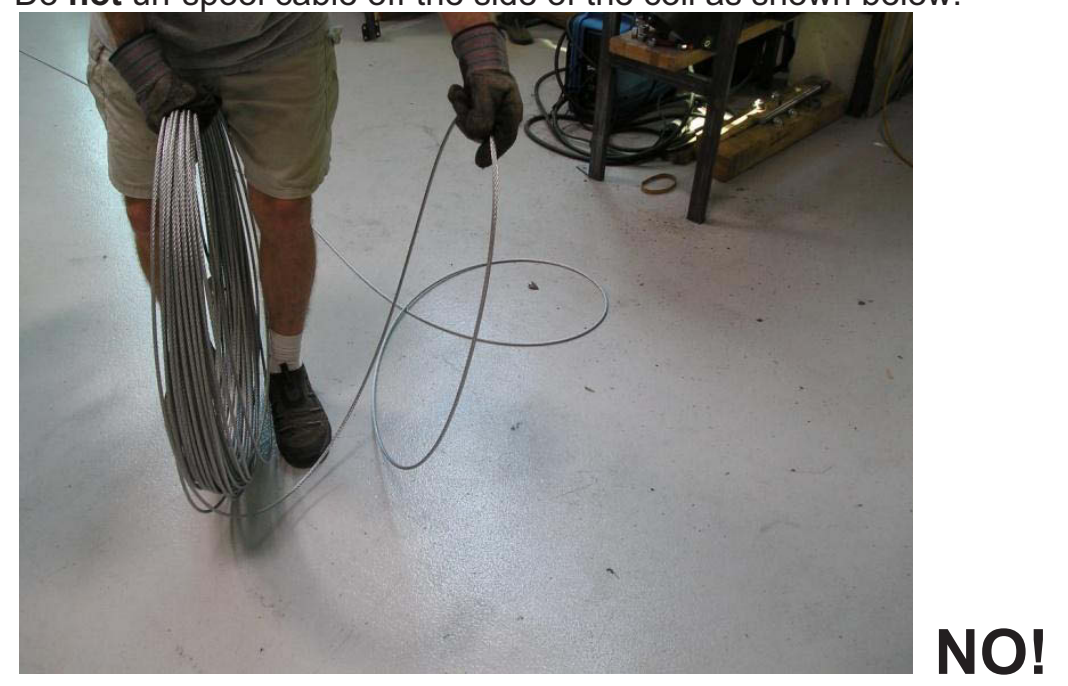

The Hankmaster can be used to roll the guy wires out to the anchors. See Appendix F for instructions for building and using a Hankmaster.

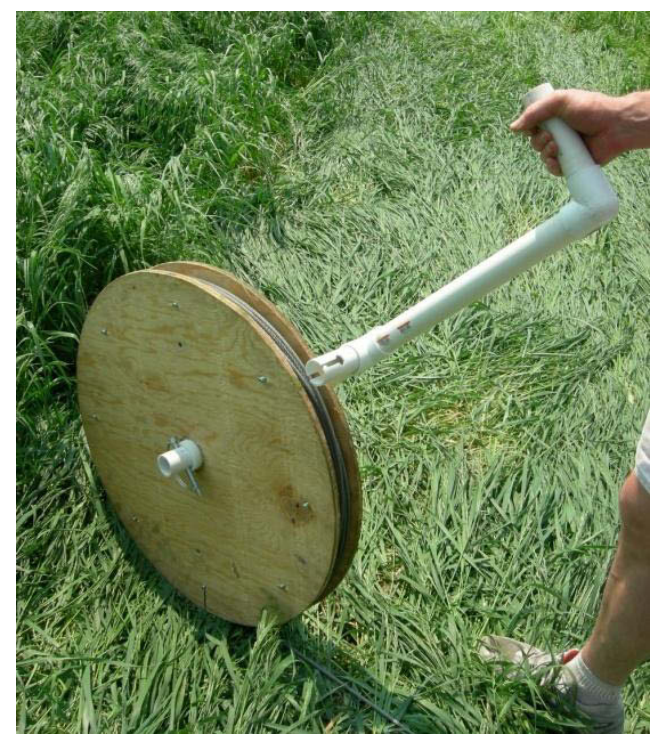


Pass the split rings through the eye of each shackle bolt to keep the shackle pins from loosening.

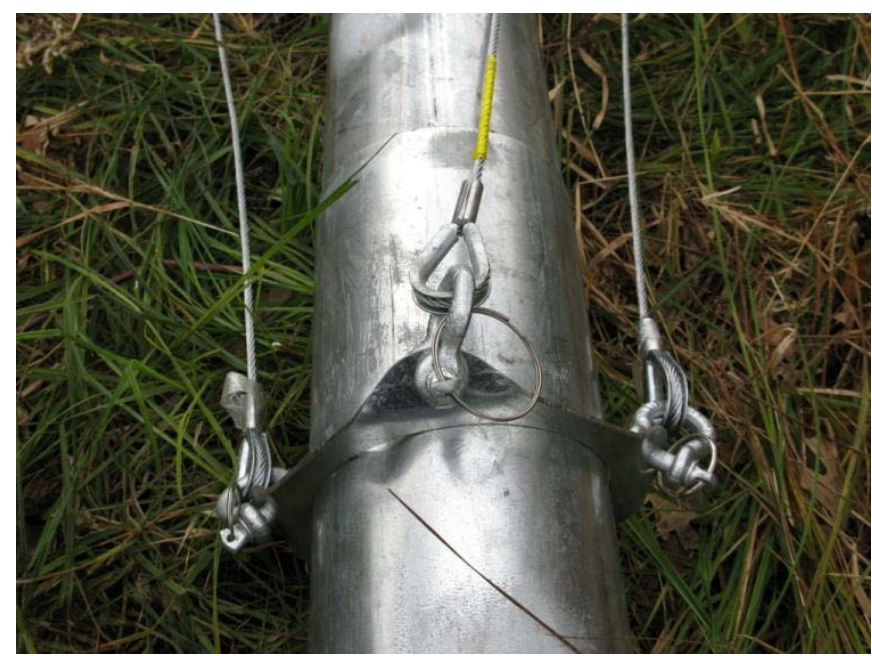

\section{Secure guy wires to the anchors}

Secure guy wires to the back and side anchors by threading the cable through the anchor loop and clamping the cable onto itself using 3 wire rope clips. For the back guy wires it is recommended that the distance to the side guys for each corresponding level be used as a reference distance for attaching to the back anchors. Place the wire rope clip on the wire so the saddle (the forged, grooved part) cradles the wire coming from the tower and the " $U$ " bolt part clamps down on the dead end of the guy wire ("Never saddle a dead horse" may help you to remember how to secure the wire rope clips).
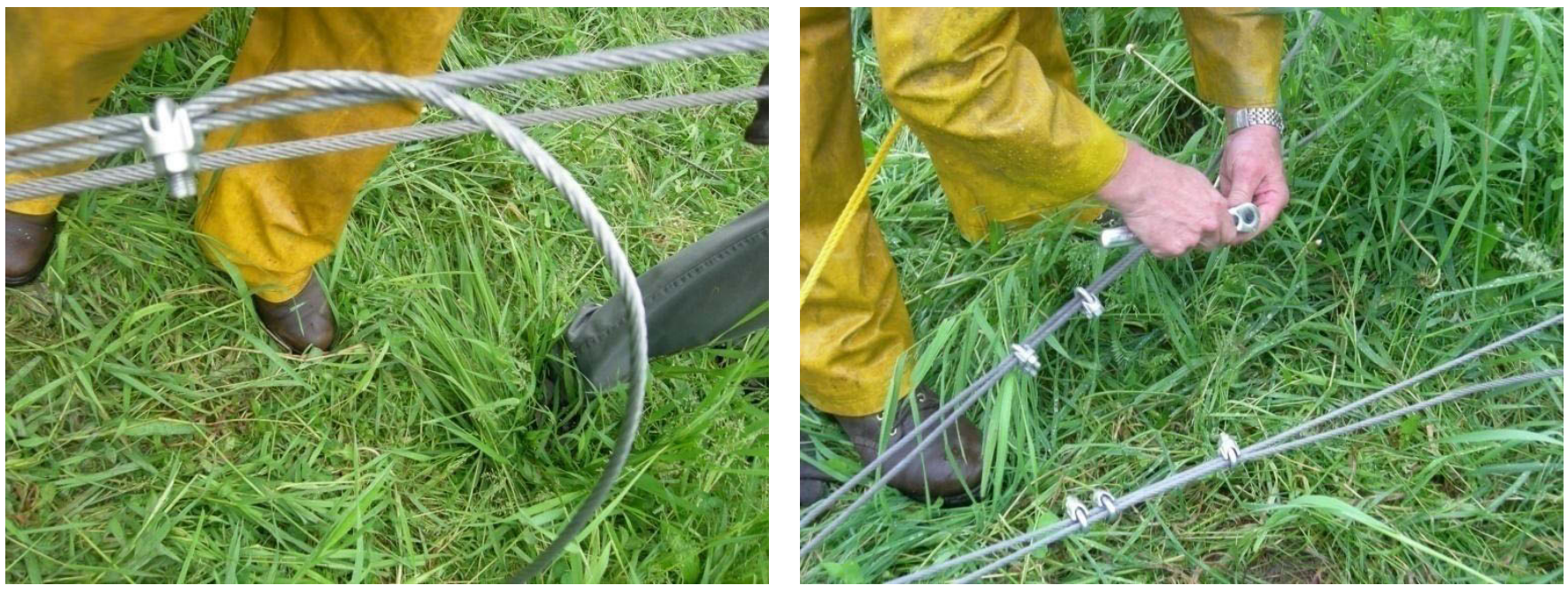

Leave a little slack in the guy wire, and tighten the wire rope clip nuts. Don't tighten the wire rope clip nuts too tightly; you will need to adjust the guy length numerous times as the tower is erected.

\section{Shackle lifter wires to the guy rings}

Secure the lifter wires to the guy ring holes on the top of the tower tube. Carefully lay out the lifters in an orderly fashion. The unattached ends can easily become entangled around each other and the other guy wires lying on the ground. Make sure that all back and side guy wires are underneath the lifter guy wires. Keeping the lifter wires organized will avoid having to stop during the lift process to untangle the lifters. 


\section{Assemble the Gin Pole}

\section{Layout the ginpole tubes}

Identify the ginpole and helper ginpole tubes and hardware. Refer to the Glossary in Appendix D for pictures and descriptions of ginpole parts.

\section{Attach the ginpole base tube to the baseplate}

The ginpole base tube will lie on top of the tower base tube. Place the ginpole base tube with hole between the baseplate's vertical channels. Insert the safety cable into the ginpole base tube. Line up the holes in the ginpole base tube with the holes in the baseplate's vertical channels and insert the $3 / 4$ " $\times 8$ " bolt through the baseplate holes and the eye in the safety cable. Secure the bolt with the provided nut.

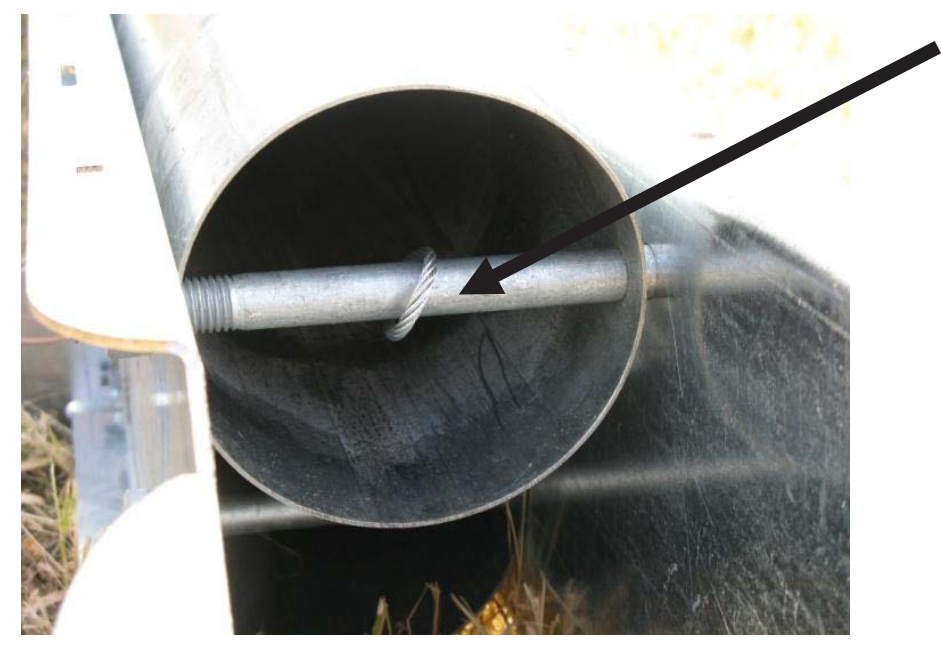

\section{Slide together the 4 tubes that comprise the ginpole}

Slide sections together until a hard stop is reached, and thread the safety cable through each tube as it is assembled. Aligning the weld seams (visible on interior of tubes) of each tower section will make it easier to slide the sections together. Place a log, sawhorse, or other type of support underneath the $3^{\text {rd }}$ or $4^{\text {th }}$ section to slightly raise the ginpole from the tower.

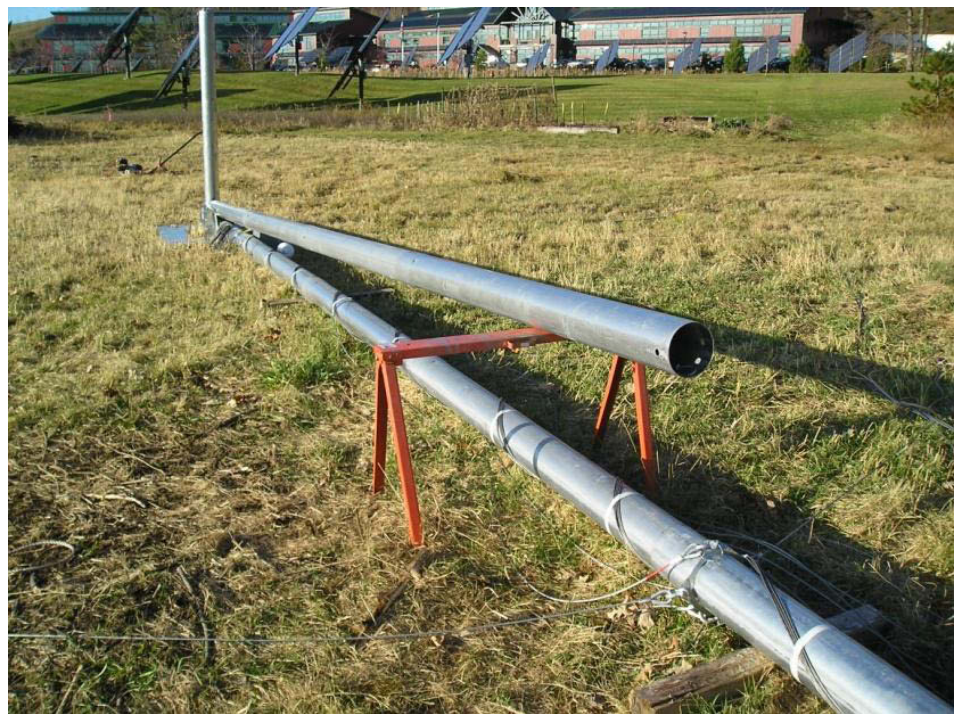

Slide the top ginpole section on so that the holes in the ginpole top are parallel to the ground. 


\section{Attach the ginpole top mounting hardware}

Bolt the rocker plates to the top section of the ginpole with the large bolt ( $3 / 4$ inch $\times 8$ inches), making sure that the bolt goes through the eye of the ginpole safety cable.

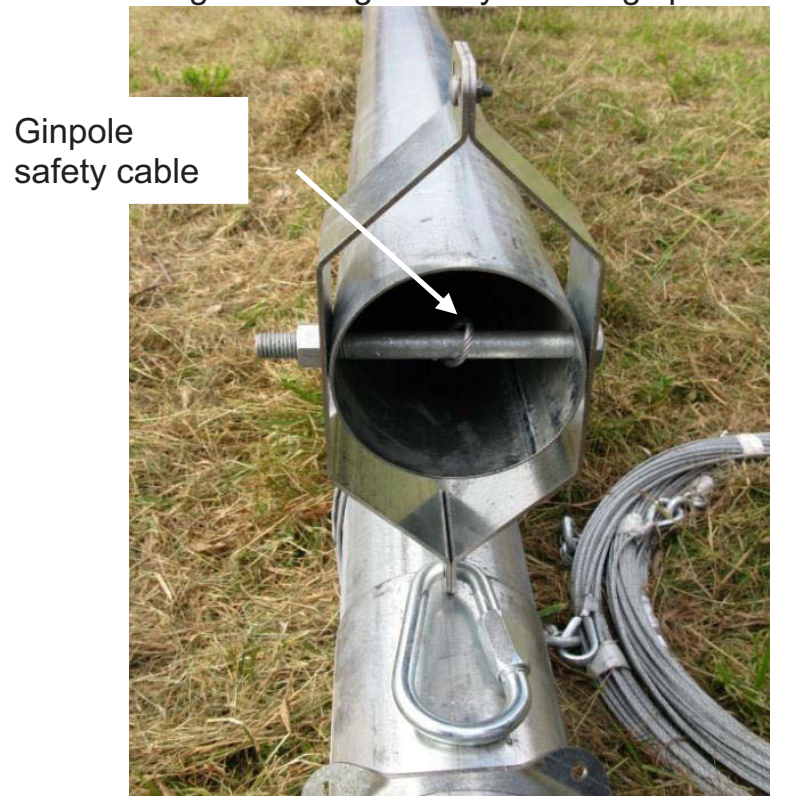

Also place the (2) supplied graded 5/16" $33 / 4$ " bolts at the ends of the rocker plates. Attach the (2) quick links to the holes on the bottom (side towards tower) of the rocker plate.

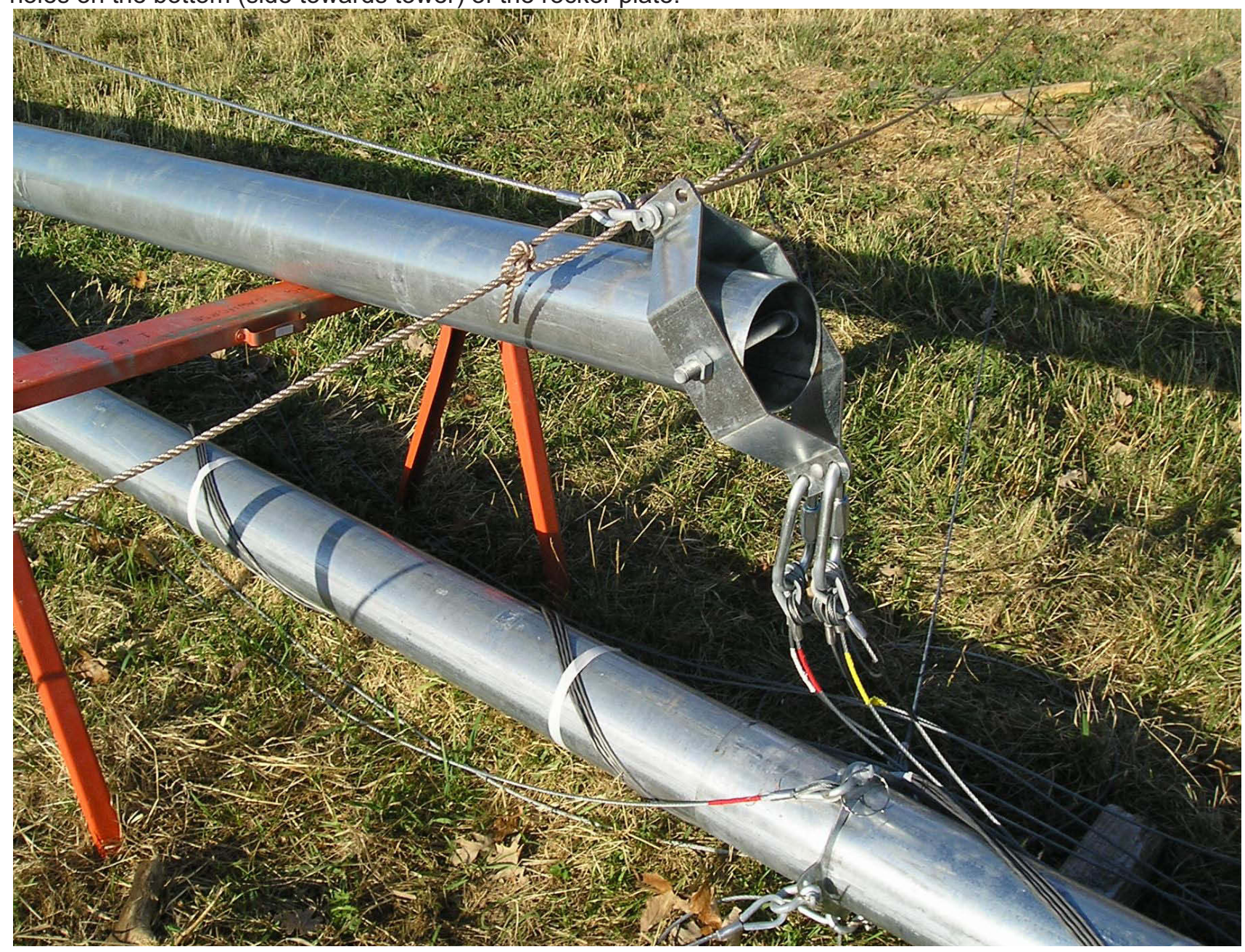


Using a two-part line to lift the tower is optional. If lifting the tower with a single part line, the turning block and one of the shackles are not needed. Simply attach the thimble end of the winch cable to the shackle on the rocker plate as shown below.

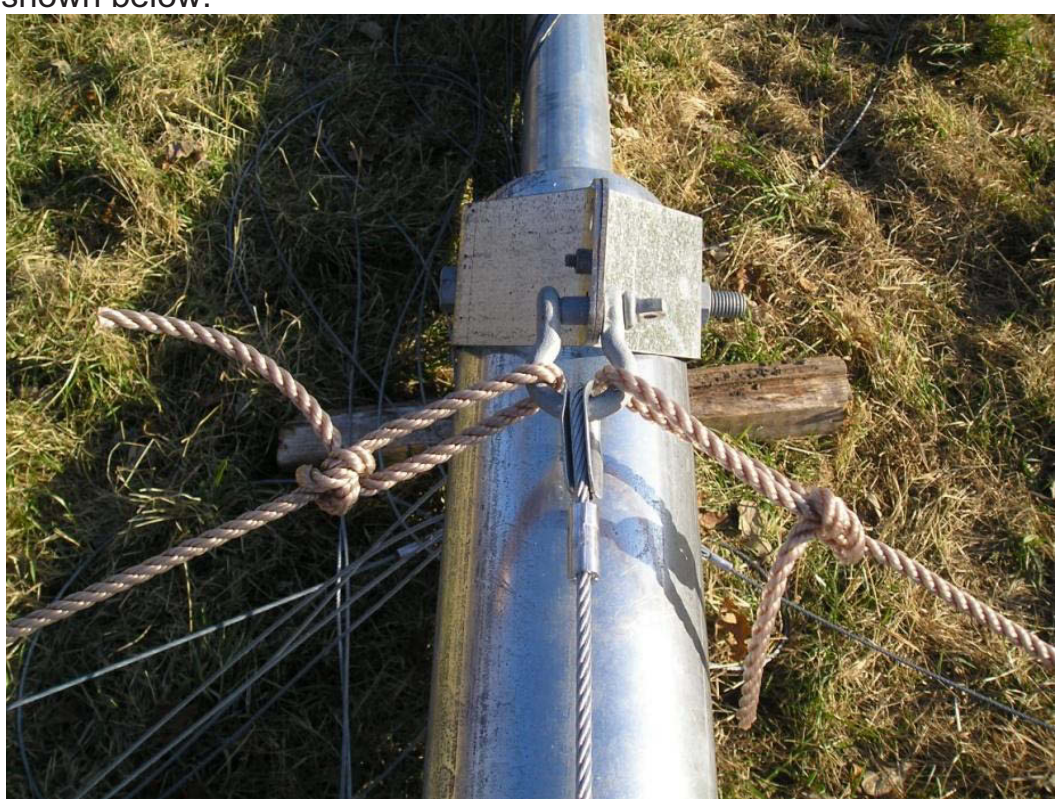

If using a two-part line to lift the tower, shackle the winch cable turning block (not supplied) to the rocker plates using the (2) shackles (not supplied) placed through the rocker plate hole shown in the picture below.

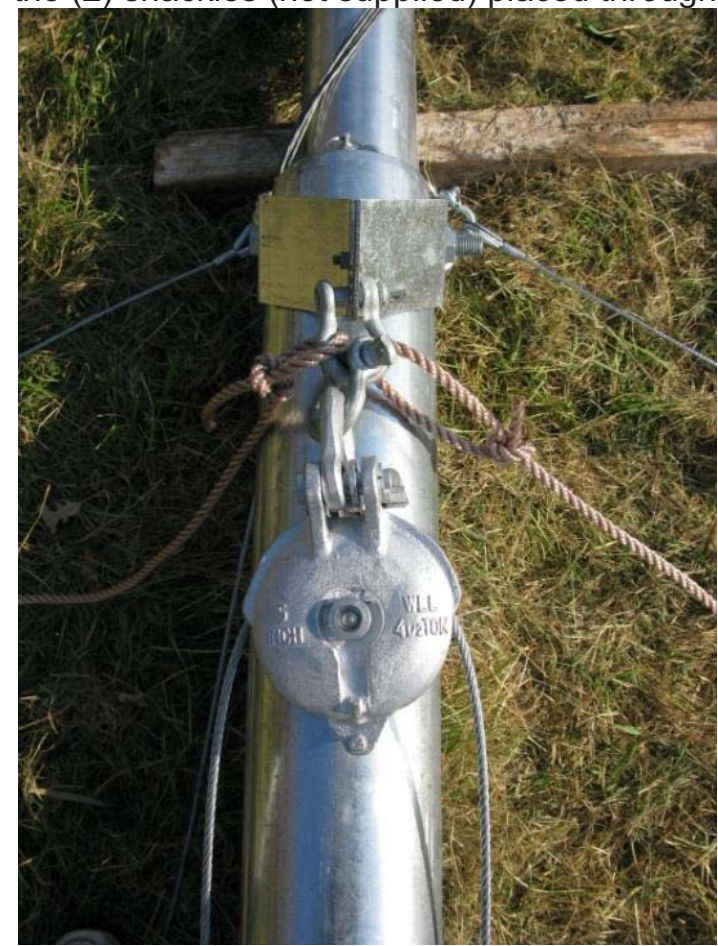

Your tower was supplied with a $45.7 \mathrm{~m}$ length of $12 \mathrm{~mm}$ (1/2 inch) diameter brown polypropylene rope. Cut the rope in half to make two $22 \mathrm{~m}$ (75 ft.) pieces. Tie one piece from each side anchor to the top of the ginpole to stabilize the ginpole while it is being raised.

Warning: Failure to use the ginpole ropes could cause the ginpole to fall over to either side during the lift. Be sure to tie the safety ropes securely to the side anchors; the ginpole is very heavy, and the safety ropes can't be controlled by hand.

NOTE: The greatest load seen by the end of the ginpole (and the winch) is $907 \mathrm{~kg}$ (2000 lbs.). The winch

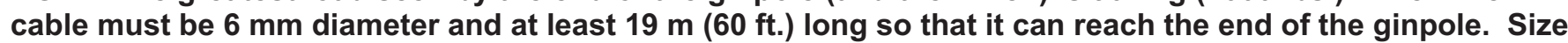
your winch and rigging accordingly. An extra anchor has been supplied with the $34 \mathrm{~m}$ tower to anchor the winch. 


\section{Attach the lifter wires}

Attach each of the four lifter wires to the ginpole using the supplied quick links. Be sure to connect them in the proper order and make sure they are not tangled with each other or side or back guy wires.

\begin{tabular}{|l|l|l|}
\hline Lifter \# & Lifter Color & $\begin{array}{l}\text { Quick Link (number indicates } \\
\text { hole) }\end{array}$ \\
\hline 4 & Yellow & 2 (top - away from base of tower) \\
\hline 3 & Black & 2 \\
\hline 2 & White & 1 \\
\hline 1 & Red & 1 (bottom - toward base of tower) \\
\hline
\end{tabular}

Table 4

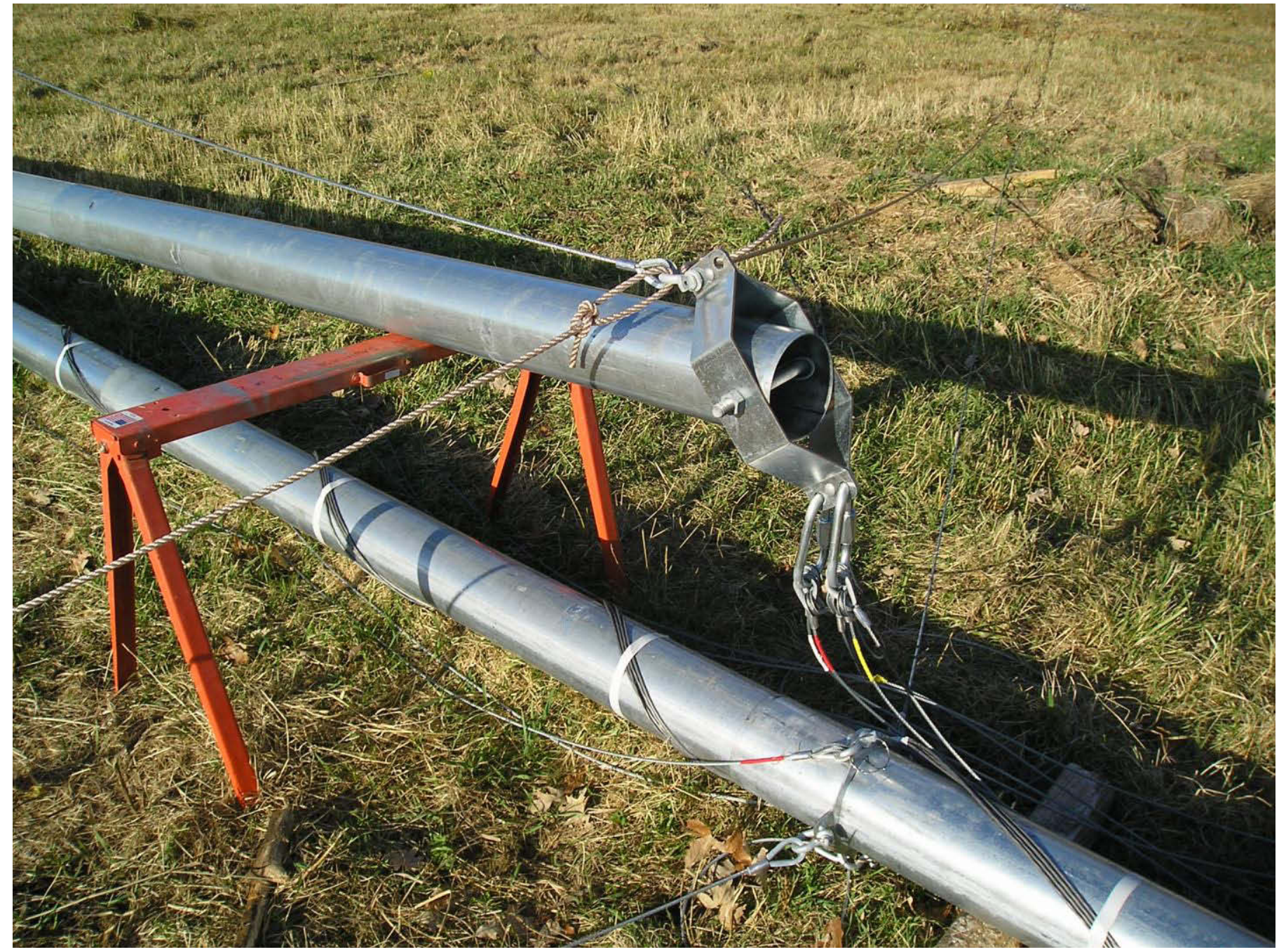

\section{Configure the helper ginpole}

Put the helper ginpole standing vertically (pulleys pointing towards the sky) on the baseplate behind the main ginpole. Line up the holes in the helper ginpole with the holes in the baseplate's vertical channels. Slide the $3 / 4$ " $\times 8$ " bolts through holes to secure in a vertical position. Secure the bolts with the provided nuts. The hardware kit contains two 5" diameter pulleys and an axle bolt to be used on the top of helper ginpole. If you are only using a one part line from the winch, the second pulley is not needed. 

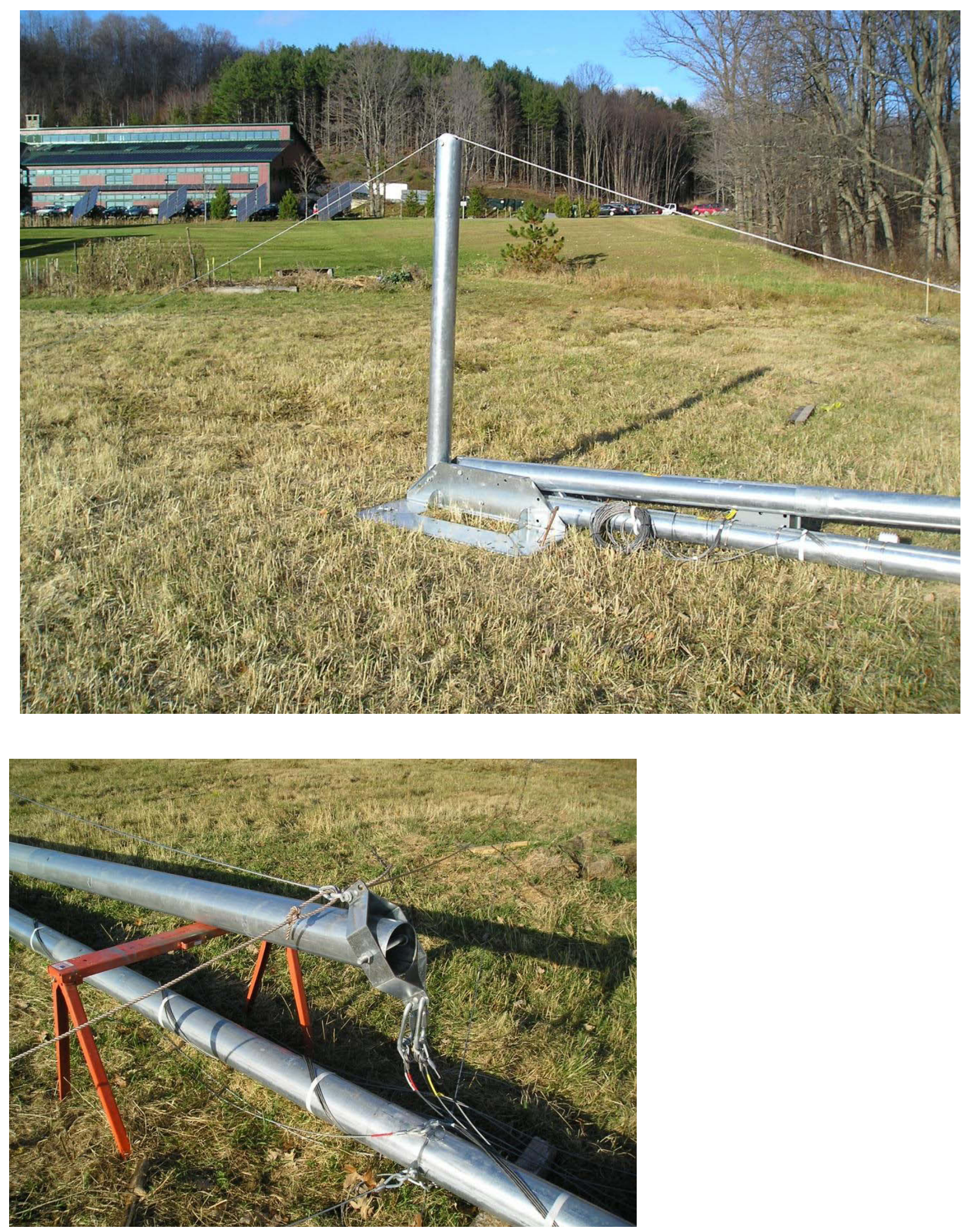


\section{Ginpole Tilt-Up}

\section{Confirm all lifters and shackles are secure}

Carefully double check all connection points to make sure everything is secure before starting to lift the ginpole.

\section{Lift the ginpole}

Make sure the ginpole remains centered side to side and that the brown ropes are both snug. If the ginpole is off center, carefully adjust the ropes to re-center. As the ginpole comes up, remove the helper ginpole when the winch cable is no longer in contact with the pulleys on the end of the helper ginpole. Pay attention to the lifters to make sure they are not caught on objects in the area (stumps, debris, rocks, equipment, etc.). Also check that they are not crossed over each other or the other guy wires. As the lifter wires tighten, stop.

Do not lift the tower yet. Check that the shackles are not twisted at the guy rings.
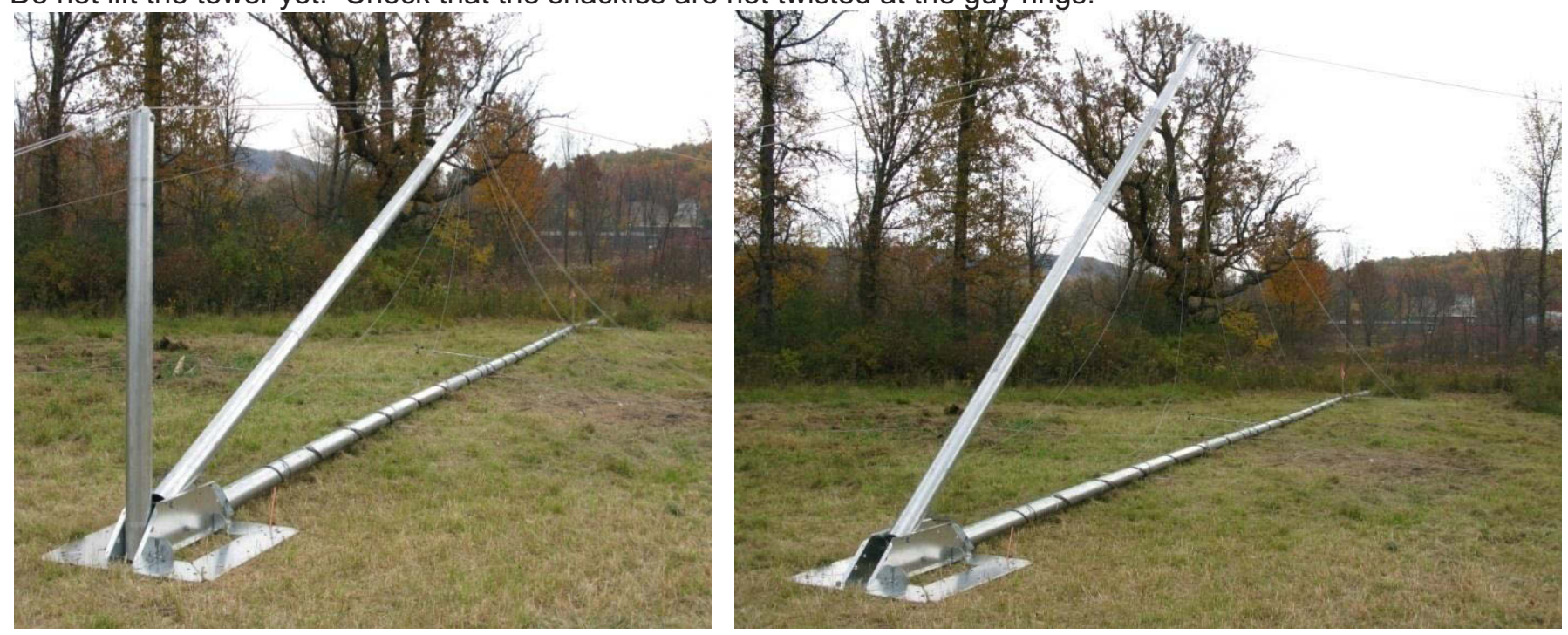


\section{Tower Tilt-Up}

\section{Understanding Guy Wire Tensioning While Raising TallTower (Do not raise the tower yet)}

As a tower is raised, unless the anchors are placed in precisely their correct positions, and unless the site is perfectly level, some guy wires will tighten and some will loosen as the tower is raised. The same is true as a tower is lowered on the same site. For this reason, guy wire tension must be checked and adjusted as needed to maintain uniform tension until the tower installation procedure is complete.

A wire that becomes too tight can put very high forces on both the anchor and the tower. This force can rapidly grow if the tower lifting or lowering procedure continues. These high forces can suddenly buckle the tower and cause it to fall, endangering the tower installation crew and possibly damaging any vehicles or equipment nearby. Do not let the tower be bowed to the side more than two tower diameters away from a straight line. If the tower is bowed more than this, the side guys should be adjusted to straighten the tower.

It is critically important that proper tension be maintained on side guy wires at all times during the lifting procedure to provide side support for the tower. Too little tension can allow the tower to buckle to the side. Too much tension may cause failure of the tower, anchors, or guy wires. There must always be visible slack in the guy wires. If no slack is visible, the tension is too great.

Once the tower is vertical, two people of average size, pulling by hand, can properly tension the guy wires.

\section{MECHANICAL TENSIONING DEVICES SHOULD NEVER BE USED TO ADJUST GUY WIRES!!}

Be sure that guy wires do not get caught on tree branches, roots, rocks, or other obstructions.

This sequence of observing, communicating observations, issuing commands to guy wire tenders, adjusting the side guy wires and re-tightening wire rope clips must be well understood before lifting a tower. The sequence will be repeated many times before a tower installation is completed on all but the most flat and level sites.

\section{Adjusting Guy Wires (the "Inchworm" method)}

\section{Loosening Guy Wires}

As the tower is raised, the side guys may become tight. To adjust the cable, start by making sure the 3 wire rope clips are secure. Tighten using a wrench. Then:

1) Loosen the upper clip and pull a length of the tail through the clip, creating a loop as shown below. Tighten the upper clip to "trap" the loop between the upper clip and the lower clips.

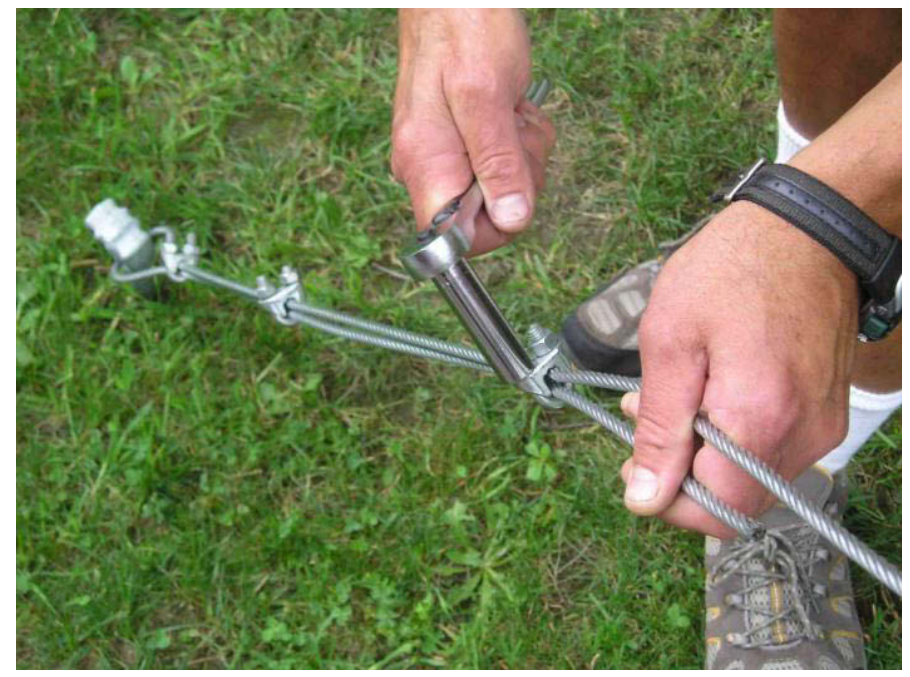



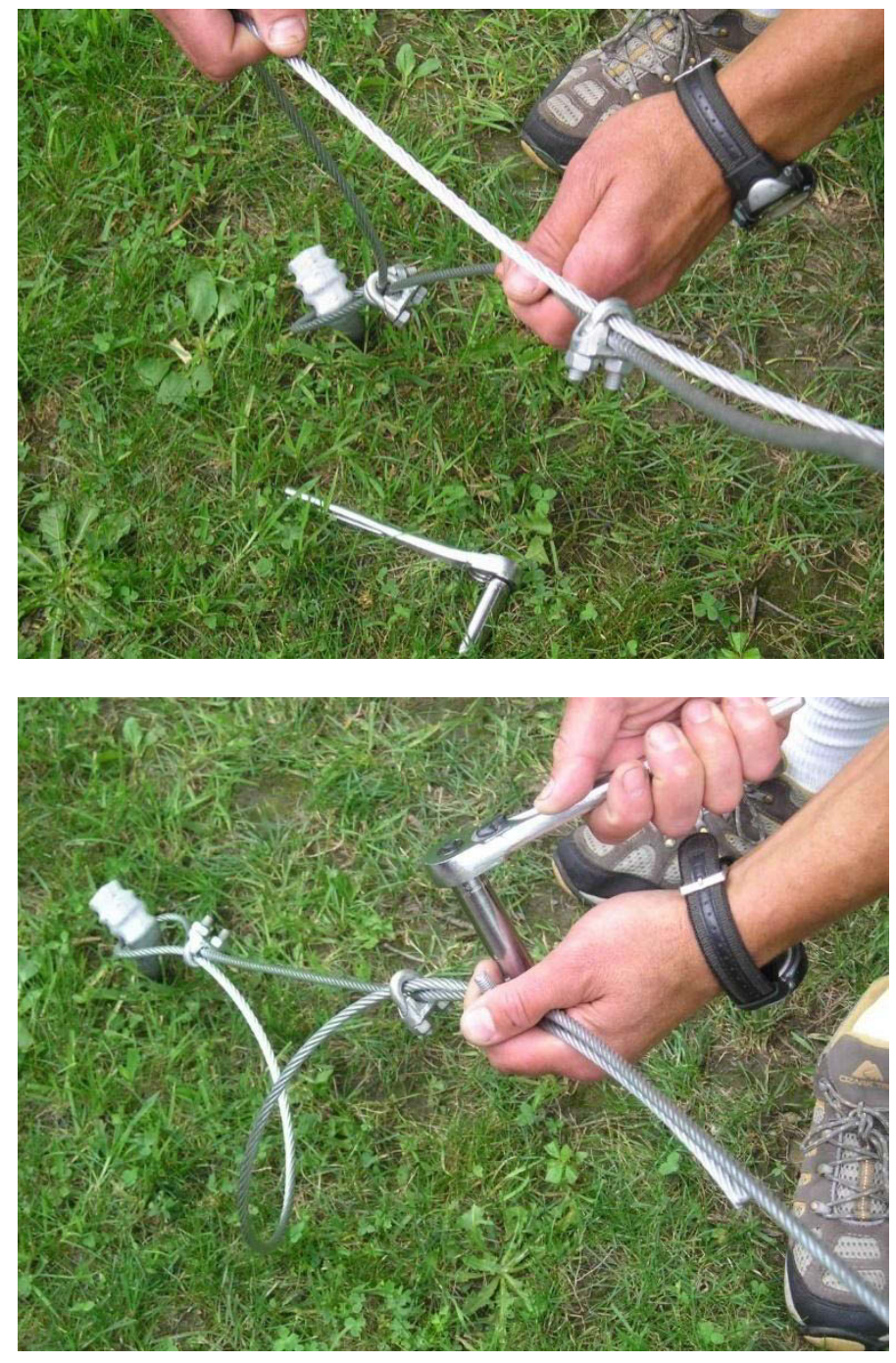

2) Now loosen the lower clips, loosening the lowest clip slowly, allowing the loop to slide, which will slacken the guy wire.

3) Retighten the lowest wire rope clip.
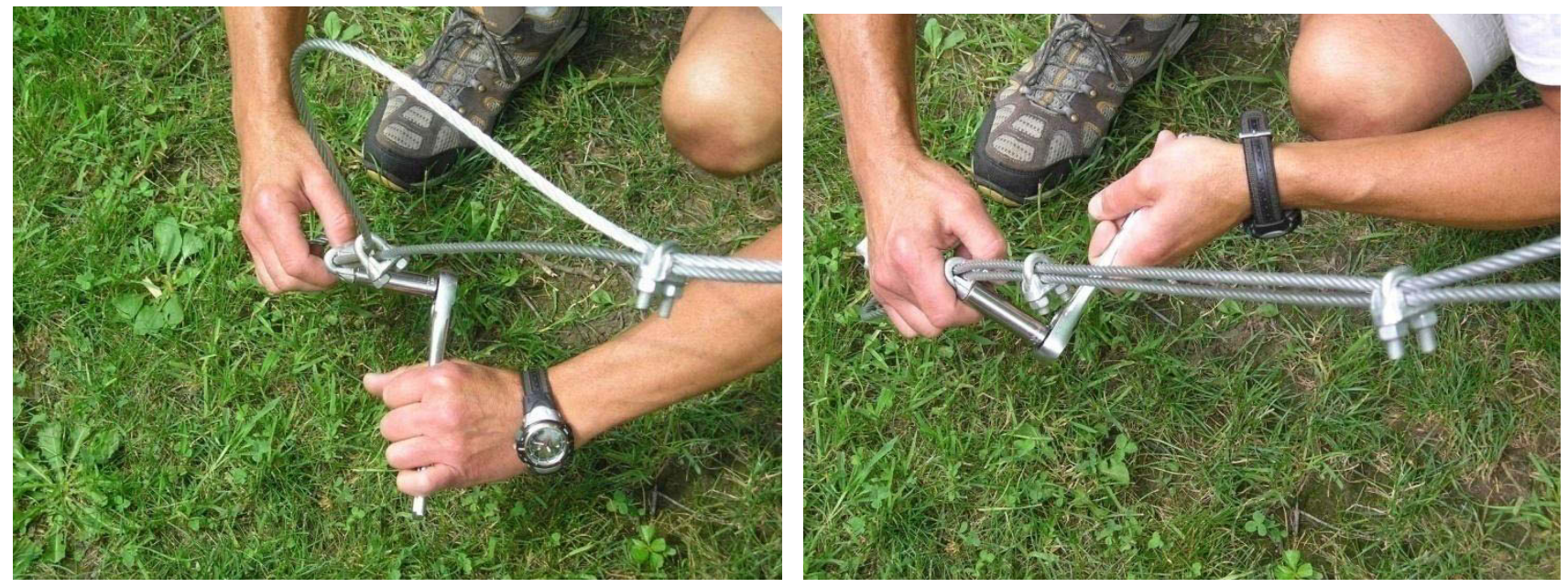

4) Repeat as necessary from step 1 to create the proper cable tension. 


\section{Tightening Guy Wires}

As with loosening, make sure to start with all 3 wire rope clips secure. Tighten using a wrench as shown below. Then:

1. Loosen the lower 2 wire rope clips as shown below.

2. Pull the 2 cables apart to form a loop (similar to the loop made while loosening), then tighten the lowest rope clip to trap the loop between the upper and lower rope clips as shown below.
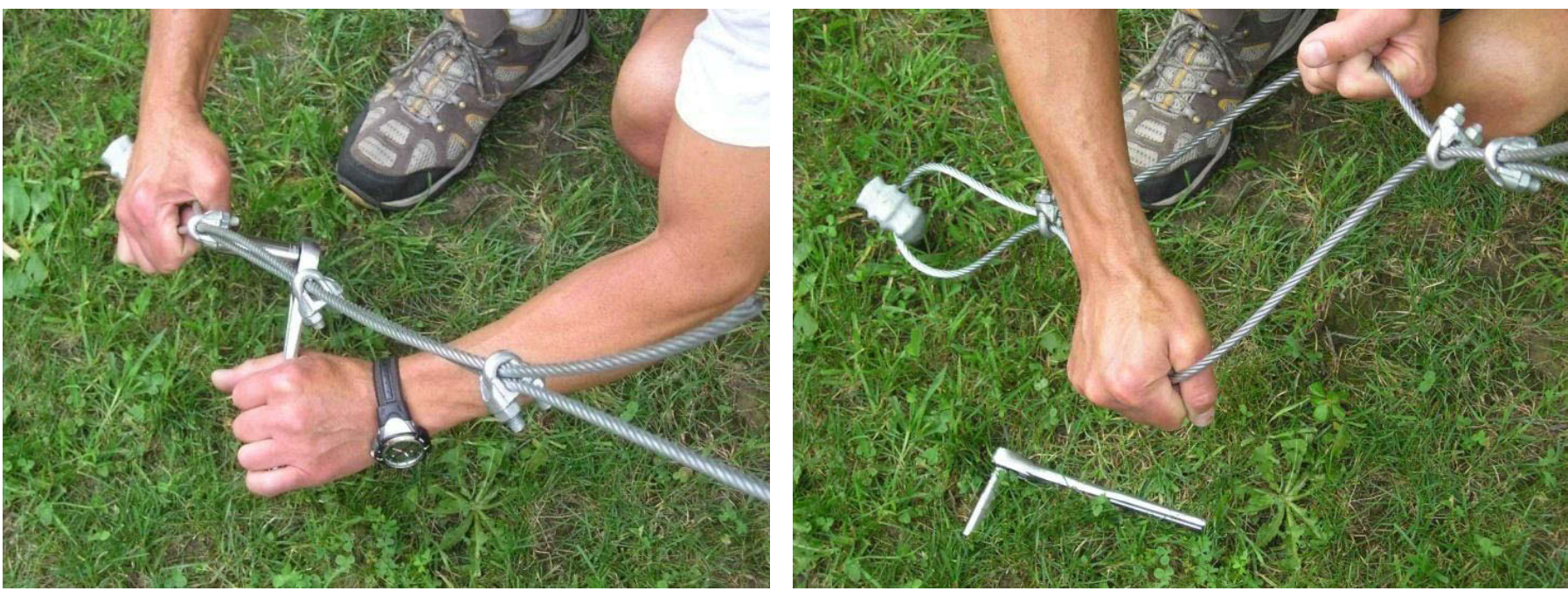

3. Loosen the upper rope clip and pull the tail to remove the loop.
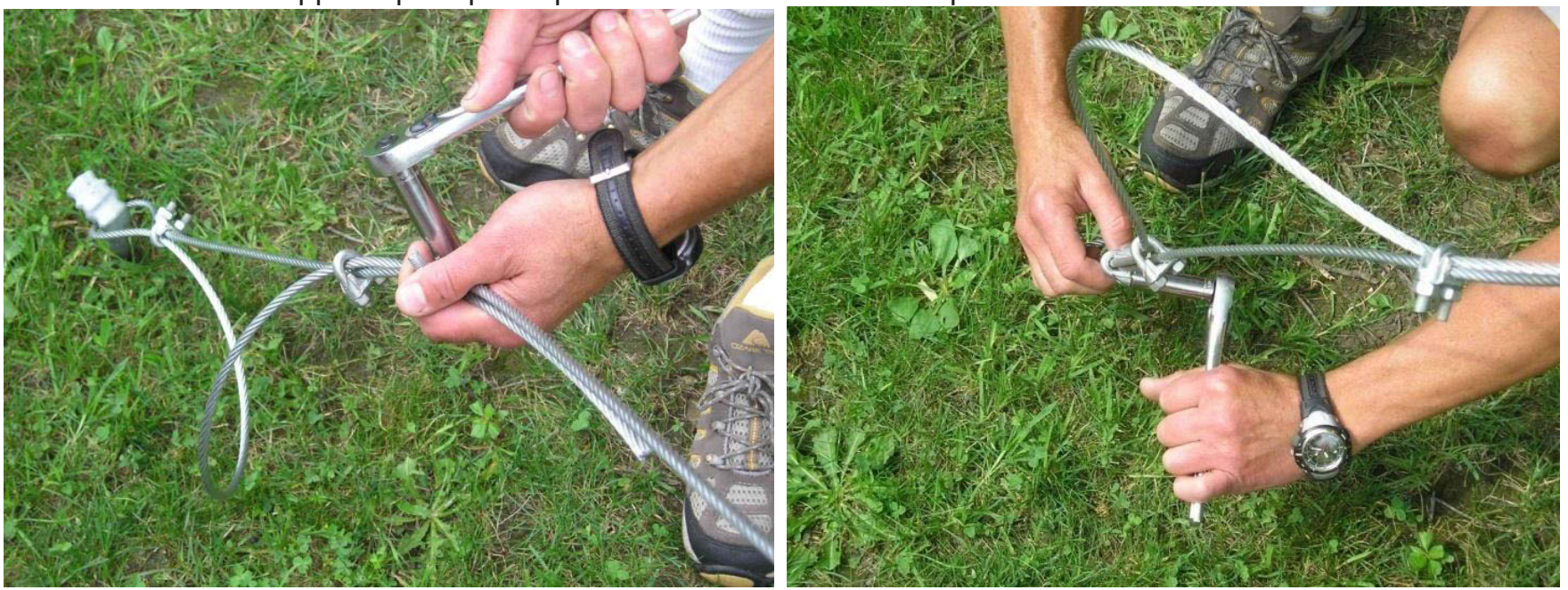

4. Finally, tighten the upper clip.

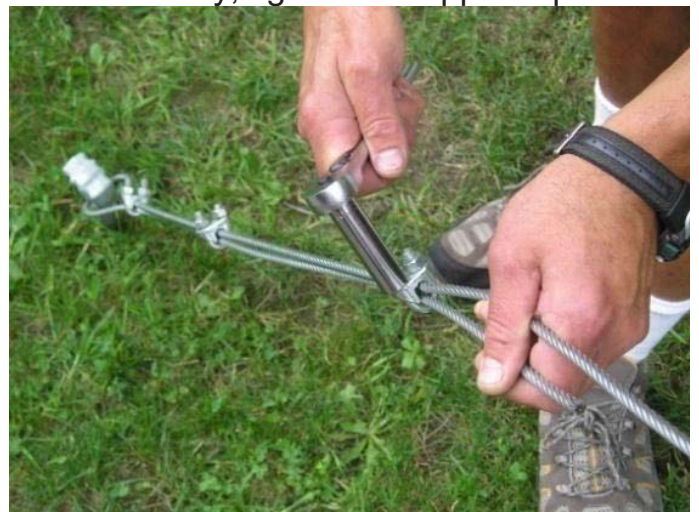

5. Repeat as necessary from step 1 to tighten the cable. 


\section{Lift the Tower}

When all crew members are ready, the winch operator will begin to lift the tower. Remember that most electric winches are designed for intermittent use, and frequent rests must be taken to prevent the winch motor from overheating. Help the cable to wind evenly by using the winch control handle to move the winch motor from side to side.

Warning: Allowing the cable to wind unevenly will result in crossovers that will damage the cable and fill the winch drum before the tower is fully raised.

Lift the tower about $1 \mathrm{~m}$ ( 3 feet) off the ground while checking side guy tensions. The lifters are set up to produce a slight bow in the tower, with the top $0.15 \mathrm{~m}$ to $0.3 \mathrm{~m}$ (6" to $1 \mathrm{foot}$ ) higher than the middle (we refer to this as a "positive curve"). This is normal, and it needs to be maintained throughout the entire lift to avoid tower buckling or collapse. Adjust the side guy wire tensions to prevent the tower from either falling off to one side or bowing which could damage the tower.

Warning: The tower must remain straight side to side and maintain a positive curve as described above. Failure to maintain the proper shape can cause the tower to collapse, endangering the crew and equipment. This is the highest stress point of the lift.

Watch the winch anchors for movement. The maximum lifting force will be experienced when the tower is first lifted a few feet off the ground. If the winch anchors will not hold, either the anchor was not installed correctly or another type of anchor is needed. See Appendix B: Anchoring Guidelines for more information.

Watch the tower baseplate for movement toward the winch. If either the winch anchors won't hold or the baseplate slips, immediately lower the tower.

If everything looks OK, continue to lift the tower a little at a time, checking side guy tension along the way. At times, it may be necessary to adjust the side guy wire tension. Do this ONLY when the winch is stopped. Readjust with wire rope clips, letting cable out or pulling loose cable in (see "inchworm" technique). Work slowly and smoothly. Fast, uneven movements tend to make the tower bounce, shake or swing. Be sure that communication between all members of the lifting team is clear and concise. Continue lifting and adjusting until the tower is about 60 degrees above horizontal (just above half way). STOP.

Beyond 60 degrees above horizontal, it is absolutely essential that tension is maintained on the back guy wires during the last part of the lift, particularly the guy wires at levels 2 and 3 . Excess tension on level 4 will remove the positive curve shape from the tower and potentially cause a collapse. So don't do it. The tower will lift very easily at this point because the weight of the ginpole and winch will be enough to tip the tower without powering the winch, causing total loss of tower control. Any wind blowing in the direction of the lift will also help reduce the load on the winch. Therefore, the crew must control the lift from this point on using the back guy wires.

Before continuing the lift, adjust the back guy wires to take out the excess slack.

Continue the lift by alternately powering the winch and smoothly and incrementally (a few feet of guy wire at a time) letting out on the back guy wires (in order from top to bottom) using the inchworm technique. Do not completely remove slack in back guy wires by running the winch too long. Continue this process until the top of the tower is directly over the base (sight with a carpenter's level).

Warning: Avoid winching in too much cable (to the point where the pulley collides with the winch). If the pulley and winch are winched tightly together, the winch cable can break, causing total loss of tower control. Please note that the winch's motor has a slightly delayed response after the switch is released, and while coasting to a stop may produce enough force to break the winch cable.

Re-check that the tension in the back guys and in the side guy wires is set up correctly to about $23 \mathrm{kgf}$ (50 pounds) of tension, allowing some slack in each guy wire. Check that wire rope clips are secure. 


\section{Transfer Lifters}

Next, you will transfer the lifting guys one at a time from the gin pole to their respective anchors. You will secure each lifter guy wire with wire rope clips. Remember that while the lifter is disconnected, you will be holding the tower! Maintain tension while transferring the guy wires.

As mentioned before, it is normal to have the tower bowed slightly away from the winch. As you transfer the lifters, you may have to add a little slack to the middle level back guy wires to allow the tower to straighten.
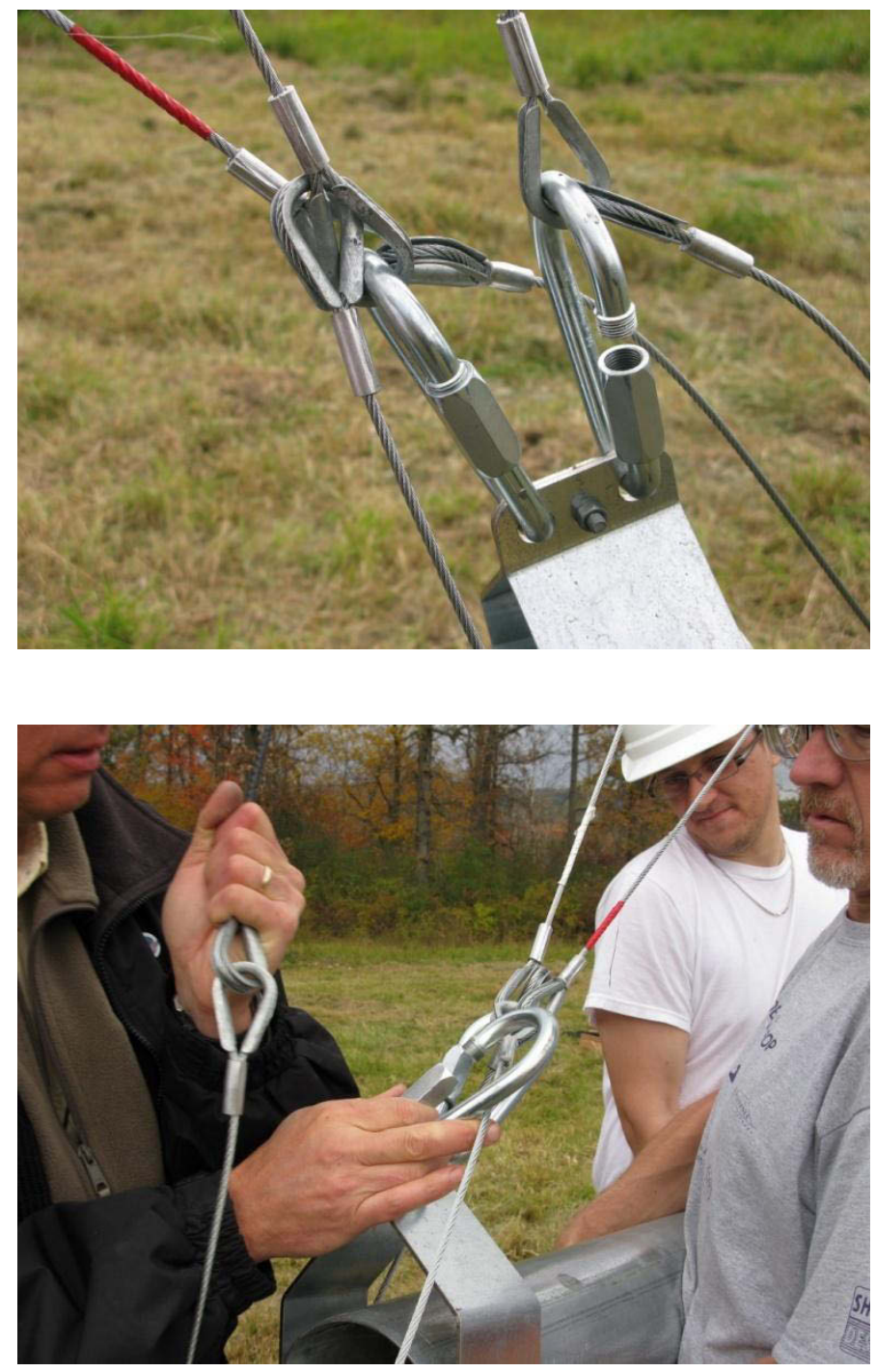

Transfer the lifters one at a time from the quick links on the ginpole to their anchor. Secure each with wire rope clips. Remember that you will be holding the tower. Maintain tension while transferring the wires. Start with the top lifter level (level 4 yellow). Adjust the guy tension on the lifter and the guy opposite to pull the tower straight and vertical. Working downward, transfer the lower level lifters one at a time to their anchor. Again, check the tension on the lifter and its opposite guy as each is transferred. To keep the tower straight, it may be necessary to winch out slightly and or adjust the opposite guys as the lifters are transferred. As you remove the last lifter, lower the ginpole to the ground. 


\section{Plumb and Straighten}

Make final adjustments to the guys. Using a carpenter's level on the base tube, adjust the lowest level guy wires as needed so the base tube is vertical. Working upward, adjust all four guys at each level while sighting up the tower from the base to straighten the tower (see picture below).

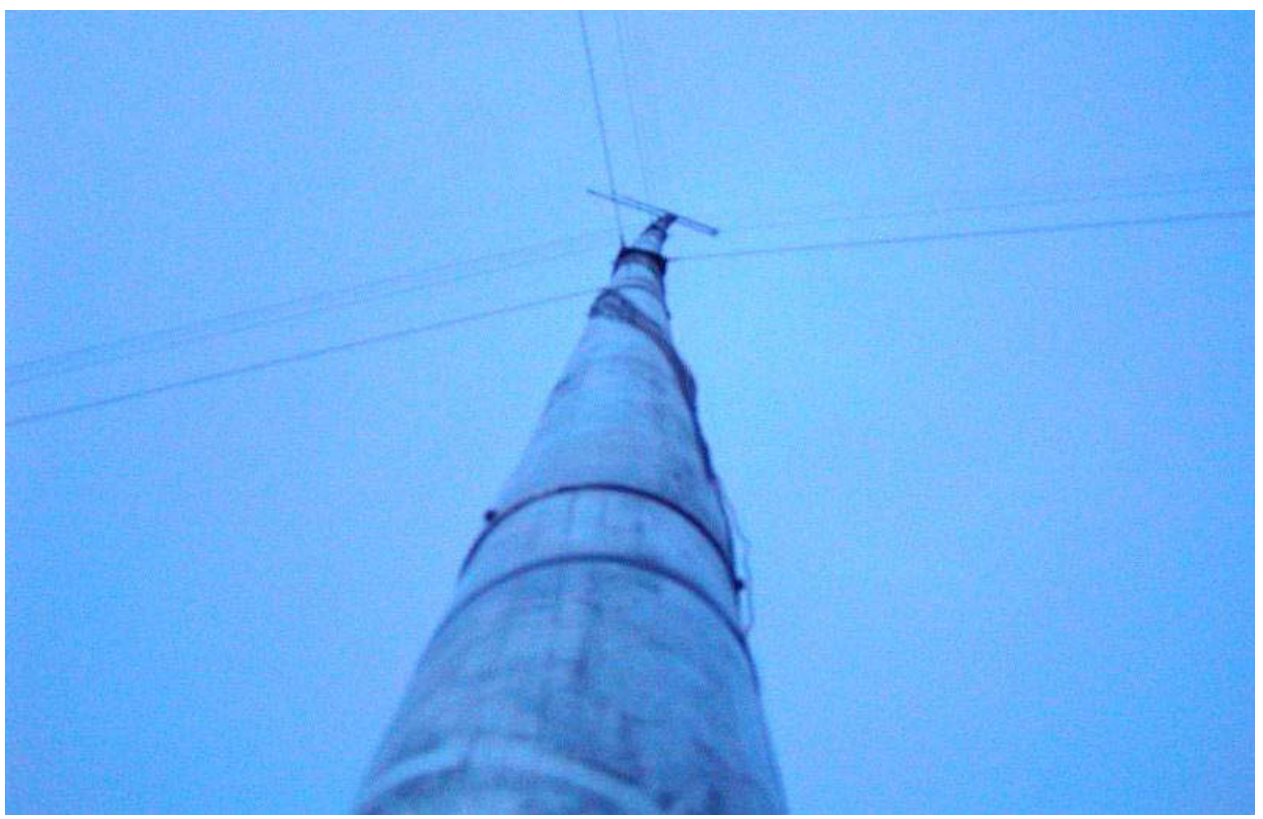

As you finalize the straightening of the tower, you will need to set the final tension on the guys. 


\section{Final Inspection and Maintenance}

Tighten all wire rope clips on each guy wire now, with about $100 \mathrm{~mm}$ to $200 \mathrm{~mm}$ (4 inches to 8 inches) between clips. $\mathrm{Re}$-check that all wire rope clips are tight. Final torque on wire rope clips should be $20 \mathrm{Nm}(15 \mathrm{ft}-\mathrm{lb})$ for $1 / 4$ inch wire rope clips. The ginpole may be left in place, or it may be removed and disassembled if desired. If using guy guards, attach one to each guy wire and one to the winch anchor as shown below.
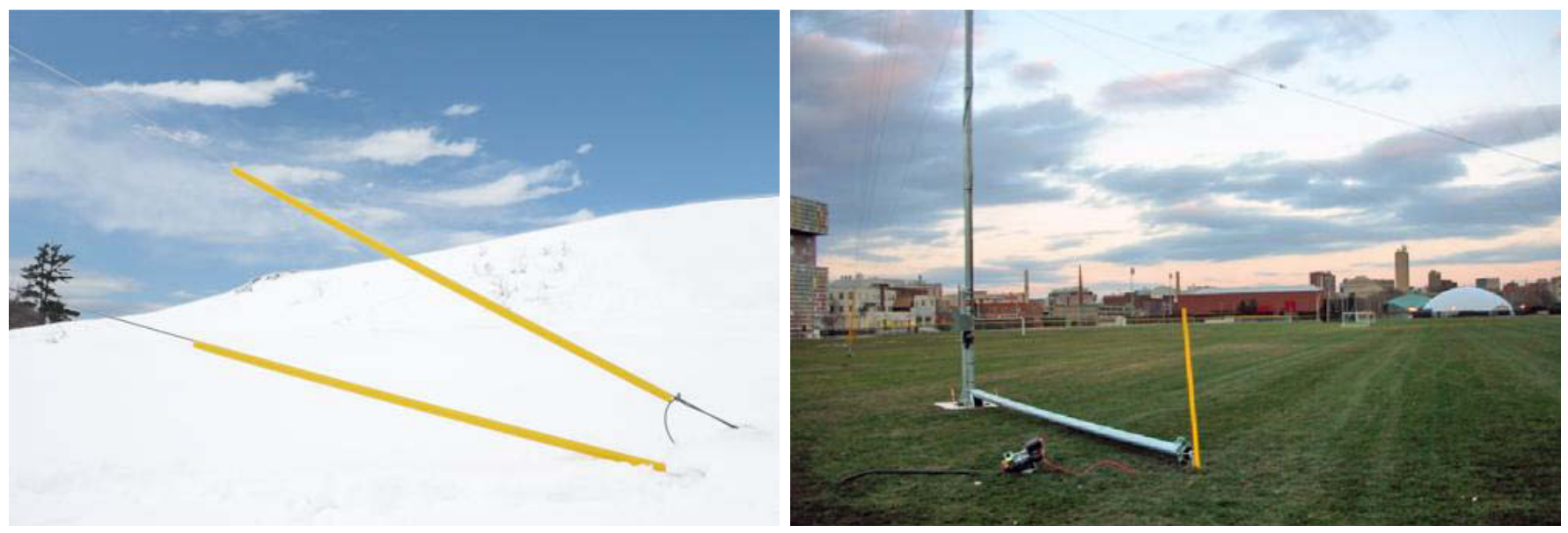

Check the tower in 2 or 3 weeks; tighten loose guys and straighten the tower if needed. It is especially important to do this before any icing events occur. Also check the guy wires after any severe ice or wind storm. Some settling of the tower or anchors may occur, and guy wires can stretch. Loose guy wires can also result when the wire rope clips securing the guys are forced down by the impact of sliding ice.

One of the most important reasons for good tower maintenance, particularly guy tension maintenance, is to avoid a form of tower failure known as "Snap-Through." Snap-Through typically occurs when the guys are allowed to become loose, and a high wind is blowing on the tower. Even in normal conditions, the upper guys work at a narrower angle to the upper tower than the lower guys, reducing their effectiveness at restraining sideways bending (see figure below). If the guys are allowed to become loose, the working angle is further decreased. If the loads are high enough, or the guys are too loose, the angle between the guy and the tower will reduce to zero, and the guy can no longer restrain the sideways motion. The result is that the upper tower "snaps through" and falls over. 


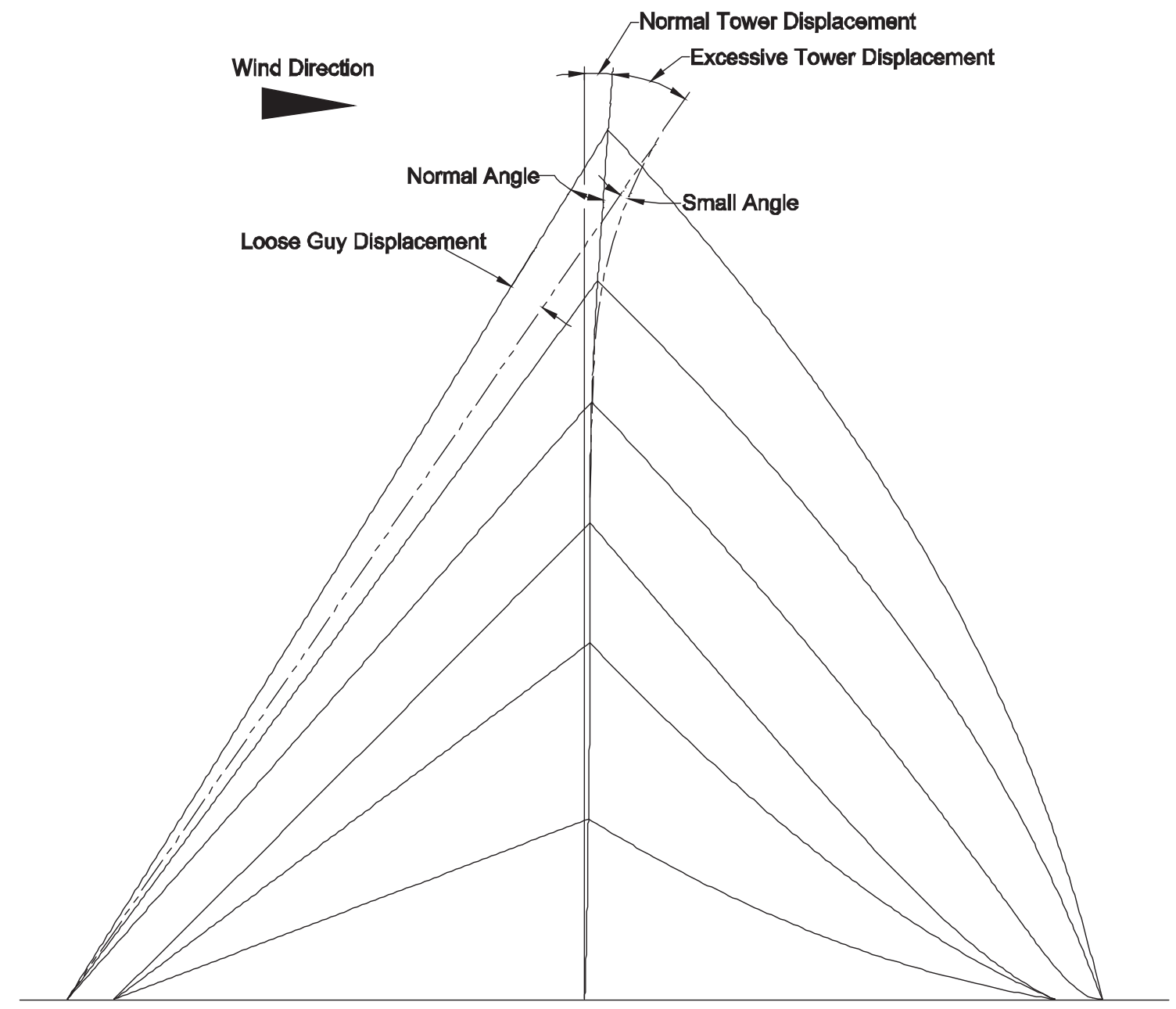

Figure 8

\section{Tower Lowering}

Lowering the tower is the reverse of raising the tower, though there are a few additional precautions to be taken. Just as side guy wire tension may vary during the lifting process, the same is true as the tower is lowered. Side guy wires will have to be tended in order to maintain proper guy tension.

If the ginpole was removed, set up the ginpole as described previously. Remember that the extensions of the coupler plate will now be facing the ground. If the tower will be lowered onto blocking, place the blocking now while it is still safe to work under the tower. Lift the ginpole and transfer the lowest level lifting guy wire from the anchor to the ginpole. Remember you will be holding the tower: maintain tension while transferring the wires. Winch in or out as needed to maintain the correct amount of tension in the guy wire when it is transferred. The winch cable must always spool and unspool from the bottom of the cable drum in order for the winch brake to work properly.

Transfer the lifter guy wires from the anchor to the ginpole, in order from lowest to highest. Tension must be applied to the back guys to pull the tower away from the winch as you begin lowering. This keeps wind loads and/or the weight of the ginpole from suddenly pushing the tower back upright, which could cause guy wire or anchor failure. Leave the guy wire attached to the anchor and pull outward on the guy wire to take out the slack. The safest way to do this is by tying a rope around the guy wire. This allows the crew members to maintain tension by hand without being under the tower. 
Maintain tension on a minimum of one mid-level and one top level guy wire during lowering. Use two crew members to tend two top level and two mid-level guy wires. These crew members should maintain tension in the back guys and take up the slack in the guy wire as the tower lowers toward them.

As the tower is lowered and reaches an angle of between 75 and 60 degrees, it will no longer be necessary to maintain tension on the back guy wires. Stop the winch at least as often as each 20 degrees to re-check side guy wire tension and to allow the winch to cool for a minute.

\section{Warning:}

The force on the winch is greatest as the tower nears the ground. Be sure to stand to either side of the winch cable and behind the winch, batteries, and power cables rather than directly in line with it.

To lower the ginpole, put the helper ginpole in place. As the ginpole nears the ground, place the winch cable (both strands if using a two part line) in the 2 pulleys on the top of the helper ginpole. The pole can then be lowered to the ground. 


\section{Appendix A: 34 m TallTower Dimensions}

\section{Tower Layout}
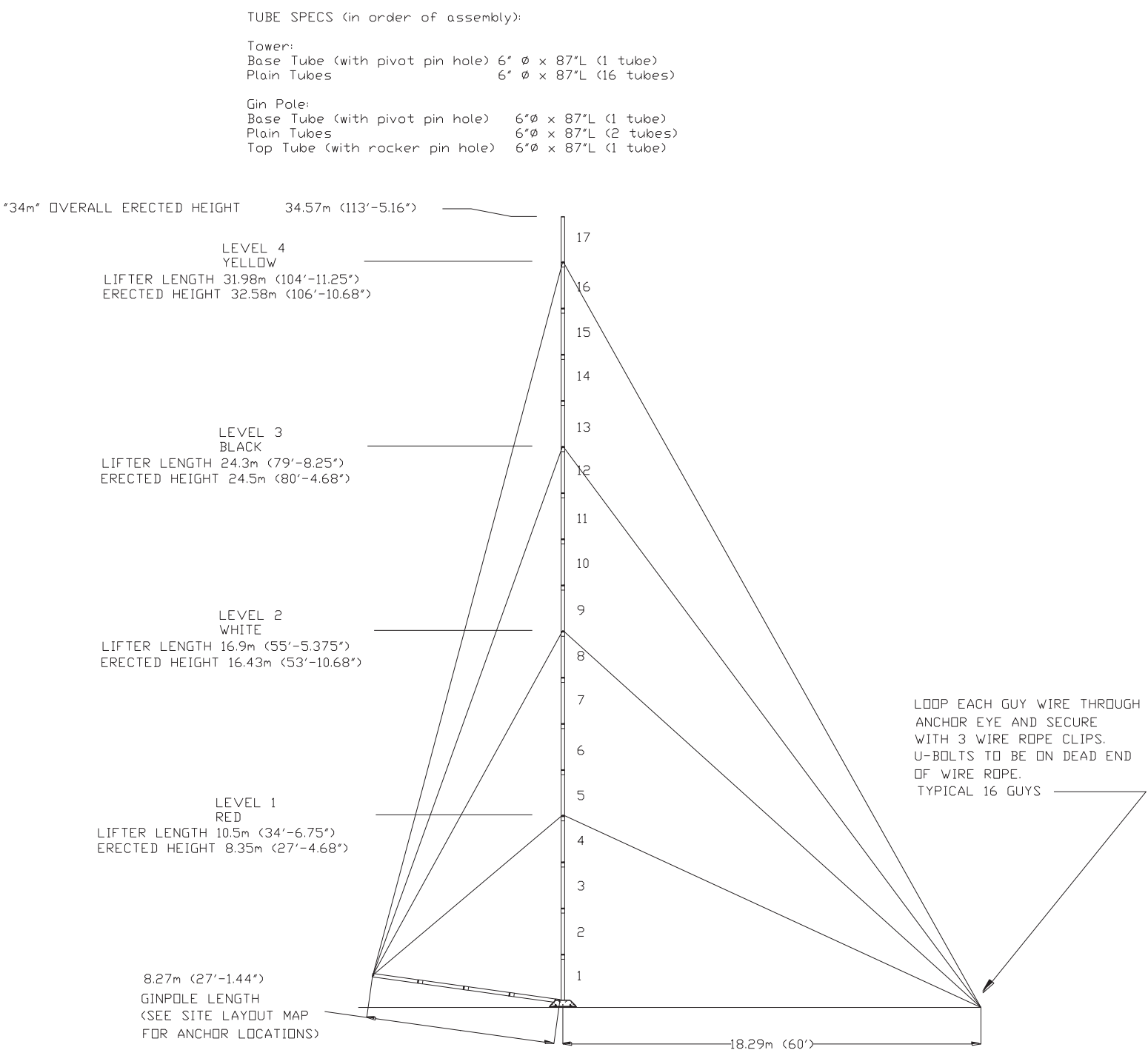


\section{Site Layout}

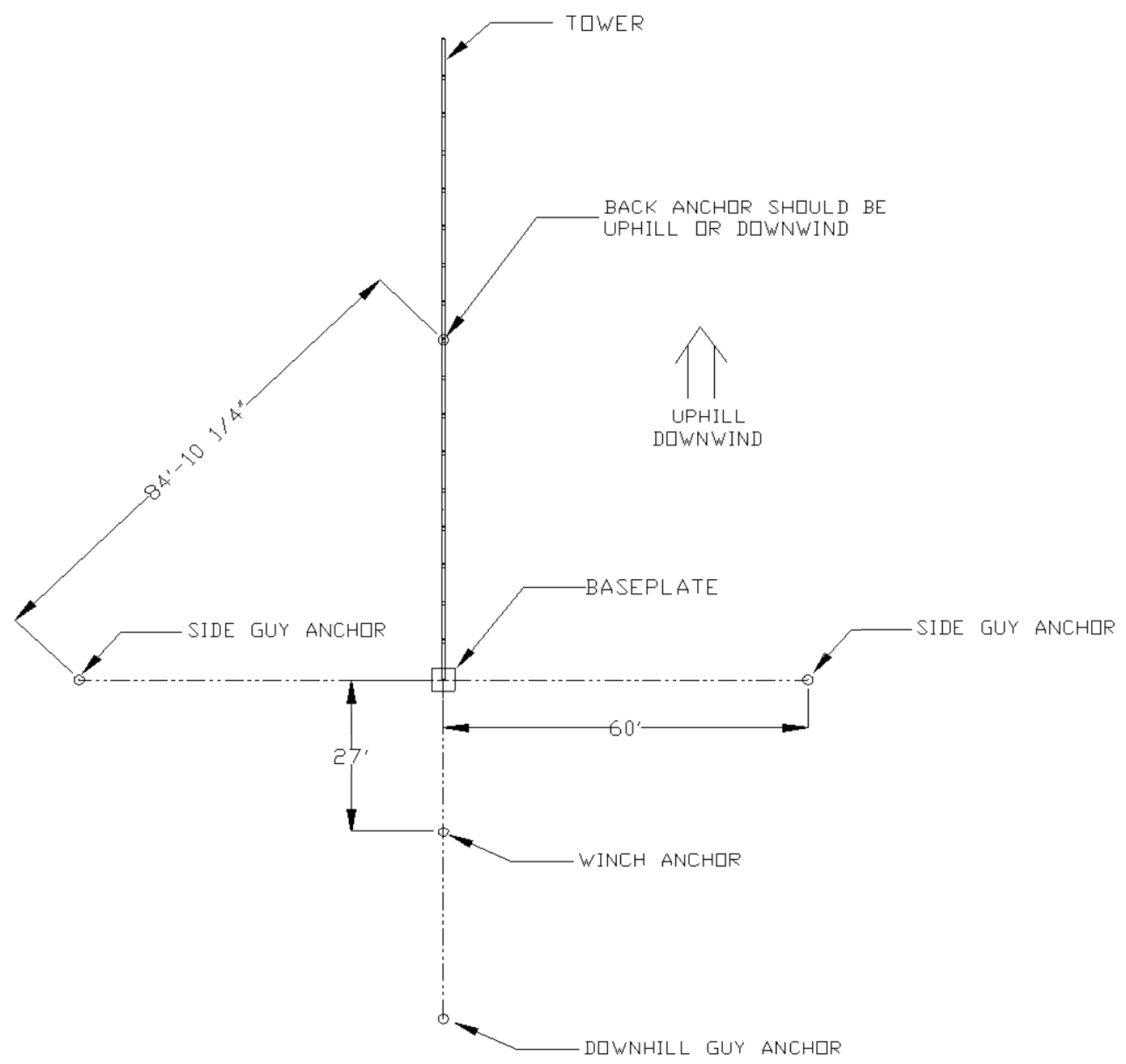




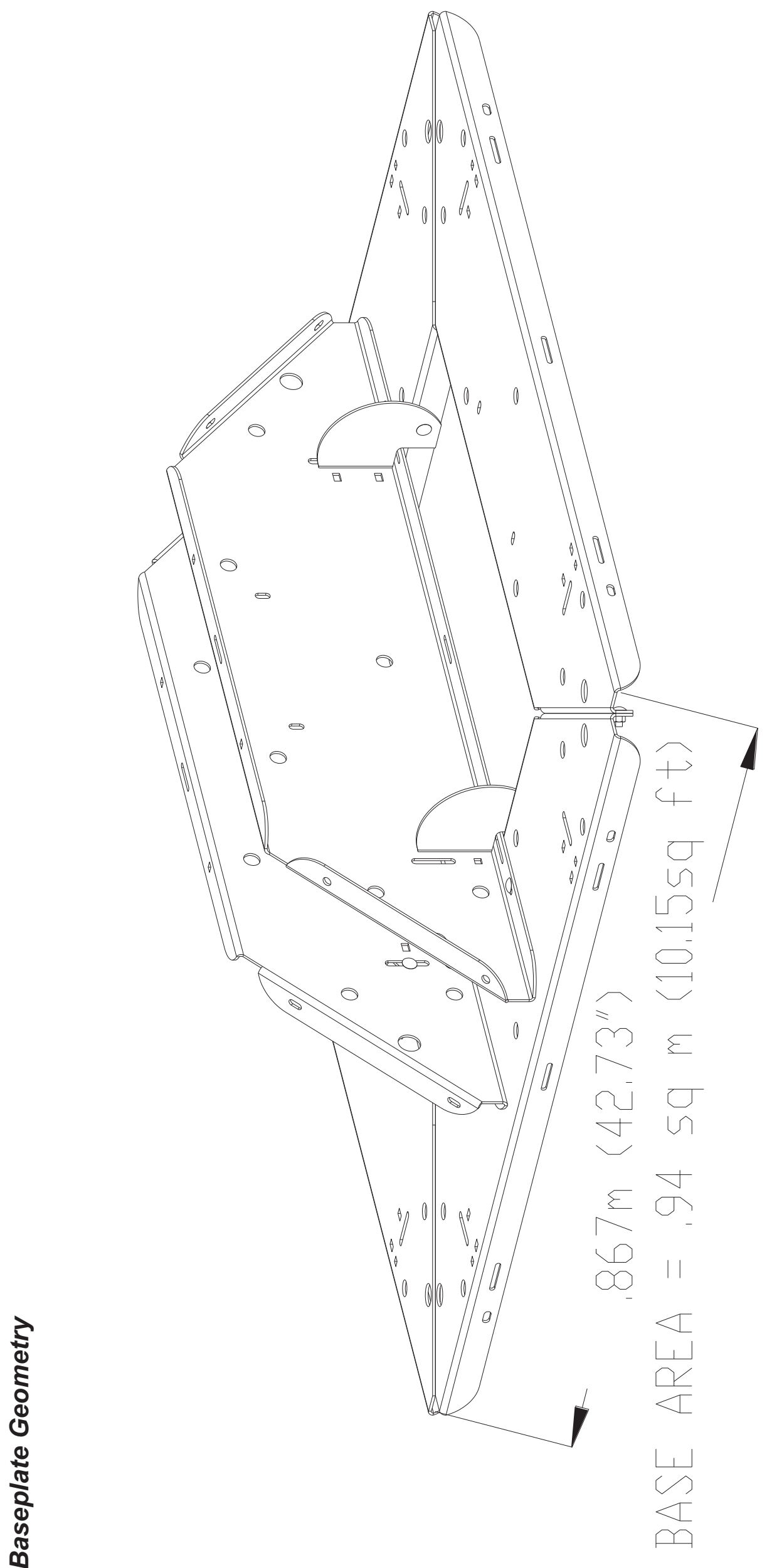




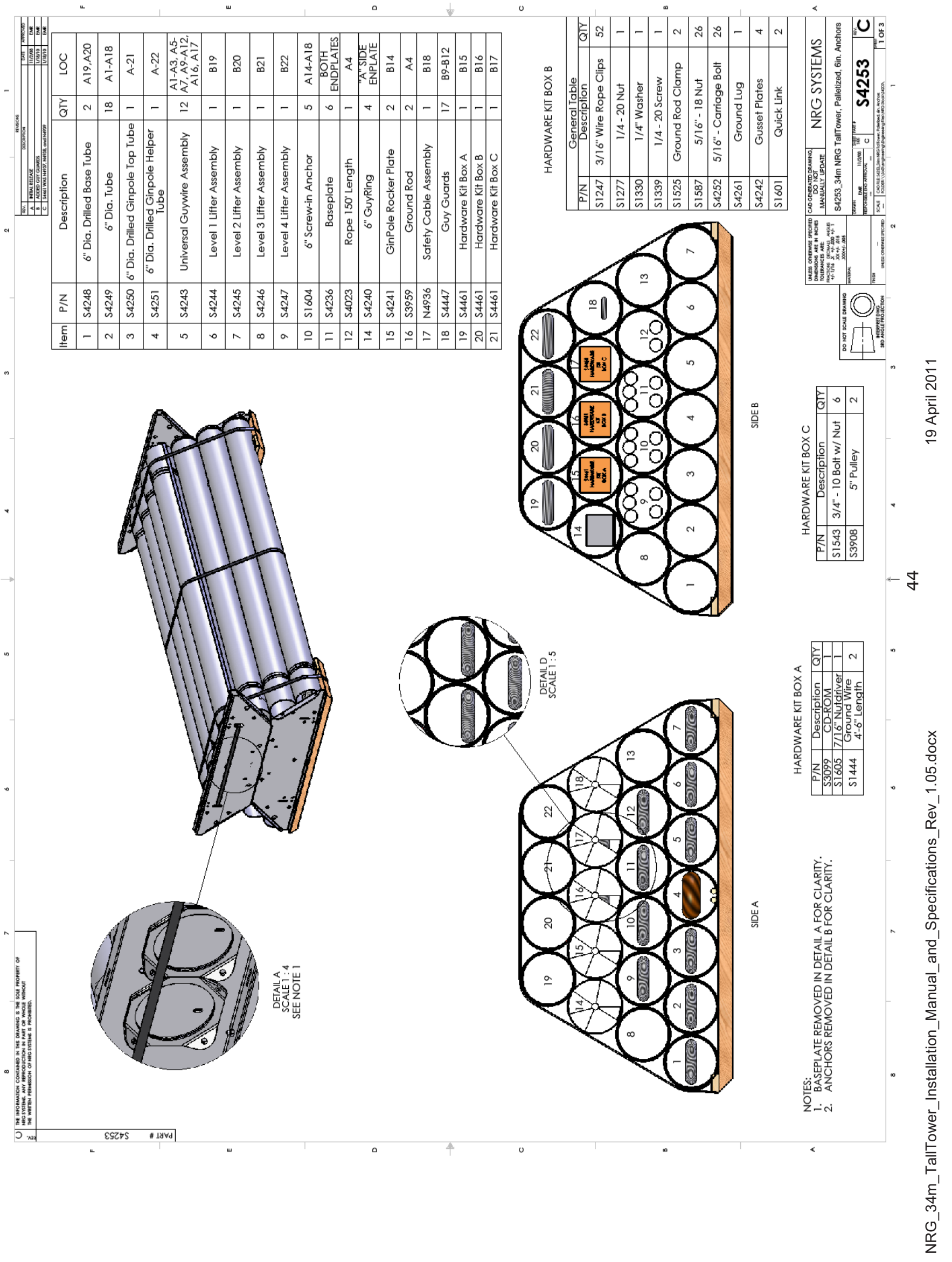




\section{Appendix B: Anchoring Guidelines}

\section{Determine site soil and anchor type before you order your tower}

Before the tower is ordered, the soil type should be determined and the correct anchors ordered. The purpose of this section is to give you the information needed to provide suitable anchoring for your TallTower. Because anchor requirements are site specific, it is the responsibility of the customer to determine anchor requirements. If you are not sure what is required, seek professional guidance.

Local utility companies can often provide useful information regarding anchoring used in the site area. Do not use rebar anchors, especially when the surface soils are loose or wet.

\section{Table 6: Soil Classes}

\begin{tabular}{|l|l|l|}
\hline Class & Common Soil Types & Geological Soil Classification \\
\hline 3 & $\begin{array}{l}\text { Dense clays, sands and gravel; hard } \\
\text { silts and clays }\end{array}$ & Glacial till; weathered shales, schist, gneiss and siltstone \\
\hline 4 & $\begin{array}{l}\text { Medium dense sandy gravel; very stiff } \\
\text { to hard silts and clays }\end{array}$ & Glacial till; hardpan; marls \\
\hline 5 & $\begin{array}{l}\text { Medium dense coarse sand and sandy } \\
\text { gravels; stiff to very stiff silts and clays }\end{array}$ & Saprolites, residual soils \\
\hline 6 & $\begin{array}{l}\text { Loose to medium dense fine to coarse } \\
\text { sand; firm to stiff clays and silts }\end{array}$ & Dense hydraulic fill; compacted fill; residual soils \\
\hline $7^{* *}$ & $\begin{array}{l}\text { Loose fine sand; Alluvium; loess; soil- } \\
\text { firm clays; varied clays; fill }\end{array}$ & Flood plain soils; lake clays; adobe; gumbo; fill \\
\hline
\end{tabular}

** In class 7 soils, it is advisable to place anchors deep enough to penetrate underlying class 5 or 6 soil. Charts reproduced by permission, The A.B. Chance Co.

\section{Anchor Choices and other considerations}

The choice of anchors must take into consideration soil type, maximum winds expected, icing or other weather that may affect the tower, and a safety factor suitable for the location and to meet any legal requirements. Considerations include but are not limited to: tornadoes, hurricanes or typhoons, locations where very high winds are expected, potential for flooding or periodic soaking of the soil, soil erosion, and icing events.

\section{Screw-In Anchor description}

Screw-in anchors are the most commonly used anchors for normal clay soils without rocks. They are installed by hand, using a cross bar to screw them into the earth like a corkscrew.

Screw-in anchors can also be used to provide the anchoring rod and eye for site-built anchors, such as concrete. Refer to the information on concrete anchors below. $150 \mathrm{~mm}$ (6.0 inches) diameter screw-in anchors are the standard anchors supplied with NRG TallTowers. $203 \mathrm{~mm}$ (8.0 inches) diameters screw-in anchors are available upon request. 
Table 7: Specifications for 152 mm (6 inches) diameter Screw-In Anchors

\begin{tabular}{|l|l|}
\hline & $150 \mathrm{~mm}$ (6 inches) Anchor \\
\hline Helix diameter: & $152 \mathrm{~mm}(6.0$ inches $)$ \\
\hline Length Overall: & $1.65 \mathrm{~m}$ (66 inches) \\
\hline Rod diameter: & $19 \mathrm{~mm}$ (0.75 inches) \\
\hline Material: & Galvanized steel \\
\hline Holding Power: (These anchors are not suitable for soils denser than class 5.) \\
\hline Class 5 soils * & $3,000 \mathrm{~kg}(6,500$ pounds $)$ \\
\hline Class 6 soils * & $1800 \mathrm{~kg}(4,000$ pounds $)$ \\
\hline Class 7 soils ** & $909 \mathrm{~kg}(2,000$ pounds) \\
\hline
\end{tabular}

${ }^{*}$ See Table 6 for soil class descriptions

${ }^{* *}$ In class 7 soils, it is advisable to place anchors deep enough to penetrate to underlying class 5 or 6 soil.

Table 7A: Specifications for 203 mm (8 inches) diameter Screw-In Anchors

\begin{tabular}{|l|l|}
\hline & $\mathbf{2 0 3} \mathbf{~ m m}$ (8 inches) Anchor \\
\hline Helix diameter: & $203 \mathrm{~mm}$ (8.0 inches) \\
\hline Length Overall: & $1.65 \mathrm{~m}$ (66 inches) \\
\hline Rod diameter: & $25 \mathrm{~mm}$ (1 inch) \\
\hline Material: & Galvanized steel \\
\hline \multicolumn{2}{|l|}{ Holding Power: (These anchors are not suitable for soils denser than class 5.) } \\
\hline Class 5 soils * & $44.5 \mathrm{kN}$ (10000 pounds) \\
\hline Class 6 soils * & $31.1 \mathrm{kN}$ (7000 pounds) \\
\hline Class 7 soils ** & $17.8 \mathrm{kN}$ (4000 pounds) \\
\hline
\end{tabular}

${ }^{*}$ See Table 6 for soil class descriptions

** In class 7 soils, it is advisable to place anchors deep enough to penetrate underlying class 5 or 6 soil. 


\section{Arrowhead Anchor description}

Arrowhead anchors can penetrate stiff and rocky soils because the unique triangular design threads its way between obstacles such as rocks, which can prevent successful installation of screw-in anchors. Arrowhead anchors are driven into the ground with a hardened steel drive rod. Once in the ground, upward force on the attached cable rotates the anchor perpendicular to the cable for maximum holding power.

\section{Table 8: Specifications for Arrowhead Anchors}

\begin{tabular}{|c|c|}
\hline Length Overall: & $1.22 \mathrm{~m}$ (48.0 inches). \\
\hline Arrowhead Length: & 203 mm (8.0 inches) \\
\hline Materials: & $\begin{array}{l}6.35 \mathrm{~mm} \text { ( } 0.25 \text { inches) galvanized }(7 \times 19) \text { steel cable; breaking strength - } 1905 \\
\mathrm{~kg}(4200 \text { pounds); with malleable iron head. }\end{array}$ \\
\hline \multicolumn{2}{|l|}{ Holding Power: } \\
\hline Class 3 soils * & $1905 \mathrm{~kg}$ (4200 pounds) \\
\hline Class 4 soils * & $1361 \mathrm{~kg}$ (3000 pounds) \\
\hline Class 5 soils * & 907 kg (2000 pounds) \\
\hline Class 6 soils * & $544 \mathrm{~kg}$ (1200 pounds) \\
\hline Class 7 soils * & $272 \mathrm{~kg}$ (600 pounds) \\
\hline
\end{tabular}

* See Table 6 for soil class descriptions

${ }^{* *}$ In class 7 soils, it is advisable to place anchors deep enough to penetrate underlying class 5 or 6 soil. 


\section{Rock Anchor description}

Rock anchors are placed into solid rock, when anchoring to either bare rock, or thin soils with solid rock near the surface. They are constructed of a threaded rod with integral eye, and two opposing wedge halves. The anchor is placed in a hole pre-drilled in the rock. Twisting the eye of the anchor forces the wedges against the sides of the hole and locks the anchor in place. Load actually increases the wedging force, developing holding power equal to the full tensile strength of the rod.

\section{Table 9: Specifications for Rock Anchors}

\begin{tabular}{|l|l|}
\hline Holding Power: & $9072 \mathrm{kgf}(20,000$ pounds) \\
\hline Rod Length Overall: & $\begin{array}{l}0.38 \mathrm{~m} \text { (15 inches), } 0.76 \mathrm{~m} \text { (30 inches) or } 1.35 \mathrm{~m} \text { (53 inches), other lengths } \\
\text { available }\end{array}$ \\
\hline Anchor Diameter: & $44 \mathrm{~mm}$ (1.75 inches) as supplied, $60 \mathrm{~mm}$ (2.375 inches) max. expanded \\
\hline Rod Diameter: & $19 \mathrm{~mm}(.75$ inches) \\
\hline Materials: & Malleable iron, dipped in rust-resisting black paint \\
\hline Required Hole Size: & $50 \mathrm{~mm}(2$ inches) diameter (nominal) \\
\hline Use Rock Drill Size: & $50 \mathrm{~mm}$ (2 inches) diameter \\
\hline
\end{tabular}

\section{Concrete Anchor description}

The most common alternative anchoring system is to place site-built concrete anchors. A hole is excavated at the anchor position. Reinforcing steel is placed in the hole. A screw-in anchor is often tied into the reinforcing steel to provide a rod and eye above ground to attach the guys. Concrete is poured in place to form the anchoring mass, and the hole is then back-filled.

The anchors must be placed carefully to provide anchor points at the proper locations for the tower. The holding power of concrete anchors is essentially due to their weight. The weight of concrete placed must exceed the required anchor holding force. Concrete anchors still depend on the soil to prevent the concrete mass from shifting toward the tower under load.

As with all anchoring systems, it is your responsibility to ensure that the anchors will perform as required. If in doubt, seek professional advice for anchor design. 


\section{Installing Screw-In Anchors}

Note: Unlike a tent stake, screw-in anchors are installed in line with the pull of the guy wires from the tower. It is important to install the anchor at an angle, so the eye of the anchor is toward the tower and the helix screws in away from the tower. If the anchor is incorrectly installed straight into the ground, the load will bend the rod and pull it through the ground, allowing the guys to go slack. Refer to the appropriate stamped drawing in the Appendix to determine the angle of the tower guys from the ground.

\section{Figure 9: Installing Screw-in Anchors}

\section{SCREW IN ANCHDR}

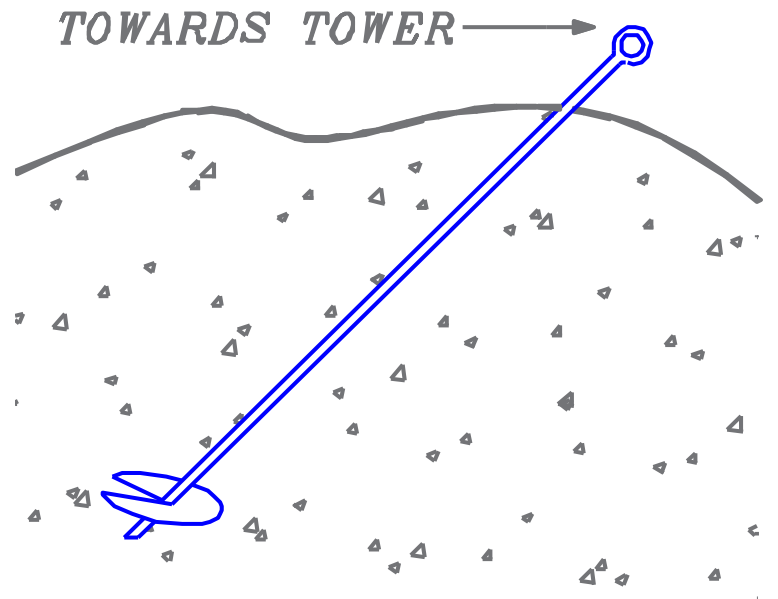

Screw the anchor into the ground by placing a stout bar through the eye of the anchor, and rotating clockwise. It is sometimes helpful to start the anchor into the ground straight down for the first turn, then push it down to the correct angle and complete the installation. Continue screwing the anchor into the ground until about $150 \mathrm{~mm}$ (6 inches) of the anchor rod remains above the ground.

If the anchor cannot be installed due to rocks in the soil, or other obstacles, try placing the anchor as much as $1 \mathrm{~m}$ ( 3 feet) from its ideal position to avoid the obstacle, or replace the screw-in anchor with the correct anchor for the soil. Arrowhead anchors are often suitable for rocky soils.

If necessary, a hole can be dug for the screw-in anchor to the proper installed depth, the anchor placed in the hole, and the hole back-filled. The earth must be tamped onto the anchor hard while back filling. The holding power of an anchor placed this way will not be as great as an anchor screwed into undisturbed soil. If in doubt, get professional advice on whether this option will work for your site.

\section{Installing Arrowhead Anchors}

Arrowhead anchors are designed for all soils but are especially effective in rocky soils. The arrowhead anchor is driven into the soil with a drive rod. The rod is removed and the anchor is left in the ground. Then the anchor must be pre-tensioned which will cause the anchor to rotate in the ground and develop its full holding potential.

Like screw-in anchors, the arrowhead anchor must be placed so the force from the guy wires pulls directly on the anchor. Drive the arrowhead anchor away from the tower at an angle into the ground. Refer to the appropriate stamped drawing in the Appendix to determine the angle of the tower guys from the ground.

Note: It is important to drive the anchor at an angle. If the anchor is incorrectly installed straight into the ground, the load will result in the anchor cable cutting through the ground until the angle is correct, resulting in significant slack in the tower guys, and possible tower failure. 


\section{Figure 10: Installing Arrowhead Anchors}

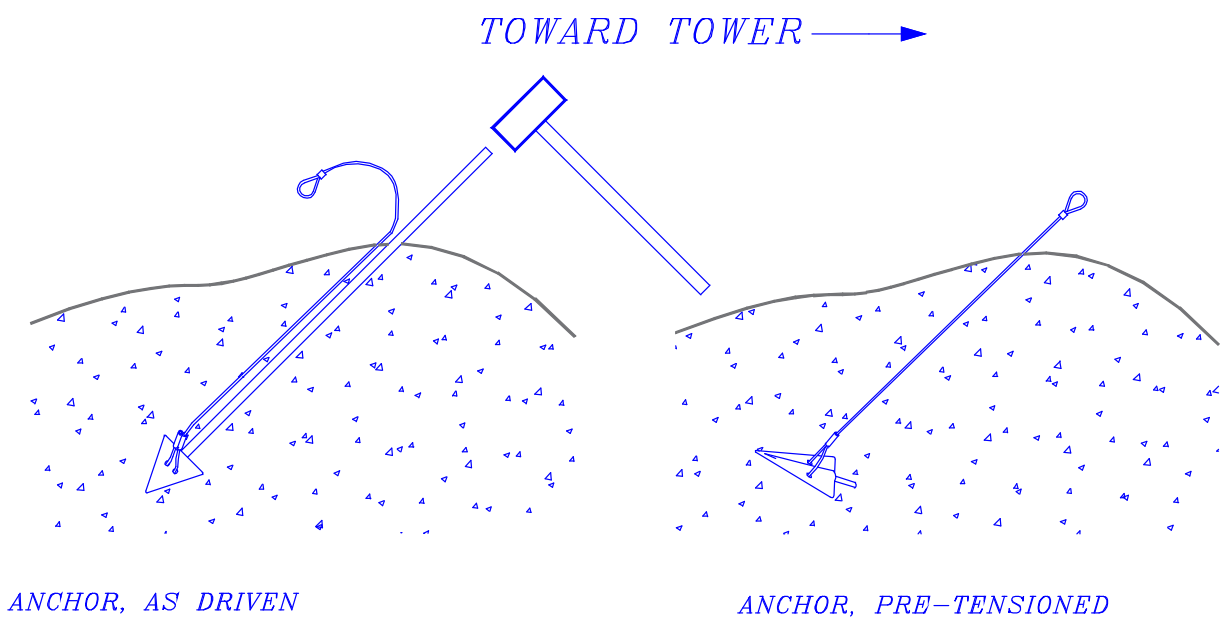

To install the anchor, place the drive rod over the anchor's shank. Drive the anchor into the soil using a sledgehammer, fence post driver, or power jackhammer, until the cable eye attached to the anchor is $50 \mathrm{~mm}(2$ inches) to $100 \mathrm{~mm}$ (4 inches) above the surface of the ground.

After the anchor is driven, remove the drive rod, leaving the anchor in the ground. The anchor must now be pretensioned by applying strain to the cable. This can be done using a lever, come-along, jack, or winch. Pretensioning causes the anchor to rotate in the ground and develop its full holding power. The pull distance will be approximately the length of the anchor head, $203 \mathrm{~mm}$ (8 inches). The tension should become significantly higher as the pre-tensioning is complete.

Note: The anchor must be properly pre-tensioned before attaching the tower guys. If it is not, the tower guy wire tension will turn the anchor later, resulting in significant slack in the guy wires and possible tower failure.

\section{Installing Rock Anchors}

Rock anchors are used when anchoring to either bare rock or thin soils with solid rock near the surface. Like any anchor, rock anchors must be placed so the force from the guy wires pulls directly on the anchor. Drill the hole for the anchor away from the tower at an angle into the ground.

Note: It is important to install the anchor at an angle, so the eye of the anchor is toward the tower and the expanding part of the anchor points away from the tower. If the anchor is incorrectly installed straight into the ground, the load will bend the rod and pull it through the ground, allowing the guys to go slack. Refer to the appropriate stamped drawing in the Appendix to determine the angle of the tower guys from the ground.

To install the anchor, a hole must be pre-drilled in the rock by hand or power tool. The hole must be $50 \mathrm{~mm}(2$ inches) in diameter, and the walls of the hole should be smooth in the area that the anchor will wedge. Place the anchor in the hole. Using a bar through the eye of the anchor, turn clockwise to tighten. The anchor will expand and wedge into the hole.

After placing the anchor, fill the hole around the rod with expanding cement grout. One brand is "Rockite" made by Hartline Products Co, Cleveland, OH, USA (telephone: +216 291 2303). Always grout rock anchors to prevent water from collecting and freezing in the drilled hole. Grouting also increases the anchor's holding strength. 


\section{Appendix C: Site Visit Procedures}

\section{Site Checklist}

When making a site visit, check the following:

- Make sure the tower is straight. Stand at the base of the tower and look up to identify any bowed sections or curves in the tower that may have developed since the tower installation. Carefully adjust guy wires as necessary to straighten the tower.

- Check guy wires for excessive slack and adjust as necessary. It is normal for guy wires to stretch over time, and it is especially important to adjust them before they are subjected to icing or high winds.

- Check each anchor for movement or loosening. A loose anchor can also cause excessive slack in guy wires.

- Check that mounting booms, cellular antennas, temperature sensors, etc. are securely attached.

- Confirm that all grounding connections on the tower and on the logger are secure and haven't corroded.

- Check instantaneous sensor readings on each channel of your data logger. Any sensor providing erroneous readings should be disconnected from the logger and tested independently and/or replaced. It is a good idea to always have spare sensors, memory cards, batteries, and a spare data logger!

- Change the data logger's batteries. Remember that batteries are cheap - it's better to change them prematurely rather than risk losing data! 


\section{Appendix D: Glossary}

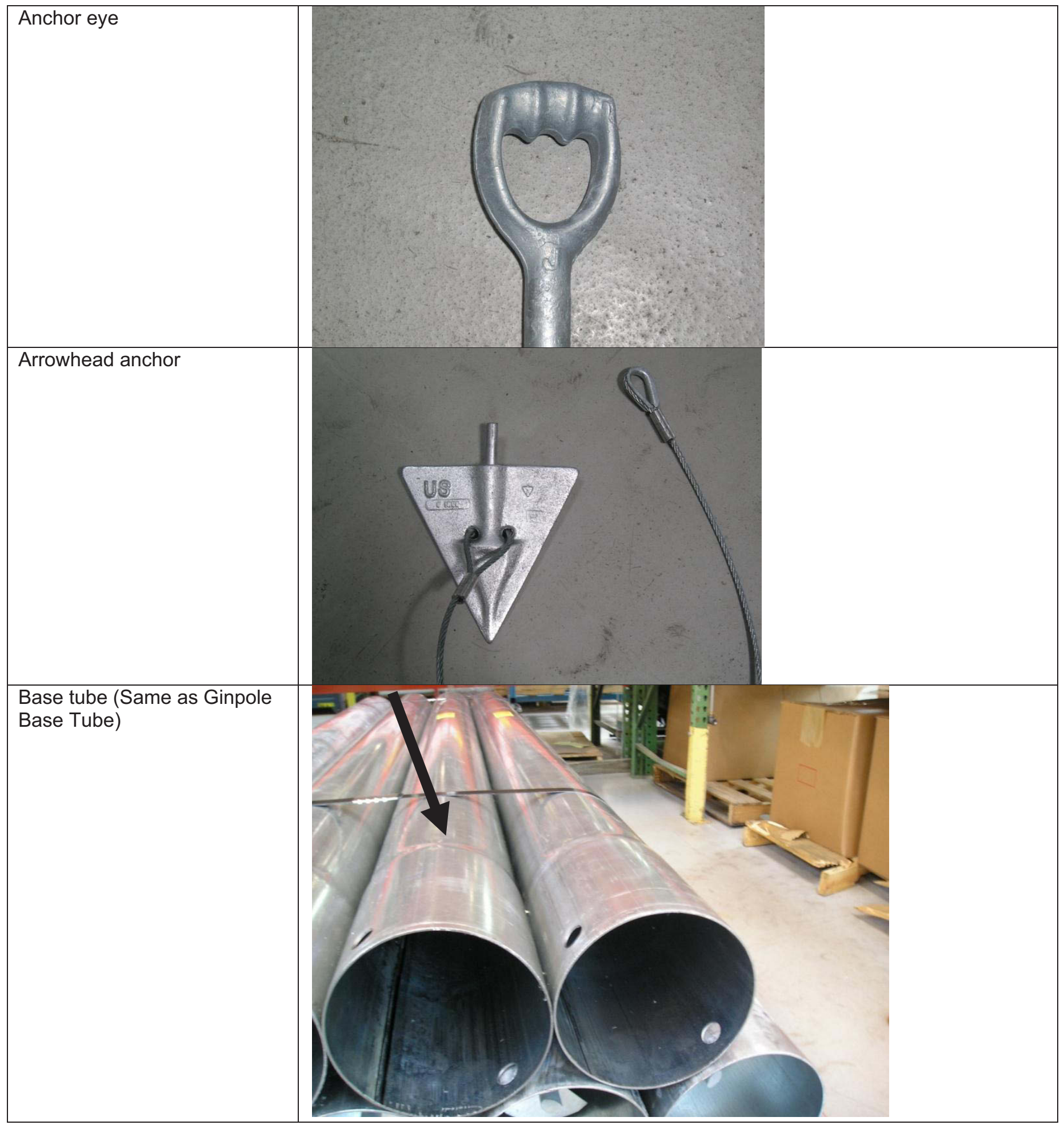




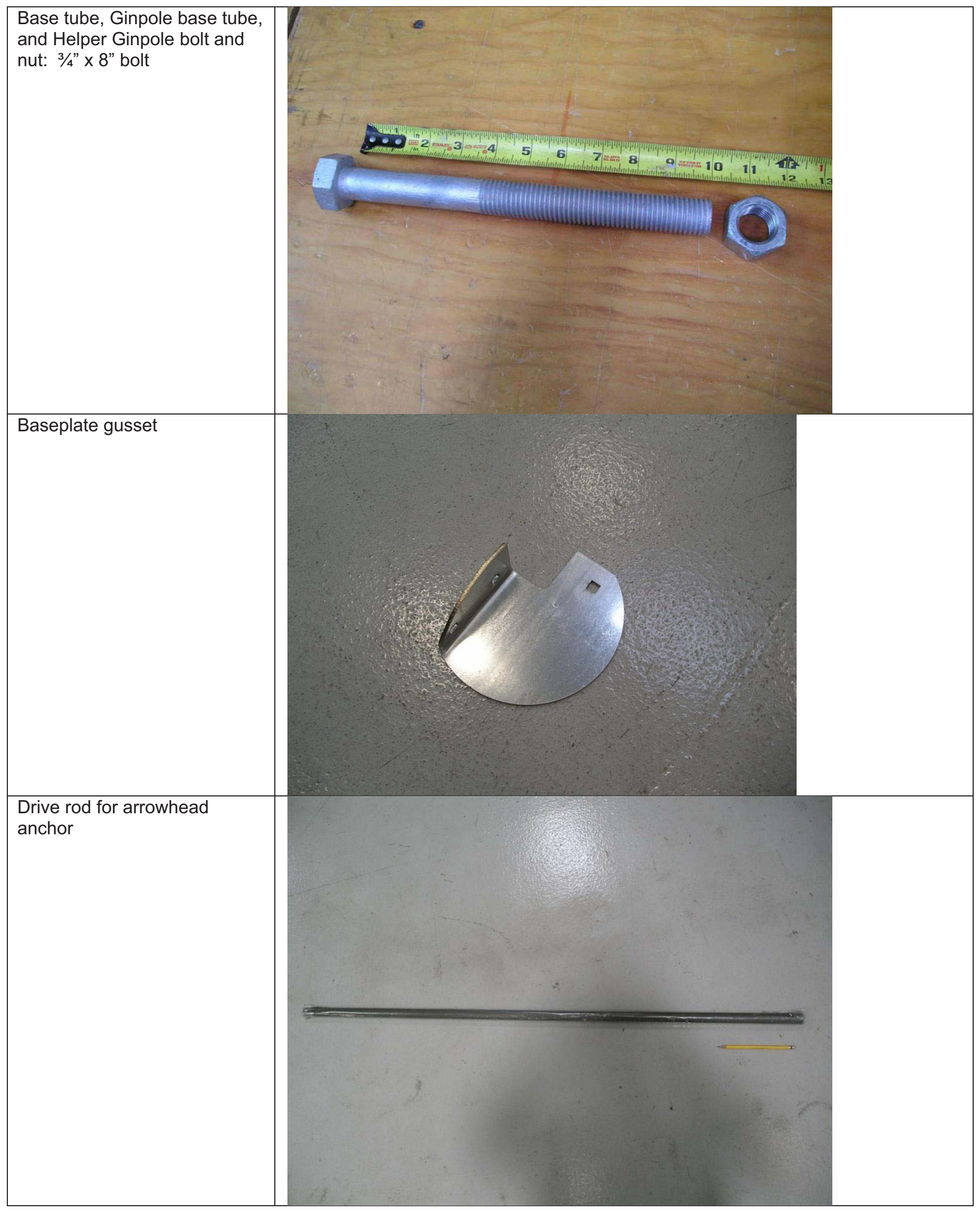




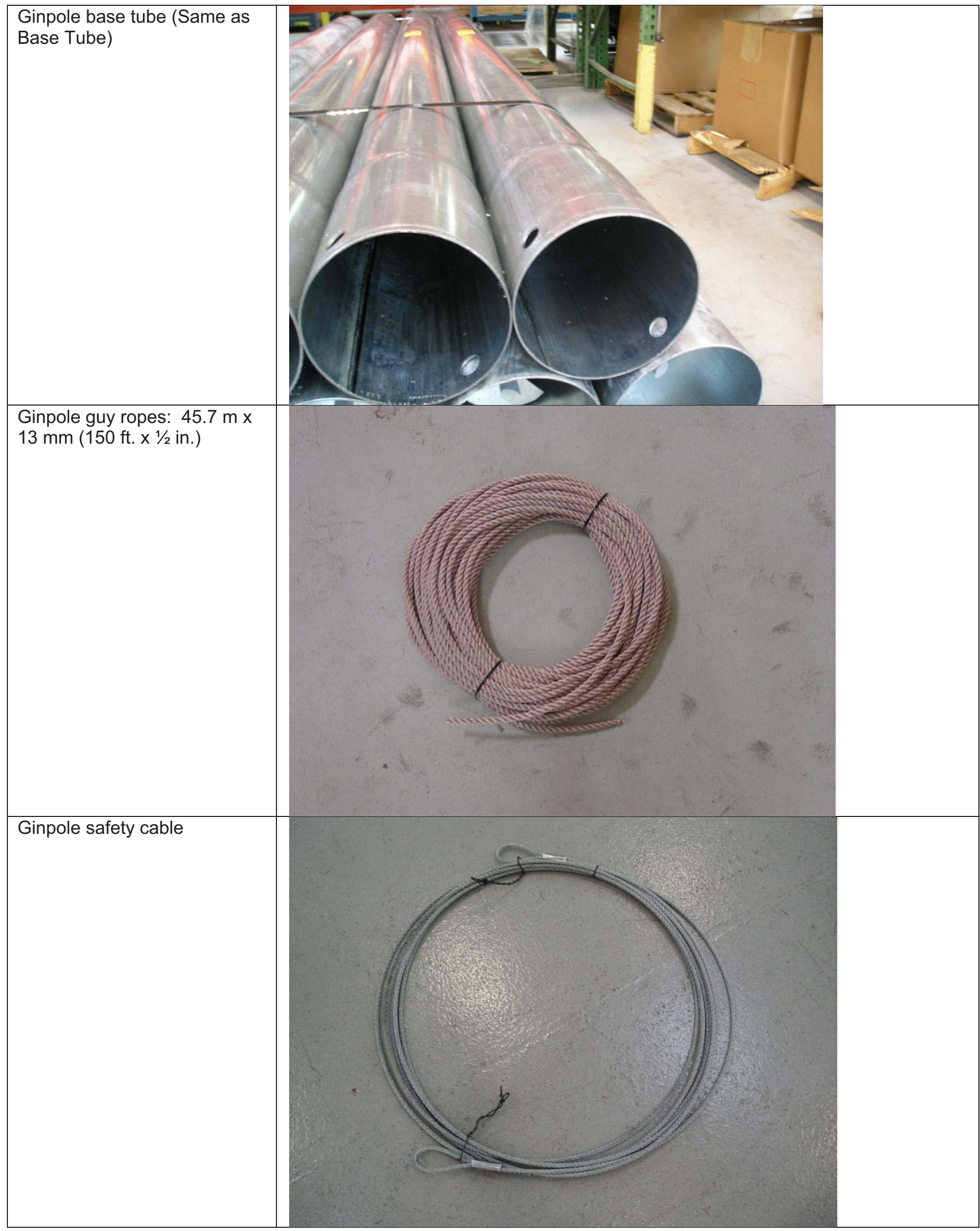




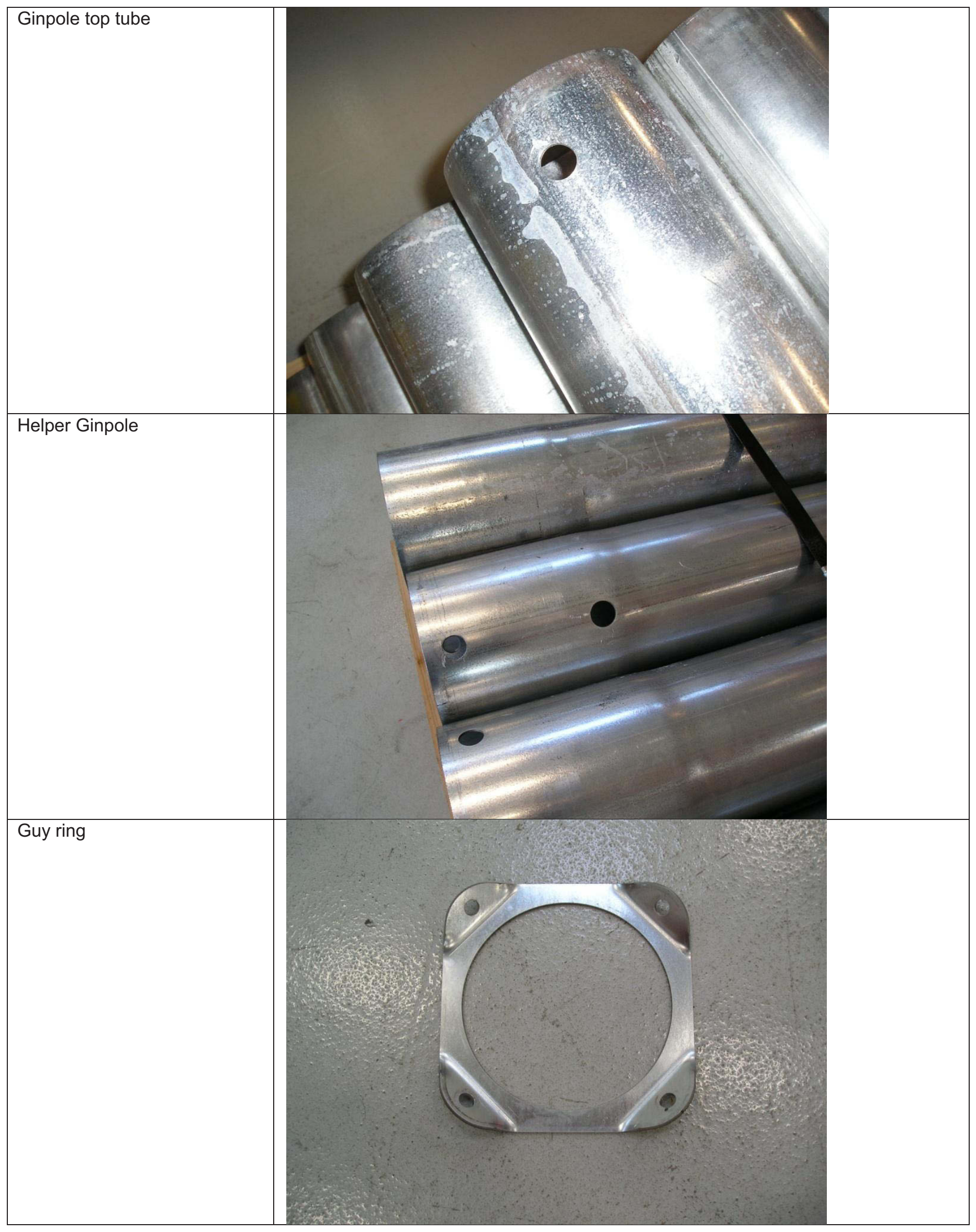




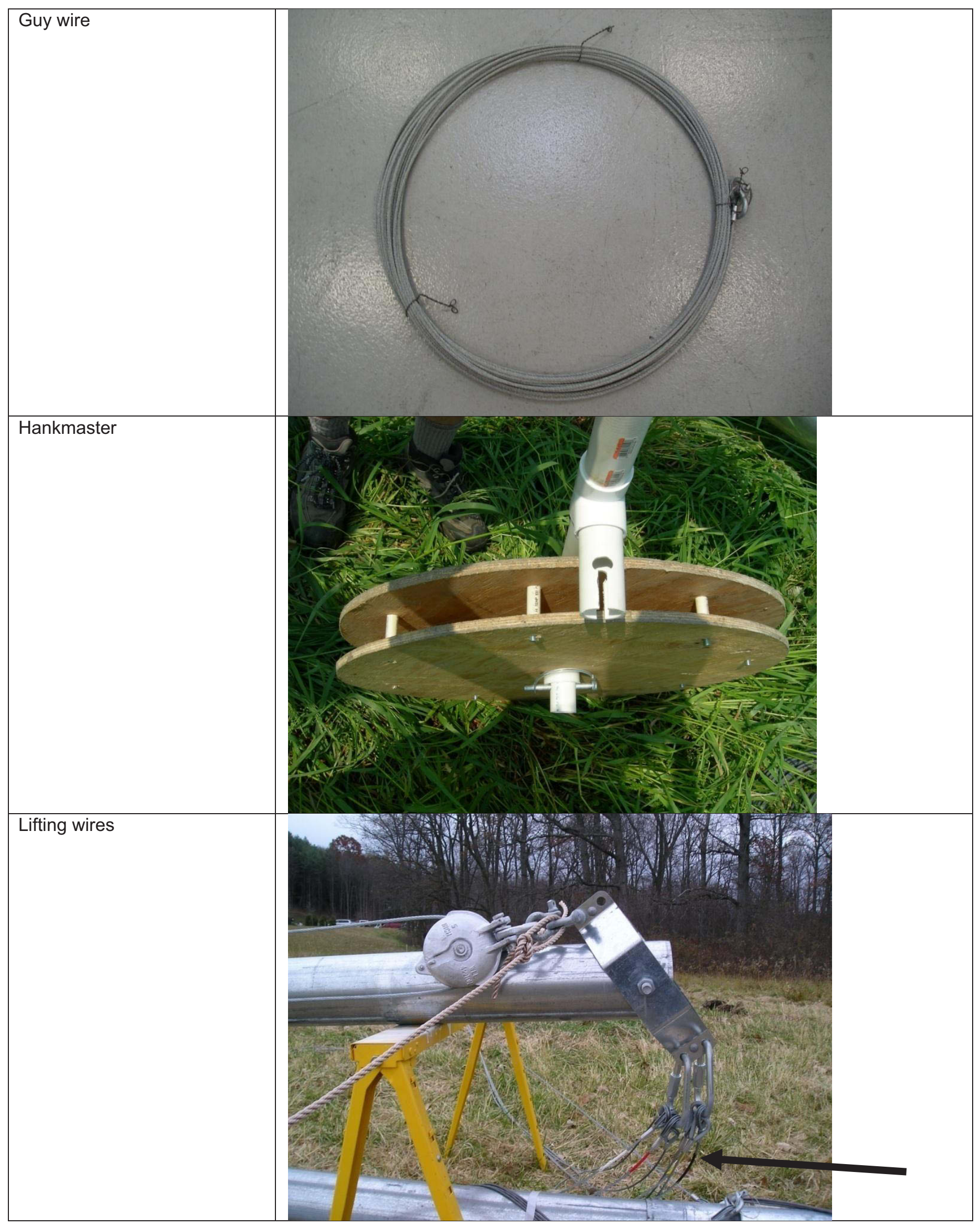




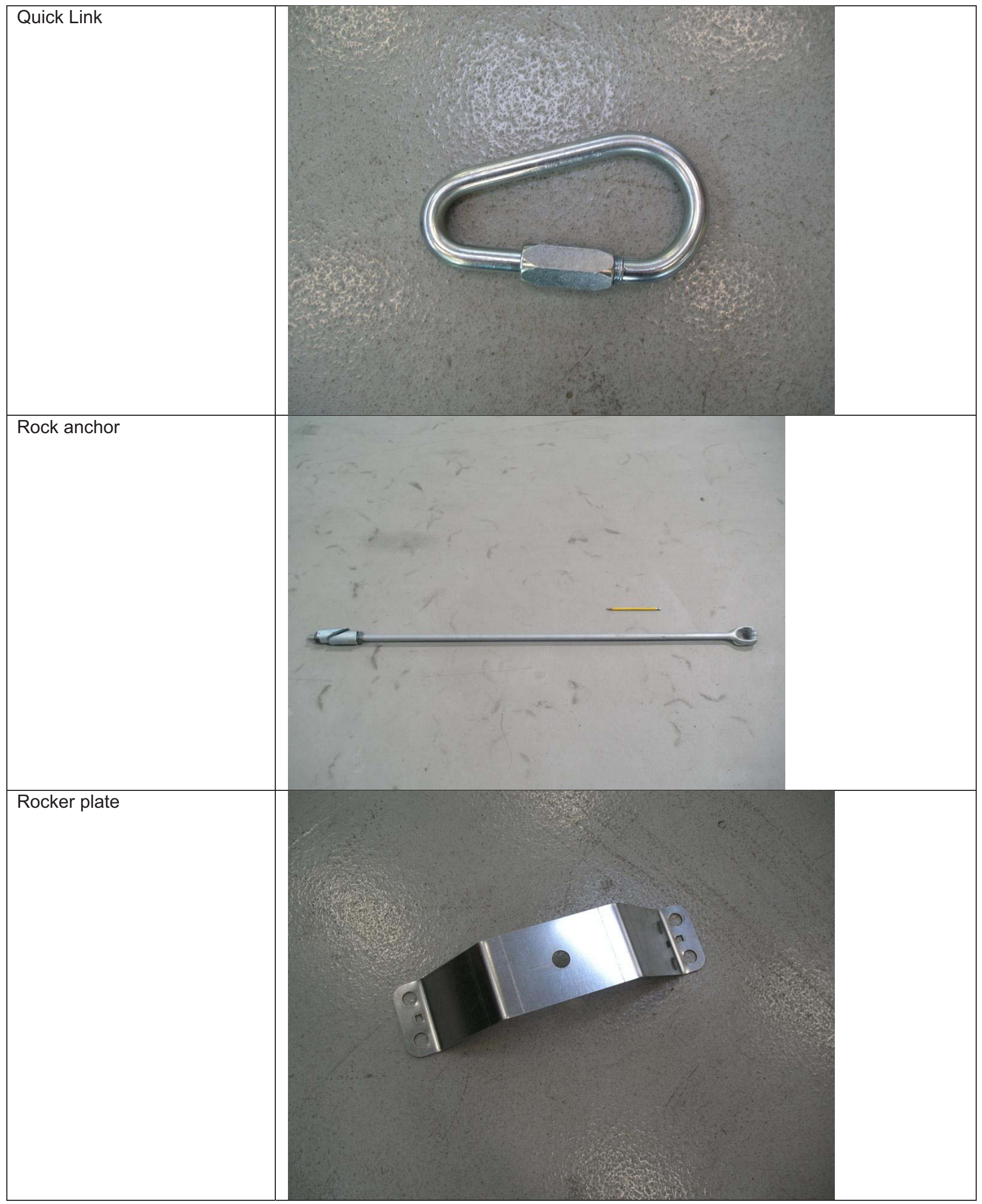




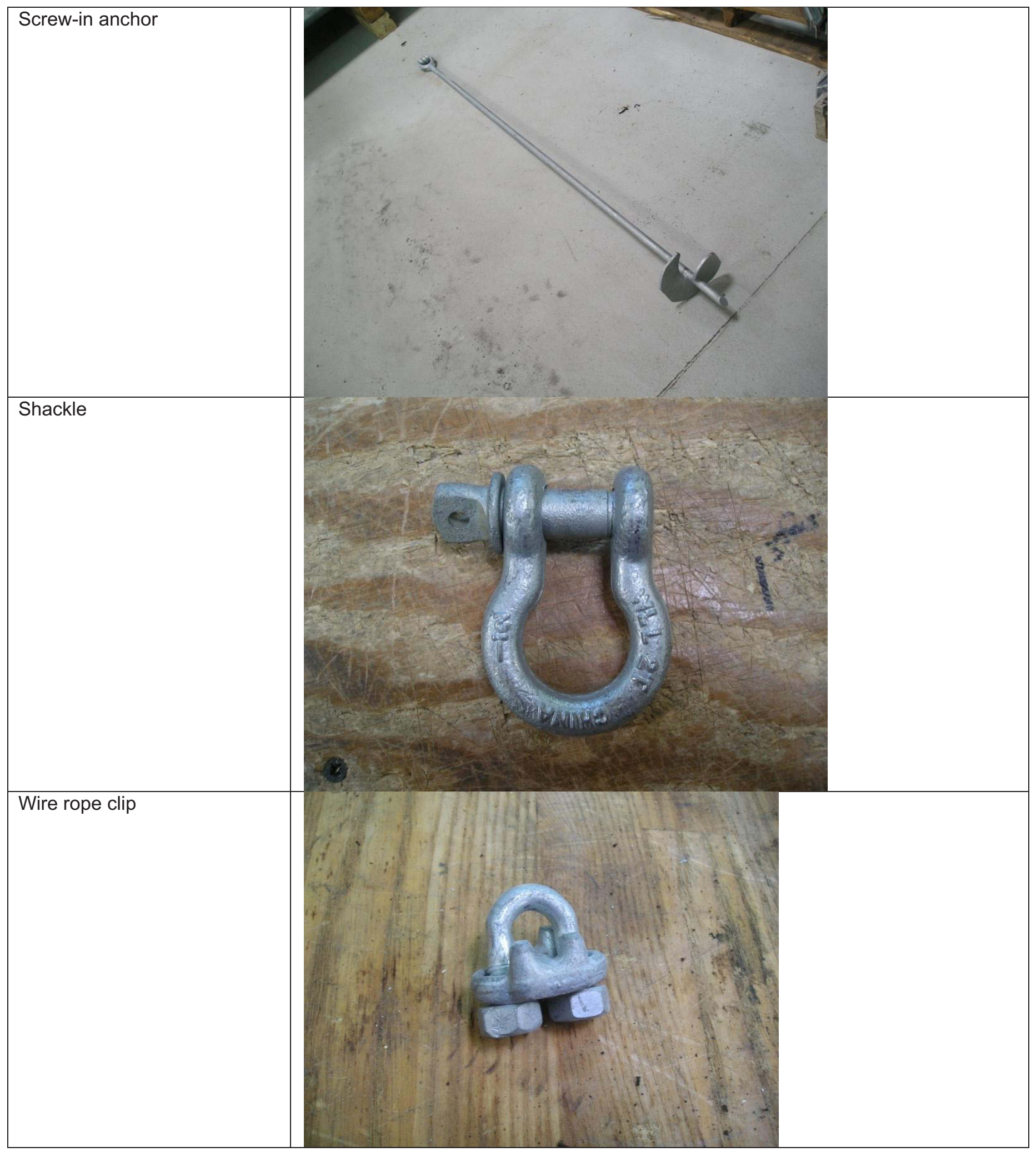




\section{Appendix E: Aligning Wind Vanes}

\section{Introduction}

Wind Vanes measure wind direction relative to the orientation of the fixed base on the sensor. This Application Note gives you the information you need to orient your wind vanes correctly when they are mounted to the tower. This note also includes information on using Offset and Magnetic Declination corrections when scaling your data to obtain properly scaled and oriented data.

\section{Magnetic Declination}

Since the earth's magnetic field is not uniform, the magnetic poles do not coincide with the true geographic poles. Moreover, a compass generally doesn't point to a true geographic pole; it points to a magnetic pole. This difference between a true geographic bearing and a magnetic bearing varies from location to location and is called magnetic declination. Magnetic declination or "compass variation" is the horizontal angle between true north (also called "geographic north" or "map north") and the direction the compass points, magnetic north.

Magnetic declination is measured as the number of degrees of error a compass shows at a site. The declination for sites located east of the magnetic north pole is expressed as the number of degrees that magnetic north is west of true north. The declination for sites located west of the magnetic north pole is expressed as the number of degrees that magnetic north is east of true north. For example, Vermont (USA) has a magnetic declination of 15 degrees west. In other words, magnetic north in Vermont is 15 degrees to the west of true north. Magnetic north in Fairbanks, Alaska (USA) is about 27 degrees east of true north; therefore, its magnetic declination is 27 degrees east.

The earth's magnetic field varies slightly in position over time. Therefore, the magnetic declination at a site also varies over time. Because of this variation, it is important that you reference an up-to-date map of declination ("isogonic map") if you choose to orient your wind vanes to magnetic north. Later you can enter a correction for magnetic declination into your wind data analysis software if desired.

\section{Mounting and Aligning Wind Vanes}

Since a magnetic compass is the simplest direction reference, it is sometimes convenient to orient wind vanes in the field to magnetic north. Most NRG customers, however, align their wind vanes to true north. Before installing your NRG logger, decide whether you want wind direction data to report north when the wind is from the magnetic north or when the wind is from true north. Be sure to make note of your choice and maintain consistency among your sites and projects.

To align a wind vane to true north:

1. Use a transparent orienteering compass with a rotating bezel and magnetic declination markings. In the example in Figure 1, 15 degrees west means that the direction of the compass needle (magnetic north) lies 15 degrees west of true north. 


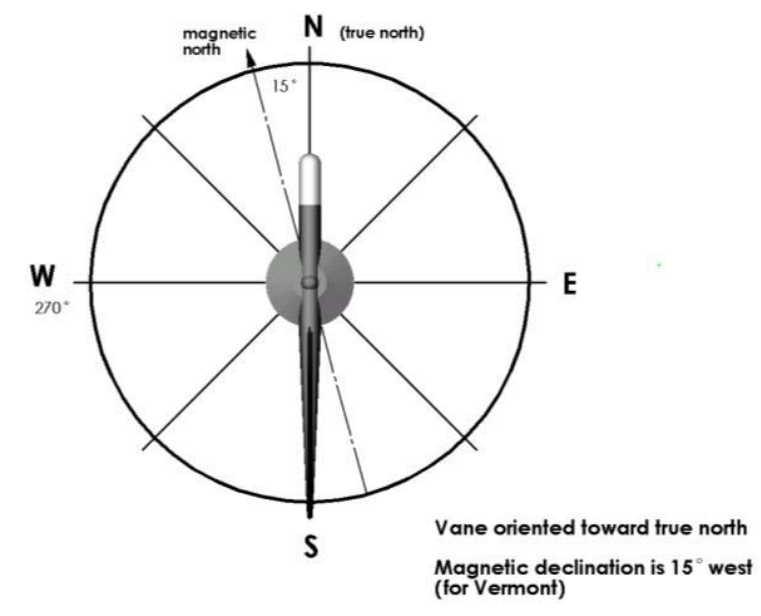

\section{Figure 1}

NOTE: Lining up the ridges on the body of the wind vane will cause the sensor to indicate a north reading. Be sure to keep this in mind when orienting the wind vane on the mounting boom.

2. Stand so that it is possible to sight along the tower from the top to the base. Align the bearing mark on the compass so that it points directly in line with the tower, top to base. The bearing of the TallTower in the example in Figure 2 is 270 degrees.

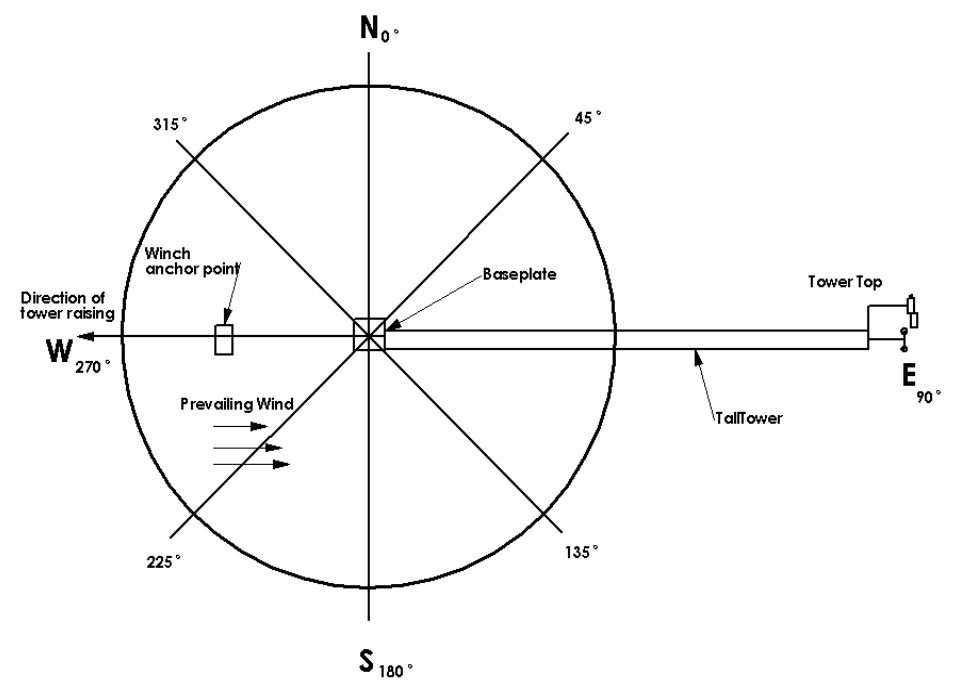

Figure 2

3. Without moving the base of the compass, rotate the bezel so the north end of the needle points to the declination mark that corresponds to local declination.

4. Loosely attach the mounting boom to the TallTower. Lift the compass to a vertical position so the bearing mark points straight up. Use a level if necessary.

5. Sight through the compass so the center of the compass is over the point where the boom contacts the tower, with the bearing mark still straight up. See Figure 3. 


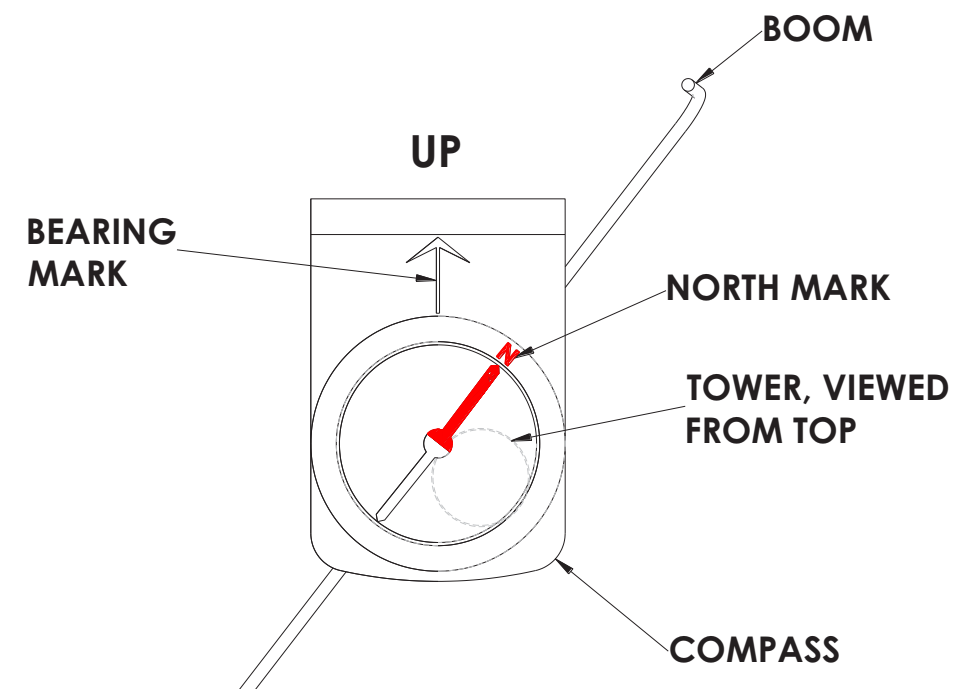

\section{Figure 3}

6. Have a crew member rotate the boom until it aligns with the north mark on the compass, and tighten the boom.

7. Attach the wind vane with the north arrow index mark on the base pointing in the same direction as the north mark on the compass. The \#200P wind direction vane is designed to mount with a cotter pin and set screw to a NRG sensor mounting boom. The cotter pin installs horizontally through drill holes in the boom and vane, allowing the base of the vane to point in one of two directions, toward the tower or away from the tower. See Figure 4.

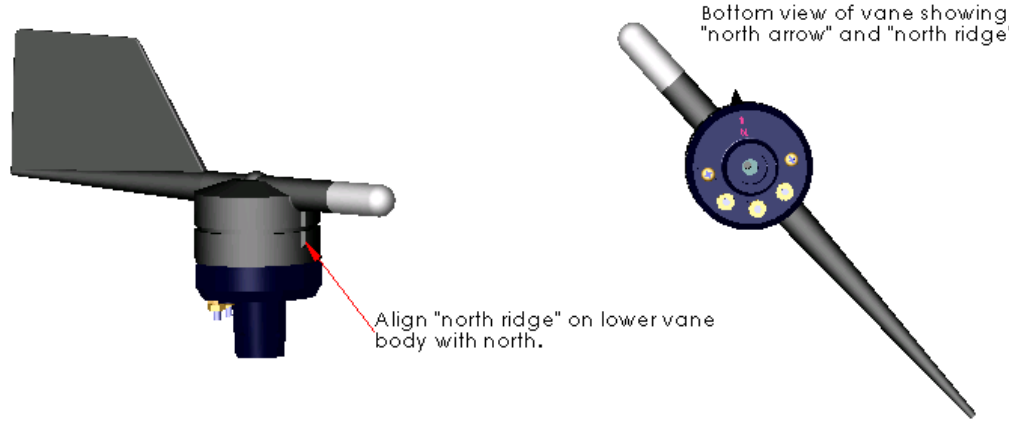

\section{Figure 4}

8. When you raise the TallTower, the north arrow on the base of the wind vane will point to true north.

9. Use the compass to verify your settings. If necessary, adjust the position of the mounting boom before raising the TallTower. 


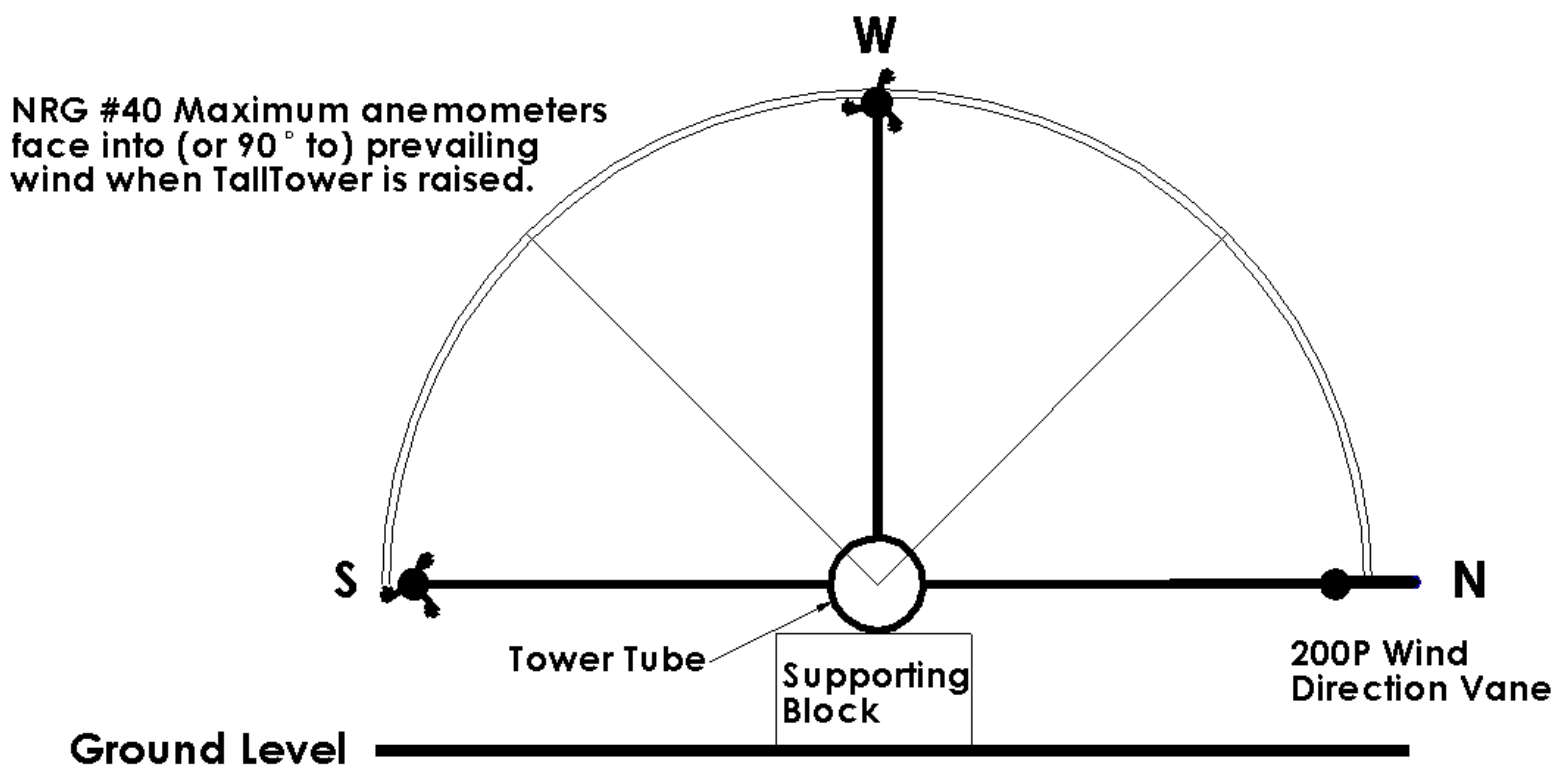

Figure 5

\section{Using Data Analysis Software to Correct for Magnetic Declination}

If you orient your wind vanes toward magnetic north but want the direction data reported relative to true north, enter the magnetic declination for the site into the offset or magnetic declination field in your wind data analysis software. NRG's BaseStation Software, for example, has a field called Mag Declin. BaseStaion applies the declination to all wind direction data for the site if the Mag Declin field is set to anything but zero. Declination is not needed if you orient your wind vanes to true north.

Note: Wind direction vanes have a small range centered around the sensor's north reading that is called the dead band and produces a zero reading. Although NRG Loggers have an algorithm that interprets north readings correctly, when the prevailing wind is from the north, it may make sense to orient the vane to a direction other than north. If you do this, compensate for the orientation by entering a value in the wind vane 'offset' field of your data analysis software. For example, if you orient your wind vane to the south (180 degrees), enter an offset of 180 for the vane.

Note: If you orient your wind vane to a magnetic bearing other than magnetic north, you need to enter values for both magnetic declination and offset in your data analysis software. Enter the site's magnetic declination so that your software can compensate for the declination; enter an offset to compensate for the orientation of the vane. If just one offset field is available in your software, such as NRG's Symphonie Data Retriever software, you will need to combine the magnetic declination value with the offset value (if wind vanes are not oriented to true north) and enter the net value. For example, if your wind vanes are oriented to the south instead of north, and your site has a magnetic declination of 15 degrees west, you would enter 165 (or -195) in the offset field. Declinations to the west of true north are subtracted from the magnetic reading, and declinations to the east of true north are added to the magnetic reading. 


\section{Appendix F: Hankmaster Tool for Unrolling Guy Wires}

The guy wire and lifter coils can be unrolled using the convenient Hankmaster tool. A Hankmaster can be built from materials available from most hardware stores using a few simple tools.

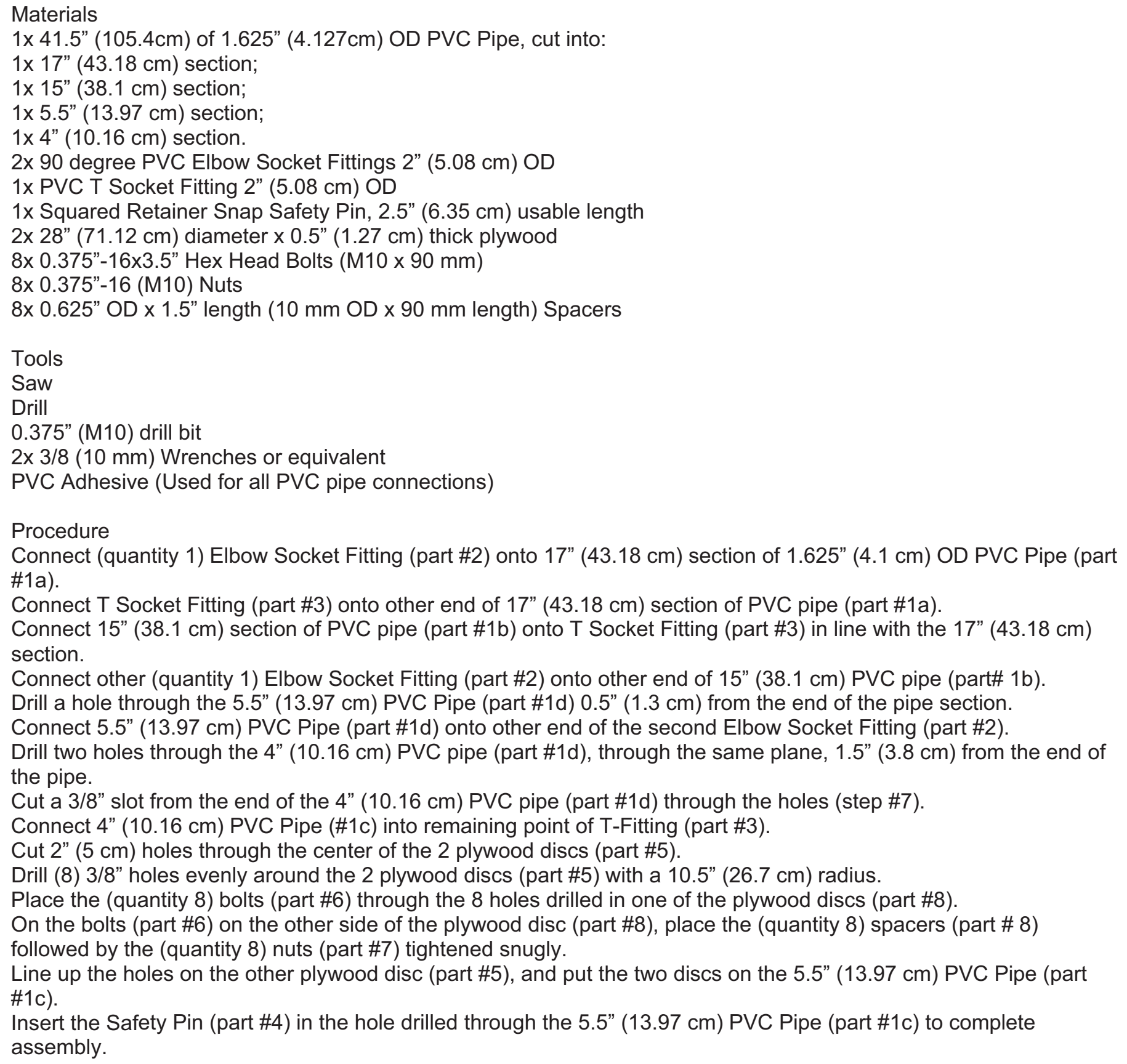




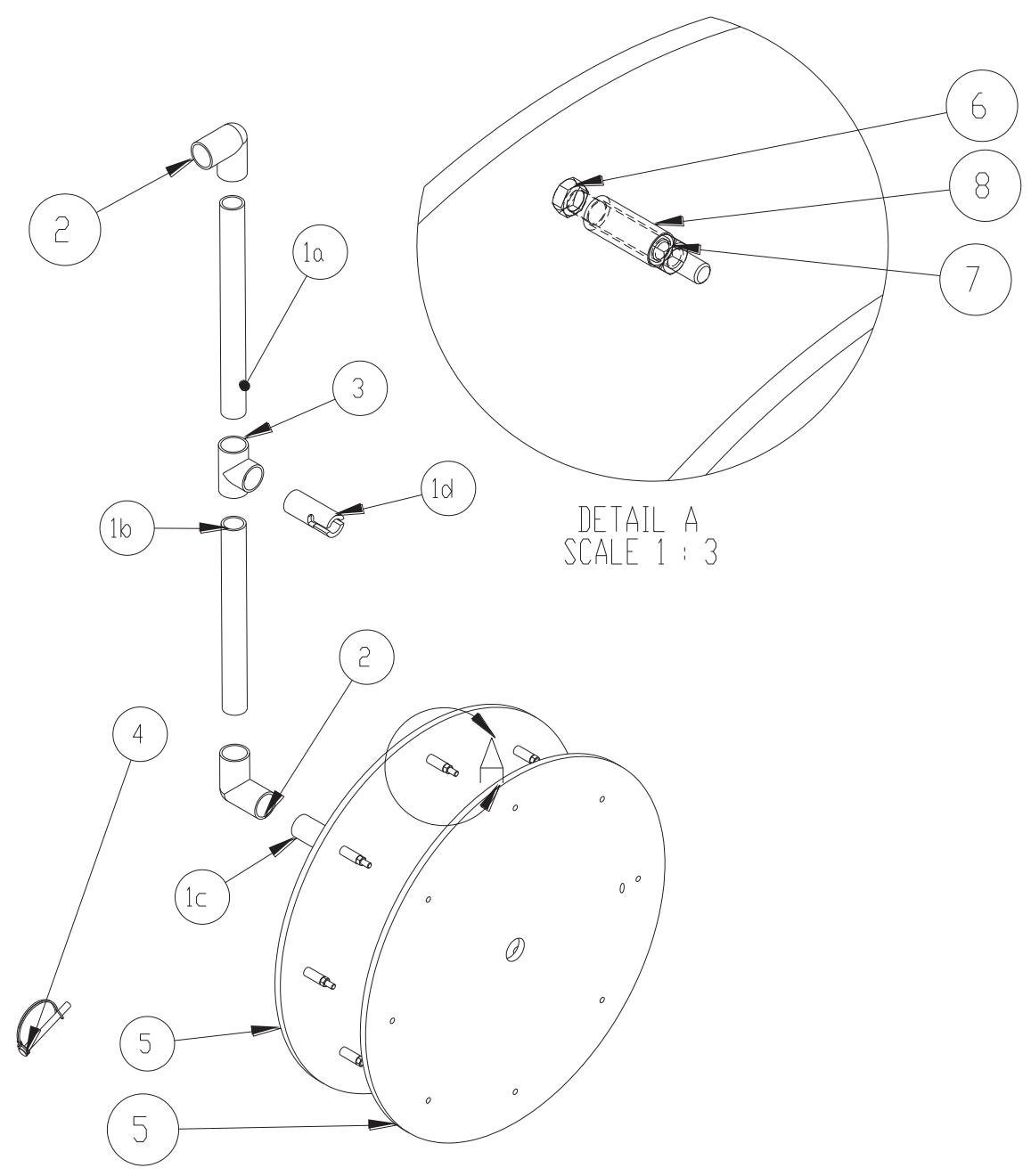

Figure 1. Completed Hankmaster $5000^{\mathrm{TM}}$

Usage

Unclip Safety Pin, remove from pipe.

Remove outer plywood disc.

Lay Hankmaster $5000^{\mathrm{TM}}$ on its side with the handle facing down.

Place coiled guy wire onto inner disc, around the 8 bolts.

DO NOT UNCLIP GUY WIRE COIL UNTIL YOU HAVE FINISHED ROLLING IT OUT TO THE ANCHOR.

Roll Hankmaster $5000^{\mathrm{TM}}$ to appropriate Guy Ring of tower.

Unclip guy wire coil; attach clip to guy ring.

Unroll guy wire coil to the appropriate anchor.

To re-coil a guy wire, simply thread guy wire through the angled hole in the outer plywood disc, and roll Hankmaster $5000^{\mathrm{TM}}$ over guy wire.

While rolling, guide guy wire through the wire guide above the plywood discs.

When coiling is complete, use a rubber band to hold the coil and prevent unspooling.

Lay Hankmaster $5000^{\mathrm{TM}}$ on its side with the handle facing down.

Remove coiled guy wire. 


\section{Index}

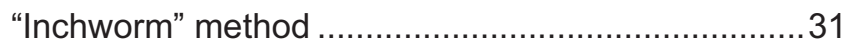

alternative anchoring .............................................. 48

anchor placement.........................................15, 49

anchor radii .......................................................... 14

anchor requirements ....................................... 45

anchoring......... 6, 8, 14, 15, 35, 45, 47, 48, 49, 50, 51

Anchoring Guidelines ........................................ 45

anchoring in solid rock .......................................... 48

anchoring the baseplate ..............................17, 18

anchors........... 6, 8, 14, 15, 19, 37, 45, 46, 47, 48, 49

Anchors ........................................................ 14

arrowhead anchors ......................................47, 49

arrowhead anchors, installing .................................50

arrowhead anchors, pre-tensioning …..................... 50

base plate................................................. $8,14,15$

base tube.................................................... 20

baseplate........... 8, 14, 15, 16, 17, 19, 20, 25, 28, 34

batteries........................................................ 51

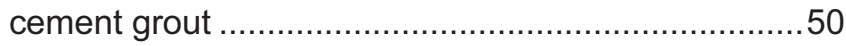

concrete anchors................................................ 45

coupler plates ...................................................26, 27

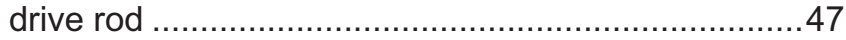

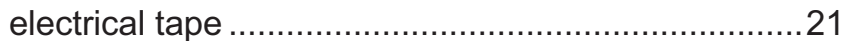

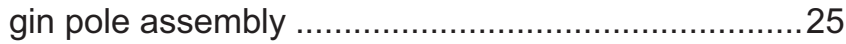

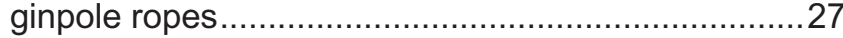

Ginpole Tilt-Up ..................................................... 30

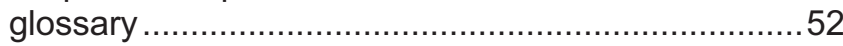

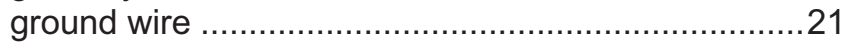

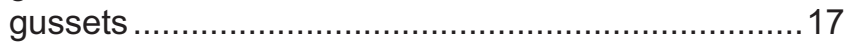

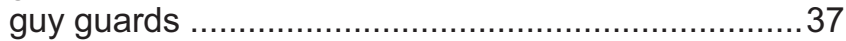

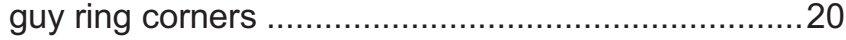

guy rings................................13, 19, 20, 22, 24, 30

guy wire tensioning .............................................. 31

guy wires ......................................................... 22

guys .................................15, 34, 36, 37, 48, 49, 50

Hankmaster ..............................9, 22, 23, 56, 63, 64

helper ginpole ........................................25, 28, 39

icing ....................................................... $37,45,51$

installing arrowhead anchors .................................. 49 installing rock anchors ........................................... 50

lifter wires................................................ 24, 28

lifters ....................................... 22, 24, 30, 34, 35

Magnetic Declination ........................................... 59

oil on tower joints ................................................... 20

pivot pipe ….......................................... 20, 25

pre-lift............................................................... 14

pre-tensioning arrowhead anchors .......................... 50

quick release pin .................................................. 20

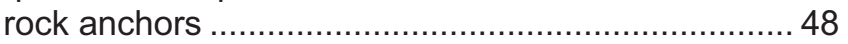

rock anchors, installing ......................................... 50

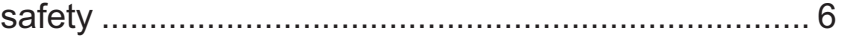

safety cable ..........................................25, 26, 54

screw-in anchors, installing .................................. 49

sensor cables....................................................... 21

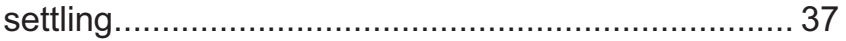

shackles ....................................................... 22, 30

Site Layout ........................................................ 14

site visit procedures ............................................. 51

site-built anchors.................................................. 45

slack in guy wires.............................. 34, 49, 50, 51

soil.................................. $6,8,45,46,47,48,49,50$

soil type........................................................ 45

straightening the tower ....................................... 36

stretch, guy wires ............................................. 37

TallTower installation on a slope .......................... 15

tension, guy wire ............................15, 31, 34, 35, 50

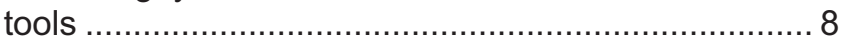

Tower Lowering ...................................................... 38

Tower Tilt-Up ..................................................... 31

transferring the lifting guys .................................. 35

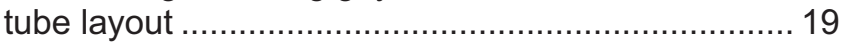

unpacking …..................................................... 11

WARNINGS ................................................. 6

winch............... 8, 9, 14, 15, 27, 34, 35, 38, 39, 50, 55

winch anchor.................................................... 14

wind vane alignment ....................................... 59

wire rope clips ..................... 8, 24, 31, 33, 34, 35, 37 

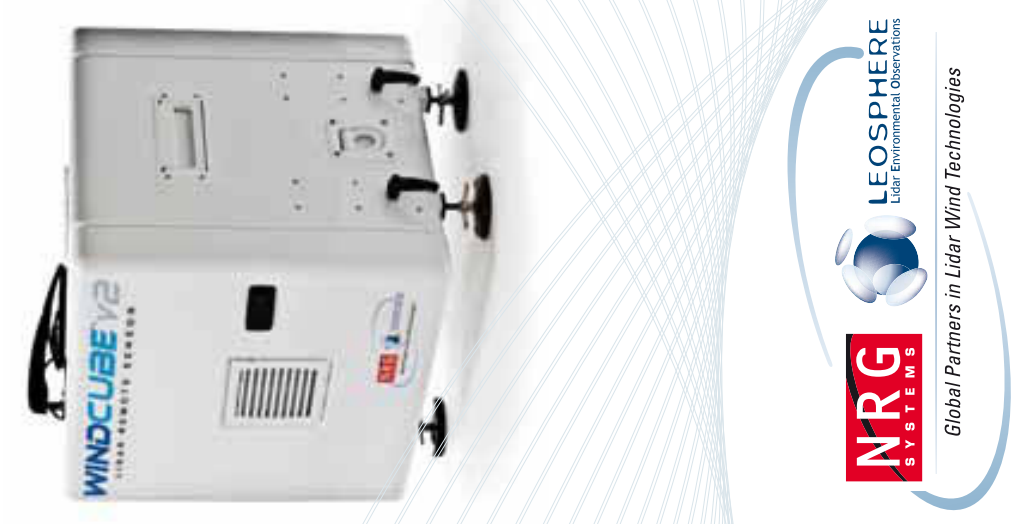

\section{y}

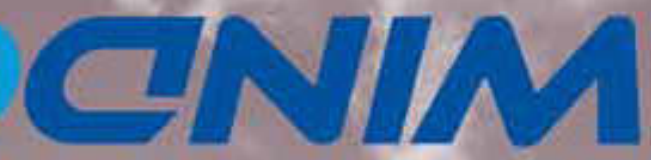



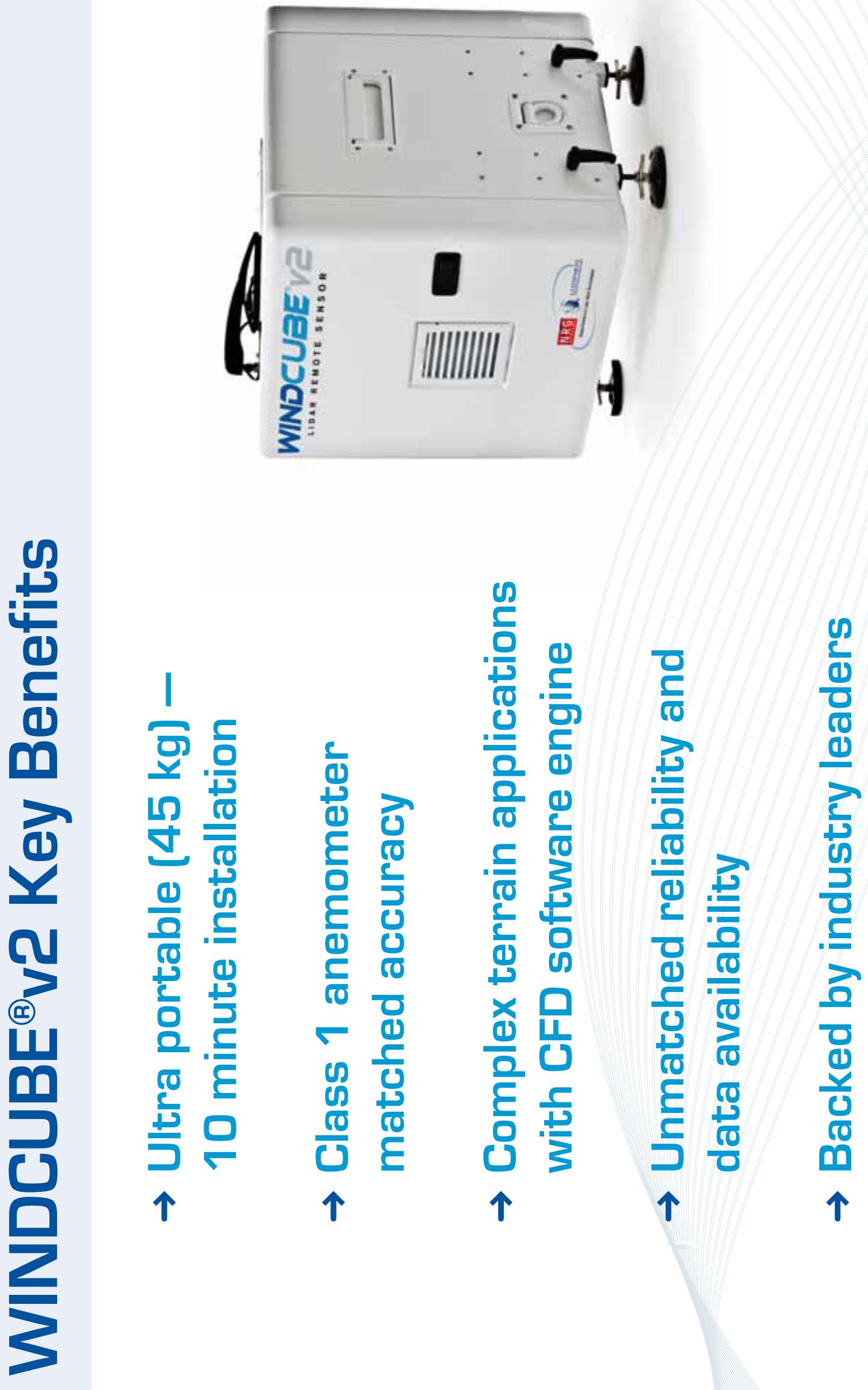


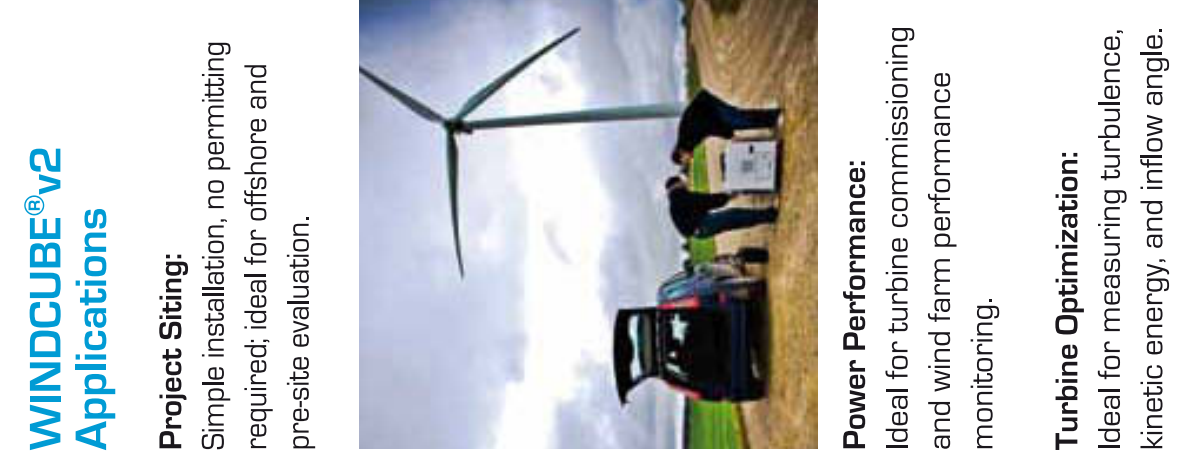

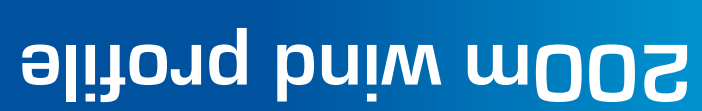

$\frac{\text { a }}{\text { 产 }}$

()

ஸ

5

(1)

c

도

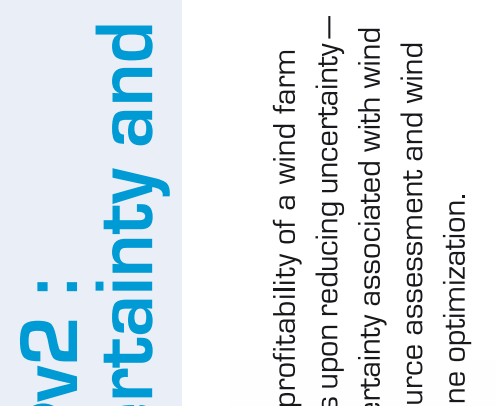

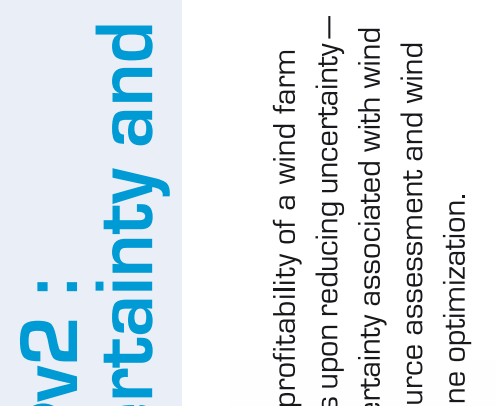

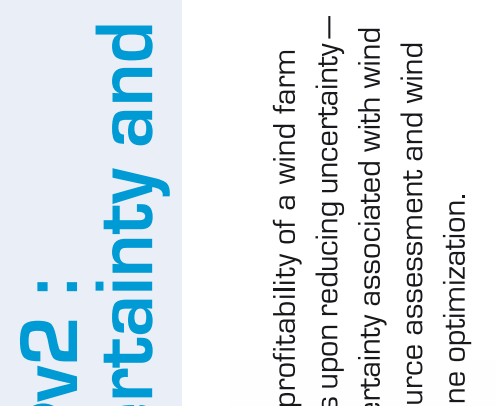

田

崩

또고ำ

U.

范

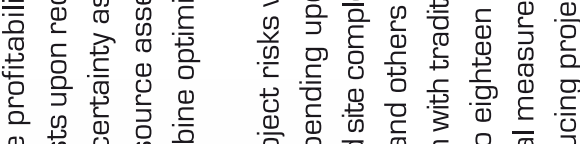

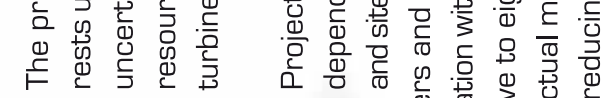

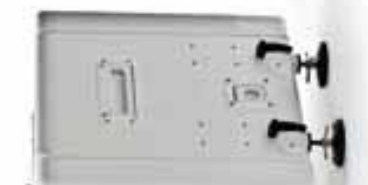

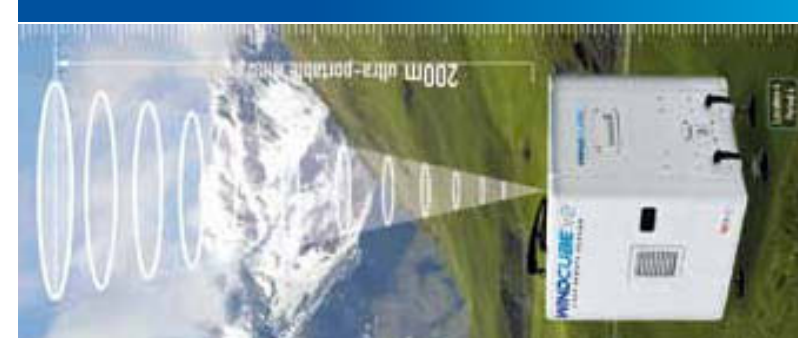

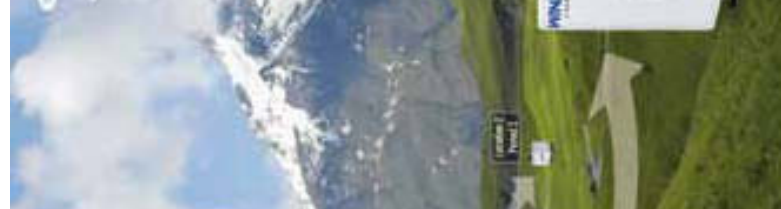

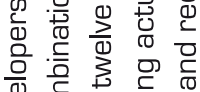

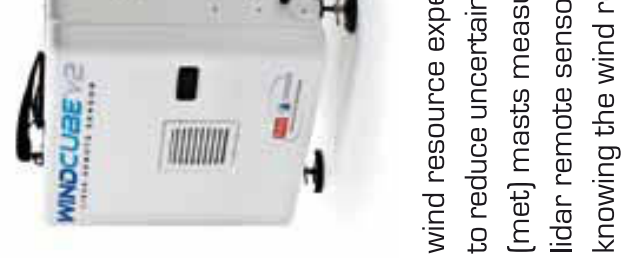
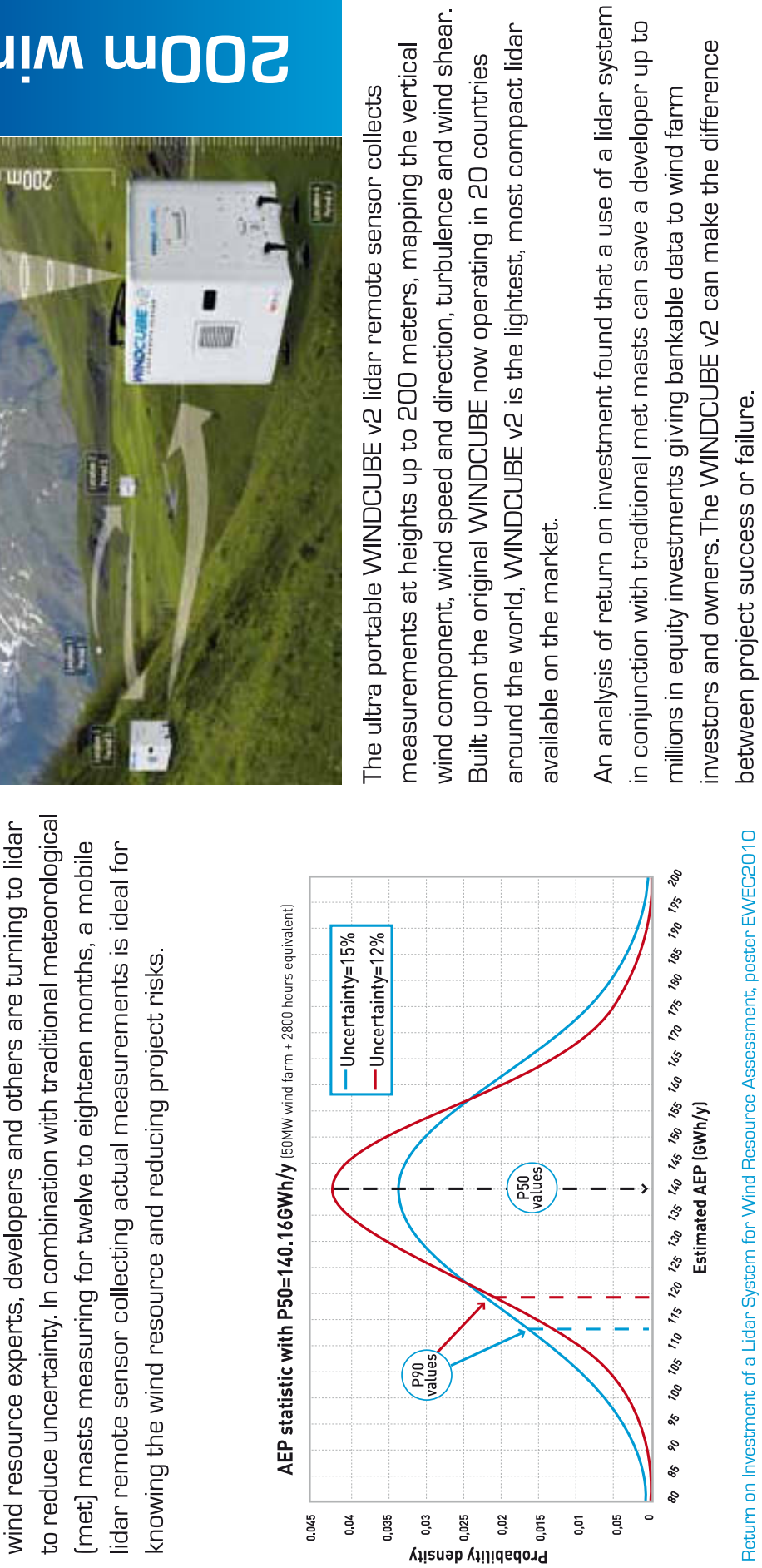

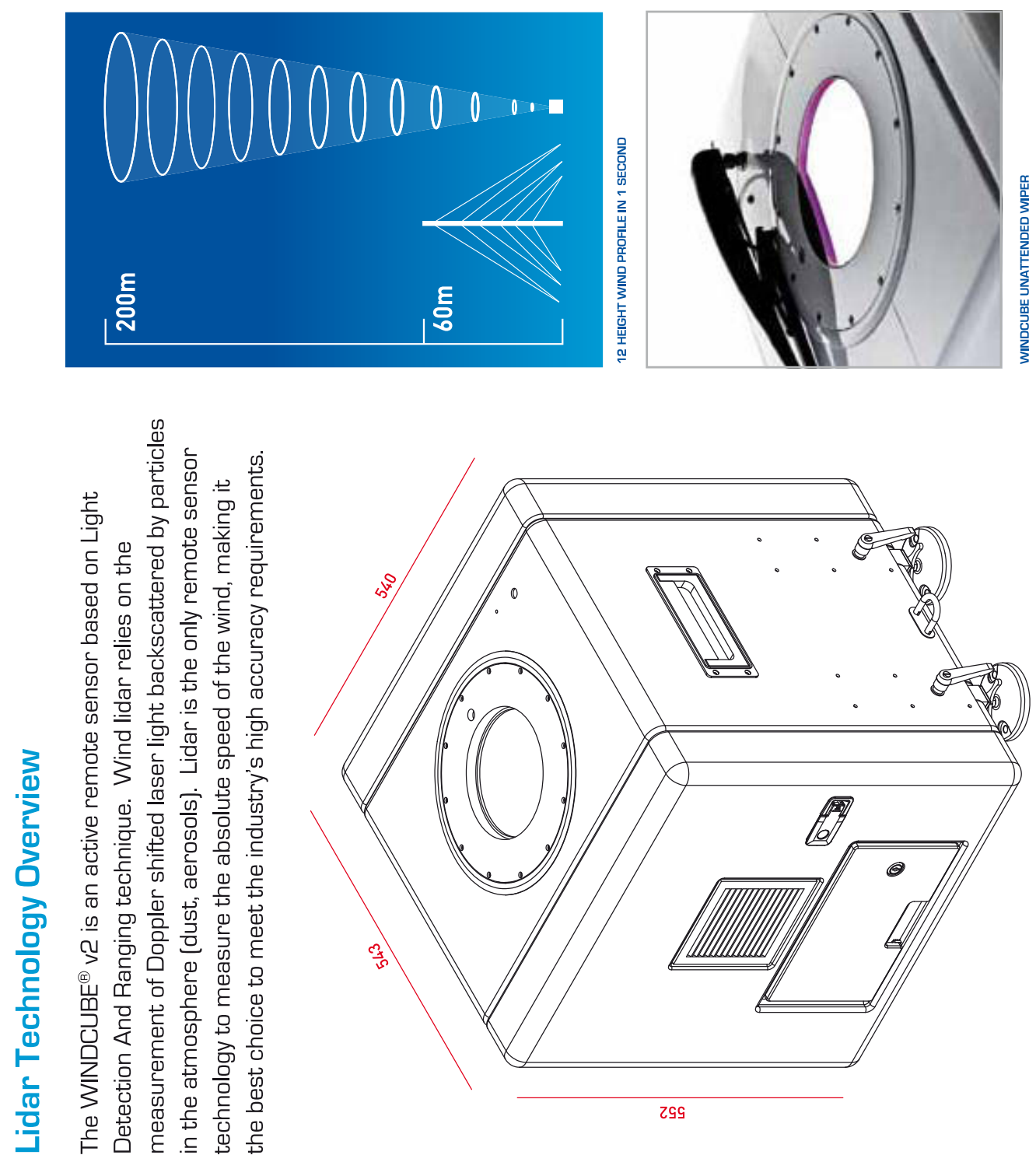

$\frac{70}{60}$
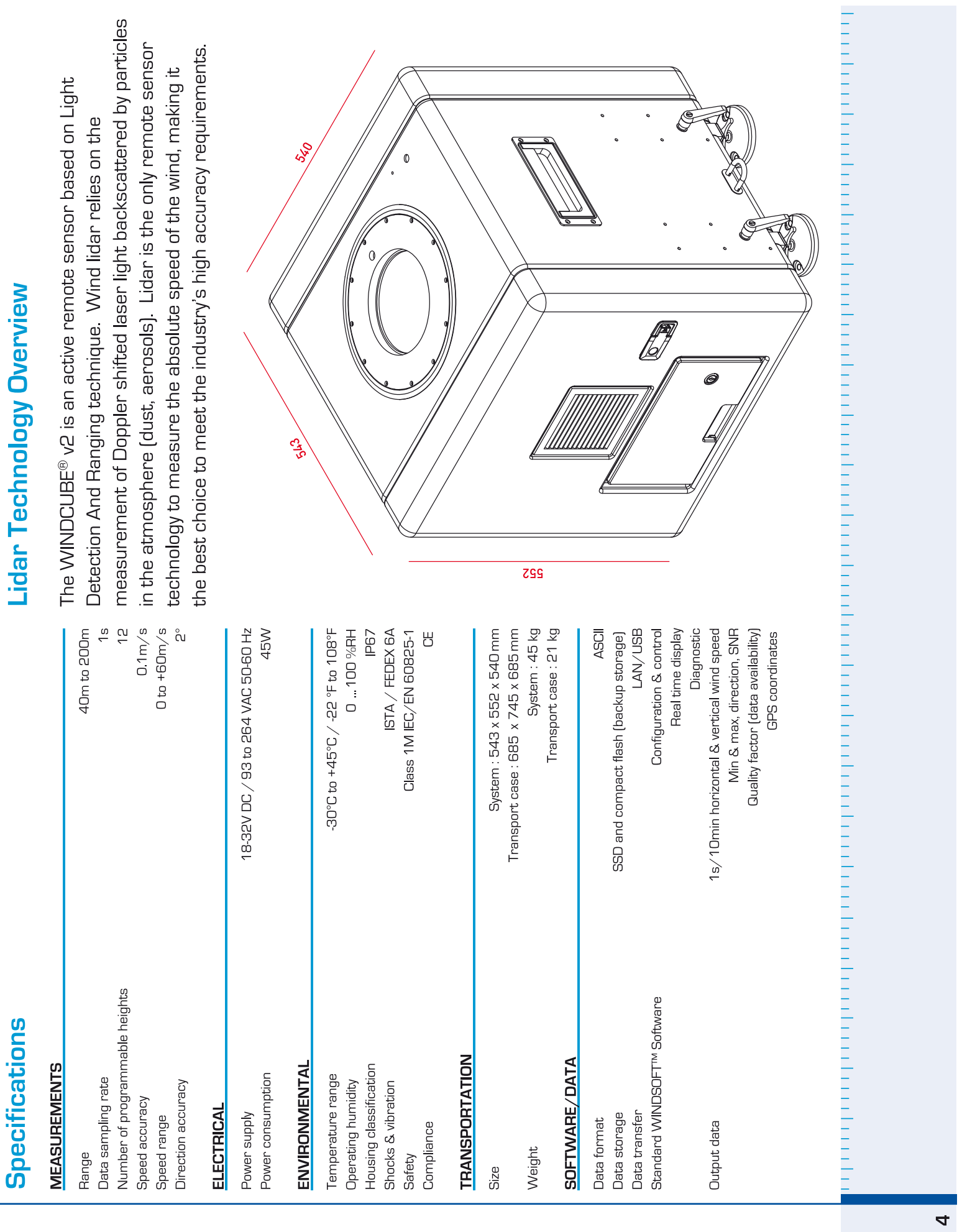


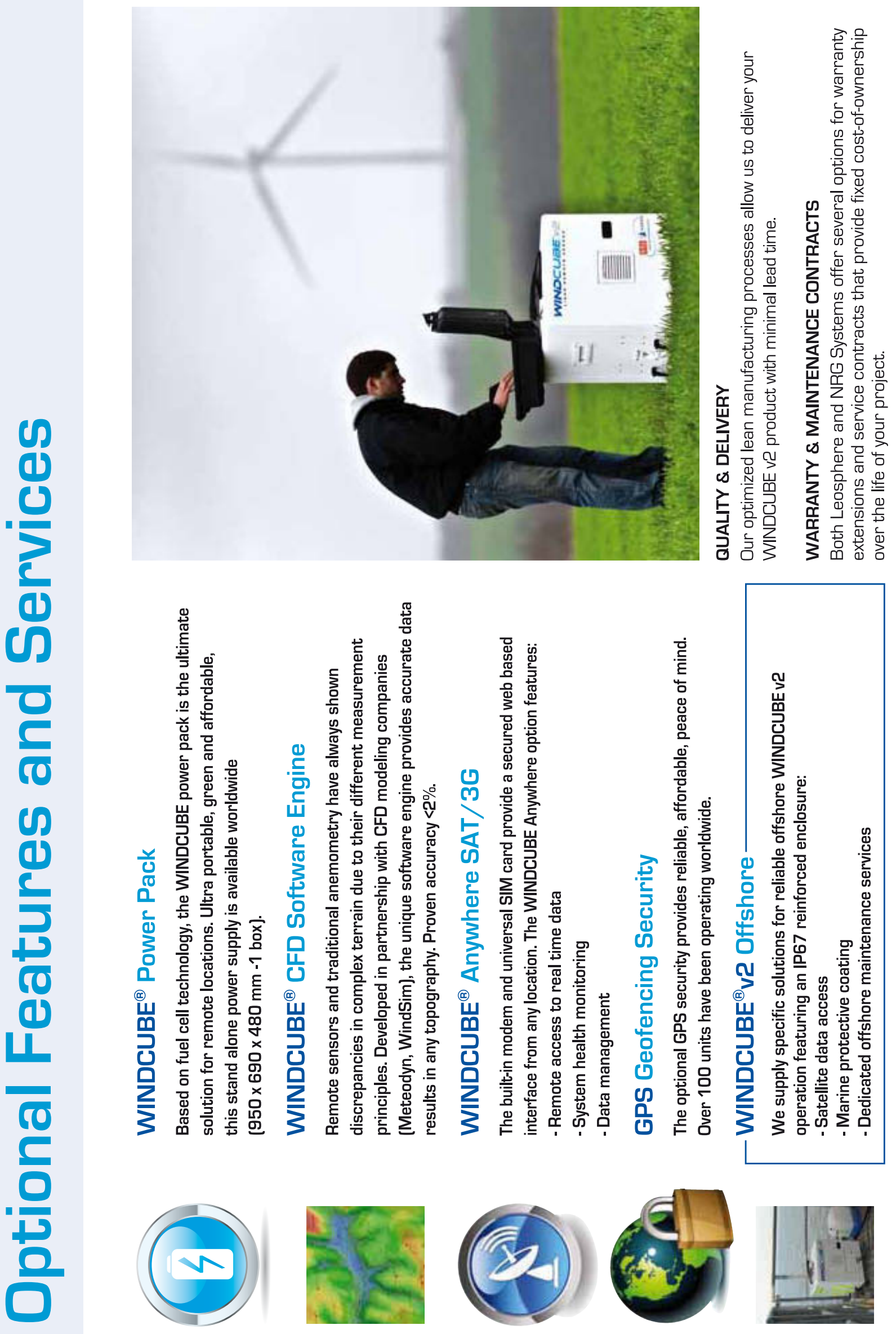




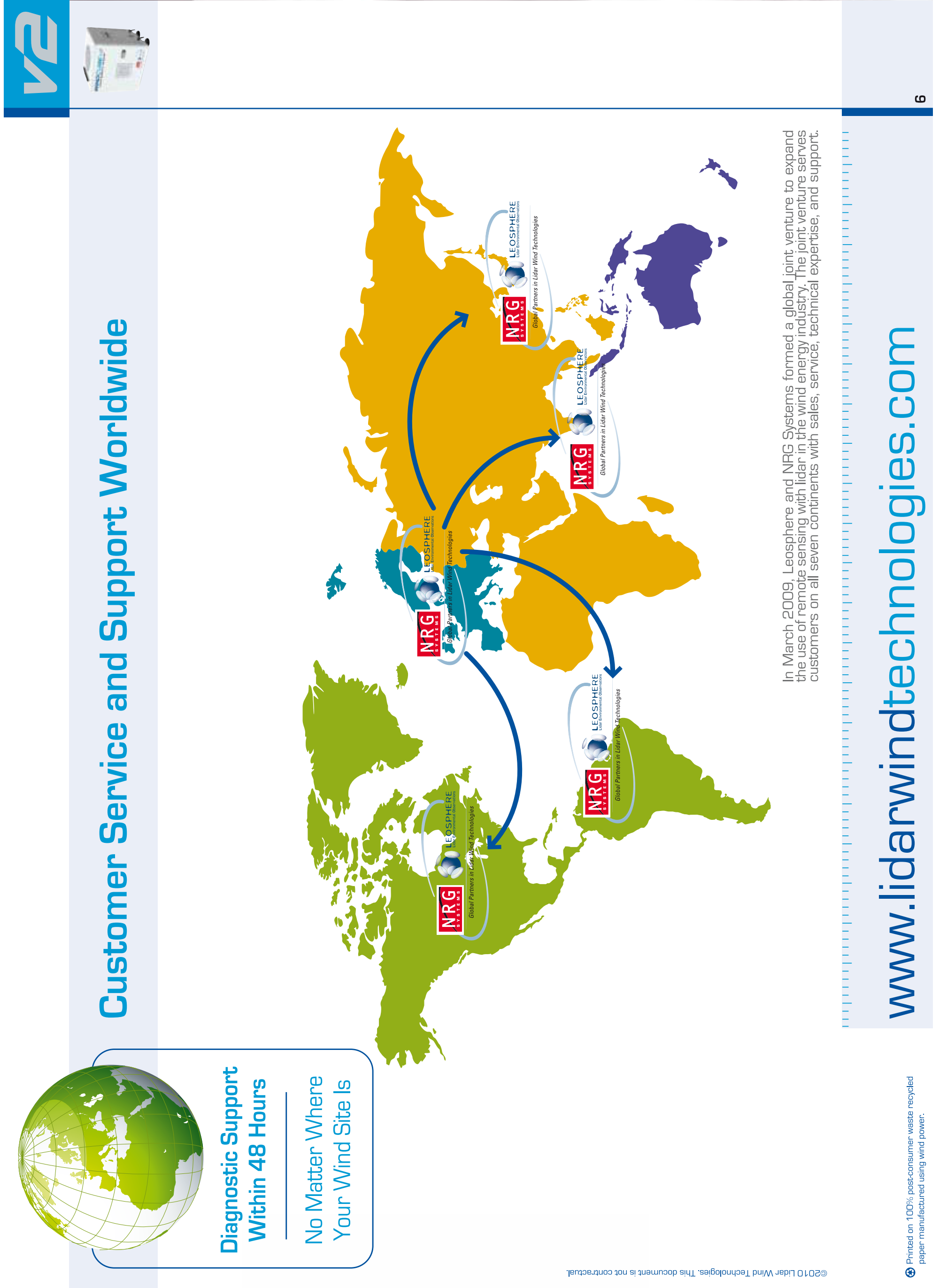




\begin{tabular}{|c|l|l|l|l|l|l|}
\hline \multicolumn{2}{|l|}{ Materials } \\
\hline \multirow{2}{*}{1} & $\begin{array}{l}\text { Outer } \\
\text { Diameter }\end{array}$ & $\begin{array}{l}\text { Wall } \\
\text { Thickness }\end{array}$ & Description & $\begin{array}{l}\text { Yeild } \\
\text { Strength }\end{array}$ & $\begin{array}{l}\text { Breaking } \\
\text { strength }\end{array}$ & Corrosion Protection \\
\hline \multirow{2}{*}{1} & 6 inch & 0.109 & MT 1015 & $50.0 \mathrm{ksi}$ & N/A & Hot Dipped Galvanized \\
\cline { 2 - 6 } & $152 \mathrm{~mm}$ & $2.8 \mathrm{~mm}$ & & $345 \mathrm{mPa}$ & & ASTM 653 \\
\hline 2 & $0.187 \mathrm{inch}$ & & $7 \times 7$ Galv & N/A & $3.7 \mathrm{kLb}$ & Galvanized \\
\cline { 2 - 6 } & $4.76 \mathrm{~mm}$ & & Aircraft & & $15.2 \mathrm{kN}$ & \\
\hline
\end{tabular}

\begin{tabular}{|r|c|c|l|}
\hline \multicolumn{4}{|c|}{ REVISIONS } \\
\hline REV & DESCRIPTION & DATE & APPROVED \\
\hline 1 & Units, notes update & $7 / 9 / 2008$ & MHW \\
\hline 2 & Reactions \& forces & $4 / 15 / 2009$ & MHW \\
\hline
\end{tabular}

\begin{tabular}{|l|l|l|}
\hline \multicolumn{3}{|l|}{ Reactions and Member Forces } \\
\hline & Imperial & $\mathrm{SI}$ \\
\hline $\begin{array}{l}10 \mathrm{~m} \text { (33 feet) wind } \\
\text { velocity (fastest mile) }\end{array}$ & $70 \mathrm{mph}$ & $31.3 \mathrm{~m} / \mathrm{s}$ \\
\hline $\begin{array}{l}\text { Top of tower wind velocity } \\
\text { (fastest mile) }\end{array}$ & $86 \mathrm{mph}$ & $38.4 \mathrm{~m} / \mathrm{s}$ \\
\hline Radial ice thickness & $0.0 \mathrm{inch}$ & $0 \mathrm{~mm}$ \\
\hline Inner guy anchor force & $1.2 \mathrm{kLb}$ & $4.4 \mathrm{kN}$ \\
\hline $\begin{array}{l}\text { Inner guy anchor force } \\
\text { (angle from horizontal) }\end{array}$ & $30^{\circ}$ & 30 \\
\hline Outer guy anchor force & $2.3 \mathrm{kLb}$ & $8.4 \mathrm{kN}$ \\
\hline $\begin{array}{l}\text { Outer guy anchor force } \\
\text { (angle from horizontal) }\end{array}$ & $49^{\circ}$ & 49 \\
\hline $\begin{array}{l}\text { Tower base force } \\
\text { (horizontal during } \\
\text { erection) }\end{array}$ & $2.2 \mathrm{kLb}$ & $8.1 \mathrm{kN}$ \\
\hline Tower base force (vertical) & $6.0 \mathrm{kLb}$ & $22.0 \mathrm{kN}$ \\
\hline Erection anchor force & $3.2 \mathrm{kLb}$ & $11.7 \mathrm{kN}$ \\
\hline $\begin{array}{l}\text { Erection anchor force } \\
\text { (angle from horizontal) }\end{array}$ & $45^{\circ}$ & 45 \\
\hline Maximum guy tension & $0.5 \mathrm{kLb}$ & $1.8 \mathrm{kN}$ \\
\hline $\begin{array}{l}\text { Maximum tower tube } \\
\text { stress (compression) }\end{array}$ & $6.1 \mathrm{ksi}$ & $42.1 \mathrm{mPa}$ \\
\hline $\begin{array}{l}\text { Maximum tower tube } \\
\text { stress (tension) }\end{array}$ & $2.5 \mathrm{ksi}$ & $17.2 \mathrm{mPa}$ \\
\hline Maximum top deflection & $11 \mathrm{inch}$ & $279 \mathrm{~mm}$ \\
\hline Initial guy tension & $0.2 \mathrm{kLb}$ & $.7 \mathrm{kN}$ \\
\hline
\end{tabular}
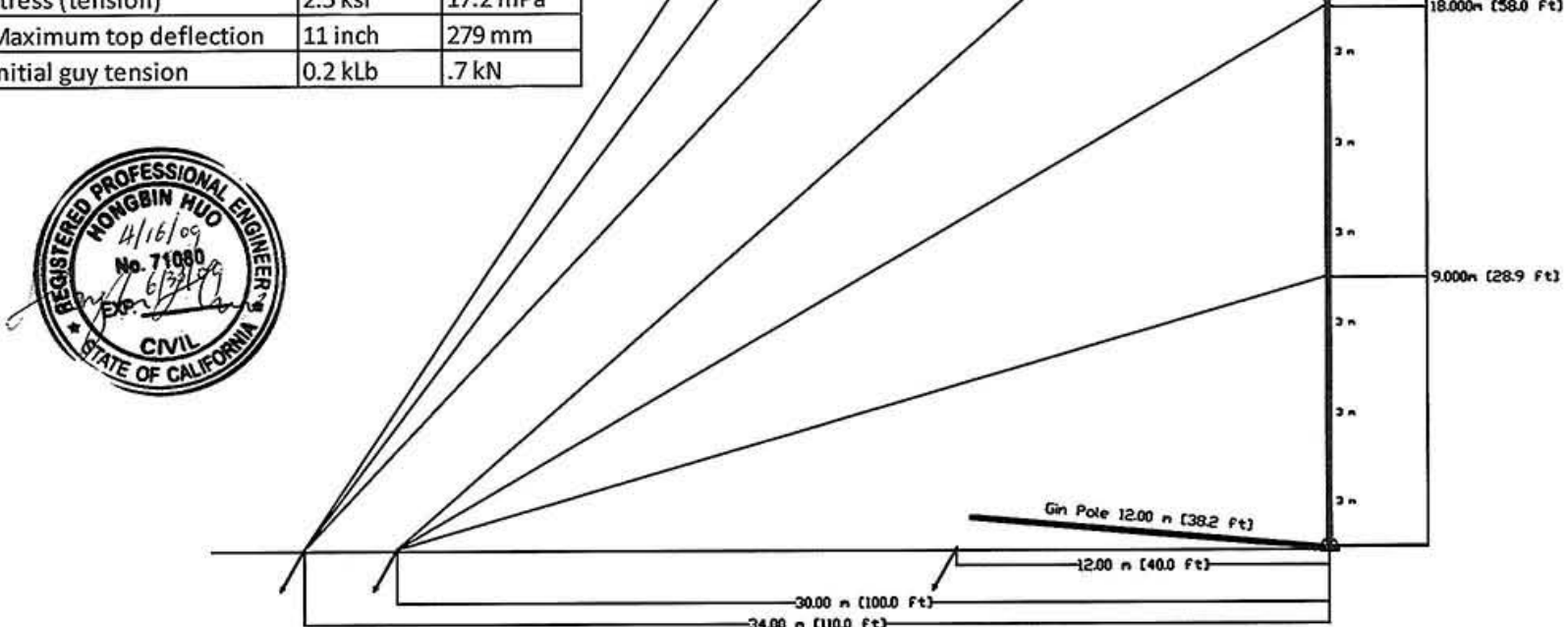

Notes
A) Wind forces and allowable member loads are calculated ANSI TIA/EIA-222-F (1996). "Structural Standards for Steel Antenna Towers and Antenna Supporting Structures".

B) Wind speeds are fastest mile wind velocity per ElA-222-F. E1A-222-F wind loading coefficients: $G=1,69, \mathrm{Cf}=1,0, \mathrm{a}=2 / 7$

C) Fastest mile (fm) wind speeds can be approximately converted to 3 second wind speeds using the equation: V $(3 \mathrm{sec})=1.22 \mathrm{~V}(\mathrm{fm})$ for V $(\mathrm{fm})<=100 \mathrm{mph}$

D) Guy joint efficiency $=0.9$ and the guy safety factor is greater than or equal to 2 .

E) An ANSYS large deflection FEA model using beam (Pipe 16) and tension (Link 10) elements with distributed wind load was used to calculate member forces and reactions

F) Tower allowable stress design per American Institute of Steel Construction (AISC) "Allowable Stress Design", 9th Edition, 1969, Chapter H, equations H-1-1, H1-2

G) This tower meets the structural requirements of EIA-222-F, sections 1,2,3,6,8 for the given loading condition. This analysis does not apply to ElA-222-F sections $7,11,12,13$.

H) Foundation design must be considered separately and is not part of this analysis. Specific foundation details must be approved for the specific application and site by a qualified professional

A locally qualified professional must determine the applicability of this analysis for the expected site conditions. Due to the lack of involvement in the siting or construction phases of this product at a specific location, liability is strictly limited to issues arising from negligence or will full misconduct by WINData or the professional engineer completing this analysis. No warranty, expressed or implied, is made concerning the suitability of this product for a given application or location.

\begin{tabular}{|l|}
\hline \multicolumn{1}{|c|}{ Units Notation } \\
\hline $\mathrm{mm}$ - Millimeters \\
\hline $\mathrm{m}$ - Meters \\
\hline $\mathrm{m} / \mathrm{s}$ - Meters per second \\
\hline $\mathrm{kN}-1,000$ Newtons \\
\hline $\mathrm{mPa}-1,000,000$ Pascals \\
\hline $\mathrm{kLb}-1,000$ US pounds \\
\hline $\mathrm{ksi}-1,000$ US pounds per in^33 \\
\hline $\mathrm{mph}-$ Miles per hour \\
\hline dia-Diameter \\
\hline
\end{tabular}

\begin{tabular}{|c|c|c|c|c|c|c|c|c|}
\hline \multicolumn{3}{|c|}{$\begin{array}{l}\text { Unless otherwise specified } \\
\text { dimensions are in inches. Tolerances } \\
\text { are: }\end{array}$} & \multirow{3}{*}{\multicolumn{3}{|c|}{$\begin{array}{l}\text { The information contained herein is the property of } \\
\text { WinData, LLCand must be maints ined in confidence. } \\
\text { No portion of the drawing may be reproduced or used } \\
\text { without permission of the compony. }\end{array}$}} & \multirow{2}{*}{\multicolumn{3}{|c|}{ WINData, Inc }} \\
\hline \multirow{2}{*}{$\begin{array}{c}\text { Fractions } \\
\pm 1 / 64 \\
\end{array}$} & \multirow{2}{*}{$\begin{array}{l}\text { Decimals } \\
. \mathrm{xx} \pm 015\end{array}$} & \multirow{2}{*}{$\begin{array}{c}\text { Angles } \\
\pm 1^{\circ}\end{array}$} & & & & & & \\
\hline & & & & & & \multicolumn{3}{|l|}{ Title } \\
\hline \multicolumn{3}{|c|}{$x x x \pm .005$} & & Approvals & Date & \multicolumn{3}{|c|}{50 Meter Guyed Met Tower 6.0 inch dia } \\
\hline \multicolumn{3}{|c|}{ DO NOT SCALE DRAWING } & Drawn & MWilde & $7 / 10 / 2008$ & Size & DWG Number & Rev \\
\hline \multicolumn{3}{|l|}{ Material } & checked & & & B & \multirow[t]{3}{*}{ WIND 50-3 } & A \\
\hline \multirow{2}{*}{\multicolumn{3}{|c|}{ Finish 1}} & \multirow{2}{*}{\multicolumn{2}{|c|}{ Issued }} & & \multirow{2}{*}{$\frac{\text { Scale }}{\text { NTS }}$} & & Sheet \\
\hline & & & & & & & & 1 \\
\hline
\end{tabular}




\begin{tabular}{|c|l|l|l|l|l|l|}
\hline \multicolumn{2}{|l|}{ Materials } \\
\hline \multirow{2}{*}{1} & $\begin{array}{l}\text { Outer } \\
\text { Diameter }\end{array}$ & $\begin{array}{l}\text { Wall } \\
\text { Thickness }\end{array}$ & Description & $\begin{array}{l}\text { Yeild } \\
\text { Strength }\end{array}$ & $\begin{array}{l}\text { Breaking } \\
\text { strength }\end{array}$ & Corrosion Protection \\
\hline \multirow{2}{*}{1} & 6 inch & 0.109 & MT 1015 & $50.0 \mathrm{ksi}$ & N/A & Hot Dipped Galvanized \\
\cline { 2 - 6 } & $152 \mathrm{~mm}$ & $2.8 \mathrm{~mm}$ & & $345 \mathrm{mPa}$ & & ASTM 653 \\
\hline \multirow{2}{*}{2} & $0.187 \mathrm{inch}$ & & $7 \times 7$ Galv & N/A & $3.7 \mathrm{kLb}$ & Galvanized \\
\cline { 2 - 5 } & $4.76 \mathrm{~mm}$ & & Aircraft & & $15.2 \mathrm{kN}$ & \\
\hline
\end{tabular}

\begin{tabular}{|r|l|r|l|}
\hline REV & DESCRIPTION & DATE & APPROVED \\
\hline 1 & Units, notes update & $7 / 9 / 2008$ & MHW \\
\hline 2 & Reactions \& forces & $4 / 15 / 2009$ & MHW \\
\hline
\end{tabular}

Reactions and Member Forces

\begin{tabular}{|c|c|c|}
\hline & Imperial & SI \\
\hline $\begin{array}{l}10 \mathrm{~m} \text { (33 feet) wind } \\
\text { velocity (fastest mile) }\end{array}$ & $70 \mathrm{mph}$ & $31.3 \mathrm{~m} / \mathrm{s}$ \\
\hline $\begin{array}{l}\text { Top of tower wind velocity } \\
\text { (fastest mile) }\end{array}$ & $86 \mathrm{mph}$ & $38.4 \mathrm{~m} / \mathrm{s}$ \\
\hline Radial ice thickness & 0.0 inch & $0 \mathrm{~mm}$ \\
\hline Inner guy anchor force & $1.2 \mathrm{kLb}$ & $4.4 \mathrm{kN}$ \\
\hline $\begin{array}{l}\text { Inner guy anchor force } \\
\text { (angle from horizontal) }\end{array}$ & $30^{\circ}$ & $30^{\circ}$ \\
\hline Outer guy anchor force & $2.3 \mathrm{kLb}$ & $8.4 \mathrm{kN}$ \\
\hline $\begin{array}{l}\text { Outer guy anchor force } \\
\text { (angle from horizontal) }\end{array}$ & $49^{\circ}$ & $49^{\circ}$ \\
\hline $\begin{array}{l}\text { Tower base force } \\
\text { (horizontal during } \\
\text { erection) }\end{array}$ & $2.7 \mathrm{kLb}$ & $9.9 \mathrm{kN}$ \\
\hline Tower base force (vertical) & $7.5 \mathrm{kLb}$ & $27.5 \mathrm{kN}$ \\
\hline Erection anchor force & $3.2 \mathrm{kLb}$ & $11.7 \mathrm{kN}$ \\
\hline $\begin{array}{l}\text { Erection anchor force } \\
\text { (angle from horizontal) }\end{array}$ & $45^{\circ}$ & $45^{\circ}$ \\
\hline Maximum guy tension & $0.5 \mathrm{kLb}$ & $1.8 \mathrm{kN}$ \\
\hline $\begin{array}{l}\text { Maximum tower tube } \\
\text { stress (compression) }\end{array}$ & $6.1 \mathrm{ksi}$ & $42.1 \mathrm{mPa}$ \\
\hline $\begin{array}{l}\text { Maximum tower tube } \\
\text { stress (tension) }\end{array}$ & $2.5 \mathrm{ksi}$ & $17.2 \mathrm{mPa}$ \\
\hline Maximum top deflection & 11 inch & $279 \mathrm{~mm}$ \\
\hline Initial guy tension & $0.2 \mathrm{kLb}$ & $.7 \mathrm{kN}$ \\
\hline
\end{tabular}

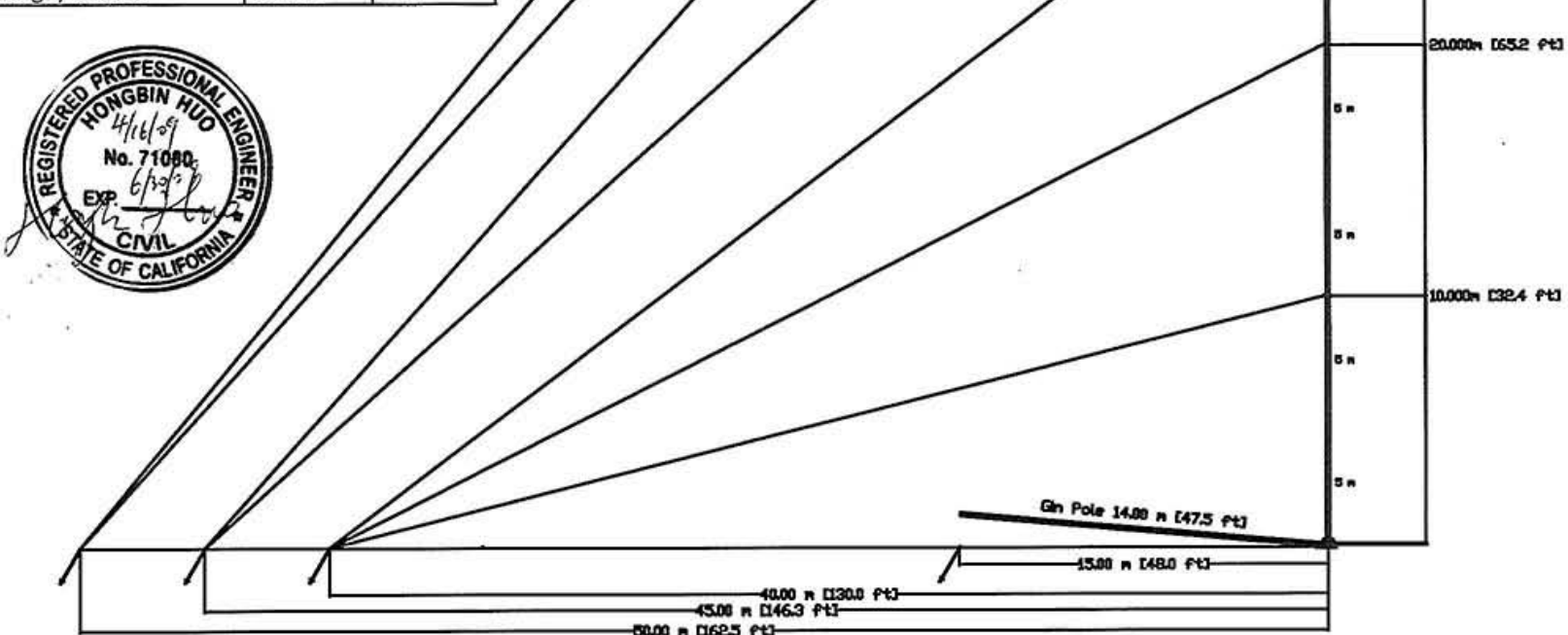

Notes

A) Wind forces and allowable member loads are calculated ANSI TIA/EIA-222-F (1996). "Structural Standards for Steel Antenna Towers and Antenna Supporting Structures".

B) Wind speeds are fastest mile wind velocity per ElA-222-F. ElA-222. F wind loading coefficients: $G f=1,69, C f=1,0, a=2 / 7$

C) Fastest mile ( $\mathrm{fm}$ ) wind speeds can be approximately converted to 3 second wind speeds using the equation: $V(3 \mathrm{sec})=1.22 \mathrm{~V}(\mathrm{fm})$ for $\mathrm{V}(\mathrm{fm})<=100 \mathrm{mph}$

D) Guy joint efficiency $=0.9$ and the guy safety factor is greater than or equal to 2.0

E) An ANSYS large deflection FEA model using beam (Pipe 16) and tension (Link 10) elements with distributed wind load was used to calculate member forces and reactions

F) Tower allowable stress design per American Institute of Steel Construction (AISC) "Allowable Stress Design", 9th Edition, 1969, Chapter H, equations H-1-1, H1-2

G) This tower meets the structural requirements of ElA-222-F, sections 1,2,3,6,8 for the given loading condition. This analysis does not apply to ElA-222-F sections $7,11,12,13$.

H) Foundation design must be considered separately and is not part of this analysis. Specific foundation details must be approved for the specific application and site by a qualified professiona

1) A locally qualified professional must determine the applicability of this analysis for the expected site conditions. Due to the lack of involvement in the siting or construction phases of this product at a specific location, liability is strictly limited to issues arising from negligence or will full misconduct by WINData or the professional engineer completing this analysis. No warranty, expressed or

implied, is made concerning the suitability of this product for a given application or location.

\begin{tabular}{|c|c|c|c|c|c|c|c|c|c|}
\hline \multirow{2}{*}{\begin{tabular}{|l|} 
Units Notation \\
\end{tabular}} & \multirow{3}{*}{\multicolumn{3}{|c|}{$\begin{array}{l}\text { Unless otherwise specified } \\
\text { dimensions are in inches. Tolerances } \\
\text { are: }\end{array}$}} & \multirow{4}{*}{\multicolumn{3}{|c|}{$\begin{array}{l}\text { The information contained herein is the property of } \\
\text { WINData, LIC and must be mainta ined in confidence. } \\
\text { No portion of the drawing may be reproduced or used } \\
\text { without permission of the company. }\end{array}$}} & \multirow{4}{*}{\multicolumn{3}{|c|}{ WINData, Inc }} \\
\hline & & & & & & & & & \\
\hline \multirow{2}{*}{$\begin{array}{c}\mathrm{mm} \text { - Millimeters } \\
\mathrm{m} \text {-Meters }\end{array}$} & & & & & & & & & \\
\hline & Fractions & Decimals & Angles & & & & & & \\
\hline $\mathrm{m} / \mathrm{s}$ - Meters per second & $\pm 1 / 64$ & $x x \pm 015$ & $\pm 1^{\circ}$ & & & & \multicolumn{3}{|l|}{ Title } \\
\hline $\mathrm{kN}-1,000$ Newtons & \multicolumn{3}{|c|}{$x x x \pm 005$} & \multicolumn{2}{|c|}{ Approvals } & \multirow{2}{*}{$\begin{array}{l}\text { Date } \\
7 / 10 / 2008 \\
\end{array}$} & \multicolumn{3}{|c|}{60 Meter Guyed Met Tower 6.0 inch dia } \\
\hline $\mathrm{mPa}-1,000,000$ Pascals & \multicolumn{3}{|c|}{ DO NOT SCALE DRAWING } & Drawn & MWilde & & Size & DWG Number & Rev \\
\hline KLb - 1,000 US pounds & \multirow{2}{*}{\multicolumn{3}{|c|}{ Material }} & & & & & & \\
\hline ksi $-1,000$ US pounds perin^3 & & & & Checked & & & B & WIND $60-5$ & A \\
\hline mph - Miles per hour & \multirow{2}{*}{\multicolumn{3}{|c|}{ Finish 1}} & \multirow{2}{*}{ issued } & & & \multirow{2}{*}{\multicolumn{2}{|c|}{ Scale }} & Sheet \\
\hline dia-Diameter & & & & & & & & & 1 \\
\hline
\end{tabular}




\section{Appendix C-10m Do-It-Yourself Manual}




\title{
$10 \mathrm{~m}$ Prospector Anemometer Tower Installation Manual and Specifications
}

\author{
Written By: \\ Erin C. Hafla and Mike R. West \\ Summer Interns from \\ Montana State University \\ $\&$ \\ University of Idaho
}

July 2, 2009 


\section{DISCLAIMER}

This information was prepared for educational purposes as an account of work by summer interns being sponsored by an agency of the U.S. Government. Neither the U.S. Government nor any agency thereof, nor any of their employees, makes any warranty, expressed or implied, or assumes any legal liability or responsibility for the accuracy, completeness, or usefulness, of any information, apparatus, product, or process disclosed, or represents that its use would not infringe privately owned rights.

References herein to any specific commercial product, process, or service by trade name, trade mark, manufacturer, or otherwise, does not necessarily constitute or imply its endorsement, recommendation, or favoring by the U.S. Government or any agency there of. The views and opinions of authors expressed herein do not necessarily state or reflect those of the U.S. Government or any agency there of. 


\section{1) Table of Contents:}

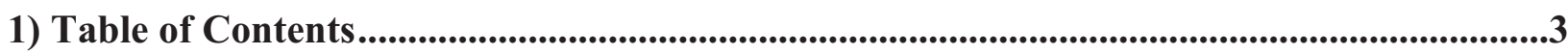

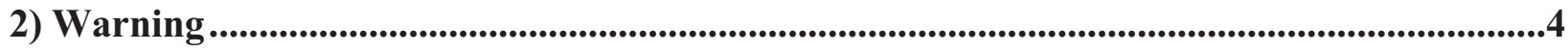

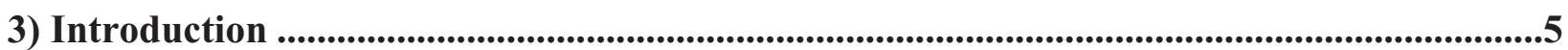

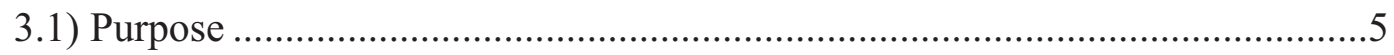

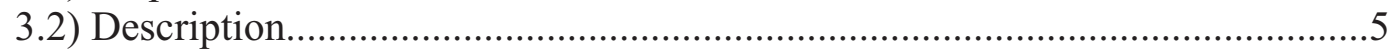

3.3) Tower Supply List and Prices....................................................................5

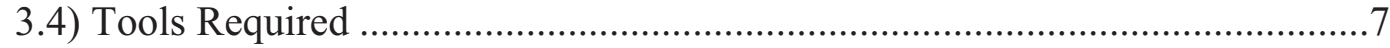

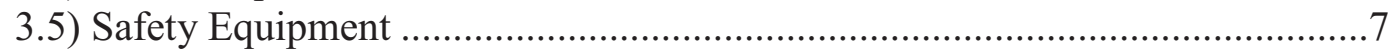

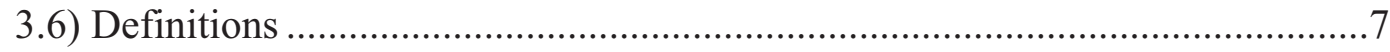

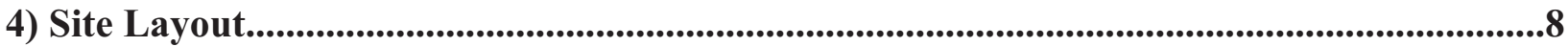

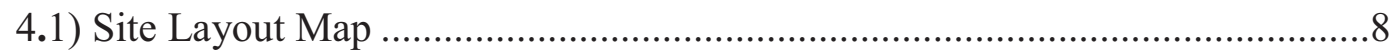

4.2) What to Look For in a Good Location ...................................................... 9

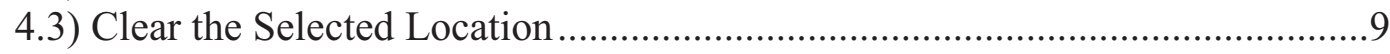

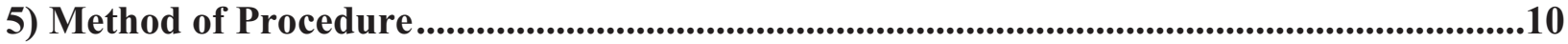

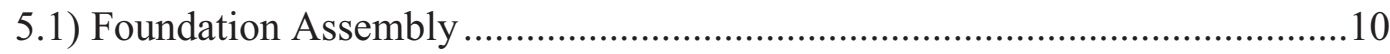

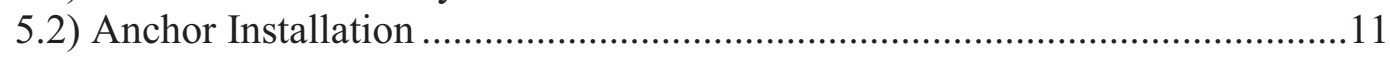

5.3) Tower Assemblage and Base Attachment ........................................... 13

5.4) Guy Wire Placement...................................................................... 13

5.5) Instrument and Boom Installation ......................................................... 15

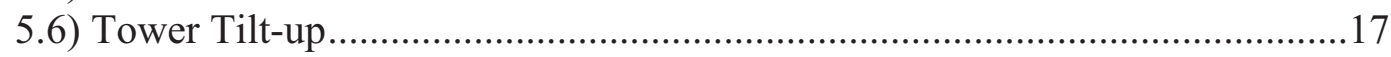

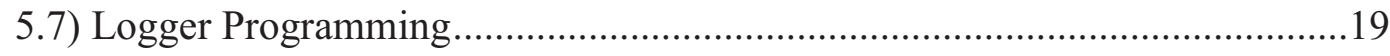

6) Appendix A- Tower Schematics......................................................................................19

7) Appendix B- Extra Pictures ...........................................................................................................21

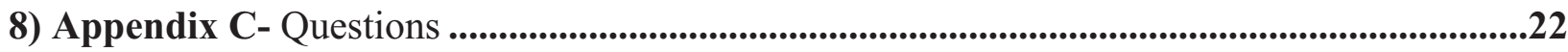




\section{2) Warning:}

The installation of guyed towers is inherently dangerous. To minimize risks, read and follow the tower installation instructions explicitly. Installation in agricultural areas may pose a threat to low flying crop dusting aircraft. Notify appropriate parties and install warning devices as needed. Neither the U.S. Government nor any agency thereof, nor any of their employees assumes any responsibility or liability in connection with any act, error, omission, or for any injury, loss, accident, delay, inconvenience, irregularity or damage related to any anemometer tower installation.

\section{Installation and Safety Considerations:}

Determine the soil type at your site and install the correct anchors.

Place tower anchors according to anchor manufacturer's recommendations.

Properly ground the tower electrically.

Review installation manual so that you are familiar with all tower parts and terminology.

If you are not thoroughly familiar with all components of the tower, including all hardware and how all components function, do not attempt to install this tower yourself. Anemometer towers are dangerous, and you or your crew can suffer serious injury or death.

Erect tower at least $1 \frac{1}{2} 2$ times below the tower height of electric power lines, roads, walkways, or buildings.

Keep unauthorized personnel off of tower site while the tower is being installed.

Avoid high or gusty winds when raising the anemometer tower.

Stand to the side of any tensioned cables, not in line with, in front of, or behind.

Do not climb the tower.

Do not oil tower joints. It can cause tower failure.

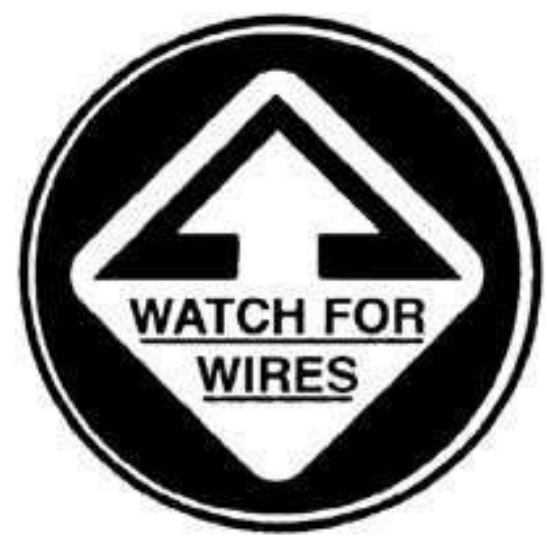

DANGER:

YOU CAN BE KILLED

IF THIS TOWER COMES NEAR ELECTRICAL POWER

LINES. FOR YOUR SAFETY, FOLLOW THESE INSTALLATION INSTRUCTIONS 


\section{3) Introduction:}

Anemometers are used to measure wind speed and direction and that data can then be used for weather reports. The determination of the wind resources available at a site is essential for estimating the productivity, in terms of power and cost savings, of a wind turbine or wind farm. One year worth of on-site weather data (including wind speed and direction, temperature, and pressure) is required to assess the wind resources of the site before initiating development. It is necessary to become familiar with the tools and equipment talked about in this manual. Furthermore, you should also be adaptable to changes and have some problem solving skills if any unexpected events were to occur in the assembly of the prospector anemometer tower. This project is for a team of three or more people. Always keep in mind the safety hazards associated with this project.

It is also important to note that this guide is a "how to" document intended to aide in wind prospecting with a small 10 meter tower. These towers are not intended to replace the need for taller wind data towers for larger wind turbine projects. It is also not intended to replace a manufacture's manual provided for specific anemometer towers such as the 30, 50, or 60 meter, etc. For towers purchased from manufacturers, and for further information about the commercially available data loggers, please refer to typical manufacturers' manuals, websites, etc.

\section{1) Purpose:}

The purpose of this manual is to provide basic instruction to assemble and erect a 10 meter anemometer tower.

\section{2) Description:}

The $10 \mathrm{~m}$ Prospector Anemometer Tower is a pole constructed of galvanized steel that is anchored to the ground and stabilized with three levels of guy wires. Four guy wires extend out from each level. The tower will extend approximately 36 feet above the ground and will rest on a piece of plywood that is stabilized with steel rods driven into the ground about one meter. This tower holds one anemometer, a data logger, a wind vane, and a solar panel to power the data logger. Three people at minimum are needed to assemble and erect the Anemometer Tower.

\section{3) Tower Supply List and Prices}

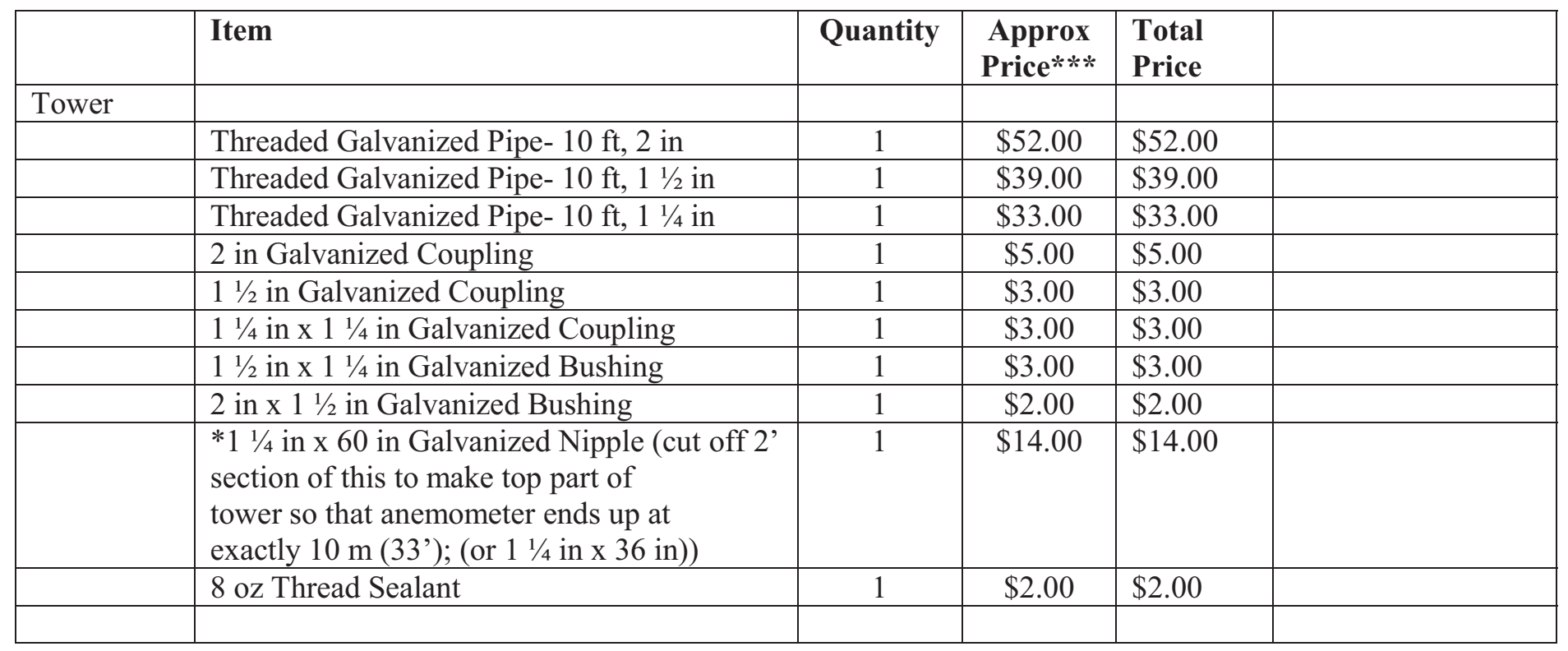




\begin{tabular}{|c|c|c|c|c|c|}
\hline Base & & & & & \\
\hline & Urethane Paint (water/weather proof) & 1 & $\$ 13.00$ & $\$ 13.00$ & \\
\hline & $\begin{array}{l}3 \text { in } x 11 \text { in Galvanized Steel Angle Framing } \\
\text { Anchor (about } 1 / 8 \text { in thick) }\end{array}$ & 2 & $\$ 4.00$ & $\$ 8.00$ & \\
\hline & $2 \times 2 \mathrm{ft}$ Panel of $3 / 4$ in thick plywood & 1 & $\$ 7.00$ & $\$ 7.00$ & \\
\hline & 36 in Round Steel Stake & 3 & $\$ 5.00$ & $\$ 20.00$ & \\
\hline & $1 / 2 \times 4$ in Galvanized Bolt & 1 & $\$ 1.00$ & $\$ 1.00$ & \\
\hline & $1 / 2 \times 1 \frac{1}{2}$ in Bolt & 4 & $\$ 1.00$ & $\$ 4.00$ & \\
\hline & $1 / 2$ in Flat Galvanized Washer & 4 & $\$ 0.25$ & $\$ 1.00$ & \\
\hline & $1 / 2$ in Galvanized Nut & 5 & $\$ 0.30$ & $\$ 1.50$ & \\
\hline \multirow[t]{5}{*}{$\begin{array}{l}\text { Anchoring } \\
\text { and Guy } \\
\text { Wires } \\
\end{array}$} & & & & & \\
\hline & $\begin{array}{l}500 \mathrm{ft} 1 / 8 \text { in or } 3 / 32 \text { in ss (or galvanized) } \\
\text { Wire Rope }\end{array}$ & 1 & $\$ 98.00$ & $\$ 98.00$ & \\
\hline & 36 in Round Steel Stake or & 4 & $\$ 5.00$ & $\$ 20.00$ & \\
\hline & NRG Screw in Anchors (5 per box) & 5 & $\$ 150.00$ & $\$ 750.00$ & \\
\hline & 1/8 in Wire Rope Clips (saddle/cable clamps) & 60 & $\$ 0.50$ & $\$ 30.00$ & \\
\hline \multicolumn{6}{|l|}{ Instruments } \\
\hline & $\begin{array}{l}\text { APRS Logger** (purchase with solar panel } \\
\text { in package) OR (next } 3 \text { lines) }\end{array}$ & 1 & $\$ 950.00$ & $\$ 950.00$ & \\
\hline & $\begin{array}{l}\text { Campbell Scientific Logger (CR800 or 850) } \\
\text { and Shelter Box OR }\end{array}$ & 1 & Unknown & & \\
\hline & NRG Symphonie Logger AND (next line) & 1 & $\$ 1350.00$ & & \\
\hline & NRG Shelter Box & 1 & $\$ 135.00$ & & \\
\hline & NRG Anemometer (or APRS NRG clone) & 1 & $\$ 140.00$ & $\$ 140.00$ & $\begin{array}{l}\text { \$285 if buying } \\
\text { from NRG and } \\
\text { using Symphonie } \\
\text { Logger }\end{array}$ \\
\hline & Pole Solar Mount (for APRS logger) & 1 & $\$ 50.00$ & $\$ 50.00$ & \\
\hline & $\begin{array}{l}9 \mathrm{ft} \text { Copper Wire (grounding) } \\
\text { (insulated, } 10-14 \text { gauge) }\end{array}$ & 1 & $\$ 3.00$ & $\$ 3.00$ & \\
\hline & NRG Wind Vane & 1 & $\$ 205.00$ & $\$ 205.00$ & \\
\hline & Stub Boom & 1 & $\$ 19.00$ & $\$ 19.00$ & \\
\hline & Z Boom & 1 & $\$ 23.00$ & $\$ 23.00$ & \\
\hline & $\begin{array}{l}* * 10 \mathrm{~m} \text { instrument cables (1-2 wire and 1-3 } \\
\text { wire) }\end{array}$ & & $\$ 60.00$ & & \\
\hline & Lightning Arrestor Kit (10m) & 1 & $\$ 110.00$ & $\$ 110.00$ & \\
\hline & Metal Hose clamps- size $6 \frac{1}{4}$ & 6 & $\$ 7.35$ & $\$ 44.10$ & \\
\hline & Several rolls of electrical tape & & & & \\
\hline \multicolumn{6}{|c|}{$\begin{array}{l}\text { Solar Panel Grounding (and extra wiring accessories) if } \\
\text { using APRS logger }\end{array}$} \\
\hline & Spade Terminal & 2 & $\$ 1.00$ & $\$ 2.00$ & \\
\hline & Ring Terminal & 2 & $\$ 1.00$ & $\$ 2.00$ & \\
\hline & Butt Splice & 2 & $\$ 1.00$ & $\$ 2.00$ & \\
\hline & $1 / 4 \mathrm{X}^{3} / 4$ in Bolt & 1 & $\$ 0.10$ & $\$ 0.10$ & \\
\hline & $1 / 4$ in Nut & 1 & $\$ 0.10$ & $\$ 0.10$ & \\
\hline & & & Total & $\$ 1,707.80$ & \\
\hline
\end{tabular}




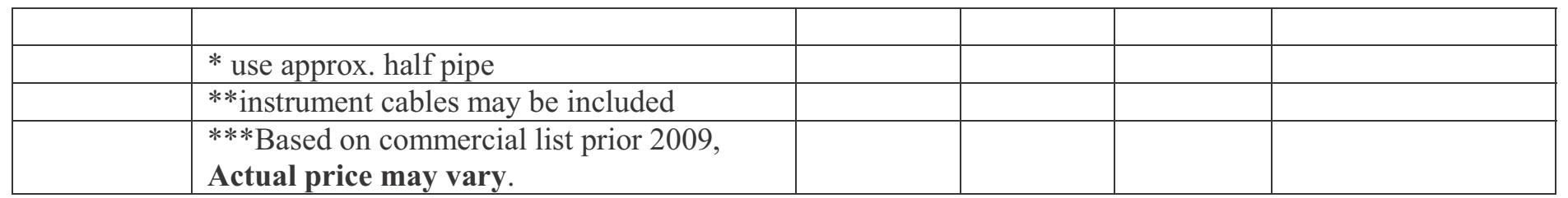

\section{4) Tools Required}

$1 / 4$ inch nut driver (for sensor installation)

$>5 / 16$ inch nut driver (wire rope clamps)

$>7 / 16$ inch nut drivers (for wire rope clips) - one per crew member

$>$ Large adjustable wrench or channel lock (for large bolts)

$>$ 9/16 inch wrench, socket or open (for base plate assembly)

$>$ Piece of rebar or similar (for turning anchors)

$>$ Hand sledge (for ground rods)

$>$ Small adjustable wrench (for opening/closing quick links, acorn clamps)

$>$ Small pliers

$>$ Small Phillips head $(+)$ screwdriver (for set screws)

$>$ Flat (-) screwdriver

$>$ Knives (to cut electrical tape) - one per crew member

$>$ Compass (for aligning direction sensors)

$>$ Permanent marker (for labeling lower ends of cables)

$>$ Wire cutters

\section{5) Safety Equipment}

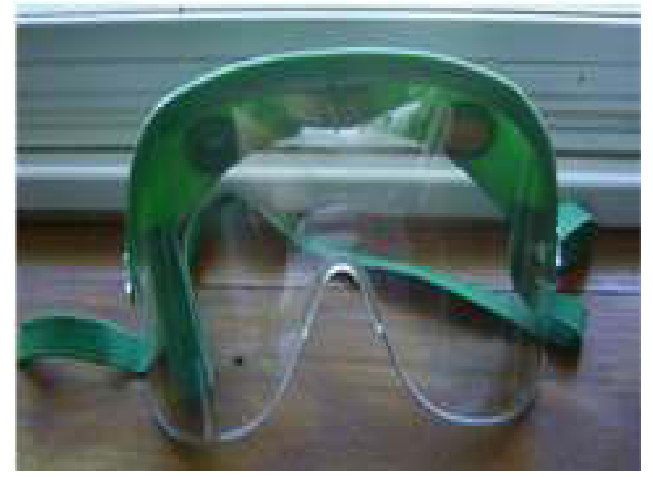

Safety Goggles

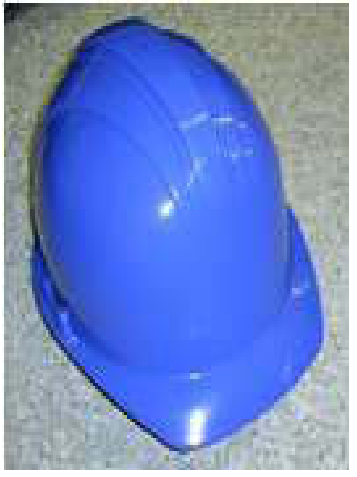

Hard Hat

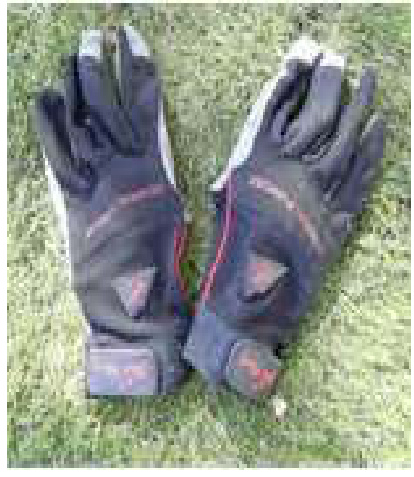

Gloves

\section{6) Definitions}

- Anemometer-an instrument for measuring and indicating the force or speed of the wind.

- Boom- a long, more or less horizontal supporting arm or brace.

- Guy wires- a rope, cable, or appliance used to guide and steady an object being hoisted, lowered, or used to secure anything likely to shift its position. 
- Wind vane-A movable device attached to an elevated object. Used for showing the direction of the wind.

\section{4) Site Layout}

It is a good idea to visit the chosen site before assembling the tower. Some site preparation may be needed and arrangements made for the transportation of the anemometer tower pieces. If the land is not specifically owned by the project manager, then approval will be needed. Also, restrictions will need to be taken into consideration. Some states have height limits. Be sure and research the site soil to determine if the site will be appropriate for an anemometer tower. If using NRG iPack or similar technology to transmit data, it is also a good idea to make sure that the area you are going to assemble the tower has cellular service available. Contact NRG for more information on iPacks.

\section{1) Site Layout Map}

Lay out locations for the tower base and the guy anchors. Lay out the site so that the tower is laid out downwind of the base, so that the tower will be lifted into the wind. If the site is on a steep slope, lay out the site so that the tower is laid out uphill of the base. Unless the slope has a steep grade, it is more important to have the tower lifted into the wind. The side Guy anchors should be in a straight line out from the base plate. If it is not possible to place them exactly in line, it is still better to place them close to that line, but no more than 1.5 meters or 5 feet off that line. If this is still not possible, a new arrangement will be needed.

Example of how the anemometer tower and guy anchors should be laid out.

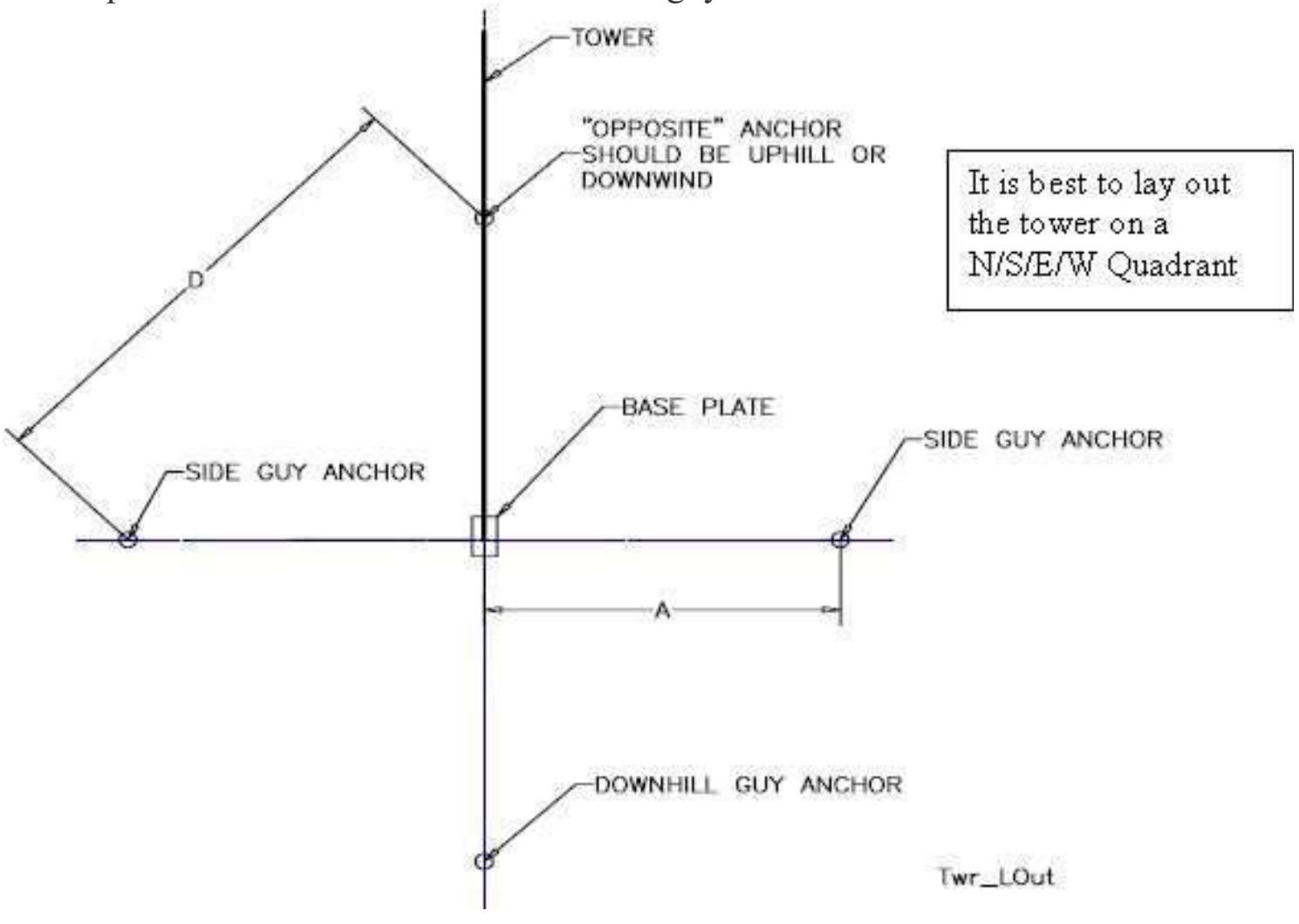

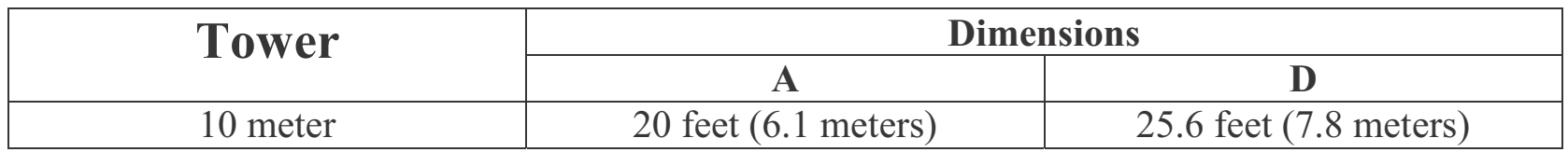




\section{2) What To Look For In A Good Location:}

$\sim$ Fairly flat land $\left(<10^{\circ}\right.$ incline $)$ - whether on a hill top or a valley floor.

$\sim$ Obvious wind

$\sim$ Relatively clear (few trees)

$\sim$ Elevated land

$\sim$ No or few surrounding buildings or power lines. Buildings can cause turbulence and interfere with the readings, while power lines present a safety hazard. Remember that a wind turbine will most likely be taller than the anemometer tower so please plan accordingly- See Figure 1 vs. Figure 2.

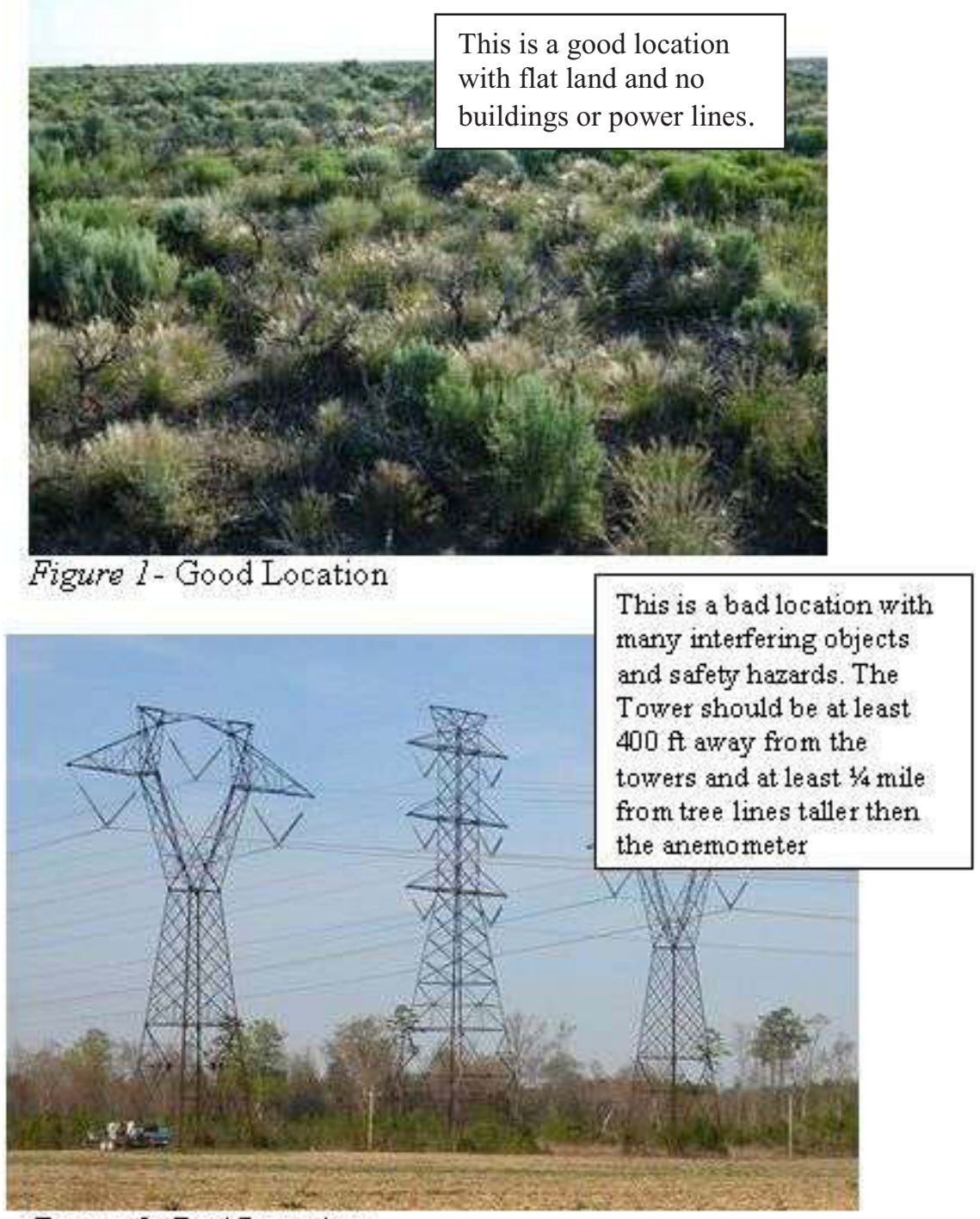

Figure 2-Bad Location

\subsection{Clear the Selected Location}

Purpose- to clear the land in preparation of construction.

- Place and center a stake in the ground where the anemometer tower will be placed.

- Using a measuring tape, measure out from the origin or the stake in a full circle. The distance outward needs to be at least the same height as the tower height, so in this case the distance will be at least 10 meter or about 33 feet. $(1 \mathrm{~m}=3.28 \mathrm{ft})$ 
- Note to where the circle extends and then clear any trees or large shrubs such as large sagebrush from that area by a handsaw, axe, etc. See Figure 3. WARNING: Read and follow the manual and precautions before using any hazardous equipment such as axe or hand saw. Wear ear and eye protection. Allow enough room when operating equipment. Be cautious of your surroundings.

Red ' $\mathrm{x}$ ' $\mathrm{s}$ ' indicate the tall plants and trees that should be removed from the area. The brown anchor indicates the spot where the tower is to stand.

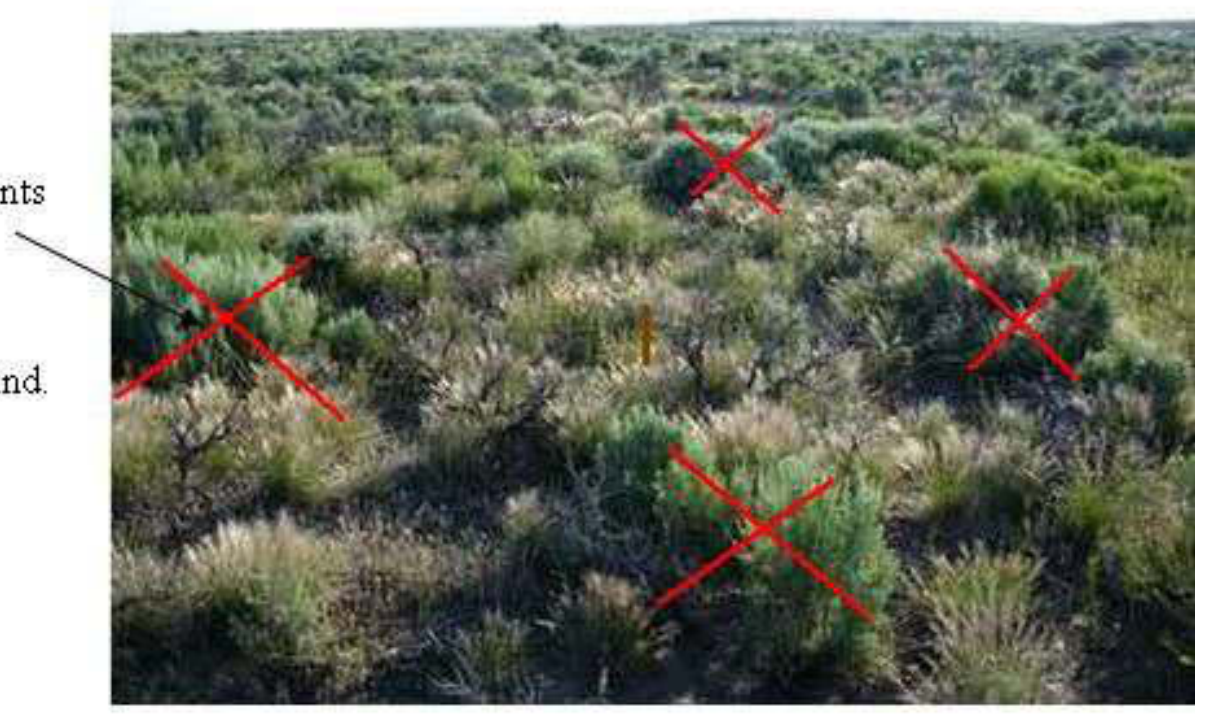

Figure 3

\section{5) Method of Procedure}

The tower parts should be transported to the chosen site by the installation team and erected as recommended by this manual.

\section{1) Foundation Assembly}

Purpose- to build a secure base for the tower to stand upon.

1. Place the plywood panel in the center of the site or the spot that has been chosen for the tower to stand. Use a compass to place the sides of the base as close as possible to the standard directions as possible (i.e. - North, South, East, West). However, the tower should be lifted into the wind if possible. Plan accordingly.

2. Thoroughly paint a layer of Urethane onto the panel so it will be protected from the weather. Be sure to read all warnings and follow all instructions provided with the Urethane. While this is drying, the assembly of the tower may begin.

3. Mount both Angle Framing Anchors. The tower will be secured in between the anchors, holding it to the base. First align the anchors on the board, putting them perpendicular to how the tower will lay on the ground. Put at least two inches in between the anchors in order for the tower to fit in between them. Drill $1 / 2$ inch holes through the ply wood for the $1 / 2 \times 1 \frac{1}{2}$ bolts that will hold the Angle Framing Anchors to the panel. There should be four in total. See Figure 4. 


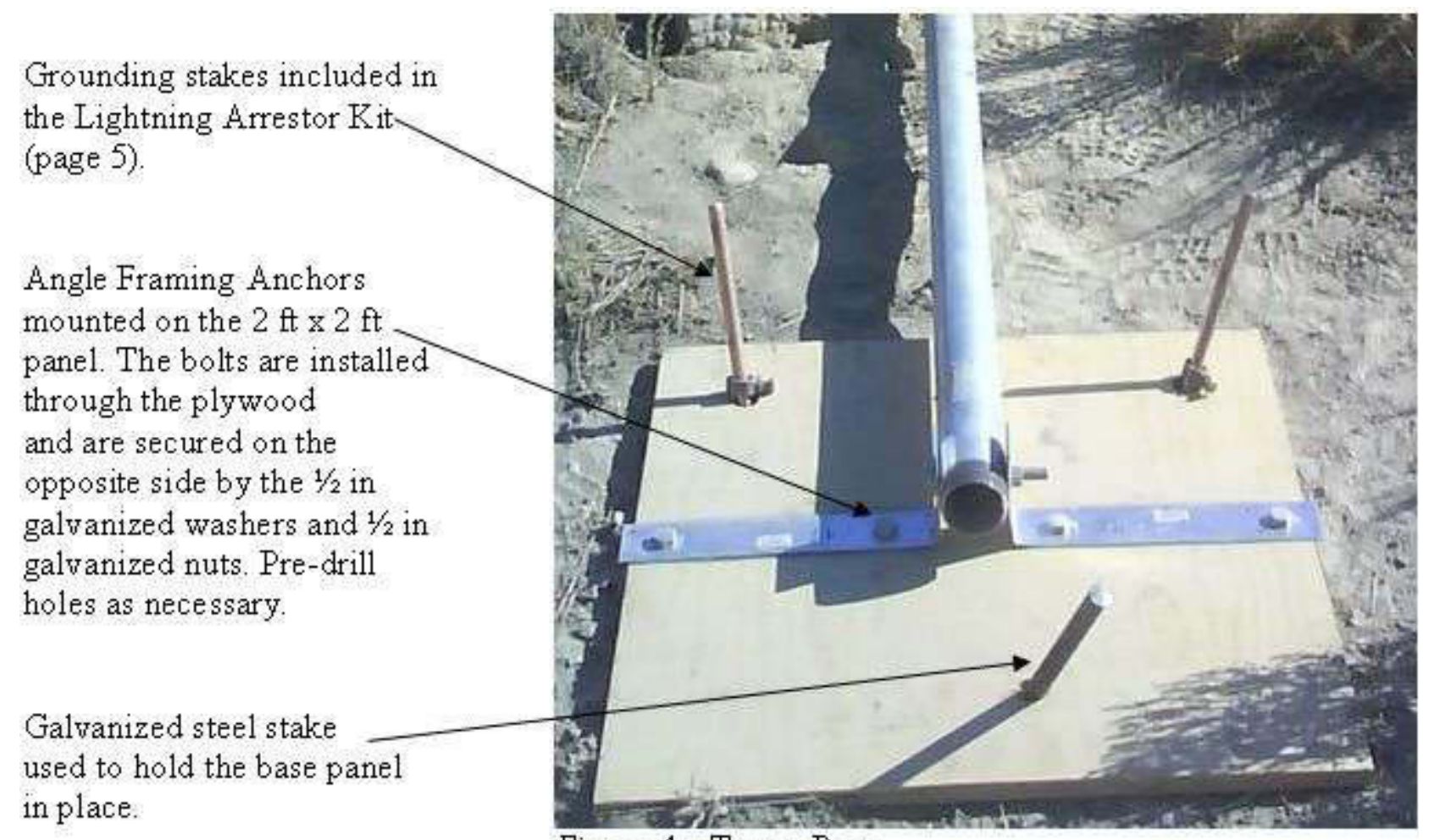

Figure 4-Tower Base

Once the $1 / 2$ inch holes have been drilled, finish attaching the anchors using the bolts, washers, and nuts. Set aside the $1 / 2 \times 4$ inch bolt and the last washer until ready to attach the tower.

4. Drill three more holes, one big enough for the 36 inch steel stake that will hold the base in place and two others big enough for the grounding rods that come with the Lightning Arrestor Kit. These should be drilled in a triangular pattern so the base is supported equally as shown in Figure 4. Note: do not pound the stake and grounding rods into the ground until the tower is ready to be attached and it is known for sure that that is the direction the base is to face and the area the base is to be located in.

\section{2) Anchor Installation}

The anchors are used to secure the guy wires and thus steady the tower, preventing collapse and lost of money and data. Note: two options for anchors are given on the supply list, the NRG Screw in Anchors and the 36 inch Round Steel Stake. Both options work well, but the NRG Screw in Anchors have a higher stress resistance than the 36 inch Round Steel Stake in most soils. Please plan accordingly. Be sure to perform a soil test to determine which anchor type to use.

1. Identify anchor placement.

-Place one anchor on each side perpendicular to the base. Each anchor should be measured out 6.1 meters (20') from the base of the tower on all four sides. Generally these are oriented to North, South, East, and West. See Figure 5.

2. Install Anchors

-Begin pushing the anchors into the ground. If using the 36 in Round Steel Stake, you will need a sledge hammer to drive it into the ground. If using the Screw in Anchors, a crowbar or any other tool that can be used to provide leverage may be needed to screw the anchor into the ground. (Leave about six inches of the anchor sticking up out of the ground at about a 45 
degree angle pointing toward the anemometer tower. If using the Round Steel Stake, angle it at about $45^{\circ}$ away from the tower. This will prevent the three guy wires from slipping.)

See Figures 6 and 7.

Distance from the tower to the anchor -

$20 \mathrm{ft}$ or $6.1 \mathrm{~m}$.

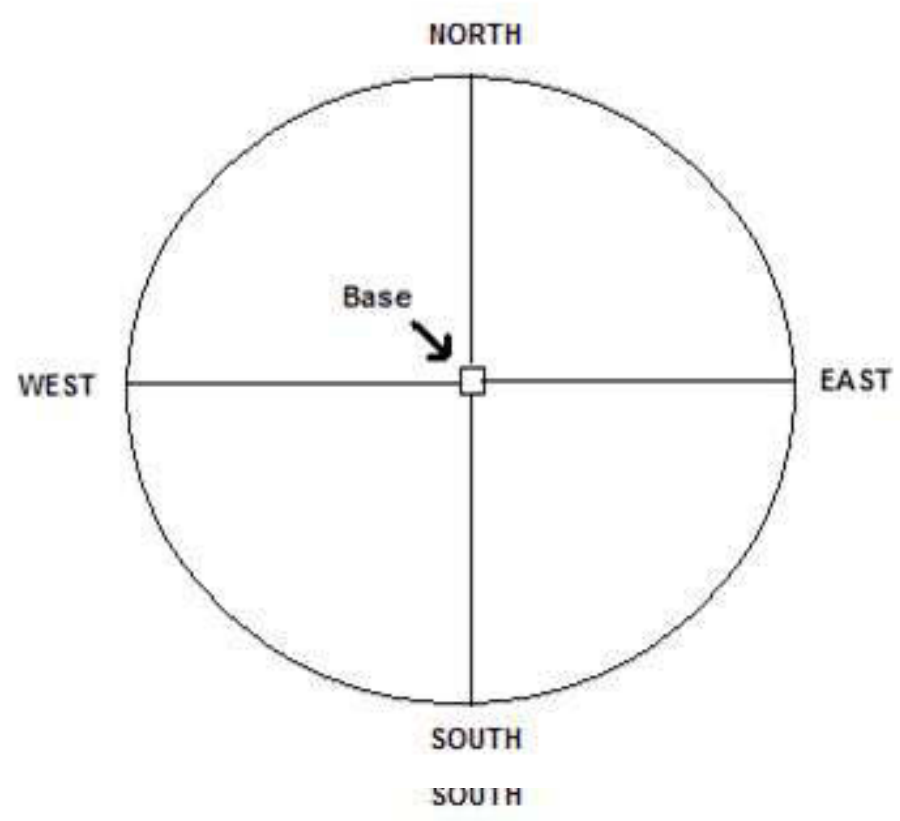

Figure 5

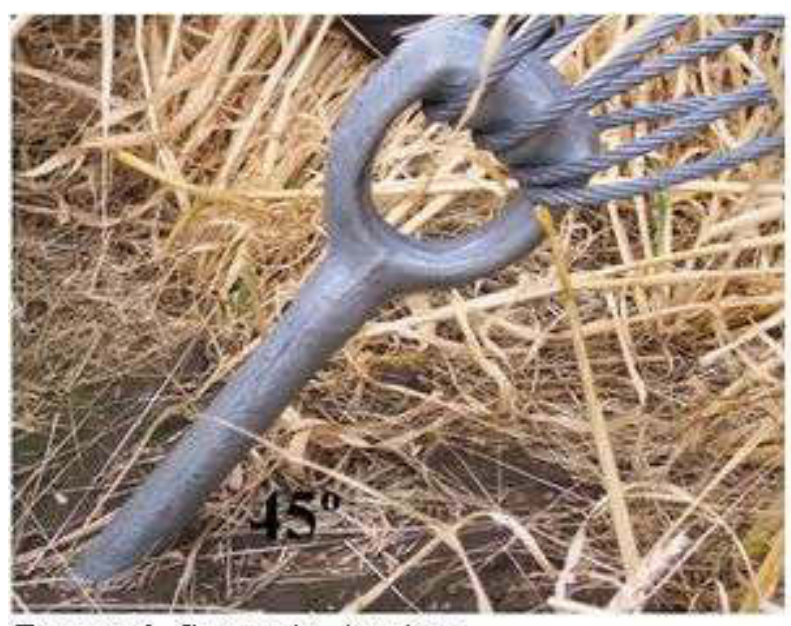

Figure 6-Screw in Anchor

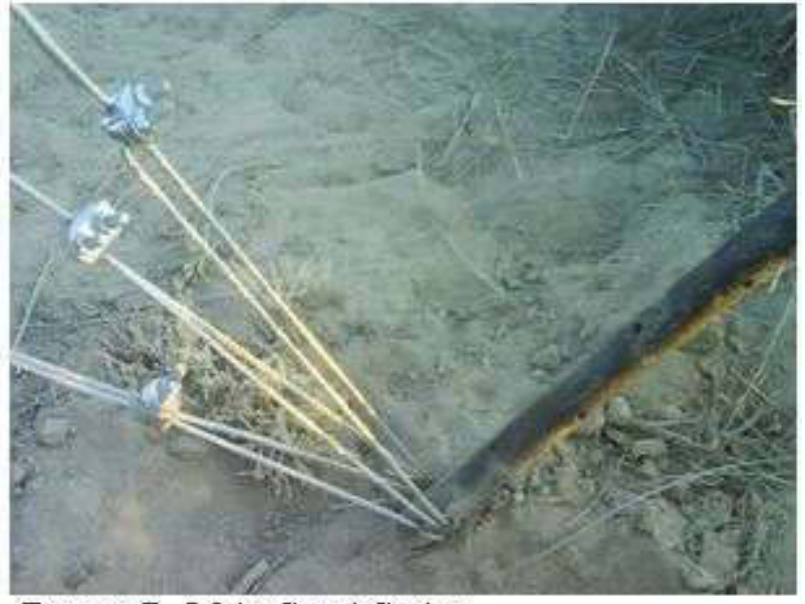

Figure 7- 36 in Steel Stake 


\section{3) Tower Assemblage \& Base Attachment}

1. Drill a $1 / 2$ in hole through the base of the 2 in section of steel pipe. This hole should be drilled at the same height as the holes in the angle framing anchors that have been attached to the base that has enough clearance so that when the tower is erected it will clear the base.

2. The tower materials should be laid out on the ground at the chosen site with the largest piece of pipe acting as the bottom of the tower. Attach the $10 \mathrm{ft} 2 \mathrm{in}$ section of galvanized pipe to the base that was constructed earlier by putting the $1 / 2$ in $x$ in bolt through the $1 / 2$ in hole that was drilled in step one. The bolt will fit through the hole in the angle framing anchors, through the pipe, back through the angle framing anchors, and secured on the other side by the $1 / 2$ in galvanized nut.

3. Once the parts are laid out in the basic structure of the tower, attach the $10 \mathrm{ft}$ sections of pipe to the couplings of the same size by screwing the bushing first into one side of the coupling and attaching both sides to the corresponding sizes of pipe sections. For example- the 2 in galvanized steel pipe, which is the bottom section, goes with the 2 in coupling which has the 2in x $1 \frac{1}{2}$ in bushing attached to it so the $1 \frac{1}{2}$ in pipe section can then screw into it. Be sure to apply the tread sealant to the inside of the couplings and bushings when attaching them to the galvanized pipes. See Figure 8.

4. After the tower sections are attached from largest to smallest, take the $1 \frac{1 / 4 \mathrm{in} \times}{60}$ in galvanized nipple and cut a 3' section.

5. Screw in the 3' section of galvanized nipple into the top of the top section of pipe. This is to make the tower exactly $10 \mathrm{~m}$ when you are done. Remember to use the thread sealant.

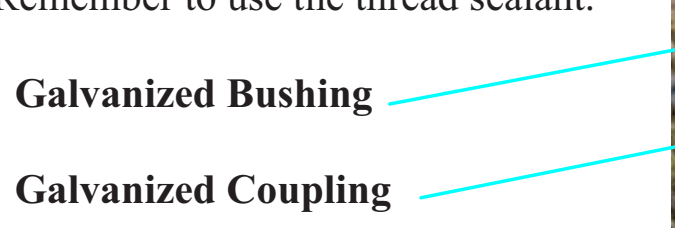

\section{Galvanized Pipe section}

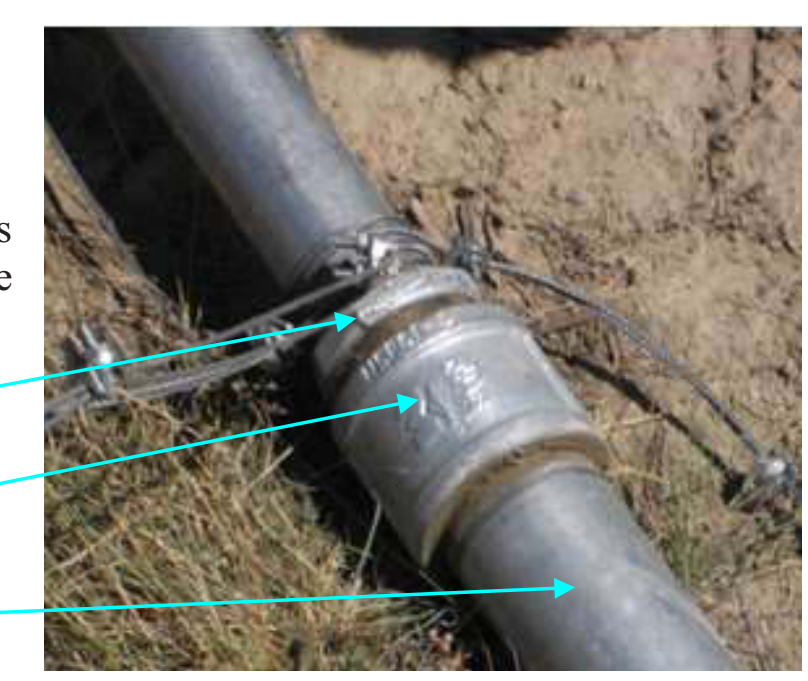

Figure 8

\section{4) Guy Wire Placement}

Correct placement of the guy wires is critical to the stability of your 10m Anemometer tower. Please be sure that the wires are secured properly, for safety becomes a large problem if they are not.

1. Cut the $500 \mathrm{ft}$ length of $1 / 8$ in or $3 / 32$ in wire rope into $450 \mathrm{ft}$ sections, $440 \mathrm{ft}$ sections, and 4 $35 \mathrm{ft}$ sections. These will be the guy wires for the anemometer tower.

\begin{tabular}{|l|l|l|l|}
\hline Section & $\boldsymbol{A}$ & $\boldsymbol{B}$ & $\boldsymbol{C}$ \\
\hline Attachment Height on tower (ft) & 30 & 20 & 10 \\
\hline Wire length (ft) & 50 & 40 & 35 \\
\hline
\end{tabular}

2. Roll out the guy wires to the side anchors. Each anchor will have one 50, 40, and $35 \mathrm{ft}$ piece of wire attached to it. Guys must be rolled out to the anchors. Wire rope can become severely 
twisted and kinked. Twisted and or kinked wire rope is very difficult to handle and may fail under load. Please use caution.

3. Once the guy wires are laid out to the corresponding heights on the tower, wrap the wire around the tower above the coupling and bushing several times and clamp with two 1/8in wire rope clamps (saddle/cable clamps). Use the clamp to connect the loose end of the wire to the end that is extending over to the anchor. Place one clamp near the Galvanized pipe and one about two feet down the wire. Use a screwdriver or socket wrench to tighten the wire rope clamp. Be sure the hold is secure. See Figure 9.

4. Connect the other end of the wire to three of the four anchors extending out in each of three different directions $90^{\circ}$ to each other. (The last set of wires will be used to assist in lifting the tower up into an upright position before attaching to the anchor.) You will need approximately $36.5 \mathrm{ft}$ of wire rope from section A to extend from the anchor to the top of the tower where the wire is attached. You also need about 29ft from section B and about $23 \mathrm{ft}$ from section $\mathrm{C}$ between the tower and the anchor for lifting.

See Figure 10.

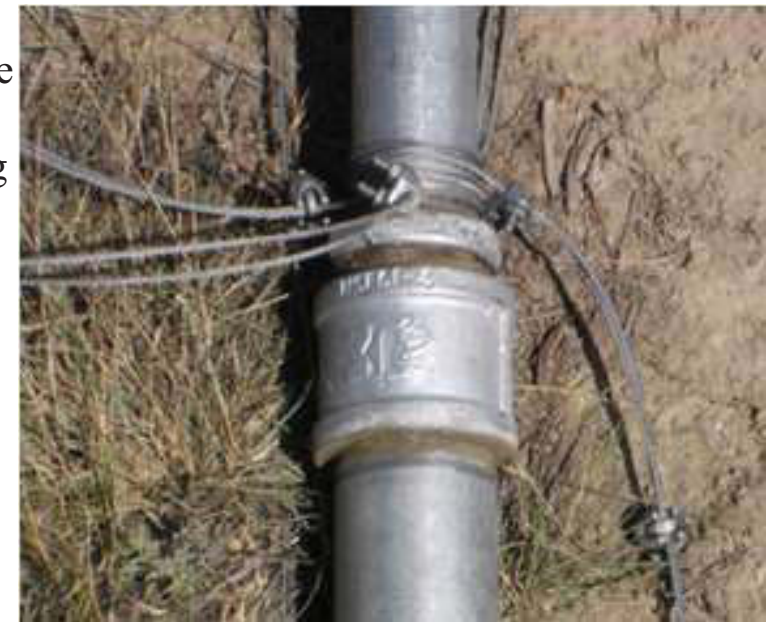

Figure 9

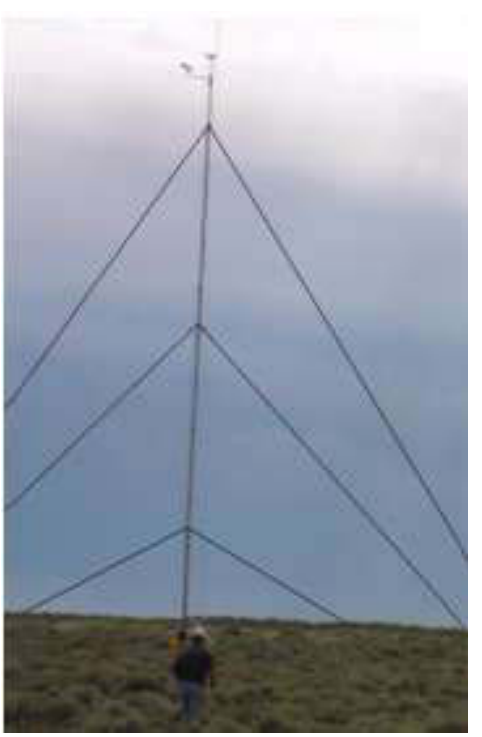

Figure 10

5. Slide three wire rope clips onto each guy wire end. Now run the guy wire end through the anchor eye or around the base of the 36in steel stake that was pounded in earlier for the anchors, double the guy back and slide the end through the first wire rope clip. Place the wire rope clip on the wire so the saddle (the grooved part) cradles the wire coming from the tower and the " $U$ " bolt part clamps down on the dead end of the guy. Leave a little slack in the guy wire, snug up the wire rope clip nuts. Don't tighten the wire rope clip too tightly; you will need to adjust the guy length as the tower is erected. Let the other two clips remain loose until the tower has been erected. See Figures 11, 12, and 13.

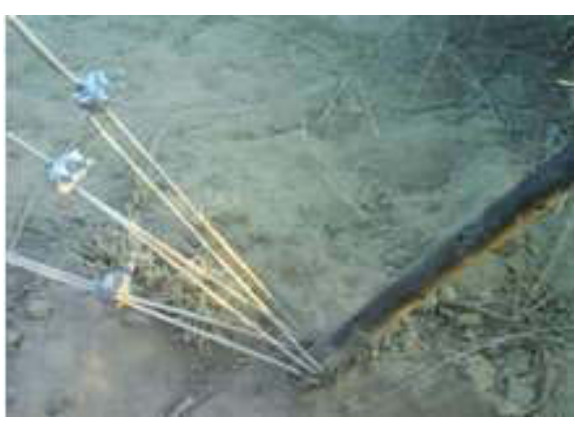

Figure 12 


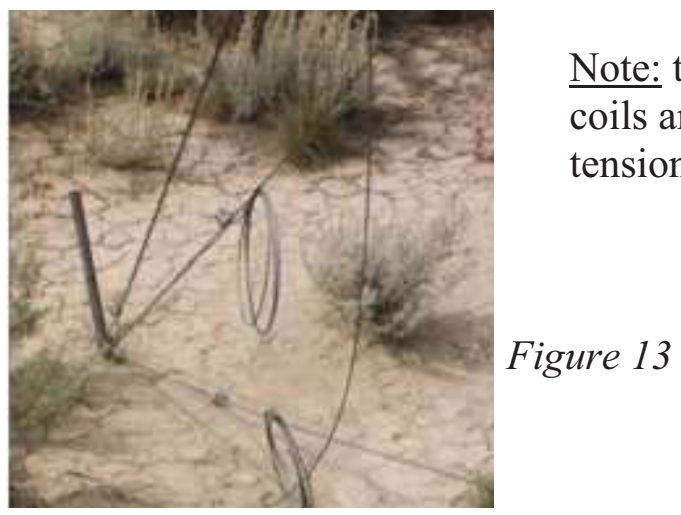

\section{5) Instrument \& Boom Installation}

The purpose of this section is to attach the instruments in order to gather data for long term wind site analysis. (Refer to Appendix A- Tower Schematics)

1. Attach the Z-boom, lightning rod, and Stub Boom. The lightning rod can be found in your lightning arrestor kit included in the list of supplies for this project. Mount the Z-boom on one side and the lightning rod on the side opposite the Z-boom. The Stub boom will be mounted from the very top of the tower so it is in between the Z-boom and the lightning rod. Once they have been positioned, secure all with two metal hose clamps on each shaft's base. See Figure 14.

2. Unroll about a meter of both the $10 \mathrm{~m}$ instrument cables. String the two wire cable down the boom that will hold the anemometer (Stub Boom) and the three wire down the boom that will hold the

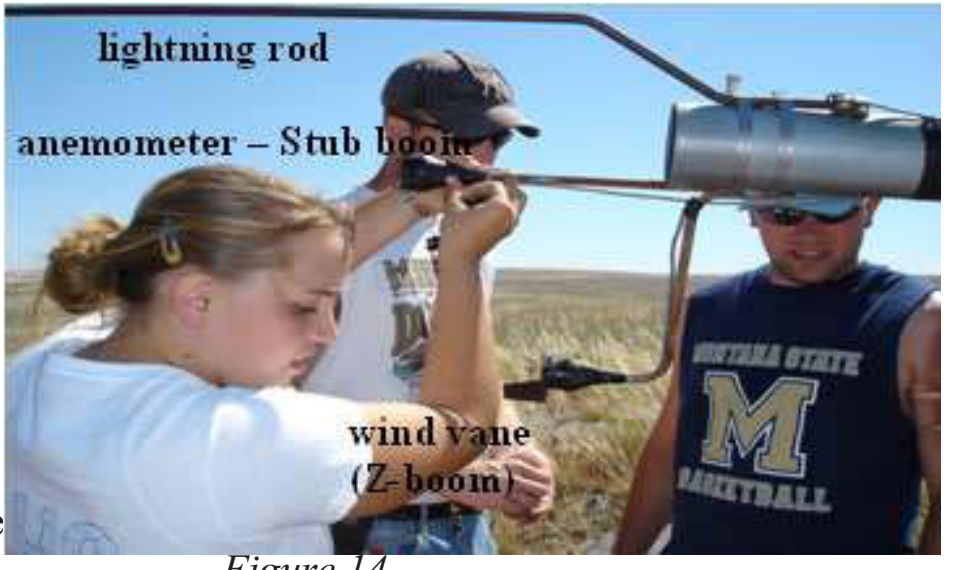

Figure 14 wind vane (Z-boom) wrapping the wire all the way. Leave the excess as a roll until ready for step 7.

3. Mount the anemometer onto the end of the Stub Boom following the instructions provided by NRG. Be sure to wrap a small amount of electrical tape around the base of the anemometer to keep the instrument cover from sliding down the boom as well as just below the rotating part of the anemometer to prevent water from seeping into the anemometer.

4. Mount the wind vane onto the end of the Z-boom following the instructions provided by NRG. Be sure to wrap a small amount of electrical tape around the base of the wind vane to keep the instrument cover from sliding down the boom as well as just below the rotating part of the wind vane to prevent water from seeping into the wind vane.

5. Attach the logger to the tower about 5 feet up from the ground. Make sure that it is facing a way that will lay it on its side when the tower is on the ground. Remember that the solar panel that is to be mounted on the tower has to face south. If using the APRS logger, use the side of pole solar mount to mount the logger onto the tower. The solar mount should include bolts to bolt the mount to the tower. If using the NRG logger, place the logger into the protective case before securing with two metal hose clamps to the tower. Be sure to follow the instructions provided with the logger. See Figure 15. 


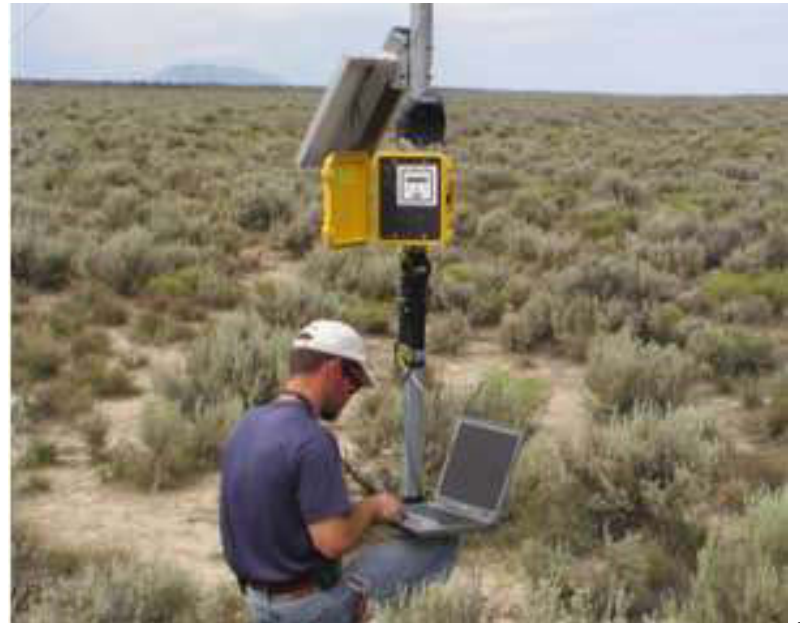

Figure 15

6. Both the APRS logger and the NRG logger include a solar panel and a solar panel mount to power the logger systems. Bolt the solar panel mount onto the anemometer tower above the logger so that the solar panel will face south. Attach the solar panel to the solar panel mount. Follow the directions provided by either NRG or APRS. The solar panel mount will need to be secured to the tower by two steel hose clamps. The hose clamps are already listed on the list of supplies. See Figures 16 and 17.
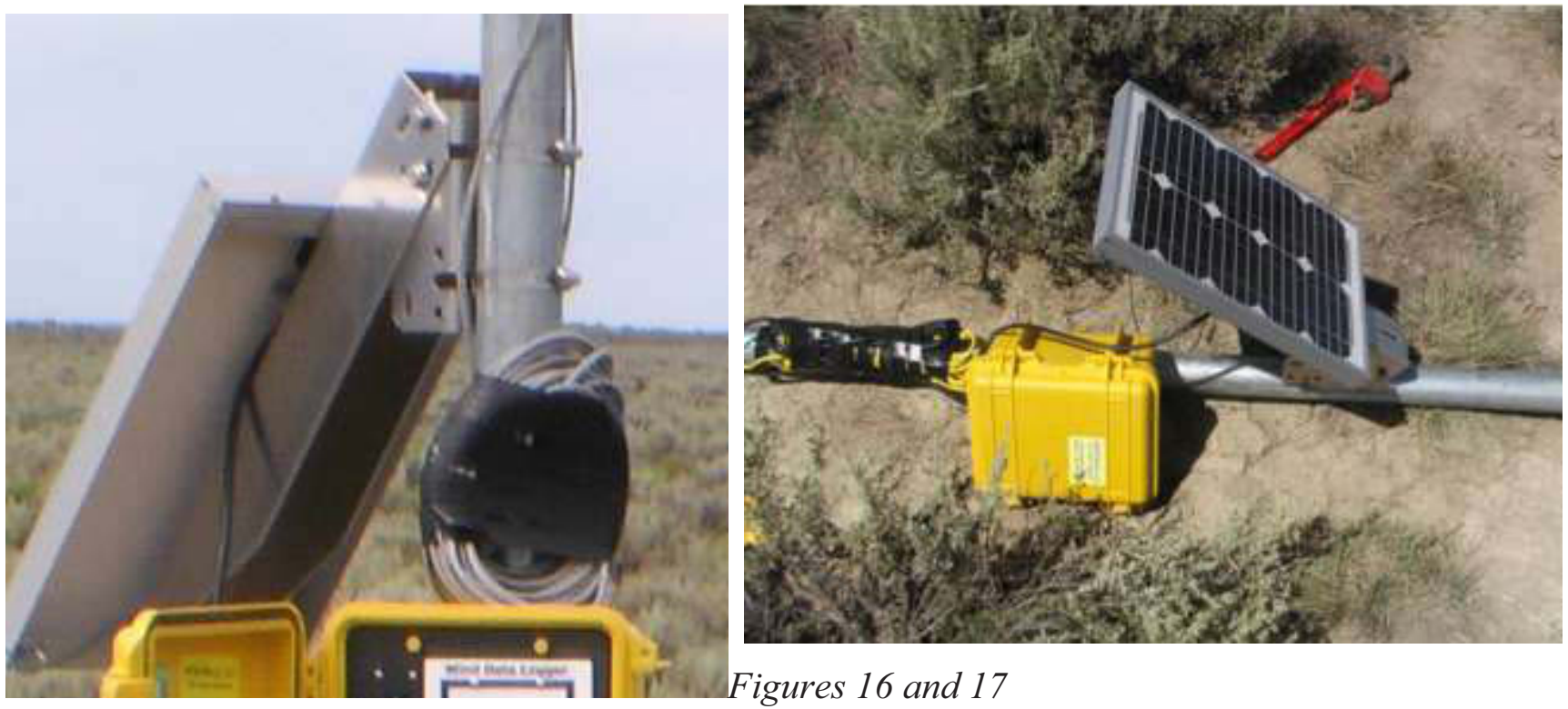

Figures 16 and 17

7. Once the instruments have been mounted correctly and the cables have been attached, begin wrapping the cables together down and around the rest of the tower. Wrap one to two times around the tower between each joint. Make sure to both tape the two cables together and tape the cables to the tower by winding electrical tape around the cables and then around the whole tower several times. Make sure that the tape is flat with few wrinkles or creases. This will increase the life time of the cables. Stop wrapping about 6 feet off the ground. The cables will go into the data logger. All excess cable can be coiled and taped securely off the ground below the logger to the tower with electrical tape. Remember to mark one of the cables with a sharpie, etc. so as to know which cable goes to which instrument. See Figure 18 . 


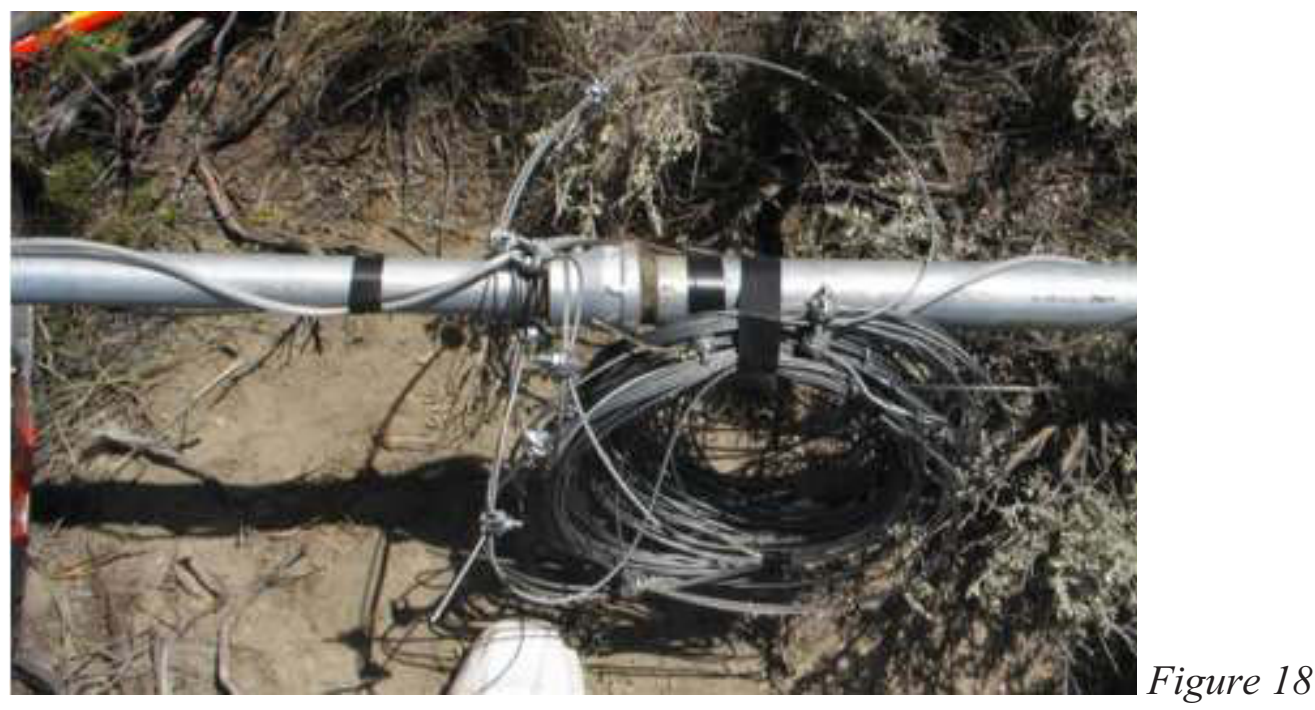

8. Run the copper wire included in the Lightning Arrestor Kit from the lightning rod at the top of the anemometer tower down to the grounding rods at the base of the tower wrapping one to two times around the tower between each joint and periodically taping it to the tower by use of electrical tape. Make sure that the copper wire is never in contact with the instrument cables. If lightning does happen to strike the tower, than any spot where the cable and wire are touching will allow the electricity emitted by the lightning to travel to the logger, effectively ruining all the data and instruments. Follow the instructions provided in the Lightning Arrestor Kit as to how to attach the copper wire to both the lightning rod and to both grounding rods.

9. Insert the cables into the data logger. If using the APRS logger, run the $9 \mathrm{ft}$ section of insulated copper wire from the grounding rods into the logger in order to ground the logger itself. If using the NRG logger, the insulated copper wire is included with the logger. However, this wire also needs to be ran from the grounding rods into the logger to ground the logger. There is a port in the bottom of the logger that has a steel nut facing outward. That is where you insert the insulated copper wire. Please follow the instructions provided by either APRS or NRG. When finished, close the box and make sure everything on the tower is secure for tilting up the tower.

\section{6) Tower Tilt-up}

- Guy Wire Tensioning

As a tower is raised, unless the anchors are placed in precisely their correct positions, and unless the site is perfectly level, some guy wires will tighten and some will go slack as the tower is raised. The same is true as a tower is lowered on the same site. Because of this, guy wire tension must be checked and adjusted as needed to maintain uniform tension, until the tower erection procedure is complete. A wire that becomes too tight can put very high forces on both the anchor and the tower, especially during the lifting and lowering of the tower. Too much slack or too much tension can cause the tower to buckle and fall. Do not let the tower become bowed to the side more than $0.3 \mathrm{~m}$ (1 foot) to $0.5 \mathrm{~m}\left(1 \frac{1}{2}\right.$ feet) away from a straight line. If the tower is bowed more than this, the guy wires should be adjusted to straighten out the tower. It is important that proper tension be maintained on side guy wires at all times during the lifting of the tower to provide side support for the tower. There must always be 
visible slack in the guy wires. If no slack is visible, the tension is too great. Once the tower is vertical, two people of average size pulling by hand can properly tension the guy wires.

\section{MECHANICAL TENSIONING DEVICES SHOULD NEVER BE USED TO ADJUST GUY WIRES!!}

- Tilt Up

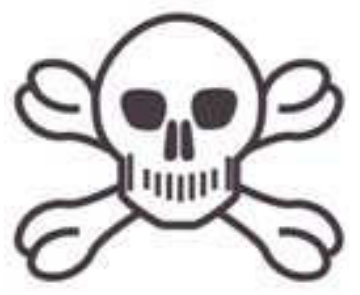

1. When ready to lift the tower up, at least 3 to 4 people will be needed, preferably 4 . One person will be pulling the front guy wire so that the tower begins to erect, while at the same time two more people will be lifting the tower from behind so as to 'push' the tower into place. They will slowly walk the tower up until the tower is straight. The last person will walk from guy wire to guy wire ensuring that the tension is not too much or too little, and adjusting the tension accordingly.

2. The guy wires that were used to pull the tower to the erect position will be transferred to their anchors.

3. Final adjustments are made to the tension wires and a check is made to ensure that the anemometer tower is vertical and straight.

4. At this point tighten the other 2 wire rope clips that were placed on each guy earlier, leaving about $100-200 \mathrm{~mm}$ (4"-8") between clips and again the wire tension is checked.

5. The site will be revisited after 2-3 weeks in order to readjust the wires, as during that time the tower settles and it is common for wires to loosen and the tower to drift to one side.

- Lowering

1. Follow the exact procedure for installation in the reverse order with the following precautions:

2. Guy wires need to be readjusted during the lowering process, just as it was necessary during the tilt-up.

3. Make sure all safety equipment is worn at all times. The tower is more difficult to control in the lowering process.

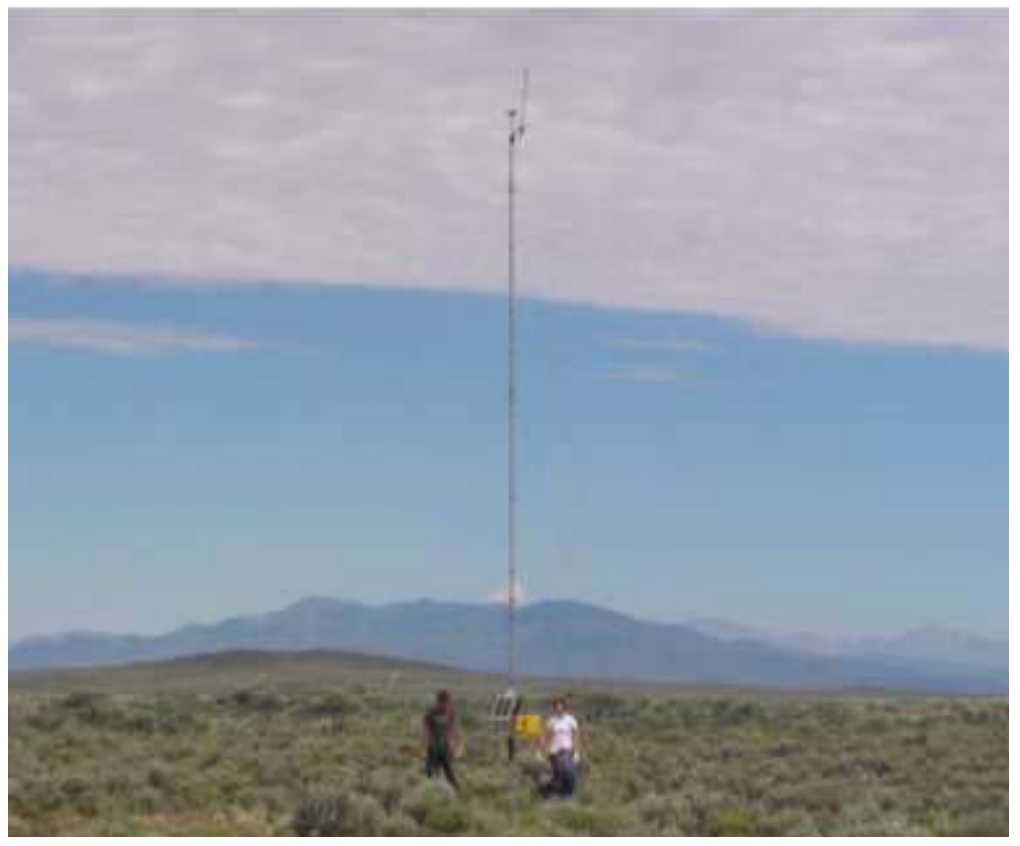




\section{7) Logger Programming}

This step will allow all the data that is collected by the anemometer and wind vane to either be transferred to either a data chip that will need to be collected at timely intervals or wirelessly transmitted to a computer where the data may be analyzed. A laptop will be required for this step.

1. Program the data logger using the instructions provided by either NRG or APRS. This step will take over an hour so prepare accordingly.

\section{6) Appendix A- Tower Schematics}

\section{Typical Wind Monitoring Site}

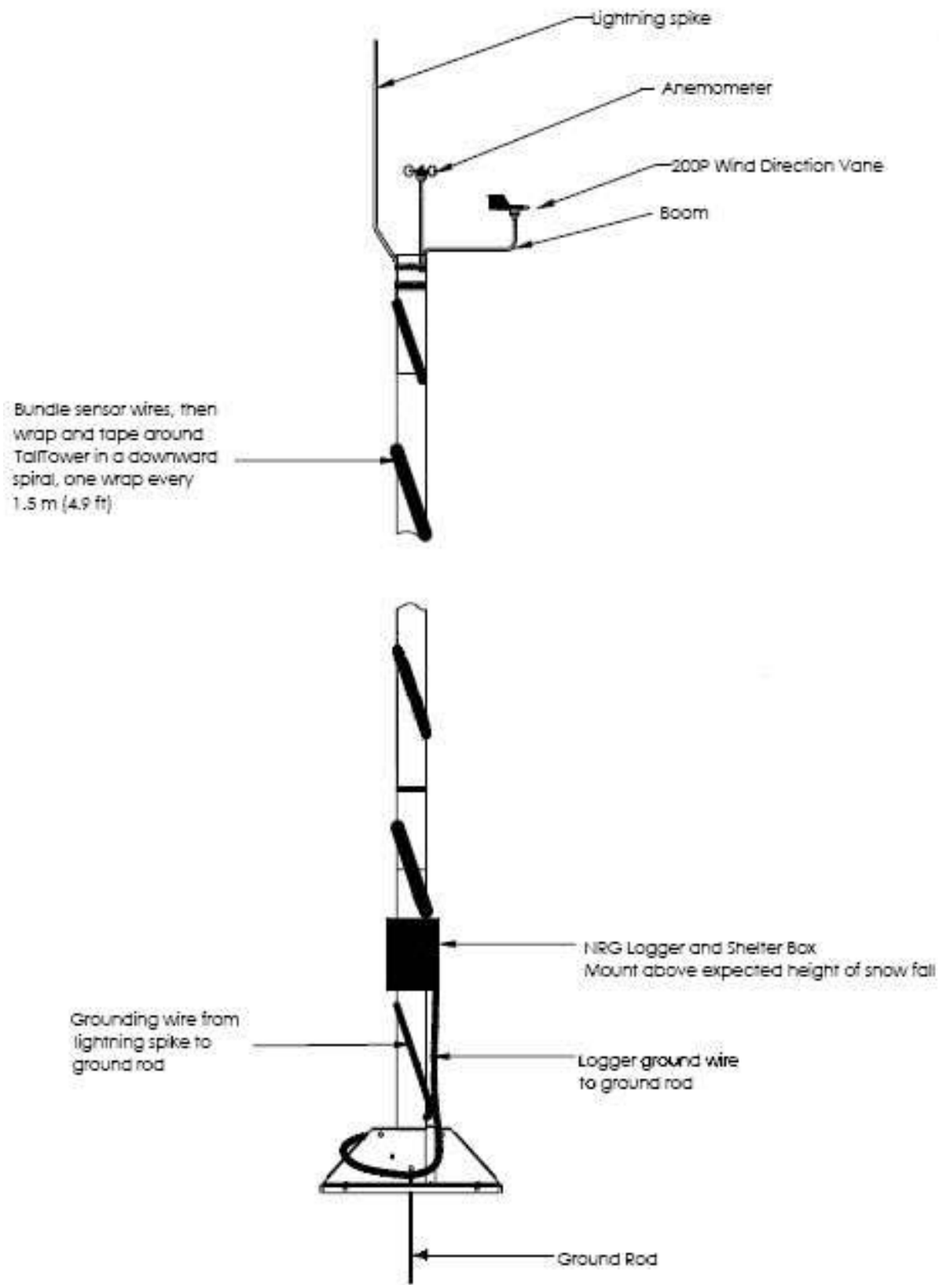




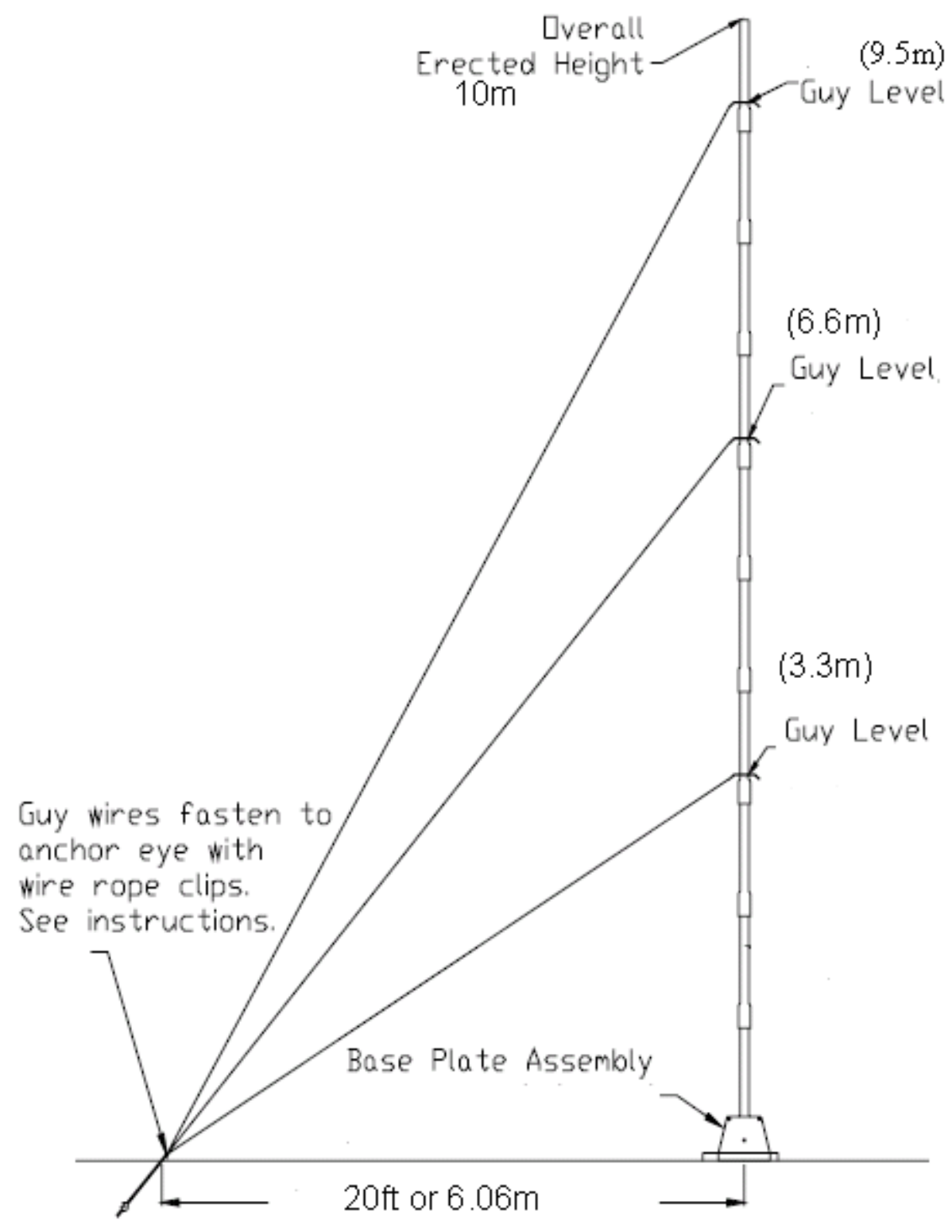


7) Appendix B- Extra Pictures

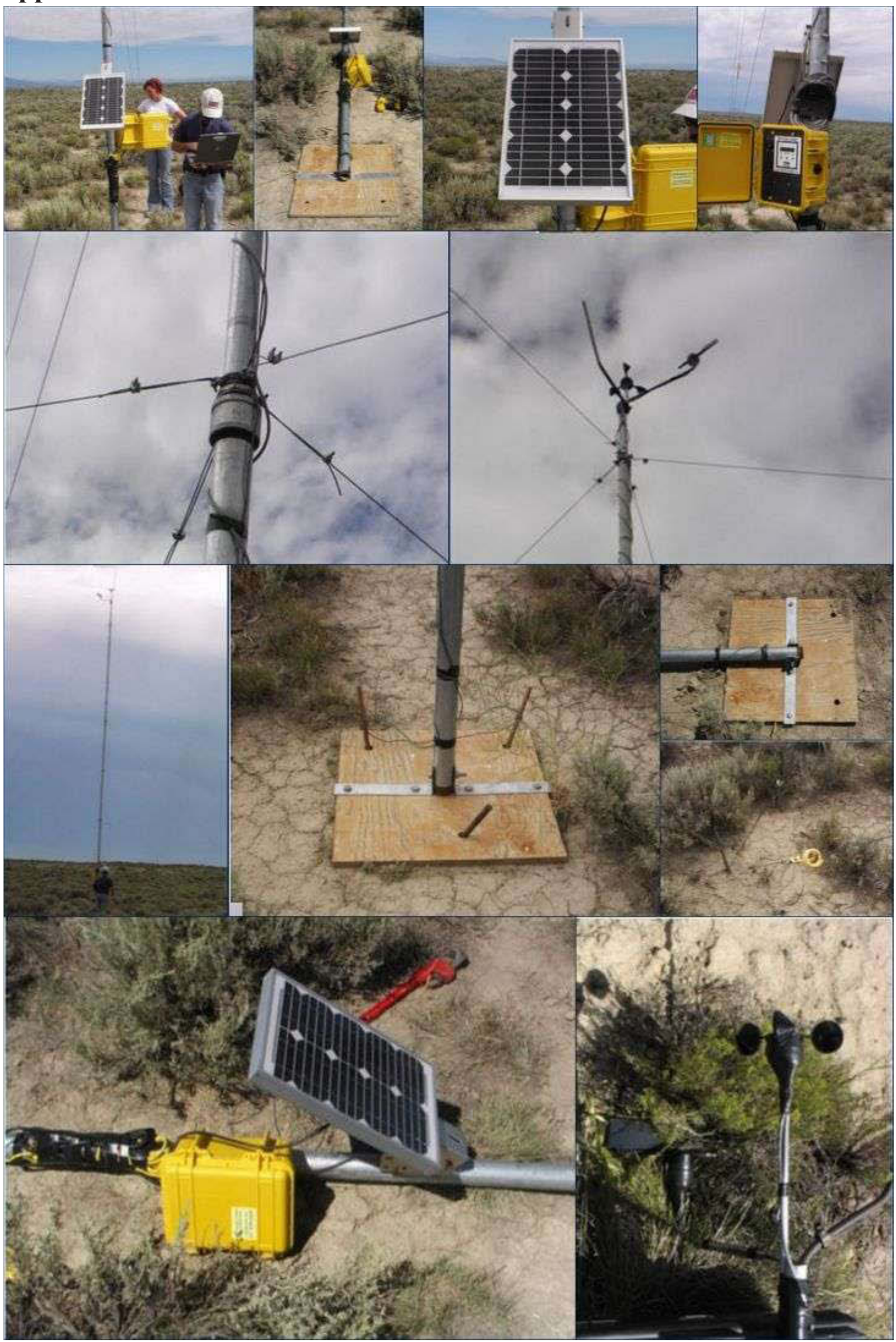




\section{8) Appendix C- Questions}

\section{Idaho National Laboratory Contacts:}

- Gary Seifert, Program Manager, Biofuels and Renewable Energy Technologies, P.O. Box 1625, Idaho Falls, ID 83415-3810, (208) 521-8385, Gary.Seifert@,inl.gov

- Kurt Myers, Staff Engineer, Biofuels and Renewable Energy Technologies, P.O. Box 1625, Idaho Falls, ID 83415-3810, (208) 526-5022, Kurt.Myers@,inl.gov

\section{Special Thanks}

- $\quad$ NRG Systems (www.nrgsystems.com)

- $\quad$ APRS World, LLC (www.aprsworld.com) 
Appendix D - EFH Assessment Worksheet 


\section{NOAA FISHERIES \\ NORTHEAST REGIONAL OFFICE \\ EFH ASSESSMENT WORKSHEET FOR \\ FEDERAL AGENCIES \\ (modified 08/04)}

\section{Introduction:}

The Magnuson-Stevens Fishery Conservation and Management Act mandates that federal agencies conduct an EFH consultation with NOAA Fisheries regarding any of their actions authorized, funded, or undertaken that may adversely effect essential fish habitat (EFH). An adverse effect means any impact that reduces the quality and/or quantity of EFH. Adverse effects may include direct or indirect physical, chemical, or biological alterations of the waters or substrate and loss of, or injury to, benthic organisms, prey species and their habitat, and other ecosystem components. Adverse effects to EFH may result from actions occurring within EFH or outside of EFH and may include site-specific or habitat-wide impacts, including individual, cumulative, or synergistic consequences of actions.

This worksheet has been designed to assist Federal agencies in determining whether an EFH consultation is necessary, and developing the needed information should a consultation be required. This worksheet will lead you through a series of questions that will provide an initial screening to determine if an EFH consultation is necessary, and help you assemble the needed information for determining the extent of the consultation required. The information provided in this worksheet may also be used to develop the required EFH Assessment.

Consultation through NOAA Fisheries regarding other NOAA-trust resources may also be necessary if a proposed action results in adverse impacts. Part 6 of the worksheet is designed to help assess the effects of the action on other NOAA-trust resources. This helps maintain efficiency in our interagency coordination process. In addition, consultation with NOAA Fisheries may be required if a proposed action impacts marine mammals or threatened and endangered species for which we are responsible. Staff from our Northeast Regional Office, Protected Resources Division should be contacted regarding potential impacts to marine mammals or threatened and endangered species.

\section{Instructions for Use:}

An EFH Assessment must be submitted by a Federal agency to NOAA Fisheries as part of the EFH consultation. An EFH Assessment must include the following information:

1) A description of the proposed action.

2) An analysis of the potential adverse effects of the action on EFH, and the managed species.

3) The Federal agency $=$ s conclusions regarding the effects of the action on EFH.

4) Proposed mitigation if applicable.

In some cases, this worksheet can be used as an EFH Assessment. If the Federal agency determines that the action will not cause substantial impacts to EFH, then this worksheet may suffice. If the action may cause substantial adverse effects on $\mathrm{EFH}$, then a more thorough discussion of the action and its impacts in a separate EFH Assessment will be necessary. The completed worksheet should be forwarded to 
NOAA Fisheries Northeast Regional Office, Habitat Conservation Division (HCD) for review.

The information contained on the HCD website (http://www.nero.noaa.gov/hcd/) will assist you in completing this worksheet. The HCD web site contains information regarding: the EFH consultation process; Guide to EFH Designations which provides a geographic species list; Guide to EFH Species Descriptions which provides the legal description of EFH as well as important ecological information for each species and life stage; and other EFH reference documents including examples of EFH Assessments and EFH Consultations. 
PROJECT NAME:

DATE:

PROJECT NO.: LOCATION:

PREPARER:

Step 1. Use the Habitat Conservation Division EFH webpage, Guide to Essential Fish Habitat Designations in the Northeastern United States to generate the list of designated EFH for federally-managed species for the geographic area of interest (http://www.nero.noaa.gov/hcd/index2a.htm). Use the species list as part of the initial screening process to determine if EFH for those species occurs in the vicinity of the proposed action. Attach that list to the worksheet because it will be used in later steps. Make a preliminary determination on the need to conduct an EFH Consultation.

\begin{tabular}{|c|c|c|}
\hline \multicolumn{3}{|l|}{ INITIAL CONSIDERATIONS } \\
\hline EFH Designations & Yes & No \\
\hline \multicolumn{3}{|l|}{ Is the action located in or adjacent to EFH designated for eggs? } \\
\hline \multicolumn{3}{|l|}{ Is the action located in or adjacent to EFH designated for larvae? } \\
\hline \multicolumn{3}{|l|}{ Is the action located in or adjacent to EFH designated for juveniles? } \\
\hline \multicolumn{3}{|l|}{ Is the action located in or adjacent to EFH designated for adults? } \\
\hline \multicolumn{3}{|l|}{ Is the action located in or adjacent to EFH designated for spawning adults? } \\
\hline $\begin{array}{l}\text { If you answered no to all questions above, then EFH consultation is not required -go to } \\
\text { Section } 5 \text {. If you answered yes to any of the above questions proceed to Section } 2 \text { and } \\
\text { complete remainder of the worksheet. }\end{array}$ & & \\
\hline
\end{tabular}


Step 2. In order to assess impacts, it is critical to know the habitat characteristics of the site before the activity is undertaken. Use existing information, to the extent possible, in answering these questions. Please note that, there may be circumstances in which new information must be collected to appropriately characterize the site and assess impacts.

\section{SITE CHARACTERISTICS}

Site Characteristics Description

Is the site intertidal, sub-tidal, or water column?

What are the sediment characteristics?

Is Habitat Area of Particular Concern (HAPC) designated at or near the site? If so what type, size, characteristics?

Is there submerged aquatic vegetation (SAV) at or adjacent to project site? If so describe the spatial extent.

What is typical salinity and temperature regime/range?

What is the normal frequency of site disturbance, both natural and man-made?

What is the area of proposed impact (work footprint \& far afield)? 
Step 3. This section is used to describe the anticipated impacts from the proposed action on the physical/chemical/biological environment at the project site and areas adjacent to the site that may be affected.

\section{DESCRIPTION OF IMPACTS}

\begin{tabular}{|l|l|l|l|}
\hline Impacts & $\mathbf{Y}$ & $\mathbf{N}$ & Description \\
\hline
\end{tabular}

\section{Nature and duration of} activity(s)

Will benthic community be disturbed?

Will SAV be impacted?

\begin{tabular}{l} 
\\
\hline $\begin{array}{l}\text { Will sediments be altered and/or } \\
\text { sedimentation rates change? }\end{array}$
\end{tabular}

Will turbidity increase?

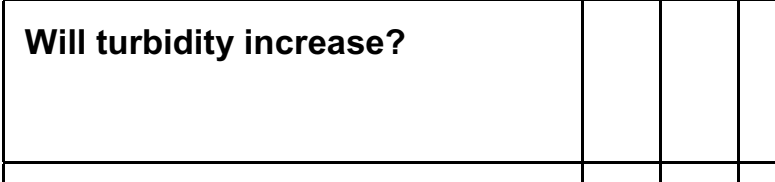

Will water depth change?

Will contaminants be released into sediments or water column?

Will tidal flow, currents or wave patterns be altered?

Will ambient salinity or temperature regime change?

Will water quality be altered? 
Step 4. This section is used to evaluate the consequences of the proposed action on the functions and values of EFH as well as the vulnerability of the EFH species and their life stages. Identify which species from the EFH species list (generated in Step 1) will be adversely impacted from the action. Assessment of EFH impacts should be based upon the site characteristics identified in Step 2 and the nature of the impacts described within Step 3. The Guide to EFH Descriptions webpage (http://www.nero.noaa.gov/hcd/list.htm) should be used during this assessment to determine the ecological parameters/preferences associated with each species listed and the potential impact to those parameters.

\begin{tabular}{|c|c|c|c|}
\hline Functions and Values & $\mathbf{Y}$ & $\mathbf{N}$ & $\begin{array}{l}\text { Describe habitat type, species and life stages to be adversely } \\
\text { impacted }\end{array}$ \\
\hline $\begin{array}{l}\text { Will functions and values of EFH } \\
\text { be impacted for: }\end{array}$ & & & \\
\hline Spawning & & & \\
\hline Nursery & & & \\
\hline Forage & & & \\
\hline Shelter & & & \\
\hline $\begin{array}{l}\text { Will impacts be temporary or } \\
\text { permanent? }\end{array}$ & & & \\
\hline $\begin{array}{l}\text { Will compensatory mitigation be } \\
\text { used? }\end{array}$ & & & \\
\hline
\end{tabular}


Step 5. This section provides the Federal agency=s determination on the degree of impact to EFH from the proposed action. The EFH determination also dictates the type of EFH consultation that will be required with NOAA Fisheries.

\section{DETERMINATION OF IMPACT}

\begin{tabular}{|l|l|l|}
\hline & $/$ & Federal Agency=s EFH Determination \\
\hline \hline \multirow{2}{*}{$\begin{array}{l}\text { Overall degree of } \\
\text { adverse effects on EFH } \\
\text { (not including } \\
\text { compensatory } \\
\text { mitigation) will be: }\end{array}$} & & $\begin{array}{l}\text { There is no adverse effect on EFH } \\
\text { EFH Consultation is not required }\end{array}$ \\
\cline { 2 - 3 } $\begin{array}{l}\text { (check the appropriate } \\
\text { statement) }\end{array}$ & $\begin{array}{l}\text { The adverse effect on EFH is not substantial. } \\
\text { This is a request for an abbreviated EFH consultation. This } \\
\text { worksheet is being submitted to NMFS to satisfy the EFH } \\
\text { Assessment requirement. }\end{array}$ \\
\cline { 2 - 3 } & $\begin{array}{l}\text { The adverse effect on EFH is substantial. } \\
\text { This is a request for an expanded EFH consultation. A detailed } \\
\text { written EFH assessment will be submitted to NMFS expanding upon } \\
\text { the impacts revealed in this worksheet. }\end{array}$ \\
\hline
\end{tabular}

Step 6. Consultation with NOAA Fisheries may also be required if the proposed action results in adverse impacts to other NOAA-trust resources, such as anadromous fish, shellfish, crustaceans, or their habitats. Some examples of other NOAA-trust resources are listed below. Inquiries regarding potential impacts to marine mammals or threatened/endangered species should be directed to NOAA Fisheries' Protected Resources Division.

\section{OTHER NOAA-TRUST RESOURCES IMPACT ASSESSMENT}

Species known to occur at site (list others that may apply)

alewife

blueback herring

rainbow smelt

Atlantic sturgeon

Atlantic menhaden

American shad

American eel

American lobster

blue mussels

soft-shell clams

quahog

Other species:
Describe habitat impact type (i.e., physical, chemical, or biological disruption of spawning and/or egg development habitat, juvenile nursery and/or adult feeding or migration habitat). 